ZASPiL Nr. 45 - September 2006

\title{
Expression of Information Structure in the Bantu Language Northern Sotho
}

Sabine Zerbian 


\title{
EXPRESSION OF INFORMATION STRUCTURE IN THE BANTU LANGUAGE NORTHERN SOTHO
}

\author{
Dis s e r t a t i o n \\ zur Erlangung des akademischen Grades \\ doctor philosophiae \\ (Dr. phil.)
}

eingereicht an

der Philosophischen Fakultät II

der Humboldt-Universität zu Berlin

von

Sabine Zerbian, M.A.

geboren am 27. Juni 1975 in Berlin/ Deutschland

Präsident der Humboldt-Universität zu Berlin

Prof. Dr. Christoph Markschies

Dekan der Philosophischen Fakultät II

Prof. Dr. Erhard Schütz

Gutachter: 1. Prof. Dr. Manfred Krifka (Humboldt-Universität zu Berlin)

2. PD Dr. Hubert Truckenbrodt (Eberhard Karls Universität Tübingen)

Tag der mündlichen Prüfung: 


\section{Contents}

Zusammenfassung vii

Acknowledgements $\quad$ xi

List of abbreviations $\quad$ xiii

1 Introduction 1

1.1 Overview ............................ 1

1.2 Information Structure . . . . . . . . . . . . . . . . 4

1.2.1 What is information structure? . . . . . . . . . 4

1.2.2 Parts of information structure ............ 5

1.2.3 Information structural units used in the thesis . . . . . . . . 10

1.2.4 Information structure in Bantu languages . . . . . . . . . . . . . 12

1.2 .5 Summary . . . . . . . . . . . . . . . 13

1.3 Controlling for focus: Methodology . . . . . . . . . . . . . . 13

1.4 A cross-linguistic survey of focus marking . . . . . . . . . . . . . . . . 15

1.4.1 Definition of grammatical marking of focus . . . . . . . . . . 15

1.4.2 Prosodic marking of focus . . . . . . . . . . . . . 16

1.4.3 Morphological marking of focus . . . . . . . . . . . . . . . 17

1.4.4 Syntactic marking of focus . . . . . . . . . . . . . . . . . 19

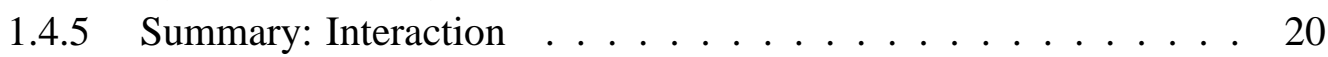

1.5 Optimality Theory . . . . . . . . . . . . . . . 21

1.5.1 The basic OT-mechanism . . . . . . . . . . . . . 21

1.5 .2 OT in $\operatorname{syntax} \ldots \ldots \ldots 25$

1.5.3 A case study for OT at interfaces: Focus in English and Italian . . 33

1.5.4 Factorial typology . . . . . . . . . . . . . . . . . . . . . . . . 39

1.5.5 OT in semantics . . . . . . . . . . . . . 40

1.6 The language Northern Sotho . . . . . . . . . . . . . . . . 41

1.6.1 Linguistic studies on Northern Sotho . . . . . . . . . . . . . . 42

1.7 Linguistic properties of Northern Sotho . . . . . . . . . . . . . . . 44

1.7 .1 Tone . . . . . . . . . . . . . . . . . . . 44

1.7.2 Basic word order . . . . . . . . . . . . . . . . . . 45

1.7.3 Agreement .................... . . 45

1.7.4 Present Tense morpheme $-a-\ldots \ldots 60$ 
2 Syntax and focus in Northern Sotho

2.1 Introduction . . . . . . . . . . . . . . . . . . 65

2.2 Syntactic reflexes of focus in Northern Sotho . . . . . . . . . . . . 66

2.2 .1 Objects and adverbials . . . . . . . . . . . . 66

2.2 .2 Subjects . . . . . . . . . . . . . . . . . . . . 69

2.2 .3 Focus on modifiers . . . . . . . . . . . . . . . . . 72

2.2 .4 Focus on prepositions . . . . . . . . . . . . . . 75

2.2 .5 Focus on the verb . . . . . . . . . . . . 76

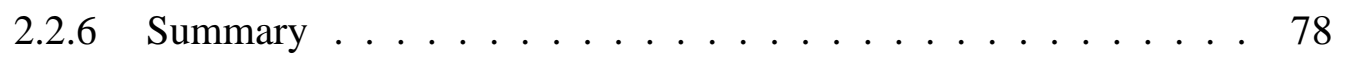

2.3 Alternative syntactic focus positions . . . . . . . . . . . . . 78

2.3.1 Left-peripheral focus position . . . . . . . . . . . . . 79

2.3.2 Immediately postverbal focus position . . . . . . . . . . 81

2.3.3 Clause-final focus position . . . . . . . . . . . . . 83

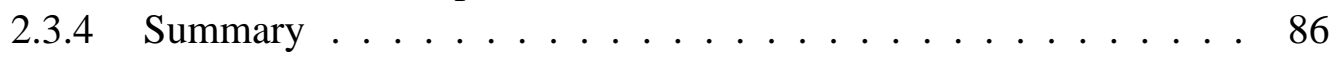

2.4 Grammatical reflexes of information structure . . . . . . . . . . . . . 87

2.4.1 Deletion and pronominalization . . . . . . . . . . 87

2.4 .2 Dislocation . . . . . . . . . . . . . . . . 92

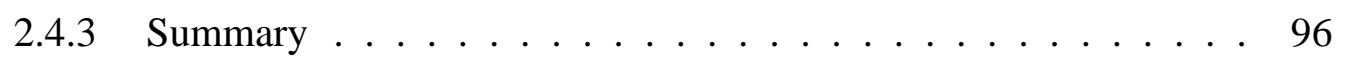

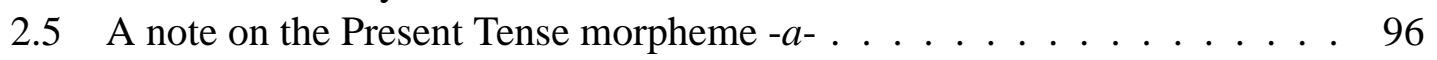

2.5.1 Information structural approach to $-a-\ldots . \ldots 97$

2.5.2 Against $-a$ - as a focus marker . . . . . . . . . . . . . . 99

2.5.3 The syntactic approach . . . . . . . . . . . . . 102

2.5.4 Discussion: Relation between syntax and pragmatics . . . . . . 103

2.6 Conclusion . . . . . . . . . . . . . . . . . . . . . 104

$\begin{array}{llr}3 & \text { Prosody and focus in Northern Sotho } & \mathbf{1 0 7}\end{array}$

3.1 Introduction . . . . . . . . . . . . . . . . . . . 107

3.2 Background . . . . . . . . . . . . . . . . . . 108

3.2.1 Penultimate lengthening . . . . . . . . . . . . . . 109

3.2 .2 Finality restriction . . . . . . . . . . . . . 111

3.2 .3 OCP . . . . . . . . . . . . . . . . 115

3.2 .4 Summary . . . . . . . . . . . . . . . . 117

3.3 Phonological Phrasing in Northern Sotho _ . . . . . . . . . . . . . . 117

3.3.1 Theoretical background . . . . . . . . . . . . 117

3.3.2 Describing the domain . . . . . . . . . . . . . . 122

3.3.3 Determining the constituent . . . . . . . . . . . . 131

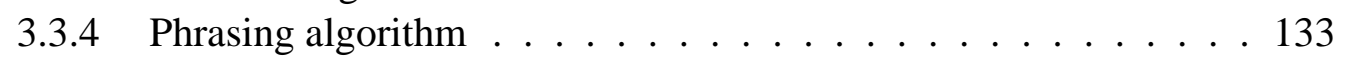

3.3.5 Prominence in Bantu . . . . . . . . . . . . . . . . . . . . . . . . . . . . . . . . . . . . .

3.3 .6 Summary . . . . . . . . . . . . . . . . . 143

3.4 Influence of focus on prosody . . . . . . . . . . . . . . . . . . . . . . . . . . . . . . . 144

3.4 .1 Introduction . . . . . . . . . . . . . . . . . . . 144

3.4.2 Prosody in tone languages . . . . . . . . . . . . . . 145

3.4 .3 Expectation . . . . . . . . . . . . . . . . . . . 148

3.5 Production study . . . . . . . . . . . . . . . . . . . 149

3.5.1 Aim . . . . . . . . . . . . . . . . . . 149 
3.5.2 Procedure . . . . . . . . . . . . . . . . . . . . . . . . . . . 149

3.5 .3 Material . . . . . . . . . . . . . . . . . . . . 150

3.5 .4 Prosodic analysis . . . . . . . . . . . . . . . . . . 151

3.5 .5 Summary . . . . . . . . . . . . . . . . 157

3.6 Perception study . . . . . . . . . . . . . . . . . . . . . . 157

$3.6 .1 \quad \operatorname{Aim} \ldots \ldots \ldots \ldots \ldots \ldots \ldots$

3.6.2 Pre-test . . . . . . . . . . . . . . . . . . . . 158

3.6 .3 Procedure . . . . . . . . . . . . . . . . . . . 158

3.6 .4 Material . . . . . . . . . . . . . . . . . . . . . . . . . . . . 159

3.6 .5 Results . . . . . . . . . . . . . . . . . . . . . 161

3.6 .6 Summary . . . . . . . . . . . . . . . . . . 163

3.7 Summary of the experimental part $\ldots \ldots \ldots \ldots \ldots$

3.8 Conclusion and discussion . . . . . . . . . . . . . . . . . . 164

3.8.1 Prominence-focus correspondence . . . . . . . . . . . . 165

3.8.2 Lack of focus marking: Areas for further research . . . . . . . 168

4 The preverbal position in Northern Sotho 171

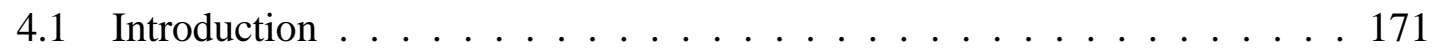

4.2 Discourse-pragmatic role of the subject $\ldots \ldots \ldots \ldots \ldots \ldots$

4.2.1 Subjects in Southern Bantu . . . . . . . . . . . . . . . . . . 174

4.2.2 Testing topic properties in Northern Sotho . . . . . . . . . . . 179

4.2 .3 Summary . . . . . . . . . . . . . . . . . . . . 190

4.3 Influence of information structure on syntax . . . . . . . . . 191

4.3.1 The interface constraint . . . . . . . . . . . . . . . . . . 192

4.3 .2 Analysis . . . . . . . . . . . . . . . . . . . 198

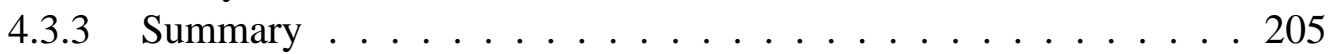

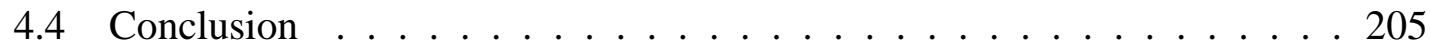

4.4 .1 Discussion . . . . . . . . . . . . . . . . . . . 206

4.4 .2 Area of further research . . . . . . . . . . . . . 207

5 The use of clefts in Northern Sotho 209

5.1 Cleft sentences in Northern Sotho _ . . . . . . . . . . . . 210

5.1 .1 The meaning of cleft sentences . . . . . . . . . . . . . 211

5.1 .2 Subject clefts in Northern Sotho . . . . . . . . . . . . . . 212

5.1.3 Non-subject clefts in Northern Sotho . . . . . . . . . . . . 213

5.1 .4 A corpus study . . . . . . . . . . . . . . . . . . . . . 219

5.1 .5 Summary . . . . . . . . . . . . . . . . . . . . 224

5.2 The structure of clefts in Northern Sotho . . . . . . . . . . . 225

5.3 Form-meaning correspondence: Clefts with objects . . . . . . . . 227

5.3.1 Simple form as the optimal form . . . . . . . . . . . . . . 228

5.3.2 Essentials of Bidirectional OT . . . . . . . . . . . . . 230

5.3 .3 Analysis . . . . . . . . . . . . . . . 231

5.3 .4 Alternative approach . . . . . . . . . . . . . . . . . 232

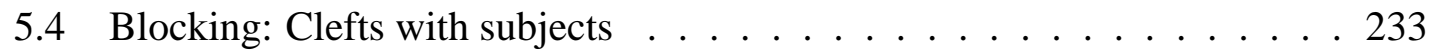

5.4.1 Restriction on transitive verbs . . . . . . . . . . . . . 233

5.4 .2 Emergence of the cleft . . . . . . . . . . . . . . 234 
5.5 Areas for future research . . . . . . . . . . . . . . . 235

5.5.1 Ambiguity in Bidirectional OT . . . . . . . . . . . . 235

5.5 .2 Optionality within OT . . . . . . . . . . . 238

5.6 Summary . . . . . . . . . . . . . . . . . . . . . 242

5.7 Recapitulatory remarks . . . . . . . . . . . . . . . . . . . 243

$\begin{array}{ll}\text { Appendix } & \mathbf{2 4 5}\end{array}$

$\begin{array}{ll}\text { Erklärung } & 273\end{array}$

$\begin{array}{ll}\text { Lebenslauf } & 275\end{array}$ 


\section{Zusammenfassung}

Der grammatische Ausdruck von Informationsstruktur als Forschungsgebiet hat in den letzten zwei Jahrzehnten eine Renaissance erlebt. Dabei sind Forschungen zu Bantusprachen vergleichsweise gering in Anbetracht der Größe der Sprachfamilie (circa 300 Sprachen). Die vorliegende Dissertation untersucht daher den grammatischen Ausdruck der informationsstrukturellen Kategorie Fokus im Nord-Sotho, einer Bantusprache der Republik Südafrika. Sie bietet eine systematische Untersuchung zur Verankerung von informationsstrukturellen Kategorien in der Grammatik dieser Sprache und verwendet dafür eine etablierte Methodologie. Dadurch soll einerseits das Verständnis erweitert werden, wie und ob die Kategorie Fokus in den Sprachen der Welt markiert ist, und zum anderen sollen die gewonnenen Daten einen sprachübergreifenden Vergleich erlauben.

Die Hauptthese dieser Dissertation ist, dass Nord-Sotho keinen obligatorischen Gebrauch von grammatischen Mitteln zur Markierung von Fokus macht, weder in der Syntax noch in der Prosodie oder Morphologie. Trotzdem strukturiert diese Sprache eine Äußerung nach informationsstrukturellen Aspekten. Konstituenten, die im Diskurs gegeben sind, werden entweder getilgt, pronominalisiert oder an den rechten oder linken Satzrand versetzt. Diese (morpho-)syntaktischen Prozesse wirken so zusammen, dass die fokussierte Konstituente oft final in ihrem Teilsatz erscheint. Obwohl die finale Position keine designierte Fokusposition ist, ist das Wissen um diese Tendenz doch entscheidend für das Verständnis einer morphologischen Alternation, die in Nord-Sotho am Verb erscheint und die in der Literatur im Zusammenhang mit Fokus diskutiert wurde.

Obwohl also ein direkter grammatischer Ausdruck von formaler F(okus)-Markierung im Nord-Sotho fehlt, ist F-Markierung trotzdem entscheidend für die Grammatik dieser Sprache: Fokussierte logische Subjekte können nicht in kanonischer präverbaler Position erscheinen. Sie erscheinen stattdessen entweder postverbal oder in einem Spaltsatz, abhängig von der Valenz des Verbs. Obwohl Nord-Sotho bei Objekten im Gebrauch von Spaltsätzen eine Korrespondenz von komplexer Form mit komplexer Bedeutung zeigt, gilt diese Korrespondenz nicht für logische Subjekte.

Die vorliegende Dissertation modelliert die oben genannten Ergebnisse im theoretischen Rahmen der Optimalitätstheorie (OT). Syntaktischer in situ Fokus und die Abwesenheit von prosodischer Fokusmarkierung können mit unkontroversen Beschränkungen erfasst werden. Für die Ungrammatikaliät fokussierter logischer Subjekte in präverbaler Position schlägt die vorliegende Arbeit die Modifizierung einer in der Literatur vorhandenen Beschränkung vor, die in Nord-Sotho von entscheidener Bedeutung ist. Die FormBedeutungs-Korrespondenz wird, wie andere Phänomene pragmatischer Arbeitsteilung auch, innerhalb der schwach bidirektionalen Optimalitätstheorie behandelt.

Die Dissertation ist wie folgt gegliedert: In Kapitel 1 werden zunächst die infor- 
mationsstrukturellen Einheiten vorgestellt und diskutiert. Das Ziel ist, die Definition von Fokus herauszubilden, die der Datenelizitation in der Dissertation zugrunde liegt. Dabei folgt die Dissertation der Definition von Fokus, wie sie aus der Alternativensemantik bekannt ist: Fokus beschreibt eine Menge von Alternativen. Die Methoden, die angewendet werden, um diese Art von Fokus im Nord-Sotho zu elizitieren, werden im Detail beschrieben. Weiterhin wird in dem ersten Kapitel anhand einer kurzen Übersicht illustriert, in welchen grammatischen Bereichen und mit welchen grammatischen Mitteln Fokus in den Sprachen der Welt ausgedrückt wird. Die Vielfalt der verwendeten Mittel rechtfertigt die umfassende Untersuchung - in den Bereichen Syntax, Phonologie, Morphologie -, die in der vorliegenden Dissertation für das Nord-Sotho unternommen ist. Kapitel 1 präsentiert auch den theoretischen Rahmen, innerhalb dessen die gewonnenen Daten erklärt werden. Optimalitätstheorie (OT) erlaubt die Modellierung der Interaktion von verschiedenen Bereichen der Grammatik innerhalb einer Meta-Theorie. Schlussendlich gibt Kapitel 1 eine kleine Einführung in die (für den vorliegenden Zweck) wichtigsten linguistischen Aspekte von Bantusprachen. Besondere Aufmerksamkeit wird dem Ton, der Wortreihenfolge und der verbalen Konkordanz gewidmet.

Kapitel 2 präsentiert den syntaktischen Ausdruck von Fokus im Nord-Sotho. NordSotho zeigt eine Asymmetrie bei der Fokussierung von Subjekten und Nicht-Subjekten. Während Objekte, Verben und Adverbien in ihrer kanonischen Position fokussiert werden, treten logische Subjekte unter Fokus nicht in ihrer kanonischen, präverbalen Position auf, sondern postverbal oder in einem Spaltsatz. Nach diesen Beobachtungen untersucht Kapitel 2 alternative syntaktische Fokuspositionen, die für andere (Bantu-)Sprachen beschrieben worden sind. Dazu gehören eine linksperiphäre, eine unmittelbar postverbale oder eine Teilsatz-finale Fokusposition. Es wird gezeigt, dass keine dieser Positionen eine mögliche Fokusposition im Nord-Sotho darstellt. Für die beobachtbare Tendenz, dass fokussierte Konstituenten im Nord-Sotho Teilsatz-final erscheinen, werden Ansätze aufgezeigt, die diese Tendenz fokusunabhängig erklären. In diesem Zusammenhang diskutiert Kapitel 2 auch die scheinbare morphologische Fokusmarkierung am Verb im Nord-Sotho und widerlegt, dass es sich um eine aktive Fokusmarkierung handelt.

In Anbetracht des Fehlens der syntaktischen Fokusmarkierung für Nicht-Subjekte untersucht Kapitel 3 den prosodischen Ausdruck von Fokus im verbalen und postverbalen Bereich in Nord-Sotho. Damit stellt die vorliegende Dissertation eine weitere Studie neben wirklich nur einer Handvoll Untersuchungen dar, die den prosodischen Ausdruck von in situ Fokus in tonalen Bantusprachen zum Thema haben. Die experimentelle Methode, die dabei angewandt wurde, wurde auch bei vergleichbaren Untersuchungen an europäischen Sprachen benutzt und liefert damit sprachübergreifend vergleichbare Daten. Die durchgeführte Produktions- und Perzeptionsstudie zeigt die Abwesenheit von jeglicher prosodischer Markierung der fokussierten Konstituente. Das Fehlen von prosodischer Markierung unter Fokus kann mittels der in Kapitel 1 vorgestellten Beschränkungen innerhalb der Optimalitätstheorie erfasst werden. Folglich stellt NordSotho einen der durch die benutzten Beschränkungen vorhergesagten Sprachtyp dar (' $\mathrm{fac}$ torial typology').

Obwohl Nord-Sotho ein vorhergesagter Sprachtyp ist, stellt die gleichzeitige Abwesenheit von syntaktischer und prosodischer Markierung eine Herausforderung für existierende Fokustheorien dar. Weithin wird angenommen, dass Fokus in einem der bei- 
den grammatischen Gebiete (oder alternativ durch Morphologie) markiert ist. Außerdem ist die Notwendigkeit eines grammatischen Merkmals für Fokus in Nord-Sotho in Frage gestellt, da die Ergebnisse in Kapitel 2 und 3 zeigen, dass ein formales F-Merkmal keine Auswirkungen auf die Grammatik in dieser Sprache hat.

Kapitel 4 kehrt deswegen zu der bereits in Kapitel 2 beschriebenen Asymmetrie bei der Fokussierung von Subjekten und Nicht-Subjekten zurück. Während Nicht-Subjekte in ihrer kanonischen Position fokussiert werden, können logische Subjekte unter Fokus nicht präverbal auftreten. Das Kapitel argumentiert, dass F-Markierung der entscheidende Aspekt ist, der das Auftreten eines fokussierten logischen Subjekts in präverbaler Position unterbindet. Es ist seit langem bekannt, dass Diskurs Syntax beeinflusst. Deswegen können Beschränkungen, die sich auf die Diskurs-Syntax Schnittstelle beziehen, als grundsätzlich unkontrovers angesehen werden. Kapitel 4 schlägt in leichter Abweichung zu vorhandener Literatur eine Schnittstellenbeschränkung vor, die F-markierte, logische Subjekte in präverbaler Position verbietet. Diese Beschränkung wird innerhalb der Optimalitätstheorie formal hergeleitet durch 'harmonic alignment' von einer Fokusskala mit einer Skala von grammatischen Funktionen. Einerseits zeigt dieses Kapitel somit, dass formale F-Markierung für die Grammatik von Nord-Sotho von entscheidener Bedeutung ist. Andererseits zeigt es, dass in Nord-Sotho, entgegen vorhandener Literatur zu anderen Bantusprachen, F-Markierung und nicht Topikhaftigkeit entscheidend ist für das grammatische Subjekt.

Kapitel 5 untersucht die Bedeutung von Spaltsätzen für Fokus in Nord-Sotho. Wie bereits in Kapitel 2 gezeigt, werden Spaltsätze obligatorisch für die Fokussierung von logischen Subjekten transitiver Verben benutzt. Bei der Fokussierung von Objekten geht der Gebrauch von Spaltsätzen mit einer semantischen Differenzierung einher, die in Einklang mit Ergebnissen zu anderen Sprachen als Restringierung der Alternativenmenge bezeichnet werden kann. Das Kapitel zeigt Beispiele für den semantischen Unterschied und belegt den Unterschied mit Frequenzdaten aus einer Korpusstudie. Die bei Objekten zu beobachtende Entsprechung von Form und Bedeutung ist ein Beispiel für pragmatische Arbeitsteilung, wonach unmarkierte Formen unmarkierte Bedeutungen tragen und vice versa. Bidirektionale Optimalitätstheorie leitet diese Arbeitsteilung formal her. Bei Subjekten transitiver Verben funktioniert diese Arbeitsteilung nicht. Das Kapitel argumentiert, dass bei Subjekten transitiver Verben eine unabhängige syntaktische Beschränkung interveniert, und somit der Spaltsatz als markierte Form auch unmarkierte Bedeutung tragen kann. 


\section{Acknowledgements}

\section{Motho ke motho ka batho!}

'A person is a person through other people.'

This thesis follows the spirit of the $u$ buntu philosophy in that it could not have been written without the help and support of many, many people (more than I am willing to cite here). I am uttermost grateful for having had the opportunity to learn so much during this work.

Most of all, I want to thank Manfred Krifka and Laura Downing for their guidance and inspiration on my linguistic way.

My warmest thanks and gratitude go to my interlocutors Lister Maphuti Matloga, Paulinah Mogodi, Makopi Mogodi, Mogoke Mogodi, Simon Mashanya, Mampaka Lydia Mojapelo, Matseleng Mokhwesana, and Deborah Mampuru for their patience with me asking about Northern Sotho.

For their interest in my work, feedback and challenging questions I want to thank Manfred Krifka, Laura Downing, Hubert Truckenbrodt, Jochen Zeller, Andreas Haida, Malte Zimmermann, Lutz Marten, Lisa Cheng, Louis Louwrens, Hans-Martin Gärtner, Tom Güldemann, Werner Frey, Bernd Pompino-Marschall, Carlos Gussenhoven, Jason Mattausch, and Vieri Samek-Lodovici.

Thanks also to Annekie Joubert for teaching me my first words in Sotho and for constantly feeding the fascination for this language and culture, and to Tracy Alan Hall and Claudia Maienborn for arising my interest in linguistics in the first place.

I am grateful to have been able to share my doubts and questions with my peers Sam Hellmuth, Andreas Haida, Florian Schwarz, and Boštjan Dvořák. Silke Hamann and André Meinunger also provided invaluable help and support. Thank you!

I would like to thank Jenny Ehrhardt, Raija Kramer and Mary-Anne Harenberg for practical help with getting literature, and the $\mathrm{HT}_{\mathrm{E}} \mathrm{X}$-users at the ZAS for help with $\mathrm{LT}_{\mathrm{E}} \mathrm{X}$. Furthermore, I want to thank Inge Kosch, Elsabé Taljard, Daan Prinsloo, the University of Pretoria (UP), and the University of South Africa (UNISA) for logistic help in South Africa, and the Embassy of South Africa for help in finding a Sotho speaker in Berlin.

Financial support from the DFG, ZAS Berlin, British Academy, DAAD, and the Linguistic department at University of KwaZulu-Natal is gratefully acknowledged.

Last but not least I want to thank all the people, friends and family, who encouraged and supported me on my way.

\section{Bathuši, montshepetšabošego ke mo leboga bo sele!}




\title{
List of abbreviations
}

\begin{abstract}
All examples from Northern Sotho are glossed according to the Leipzig Glossing Rules which comprise conventions for interlinear morpheme-by-morpheme glosses. For examples taken from other sources, the glosses have been adjusted to the best of my knowledge in order to provide consistency. This leads to quite a number of one-to-many correspondences. I apologize in advance for any misinterpretations. The Northern Sotho examples have been given in their orthographic form in order to enable recall. The Northern Sotho orthography treats morphemes as words most of the time in writing them separately. The following abbreviations have been used:
\end{abstract}


Table 1: List of abbreviations used

\begin{tabular}{|l|l}
1 & 1st person \\
2 & 2nd person \\
- A- & so-called Present Tense -a- \\
ACC & accusative (examples from É. Kiss 1998) \\
AFF & affirmative (examples from Baker 2003) \\
APPL & applicative \\
AUG & augment vowel (examples from Baker 2003) \\
CLn & noun class $n$ \\
COP & copula \\
DAT & dative (examples from É. Kiss 1998) \\
DEM & demonstrative \\
DS & dummy subject (examples from Watters 1979) \\
EXT & extended mood marker (examples from Baker 2003) \\
FUT & future \\
HAB & habitual mood (examples from Bresnan \& Mchombo 1987) \\
LOC & locative \\
NEG & negation \\
PAR & particle \\
PASS & passive \\
PERF & Perfect (examples from É. Kiss 1998) \\
PERSPRN & personal pronoun \\
PL & plural \\
POSS & possessive \\
POT & potential \\
PREP & preposition \\
PRES & Present (examples from Bresnan \& Mchombo 1987) \\
PRN & pronoun \\
PROP.NAME & proper name \\
PST & Past \\
QUAL & qualitative \\
QP & question particle \\
SM & subject marker (examples from Watters 1979) \\
REC & reciprocal \\
REFL & reflexive \\
REL & verbal relative clause marker \\
T & tense marker (examples from Baker 2003) \\
&
\end{tabular}




\section{Chapter 1}

\section{Introduction}

\subsection{Overview}

Over the last two decades, the expression of information structure in grammar has been revived as a prominent topic in linguistic research. Though the Bantu languages form the largest language family in Africa, consisting of approximately 300 languages (see Nurse \& Philippson, 2003: 2f), relatively little research has been carried out on the grammatical expression of the information-structural categories topic and focus, as compared to European languages. This thesis contributes to the ongoing debate by investigating focus marking in Northern Sotho, a Bantu language spoken in the northern part of the Republic of South Africa, thereby deepening the understanding of whether and how the category focus is represented and marked in the languages of the world. It provides a systematic overview, description and investigation of aspects related to information structure in the grammar of Northern Sotho by applying methodology that allows cross-linguistic comparison of the data.

The overall claim of the thesis is that there is no grammatical marking of focus (Fmarking) in Northern Sotho, neither by syntax nor by prosody. Nevertheless, the language does structure utterances dependent on their information structure. Thereby, it targets discourse-old constituents which get either deleted, pronominalized or dislocated to either the left- or right sentence periphery. These (morpho-)syntactic processes conspire in such a way that the focused constituents often end up in clause-final position. Awareness of this fact is essential for an understanding of a morphological alternation that occurs on the verb in Northern Sotho and that has sometimes been described as focus marking in the literature.

Formal F-marking is nevertheless important for the grammar of Northern Sotho, although it is not directly reflected in neither syntax nor prosody nor morphology: F-marked logical subjects must not appear in their canonical preverbal position. Although Northern Sotho shows a strict correspondence between form and meaning for different foci in the case of objects, this correspondence breaks down in the case of focused logical subjects of transitive verbs. Because they cannot appear neither postverbally nor preverbally, they have to be focused by means of a cleft sentence.

The thesis outlines how all the aspects mentioned above can be modeled in the framework of Optimality Theory (OT). For the modeling of syntactic in situ focus and the lack 
of prosodic expression of focus, it retreats to constraints which are uncontroversial in the relevant literature. The interface constraint *F-MARKED/ SUBJECT, which is proposed here to moderate between syntax and discourse-pragmatics, has its precedents in the literature but differs in that the prominence scales involved are crucially modified. The derivation of the form-meaning correspondence for objects in chapter 5 provides an example of 'division of pragmatic labor' according to which unmarked forms are used for unmarked meanings and vice versa.

The lack of prosodic expression of focus and the ban of F-marked logical subjects in preverbal position in Northern Sotho constitute two 'languages' that are predicted by the factorial typologies of the constraints involved in the analysis. Therefore, the data presented here are important for showing the universality of the constraints proposed.

Moreover, the overall result raises interesting questions for existing focus theories. Focus theories assume that focus is marked somehow in grammar, either by prosody, syntax, or morphology. The data presented in this thesis show that grammatical focus marking is no language universal but rather that the role of context deserves more attention. Context is necessary to resolve focus ambiguities in languages like English and German, and the results presented here suggest that focus interpretation through context is the path followed by Northern Sotho in all contexts. The results therefore underline the importance of typological research for the development and improvement of linguistic theories.

The thesis is structured as follows: Chapter 1 provides a discussion of information structure with the objective to establish the notion of focus that is referred to throughout the thesis: Focus denotes the set of alternatives. The methodology that has been used in the thesis to elicit this kind of focus is outlaid in detail. Furthermore, a short literature survey presents means for grammatical focus marking from different areas of grammar (phonology, morphology, syntax) and from different languages of the world. The variety of means of focus marking found in the languages of the world justifies the investigation of all areas of grammar - syntax, phonology, morphology - that is undertaken for Northern Sotho is this thesis. Chapter 1 also presents the theoretical framework in which the data of Northern Sotho are accounted for in this thesis. It describes the basic machinery of OT and illustrates its wide application by means of case studies from different areas of grammar. Lastly, chapter 1 familiarizes the reader with the essential characteristics of Northern Sotho grammar: tone, word order, and agreement.

Chapter 2 investigates the syntactic expression of focus in Northern Sotho. It shows the subject/object asymmetry in Northern Sotho which entails that logical subjects are not focused in their canonical position, but either postverbally or by means of a cleft. Objects, adverbials, and the verb are focused in their canonical position. The chapter further investigates alternative syntactic focus positions, as studies on other Bantu languages have shown that these languages dispose of a designated focus position. This is claimed to be either left-peripheral, immediately postverbal, or clause-final. This thesis shows that neither of these positions is a designated focus position in Northern Sotho. Non-subjects are simply focused in situ. The chapter also discusses the observable tendency of focused constituents to appear clause-finally in Northern Sotho, but claims that this tendency is independent of focus marking. Alternative approaches are presented. In this connection, apparent morphological focus marking on the verb is critically discussed.

In light of the lack of syntactic means of focus marking, chapter 3 investigates the 
prosodic expression of focus of verbal and postverbal constituents in Northern Sotho. It applies experimental methodology that has been tested on Indo-European languages and thereby makes the data comparable cross-linguistically. The production and perception studies carried out show the absence of prosodic marking with the simultaneous lack of syntactic marking for in situ focus in the verbal and postverbal domain in Northern Sotho. The lack of prosodic expression of focus can be accounted for by the constraints stated for focus in English and Italian in one of the case studies in chapter 1, and consequently support the factorial typologies predicted by these constraints. Though inherently predicted by work on the syntax-prosody interface within OT, the absence of grammatical marking of focus challenges existing theories of focus that predict focus to be marked by some grammatical means in a language. The need of formal F-marking for the grammar of Northern Sotho is challenged by the data presented in chapter 2 and 3, as F-marking does not have any consequence for its grammar so far.

Chapter 4 therefore returns to the subject/object asymmetry in focus-related contexts which was initially illustrated in chapter 2 . Whereas non-subjects are focused in their canonical position, focused logical subjects must crucially not appear in their canonical preverbal position. The chapter shows that the crucial notion for the ban of logical subjects from their canonical preverbal position is formal F-marking. The need for interface constraints that relate syntax to discourse is known since at least Behagel's "Stellungsgesetze" (1932: 5) for German. Therefore, the necessity of those interface constraints can be considered uncontroversial. This restriction is derived within OT by harmonic alignment of prominence scales relating to discourse prominence and grammatical functions. Thereby, the necessity of formal F-marking for the grammar of Northern Sotho is given evidence for. Furthermore, the chapter shows in detail that, contrary to what has been claimed in the literature, the grammatical subject in Northern Sotho is not always an aboutness topic.

In chapter 5, the importance of cleft structures for the expression of focus in Northern Sotho is investigated. For Northern Sotho, cleft sentences can be shown to have a semantic differentiation when used with objects, which is not present when used for focused subjects. This result is supported by frequency data from a corpus study. The correlation between form and meaning can be formally derived when adopting the view that not only prosodic and syntactic structure but also semantic interpretation need to be evaluated. The chapter presents an analysis of the form-meaning correspondence within bidirectional OT, and also treats the blocking of the correspondence in the case of focused subjects of transitive verbs. Subjects of transitive verbs have to appear in a cleft construction because syntactic restrictions rule out a postverbal appearance.

Within the present chapter, section 1.2 discusses the basic concepts of information structure. Section 1.3 presents the methodology used in thesis for the collection of primary and secondary data. Section 1.4 defines grammatical marking of focus and gives examples from different areas of grammar and from different languages of the world how focus can be encoded in grammar. Section 1.5 motivates Optimality Theory (OT) as one theoretic framework which allows to model the interaction of prosody, syntax and discourse-pragmatics in a language. Section 1.6 and 1.7 introduce the language Northern Sotho with its basic linguistic characteristics. 


\subsection{Information Structure}

The following section discusses the basic concepts of information structure. The entities of information structure are presented and reviewed in this section and the term focus that is adopted in this thesis is defined.

There is a long tradition of investigating the information packaging of a sentence, starting at least with Paul (1880). Terminology and views changed greatly over time and I gratefully acknowledge the clarifying outline and presentation of this topic in Krifka's lecture on information structure (Krifka 2004/2005) ${ }^{1}$ which is adhered to in the following presentation.

\subsubsection{What is information structure?}

Information structure of a sentence refers to the structuring of linguistic information with the objective of optimizing the information transfer in discourse. The term 'information structure' has been coined by Halliday (1967) to refer to the partition of spoken language into informational units, which do not necessarily overlap with syntactic units. The term 'information structure' does therefore not refer to the information itself but rather how it is transferred to the hearer. Chafe (1976:27) draws the association to 'packaging': information structure is about how a message is transferred to a receiver, not about the content of the message itself. A certain information might be packed differently depending on the background and the goal of the discourse. The examples in (1) and (2) from German illustrate this.

(1) a. Der Gärtner hat mit der Köchin am Freitag gesprochen.

b. Mit der Köchin hat der Gärtner am Freitag gesprochen.

c. Am Freitag hat der Gärtner mit der Köchin gesprochen.

'The gardener talked to the cook on Friday.'

German allows free word order. Therefore, either the subject (1-a), a prepositional object (1-b), or a temporal adverb (1-c) can appear in sentence-initial position. The sentences in (1) differ not only in word order, but also in their information structure: (1-a) is an utterance about the gardener, (1-b) about the cook, and (1-c) sets 'Friday' as the temporal frame in which the predication holds. The sentences in (2) constitute another example. Throughout the thesis words bearing the sentence accent are marked by small caps.
a. Der Gärtner hat mit der Köchin am FREITAG gesprochen.
b. Der Gärtner hat mit der KÖCHIN am Freitag gesprochen.
c. Der GÄRTNER hat mit der Köchin am Freitag gesprochen.
d. Der Gärtner HAT mit der Köchin am Freitag gesprochen.
'The gardener talked to the cook on Friday.'

In the examples in (2), the canonical SVO word order remains constant. The sentences differ with respect to the accent placement only. In an unmarked declarative utterance, sentence accent is rightmost in German. Leftward movement of accent correlates with

\footnotetext{
${ }^{1}$ Notes available online: http://amor.rz.hu-berlin.de/ h2816i3x/, last access 10.11.2005
} 
a change in discourse meaning. All sentences in (2) have different discourse functions, which can be illustrated by means of the questions they provide answers to. Sentence (2-a) answers the question 'When did the gardener talk to the cook?', sentence (2-b) answers the question 'Who did the gardener talk to on Friday?', sentence (2-c) answers the question 'Who talked to the cook on Friday?' and finally, sentence (2-d) answers the question 'Did the gardener talk to the cook on Friday?'.

Crucially, all sentences in (1) and (2) have the same truth-value. That means, the condition under which all sentences in (1) and (2) are true, is the same. They are true when there is a gardener who talked to a cook on a Friday. The differences mentioned in (1) and (2) relate to the information structural units topic and focus respectively. The sentences in (1) each have a different topic, the sentences in (2) each display a different focus. Topic and focus will be discussed in section 1.2.2 in detail.

In optimizing the information transfer in discourse, information structuring takes into account the needs of the hearer of the message. Prince (1981) describes information packaging as

"the tailoring of an utterance by a sender to meet the particular assumed needs of the intended receiver. That is, information packaging in natural languages reflects the sender's hypotheses about the receivers assumptions and believes and strategies." (Prince 1981: 224)

Defining information structure as in Prince (1981) makes the speaker's intention to one central aspect of the research area. However, for linguistic research only those speaker's intentions are relevant that are reflected in the grammar.

"We are, therefore, not concerned with what one individual may know or hypothesize about another individual's belief-state except insofar as that knowledge and those hypotheses affect the forms and understanding of linguistic productions." (Prince 1981: 233)

To sum up, a definition of the term 'information structure' contains both speaker intention and grammatical form (see also Lambrecht 1994). It refers to the partition of an utterance into information units on the basis of the intended receivers needs and in a linguistically relevant way.

\subsubsection{Parts of information structure}

Like in every work on information structure since at least Levinson (1983), also in the present thesis the confusing and inconsistent use of the basic terminology in this field has to be pointed out before presenting an overview of the terminology found in the literature:

"Terminological profusion and confusion, and underlying conceptual vagueness, plague the relevant literature to a point where little may be salvageable." (Levinson 1983)

The basic terminology with respect to information structure appears pairwise and is listed in (3) (following Büring 1997). 
(3)

$\begin{array}{ll}\text { Terminology } & \\ \text { a. psychological subject } & \text { psychological predicate } \\ \text { b. Topic } & \text { Comment } \\ \text { c. Theme } & \text { Rheme } \\ \text { d. Given/Old } & \text { New } \\ \text { e. Background } & \text { Focus } \\ \text { f. Presupposition } & \text { Focus }\end{array}$

The polar structuring of these complementary pairs is uncontroversial although also other groupings can be found, as e.g. topic/focus. The following subsections discuss some of these pairs in detail.

\section{Topic/comment}

The pairs in $(3-a, b)$ fall together as nowadays topic/comment is used to refer to what von der Gabelentz (1891) and Paul (1880) term 'psychological subject' and 'predicate'.

"Das Bild des Ganzen schwebt mir vor: die Theile halte ich in den Händen, um sie nachschaffend aufzubauen. Was bestimmt mich, erst diesen [sc. Theil] aufzustellen, dann den, dann jenen? Offenbar ist es dies, dass ich erst dasjenige nenne, was mein Denken anregt, worüber ich nachdenke, mein psychologisches Subject, und dann das, was ich darüber denke, mein psychologisches Prädicat, und dann wo nötig wieder Beides zum Gegenstande weiteren Denkens und Redens mache."2(von der Gabelentz 1891: 370f)

Just like the terms psychological subject and predicate, also the dichotomy topic/comment refers to the proposition (comment) that has been made about something (topic). A differentiation along these lines can also be found in Chafe (1976) and Reinhart (1981) among others. Reinhart (1981) has coined the term aboutness topic for this use of the term topic that refers to what the rest of the sentence is about (also common: sentence topic, Reinhart 1981). Because of the criterion that the rest of the sentence is about the topic, there are certain restrictions on this expression which can be used as tests for aboutness topics (see Reinhart 1981, see also section 4.2.2 for testing these properties with respect to the preverbal subject in Northern Sotho).

First, aboutness topics cannot be unspecific and indefinite (with the exception of generic expressions) as a sentence cannot be about an unspecific, indefinite entity. Second, certain quantificational expressions like at least, nearly all cannot be aboutness topics for semantic reasons. Third, the intuitive notion of aboutness can be lexicalized by a paraphrase such as as for or about in languages like English. An example is provided in (4).

(4) Paraphrase for topic

As for the cook, the gardener talked to her on Friday. (cf. 1b)

\footnotetext{
2"I have the whole picture in mind: I hold its parts in my hands in order to build it together. What determines which part to take first? Obviously I start by naming what initiates my thinking, the psychological subject, followed by what I think about it, the psychological predicate. If necessary I can return to both parts in speaking or thinking afterwards." [translation SZ]
} 
Next to aboutness topics we also find frame setting expressions (see Jacobs 2001). Frame setting expressions are marked similarly to aboutness topics in languages like German (by lack of accent) and Japanese (by insertion of the topic marker $w a$ ), but are different in their function. The example in (5) illustrates:

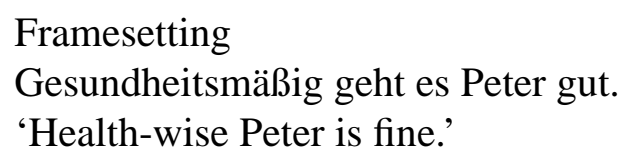

The sentence in (5) is not a statement about Peter's health. 'Gesundheitsmäßig' sets the (modal) frame in which the statement holds (see also Chafe 1976: the topic sets "a spatial, temporal or individual framework within which the main predication holds").

The topic/comment distinction addresses the hearer-oriented aspect of information structure with respect to linear order of constituents. The sentence topic precedes the statement about this topic. The preference for this order might be related to parsing requirements.

\section{Theme/rheme}

The terminological pair theme/rheme was first introduced in order to refer to the psychological subject and predicate. Later, it was used either in the sense of topic/comment (e.g. in Halliday 1967) or in the sense of given/new (Prague School). It will therefore not be dealt with separately.

\section{Given/new}

The terminological pair given/new refers to the contextual givenness of linguistic expressions. Given refers to constituents that have been mentioned before in discourse (implicitly or explicitly). New refers to newly introduced discourse constituents. A conflation of the termini given/new and topic/comment occurs because in most of the cases the topic constituent is given and the comment is new (see section 1.2.4 which shows this for the literature on Bantu languages). Sometimes a discrimination of these two terminological pairs is consciously avoided, as in Danes (1970), cited following von Heusinger (1999):

"Taking for granted that in the act of communication an utterance appears to be, in essence, an enunciation (statement) about something [...], we shall call the parts theme (something that one is talking about, topic), and rheme (what one says about it, comment). Following the other line, linking up utterance with the context and/or situation, we recognize that, as a rule, one part contains old, already known or given elements, functioning thus as a 'starting point' of the utterance, while the other conveys a new piece of information (being thus the 'core' of the utterance).

But, as in most cases, the two aspects coincide, we shall, in our following discussion, disregard the said distinction."

However, minimal pairs exist where the distinction does not coincide (see Halliday 1967). It is therefore necessary to treat topic/comment and given/new separately. The example in (6) illustrates Halliday's claim for English. 
(6)

topic/comment vs given/new

a. Mary always goes to TOWN on Sundays.

b. Mary always goes to town on SUNDAYS.

Both sentences in (6) have the same topic/comment structure. 'Mary' is the topic, i.e. that entity that the rest of the sentence makes a statement about. However, the sentences in (6) differ with respect to the given/new distinction within the comment. In (6-a), 'town' is the new information. A sentence as in (6-a) could answer a question like 'Where does Mary go on Sundays?'. In (6-b), the temporal adverbial is the new information. Sentence (6-b) could be an answer to a question like 'When does Mary go to town?'.

The given/new distinction has been extended in order to address the hearer-oriented aspect of information structure. Chafe (1976: 30) interprets the given/new distinction psychologically.

"Given (or old) information is that knowledge which the speaker assumes to be in the consciousness of the addressee at the time of the utterance. Socalled new information is what the speaker assumes he is introducing into the addressee's consciousness by what he says."

The basic distinction made by Chafe (1976) laid the basis for more fine-grained distinctions, e.g. of more or less given/new expressions (Prague School, see e.g. Firbas 1964) or of a familiarity scale for referentiell expressions (Prince 1981).

\section{Background/Focus}

The term focus is sometimes used to refer to the new, accented constituent within a comment (Halliday 1967, but also Vallduví \& Engdahl 1998). This can be illustrated in reconsidering example (6). Although having the same comment, the sentences in (6-a) and (6-b) differ in focus. In (6-a), 'town' is the focus of the comment, in (6-b) it is 'Sundays'.

Since Rooth $(1992,1996)$ focus is considered the expression that introduces alternatives. The other constituents of the sentence are called background. The example in (7) illustrates this.
a. A: Wann ist Karl nach Berlin gefahren?
'When did Karl go to Berlin?'
b. B: Karl ist GESTERN nach Berlin gefahren.
'Karl went YESTERDAY to Berlin.'

By posing the question in (7-a), A wants to know which proposition from the propositions 'Karl went to Berlin at $t$ ' is true, whereby $t$ varies over times. Speaker B chooses one alternative from the propositions and indicates the choice by the accent on the temporal adverbial gestern in (7-b). Focus as defined in this way does not only appear in answers to questions but also in contrasting statements, as in (8-a), or in utterances with certain (focus-sensitive) particles, as in (8-b,c). 
(8) Focus with contrast and with particles
a. (i) A: Karl ist vorgestern nach Berlin gefahren.
'Karl went to Berlin the day before yesterday.'
(ii) B: Nein, Karl ist GESTERN nach Berlin gefahren.
'No, Karl went to Berlin YESTERDAY.'
b. Peter weiss nur, dass Karl GESTERN nach Berlin gefahren ist.
'Peter only knows that Karl went to Berlin YESTERDAY.'
c. Peter weiss nur, dass Karl gestern nach BERLIN gefahren ist.
'Peter only knows that Karl went to BERLIN yesterday.'

The focus constituent does not necessarily have to be discourse-new. This is illustrated by the example in (9).

(9) Focus on discourse-old material

a. A: Wann ist Karl nach Berlin gefahren- gestern oder vorgestern?

'When did Karl go to Berlin- yesterday or the day before yesterday?'

b. B: Karl ist GESTERN nach Berlin gefahren.

'Karl went to Berlin YESTERDAY.'

Chomsky (1971) introduced the terminology of focus/presupposition which was taken up by Jackendoff (1972). A presupposition of a sentence denotes the logical implementation of a sentence that remains constant across semantic modifications such as negation, modification, and question formation, as illustrated in (10).

(10) Semantic modifications
a. Karl ist GESTERN nach Berlin gefahren.
'Karl went to Berlin YESTERDAY.'
entails: Karl went to Berlin sometime.
b. Karl ist nicht GESTERN nach Berlin gefahren.
'Karl didn't go to Berlin YESTERDAY.'
entails: Karl went to Berlin sometime.
c. Karl ist vielleicht GESTERN nach Berlin gefahren.
'Perhaps Karl went to Berlin YESTERDAY.'
entails: Karl went to Berlin sometime.
'Did Karl go to Berlin YESTERDAY?'
entails: Karl went to Berlin sometime.
d. Ist Karl GESTERN nach Berlin gefahren?

All sentences in (10) entail that Karl went to Berlin sometime. More specifically, utterances with focus usually entail an existential presupposition, i.e. that there is a time that Karl went to Berlin. This is formulized in (11).

(11) Karl ist GESTERN nach Berlin gefahren.

'Karl went to Berlin YeSTERDAY.'

$\lambda \mathrm{t}$ [Karl went to Berlin at $t$.]

Consequently, a question as in (10-d) that contains a focus, cannot be answered by 'Karl 
never went to Berlin'. By making use of the semantic concept of presupposition, the notion of background can be formalized as the existential presupposition. Because the expression in focus is substituted by a variable which is bound by an existential quantifier, the existential presupposition is identical to the background of a focus.

\subsubsection{Information structural units used in the thesis}

The thesis adopts the definition of focus whereby focus indicates a set of alternatives of which one alternative is chosen (Rooth 1992, 1996). Alternatives are at play in question/answer pairs but also in contrastive contexts like correction, or with focus-sensitive particles. The focused constituent is marked with a morphosyntactic feature $\mathrm{F}$, following Jackendoff (1972). The focused constituent receives special discourse prominence in languages like English and German. However, focus as a set of alternatives is a universal category whose definition is independent of actual focus marking in a specific language. No formal differentiation of so-called contrastive and information focus is made because both kinds of focus involve a set of alternatives (see É. Kiss 1998). The difference in the size of the set of alternatives and in the interaction of the focused constituent with other alternatives leads to different pragmatic readings (corrective, selective, new information focus).

The category focus as denoting a set of alternatives is different from focus denoting new information. This is illustrated by the examples in (12).

a. (i) A: Wann ist Karl nach Berlin gefahren- gestern oder vorgestern?

'When did Karl go to Berlin- yesterday or the day before yesterday?'

(ii) B: Karl ist GESTERN nach Berlin gefahren.

'Karl went to Berlin YESTERDAY.'

b. (i) A: Von wo hast du denn die schöne Schale?

'Where did you get this nice bowl from?'

(ii) B: Die habe ich gestern auf dem FLOHMARKT gekauft.

'I bought it at the FLEA MARKET yesterday.'

The example in (12-a), repeated from (9) above, shows that focus does not necessarily have to be new information. The example in (12-b) shows that not all new information in an utterance is necessarily focused. The preceding question in (12-b) marks the local adverb as the questioned constituent (=focus). Although the temporal adverb and the lexical content of the verb are also new information in the answer in (12-b), they are not focused according to the definition of focus adopted here.

In the thesis, the common differentiation between narrow and wide focus will be followed. Narrow focus refers to focus on one syntactic constituent. This is prototypically the case in answers to wh-constituent questions, as in (13-a). Wide focus refers to focus on a larger clause-like syntactic constituent, either VP-focus or sentence focus, as in (13-b). 

a. Who ate pizza?
$[\text { Peter }]_{F}$ ate pizza.
b. What happened at the party?
[Peter ate pizza. $]_{F}$

The differentiation between narrow and wide focus is important for two reasons: first, as indicated in the example in (13), the grammar makes a distinction whether a constituent is in narrow focus or part of a wider focus. In German, the difference manifests itself in the pattern of the pitch accent. An $\mathrm{H}^{*} \mathrm{~L}$ pitch accent is used for constituents in narrow focus, a $\mathrm{L} * \mathrm{H}$ pitch accent is used for non-final elements in wide focus. Second, the sentences in (13) also differ in the alternatives they evoke. This is represented in (14).
a. $\lambda x[\mathrm{x}$ ate pizza]
alternatives:
Peter, Paul, Mary...
b. $\lambda \mathrm{p}$ [p happened] alternatives: Peter ate pizza, Peter kissed Mary, Peter hit Paul ...

Whereas the alternatives for narrow focus on the subject are other possible referents, the alternatives for wide sentence focus are other possible situations or events. Although the subject in (14-b) is also new information, it differs from the subject in (14-a) as it is not the questioned constituent. A differentiation is therefore necessary between questioned constituent and new information, and the thesis will refer to focus as the questioned constituent or the constituent that makes reference to possible alternatives. Jackendoff (1972) in his original proposal captured the difference by assigning the whole sentence in (14-b) an F-feature. Selkirk $(1978,1995)$ proposed to introduce two F-features to capture the difference. According to her view, each element in (14-b) bears an F-feature as it is new information, and the whole sentence carries a FoC-feature indicating that the whole sentence is the questioned constituent. The two views are represented in (15).

$$
\begin{aligned}
& \text { What happened at the party? } \\
& \text { a. Jackendoff }(1972) \\
& \quad[\text { Peter ate pizza }]_{F} \\
& \text { b. Selkirk }(1978,1995) \\
& \quad\left[\text { Peter }_{F} \text { ate }_{F} \text { pizza }_{F}\right]_{F o c}
\end{aligned}
$$

The thesis adopts Jackendoff's notation for morphosyntactic focus marking. Therefore, when stating the generalization that the subject must not be F-marked in Northern Sotho in chapter 4 , it is meant that the subject must not be narrowly focused. By showing the relevance of F-marking for the grammar of Northern Sotho, it is automatically accepted, following the terminological dichotomies established above, that all non-focused information is background.

Due to the definition of focus adopted in the thesis, specific contexts need to be elicited when investigating the grammatical expression of focus in Northern Sotho. Among them are question/answer pairs, correction contexts through yes/no-questions or focused negation, and structures containing focus-sensitive particles such as fela-'only'. Data from these contexts are compiled through direct elicitation, by means of a questionnaire, and by evaluation of (small) amounts of text. The uniform treatment of contrastive focus and information focus is borne out in the data in Northern Sotho, as no grammatical differ- 
entiations appear for different types of foci in the contexts just mentioned. Chapter 5 , however, is devoted to a syntactic and semantic differentiation of focus, that manifests itself in contexts of preconstructed domains.

Apart from focus, also the relevance of the notion of topic will be investigated in this thesis. The differentiation into familiarity and aboutness topic is followed and it is investigated if either of the two can serve to define the properties of the preverbal subject in Northern Sotho. As will be shown in chapter 4, the notions have no direct relevance for the grammar of Northern Sotho. Rather, they emerge as a category due to the incompatibility of certain grammatical functions with focus.

\subsubsection{Information structure in Bantu languages}

The role of information structure for the grammar of Bantu languages has been acknowledged since at least Givón (1976), especially the importance of the notion topic. In functional and generative approaches the incompatibility of narrowly focused subjects in their canonical preverbal position has been attributed to their discourse-pragmatic properties. Subjects in Bantu languages are regarded topics (Givón 1976, Louwrens 1979a, Demuth \& Johnson 1989, Bresnan \& Mchombo 1987). The sources cited use different definitions of the term topic. Givón (1976: 152f) uses the term topic both in its meaning of old information and of topic of discussion. Bresnan \& Mchombo (1987: 746), referring to work by Givón (1976), Chafe (1976) and Wald (1979), define the ToPIC constituent in Lexical-Functional Grammar (LFG) as the constituent under discussion, whether previously mentioned or assumed in discourse. Demuth \& Johnson (1989) follow the work of Bresnan \& Mchombo (1987) and also adopt their definition of topic. Louwrens (1979a) defines the topic as old information. All these approaches have in common that they refer to the topic as old discourse information that has been under discussion (explicitly or implicitly) or has been mentioned before. Evidence for this claim comes from three different areas: diachronic evidence, (morpho-)syntactic evidence, and textual evidence (for a detailed discussion of this evidence see section 4.2.1).

However, as has been shown in the discussion of the relevant terminology of information structure, the notions of given, new, and topic might overlap with the notion of focus in some specific contexts. It is therefore necessary to investigate in detail which of these notions is the relevant one for the grammar of Northern Sotho.

The case of subject focus in Northern Sotho shows that the terms topic and given cannot account for the data in this language. The fact that the subject cannot be focused in its preverbal position supports the view that the preverbal subject in Bantu languages is a topic. However, as will be shown in chapter 4, the subject does appear in its preverbal position if it is in wide focus. This is problematic when considering the grammatical subject an obligatory topic, as a subject under wide focus is not an aboutness topic. An all-new sentence is not a statement about the subject of this sentence but about the whole situation. Reference to topicness, therefore, does not account for the data, as it stretches the notion of aboutness topic beyond its original concept in order to accommodate the cases of wide focus. The data suggest, however, that the valid generalization is that the preverbal subject in Northern Sotho must not be F-marked. The general observation that subjects tend to be topics can be derived in interaction with F-marking, however. This 
will be discussed and derived in chapter 4 .

\subsubsection{Summary}

In this section, the information structural entities have been motivated from a cognitive or psychological perspective, independently of their expression in grammar. However, in order to be interesting for linguistic theory, the information structural entities mentioned above need to show some influence on grammar. The research question of this thesis can be stated as to whether there is grammatical marking of focus in Northern Sotho.

Why should information structural aspects such as topic or focus be reflected in the grammar anyway? The answer lies in the general task a grammar fulfills: A grammar of a language encodes meaning/information and the task of syntax, morphology/lexicon and prosody is to encode meaning in an unambiguous way to make communication work. Across languages, grammatical reflexes of information packaging can be found in all grammatical areas, in syntax, in morphology/lexicon, and in prosody. An example for the influence of information structure on syntax has been given in (1) from German. In the examples in (1), the topic of a sentence is expressed in sentence-initial position. The examples in (2) exemplified the use of prosody (accent) for the grammatical marking of focus in German.

A grammatical model of a language must therefore be able to account for the influence of information-structural categories on the grammatical expression. Chomsky (1971) points out that phenomena of prosodic structure, like diverging accent patterns, and syntactic phenomena, like cleft sentences, lead to a change in the semantics. Semantics therefore has to take surface structure into consideration. A different view is taken here: It is assumed that it is not different syntactic structures that lead to different semantic interpretations but also vice versa, namely that different semantics can lead to different surface structures.

\subsection{Controlling for focus: Methodology}

A recent conference announcement ${ }^{3}$ argues for linguistic studies to collect "evidence from multiple data types because all sort of linguistic data are inherently complex and reflect performance and production factors as well as the constructs that are the subject of linguistic theory". The present thesis follows this desideratum in bringing together data from different sources: from controlled elicitation, from (guided) spontaneous speech, from a corpus study and from texts.

Though free spontaneous speech is always preferred over elicited data, the researcher is confronted with the problem that complete naturalness is coupled with complete lack of control. This means on the one hand, that the construction, word or intonation contour of interest might occur only very rarely in running speech ('Zipfian' problem), which makes it simply impractical to use free conversation for linguistic research of a pre-determined aspect. On the other hand, a potential issue that is outside control specifically concerning

\footnotetext{
${ }^{3}$ 'Linguistic Evidence: Empirical, Theoretical and Computational Perspectives', Workshop in Tübingen, Febr. 2006, announced on LinguistList 16.2324 of 04.08.2005, last access 05.12.2005.
} 
prosody, is that 'prosodic' features are used both for regulation of conversation (turntaking) and for conveying sentence-related meaning (e.g. question vs statement). Therefore, elicitation methods with differing degrees of control (and naturalness) were used for the elicitation of the data that went into this thesis.

Data from spontaneous speech were collected by help of the questionnaire 'Information Structure' that was developed in the project D2 of the SFB 632 of HumboldtUniversity Berlin and University of Potsdam. ${ }^{4}$ It contains structured games and metalinguistic triggers such as pictures and short video clips, which yield at the pronunciation of differing information structures. Two native speakers worked together through the whole questionnaire. Data in this thesis that are taken from the questionnaire are marked by QUIS.

The data collected by conventional elicitation were controlled for their focus structure by adopting the definition of focus as indicating alternatives that has been laid out in detail in section 1.2. Therefore, mainly question/answer contexts, focused negation and sentences with focus-sensitive particles have been elicited. As these contexts have also been used for the eliciation of focus structures in other languages, this method of direct eliciation provides data which are comparable cross-linguistically. The same applies to the production and perception data presented in chapter 3. Although they too, are highly controlled, it is exactly this control which makes them comparable cross-linguistically. Again, having native speakers working in pairs increased the naturalness of the elicitation situation.

A corpus study was done searching for questions (see section 5.1.4). The corpus of Northern Sotho ${ }^{5}$ consists of texts written in Northern Sotho and contains bible texts (old and new testament), novels, plays, (some) poetry, magazine (there is no newspaper in Northern Sotho), official internet pages, and academic writing. The corpus comprises approximately 6,2 million words in total. Though it is only a small corpus and there are some serious caveats with it, one being that the the corpus is quite heteregoneous (e.g. the bible is in old translation therefore in a formal register and archaic), it was chosen to work with this tool for the following reasons: First, it is specific to the language under investigation and therefore provides quantitative evidence for language-specific structures, and second, it broadens the general data base from which to work. The restriction of the search strategy to questions was done for methodological and practical reasons. As the corpus is not annotated syntactically, the only possible searching strategy was for question words. The inference from question structures to focus structures was done following the standard assumption in the literature that the distribution of $w h$-words corresponds to the distribution of focus.

Finally, the data taken from texts can be considered natural, though here too, a lack of control can be assessed. The exact determination of information packaging in texts often is subject to subjective analysis. Though the analysis of texts undoubtedly provides valuable insights, the cross-linguistic comparability of the data remains a difficult issue.

The next section comes back to information structure in grammar and gives an overview of grammatical means of focus marking that are used in different languages of the world.

\footnotetext{
${ }^{4} \mathrm{I}$ thank the members of this group for letting me use this material.

${ }^{5}$ Access only on-site via University of Pretoria, Department of African Languages, Prof. Daan Prinsloo or Dr. Elsabé Taljard.
} 


\subsection{A cross-linguistic survey of focus marking}

That focus and topic are relevant notions for the grammar of the languages of the world is mirrored by the vast amount of literature on the grammatical expression of these categories. Especially in the last decades not only the discussion about the semantics of focus revived (see a.o. Rooth 1992, Schwarzschild 1999, Krifka 2001 a.o.), but also descriptions of the grammatical expression of focus in the languages of the world received more attention. Especially the study of less-known languages revealed interesting challenges for existing focus theories. Northern Sotho is one such example.

This subsection aims at providing an overview over the grammatical means of focus marking found in the languages of the world. It lists languages that make use of phonological, morphological, and syntactic means in order to indicate which of the constituents is focused. Thereby, the following precautions apply: First, referring back to section 1.2, there is much terminological confusion with respect to focus and topic. Therefore, the works cited do not agree on the definition of focus. For details, the reader is referred back to the references given. Second, this list is by no means exclusive but rather cites a small sample of the relevant literature. Exclusion of other studies does not entail a judgement about their significance. Third, the classification into prosodic, morphological, and syntactic means does not mean that the languages mentioned only use one of these means (see also section 1.4.5). Fourth, the classification of a focus strategy, as e.g. syntactic or phonological, might depend on the analysis.

\subsubsection{Definition of grammatical marking of focus}

The thesis distinguishes between grammatical reflexes of focus (or information structure more generally) and grammatical marking of focus.

The term grammatical marking of focus refers to rules or generalizations that relate a certain grammatical structure or property, either syntactic, morphological or prosodic, to a $\mathrm{F}$ (ocus)-marked constituent. One example of grammatical marking of focus is the occurrence of a pitch accent on F-marked constituents in languages like English and German. The rule for the distribution of pitch accent makes direct reference to F-marking.

The term grammatical reflex of focus refers to a linguistic phenomenon, either syntactic, morphological or prosodic, that occurs in connection with information structure but which cannot be generalized by assigning a certain grammatical structure or property to an F-marked constituent. One example of a grammatical reflex of focus is deaccentuation of given material in languages like English and German. The rules that deaccentuate constituents which are given in discourse do not refer to F-marked constituents. Nevertheless, they occur in connection with the information structuring of an utterance. Morphosyntactic reflexes of information structure are topic marking in Japanese. Scrambling in German can be described as a syntactic reflex of information structure: non-focal material intervening between the focus constituent and the verb is moved in order for the focused constituent to be target of the neutral sentence accent (e.g. Krifka 1998). In Catalan, discourse-old material is moved out of the core sentence (Vallduví \& Engdahl 1996).

The distinction into grammatical marking and reflex of focus seems necessary as these two aspects do not necessarily coincide. Whereas grammatical marking of focus always 
results in a grammatical reflex of focus, a grammatical reflex of focus cannot be equated with grammatical marking. The thesis will show that there are grammatical reflexes of focus in Northern Sotho, although Northern Sotho does not have grammatical marking of focus.

The next sections give examples for prosodic, morphological, and syntactic marking of focus from the languages of the world.

\subsubsection{Prosodic marking of focus}

Prosodic marking of focus refers to the assignment of special intonational or suprasegmental features to the F-marked constituent or to the constituent that contains the Fmarked element. The prosodic means found in the languages of the world include the ones given in (16). ${ }^{6}$
Prosodic means of focus marking (Selkirk 2004)
a. Assignment of pitch accents
b. Assignment of tonal morphemes
c. Demarcation by a prosodic phrase edge
d. Appearance in a higher pitch range
e. Vowel length under main phrasal stress

It has been proposed in the literature to capture all these prosodic means as languagespecific expressions of prosodic prominence (Truckenbrodt 1995, 1999, Selkirk 2004). With respect to (16-a), pitch accent distribution in Germanic languages is up to today the best-studied case of focus marking by prosodic means. In English (Selkirk 1984), German (Féry 1993, Selkirk 1984, Uhmann 1991), and Dutch (Gussenhoven 1983a) the distribution of pitch accents in a sentence allows implications about its focus structure. It is argued that the focused constituent bears a pitch accent. Selkirk $(1984,1995)$ proposes that pitch accents are a default reflex of the presentational focus status of a word in English and that therefore focus in English is not marked by a special pitch accent but by a default pitch accent. In European Portuguese it is the use of a special pitch accent, namely a $\mathrm{H}^{*}+\mathrm{L}_{F o c}$ pitch accent (Frota 2000), that marks the focused constituent.

With respect to (16-b), Bengali is an example of a language that uses tonal morphemes to indicate the focused constituent. In Bengali, a $\mathrm{H}_{F o c}$ phrase-edge tone indicates the focused constituent (Hayes \& Lahiri 1991). In Kinande, a Bantu language spoken in Eastern Zaire, a L intonational tone follows the completed assertion (Hyman 1990).

With respect to (16-c), some languages use suprasegmental means other than pitch accents to draw the attention to the focused constituent. The following languages have been analysed as implementing a prosodic phrase break after the focused constituent. The phonetic correlates that indicate the prosodic phrase boundaries are language-specific. In Haya (Byarushengo et al. 1976) and Chichewa (Kanerva 1990, Downing et al. 2004), Bantu languages spoken in Tanzania and Malawi respectively, information focus is marked by a prosodic boundary that induces tonal changes. Moreover, Downing et al. (2004) have shown for Chichewa that prosodic phrase boundaries also explain the observable manipu-

\footnotetext{
${ }^{6}$ The list and part of the examples are taken from Selkirk (2004).
} 
lation of downdrift under focus. L-palatalization in Hungarian is a segmental process that is sensitive to prosodic phrases. Vogel \& Kenesei (1990) show that focus influences the position of these prosodic boundaries in that a focused constituent is not followed by an Intonational Phrase boundary. For Shanghai Chinese, the observation that lexical tones of a word in focus are realized making use of a wider-than-normal pitch range as been accounted for by prosodic phrases in Selkirk \& Shen (1990). The Kwa languages of the Ivory coast are reported to use a prosodic boundary before the focused constituent (Firmin $\&$ Leben 2003). This is indicated by the blockage of elision and by blocking of low tone spreading.

With respect to (16-d), the appearance of the focused constituent within a higher pitch range has been reported for Japanese (Pierrehumbert \& Beckman 1988), Hausa (Inkelas \& Leben 1990) and the Kwa languages (Firmin \& Leben 2003). In a detailed and controlled phonetic study, $\mathrm{Xu}$ (1999) has shown that in Mandarin Chinese, focus modulates the global shape of the $\mathrm{F}^{0}$-curve. For the Bantu language Makua, Stucky (1979: 369) reports that the tone patterns of nouns are influenced by focus in that they shift to low.

With respect to (16-e), Frota (2000) reports for European Portuguese that prosodic focus marking coincides with vowel length. The same can be said for Chichewa (Kanerva 1990), although also non-focused constituents might show vowel length in this language.

This short literature overview shows the variety of prosodic means to express focus which are used in the languages of the world. Also within Bantu languages, a range of different prosodic means has been reported: suprasegmental changes associated with prosodic phrasing, boundary tones, or the manipulation of downdrift. The prosodic means for focus marking in Northern Sotho will be investigated in chapter 3 of this thesis.

\subsubsection{Morphological marking of focus}

Morphological means of focus marking refer to the assignment of a certain morphological element to the F-marked constituent or to the constituent that contains the F-marked constituent. Among the morphological means used in the languages of the world are the ones given in (17).

$$
\begin{aligned}
& \text { Morphological means of focus marking } \\
& \text { a. Assignment of a focus affix or particle } \\
& \text { b. Verb morphology dependent on the focus status of the verb } \\
& \text { c. Nominal affixes dependent on the focus status of the noun }
\end{aligned}
$$

The most prominent work on morphological focus-marking systems, their origin, and their development has been written on the basis of data from African languages (Heine \& Reh 1983). Drubig \& Schaffer (2001) show that morphological focus-marking systems are by no means restricted to African languages but that they occur in Asian and some European language as well.

With respect to (17-a), in Gùrùntùm, a Chadic language spoken in Nigeria, a particle is systematically prefixed onto the focused constituent (Hartmann \& Zimmermann 2005). Also the West African Mandingo cluster is claimed to have systematic in situ insertion of a focus particle (Bearth 1999, citing Creissels 1983). However, focus particles are far from showing a simple and direct mapping on the focused constituent in all languages. 
Instead, among particles or affixes that are used for indicating focus, one finds interesting variation across the languages of the world with respect to the focus they indicate, the grammatical category they cover and their co-occurrence restrictions. Yukaghir, spoken on the Kamchatka peninsula in Russia, is a language that has focus marking morphemes for broad and narrow focus (Gundel 1988, citing Krejnovich 1968). Also Duala and Tamil differentiate in the marking of narrow and broad focus. Here, the morphological focus marker is only employed in narrow focus (Gundel 1988, citing Epée 1976 and Gair 1980 respectively). Yoruba, a Benue-Congo language spoken in Nigeria, is claimed to show different focus markers (which are derived from the copula) for presentational focus and contrastive focus (Bisang \& Sonaiya 2000). Somali, a Cushitic language, differentiates within the narrow focus marking category between a prefixal morpheme for the verbal complex and a suffixal morpheme for arguments (Frascarelli \& Puglielli 2004, but see Bearth (1999) for a critical literature review of diverging views of focus marking in Somali). In other languages, a focus particle appears with the focused constituent in a certain position: In Quechua, a Peruan language, focus is marked by a particle on a constituent that appears in preverbal position (Gundel 1988, citing Creider 1979). In Gungbe, a Kwa language of West Africa, and Babine-Witsuwiten, an Athabaskan language, focus is marked by a particle on a constituent in sentence-initial position (Drubig \& Schaffar 2001, citing Aboh 1999 and Denham 1997 respectively).

With respect to (17-b), a borderline case between prosodic and morphological marking is found in Toura, a Southern Mande language spoken in Ivory Coast (Bearth 1992). Tone lowering on the verb marks postverbal focus. This strategy equals a morphological strategy which is most commonly found in African Bantu languages: verb morphology which is dependent on the focus status of the verb. Bantu languages like Bemba and Kirundi (Givón 1975), Aghem (Hyman \& Watters 1984, Watters 1979), Haya, Makua (Stucky 1979), Kimatuumbi (Odden 1984), Tswana (Chebanne et al. 1997, Creissels 1996), and Zulu (Doke 1927/1992) among others, show a difference in the segmental make-up of the verb depending if it is in the scope of focus or not. These languages vary, however, to the extent to which this difference is present in the verbal paradigm across tenses and in resulting tonal changes a.o. Whereas in the Southern Bantu languages (Tswana-Sotho, Nguni) the differentiation only exists in the Present and perhaps Perfect Tense, it is more wide-spread in the verbal paradigm of the more northern Bantu languages (Givón 1975, Hyman \& Watters 1984, see Güldemann 1996, 2003 for an overview).

The only non-African language for which a similar pattern has been reported is Chin, a Tibeto-Burman language (Drubig \& Schaffar 2001, citing Osborne 1975: 71ff). In Chin, the use of primary and secondary verb stems is reported to have implications for the information structural status of the verb.

With respect to (17-c), again mainly reported for Bantu languages, one finds the use of special nominal forms reflecting the information status of this constituent. One example is the use of the 'out-of-focus' determiner in Aghem, a Grassfields Bantu language spoken in Cameroon (Watters 1979, Hyman \& Watters 1984). Another example is the use of the so-called augmented nominal forms in some Bantu languages (see e.g. Meinhof 1948: 68f). The addition of a pre-prefix has consequences for the semantic interpretation with respect to definiteness. As there is a relation between definiteness and focus, these nominal markers could very well, in some languages, be interpreted as (anti-)focus 
marker.

This short literature overview shows the variety in morphological means of focus marking found in the languages of the world. For the Bantu languages, mainly verb morphology has been reported as a morphological cue to the information packaging of the sentence. The morphological expression of focus in Northern Sotho wil be dealt with in section 2.5.

\subsubsection{Syntactic marking of focus}

Syntactic means of focus marking refer to the assignment of a certain syntactic structure to the F-marked constituent or to the constituent that contains the F-marked constituent. Among the syntactic means used in the languages of the world are the ones given in (18).

Syntactic means of focus marking

a. Use of cleft sentences

b. Syntactic dislocation of the focused constituent

One wide-spread syntactic structure that is used for focus is the cleft-construction. The cleft-construction is exemplified for English in (19).

Cleft sentence in English

It was a hat that Mary bought.

The cleft structure in English is characterized by a matrix clause containing a copula as well as the focused constituent being followed by a relative clause that states the presupposition.

In descriptions of focus strategies in the languages of the world, cleft sentences are often characterized by the simultaneous occurrence of syntactic displacement and the occurrence of a 'focus particle' (which can often be reconstructed as the copula) as well as relative clause morphology on the verb. Cleft sentences have to be treated with care when describing the syntactic means a language uses for marking focus. It has to be differentiated if cleft sentences are an obligatory focus-marking strategy or if they co-exist with e.g. in situ structures. Only in the former case they are interesting for a typological overview, as one can assume that every language can create sequences of copula and relative clause. Furthermore, the cleft strategy might imply additional semantic meaning (see e.g. É. Kiss 1998 for Hungarian and English).

For some Bantu languages, it has been argued that the copula underwent grammaticalization towards a focus particle. Though the ex situ focus structures can be reconstructed as being derived from sequences of copula and relative clause (see Heine \& Reh 1983), it has been argued that synchronically these structures can better be described as syntactic displacement in connection with a morphological focus marker (e.g. Bergvall 1987, Schwarz 2003 for Kikuyu, Sabel \& Zeller, to appear, for Nguni). Section 5.1 deals with these questions for Northern Sotho.

A second syntactic strategy to mark focus is to reserve a certain syntactic position for the focused constituent without other changes in sentence structure (such as relativization in cleft sentences). Languages that employ this strategy are known as discourse- 
configurational languages (see É. Kiss 1995a for an overview).

Among the languages that show a sentence-initial focus position are Basque (Primus 1993, citing Saltarelli 1988), Georgian (Primus 1993, citing Harris 1982), Standard Arabic (Drubig \& Schaffar 2001, citing Ouhalla 1993: 277), Greek (Morimoto 2000, citing Tsimpli 1995), Yagua (Morimoto 2000, citing Payne 1990), and Toura (Bearth 1992).

Languages that show a preverbal focus position are Hungarian (É. Kiss 1998), Turkish (Erguvanli 1984), Tamil (Morimoto 2000, citing Herring \& Paolillo 1995), and Korean (Morimoto 2000, citing Choe 1995).

Among the languages that show an immediately postverbal, verb-adjacent focus position are the Chadic languages Podoko and Western Bade (Tuller 1992), the Grassfields Bantu language Aghem (Watters 1979, Hyman \& Watters 1984), the Bantu language Chichewa (Mchombo 2004: 94), and the Khoisan language Ju|'hoan (Güldemann 2004).

Among the languages that are reported to show a sentence-final focus position are Italian (Zubizaretta 1998, Samek-Lodovici 2005), the Chadic languages Tangale and Kanakuru (Tuller 1992) and the Bantu language Dzamba (Bokamba 1976). Krifka (1985: 28) reports that in double object constructions in Swahili postverbal word order is determined by focus in that it is the focused constituent that appears clause-finally.

This short literature overview shows the variety found in the languages of the world in what concerns the syntactic means of focus marking. For the Bantu languages, a syntactic focus position has been proposed in the literature for some languages. Chapter 2 investigates syntactic focus positions for Northern Sotho.

\subsubsection{Summary: Interaction}

The overview of the grammatical means of focus marking used in the languages of the world shows first, that the notion of focus has linguistic relevance as it has direct influence on grammar in many languages of the world. Second, the huge variety of focus marking devices becomes clear. Sometimes the grammatical means of different grammatical areas even interact with each other. Third, the studies carried out for Bantu languages, though relatively small in number, show that focus marking can be found in phonology, morphology, and syntax. A thesis dealing with the expression of focus in a Bantu language therefore has to investigate all three areas before making a general statement about focus marking in that language.

Though the presentation of grammatical marking of focus in the languages of the world in the preceding subsections suggests that every language uses either one or the other means, this turns out not to be always the case. Different grammatical areas may interact at least twofold in the expression of focus: either a language has means from two or more grammatical areas at its disposal which interact more or less independently, or the use of means of one grammatical area is determined by independent grammatical considerations.

An example for the first case of interaction can be found in German. Pitch accent as a prosodic means is the major cue to focus in German. However, word order also provides cues to focus.

An example for the second case of interaction is the syntactic expression of focus in Italian and other Romance languages by prosody. Dislocation of the focused constituent 
to clause-final position is a purely syntactic means of focus marking. However, it has been claimed that the reason for this syntactic marking of focus lies in the prosodic structure of sentences in Italian in which stress is always clause-final. Focus in Italian is also the topic of section 1.5.3.

The German and Italian examples of phenomena at the prosody-syntax interface that manifest themselves in connection with focus show that in order to account for the observable interaction, a theoretical framework is needed that can model the influence of grammatical areas onto each other. Optimality Theory is such a framework. ${ }^{7}$ Its use will be motivated in the next section as well as its machinery.

\subsection{Optimality Theory}

Optimality Theory (OT) originated in phonology (Prince \& Smolensky 1993) in order to represent competing tendencies in grammar. It is a formalism of constraint interaction in Universal Grammar and is therefore also applicable to other areas of grammar. This section gives an overview of the basic machinery of OT (section 1.5.1) and its application to syntax (section 1.5.2). As OT is a metatheory for all areas of grammar, it allows to integrate influences of different origin into one coherent model. The expression of focus in Italian and English is given as a case study of an interface phenomenon in section 1.5.3. Apart from modeling interacting tendencies in language, one of the strengths of OT is its description of individual languages with explanation of language typology. This issue is adressed in 1.5.4. Section 1.5.5 addresses the use of OT in semantics.

This section cannot give a detailed introduction to OT with all its problematic issues. For this, the reader is refered to the original work of Prince \& Smolensky (1993) as well as the introductions by Archangeli \& Langendoen (1997), Kager (1999), and McCarthy (2002).

\subsubsection{The basic OT-mechanism}

Whereas many theories of language are rule-based or transformational in nature, OT is a comparative theory in that the actual linguistic output is chosen as the optimal member from a set of competing candidate output forms. The OT-mechanism consists of three components: the candidate Generator (GEN), the Evaluator (EVAL), and the universal constraint set (CON). For every input, the Generator produces a candidate set. The candidate set is evaluated against a universal constraint set obeying a language-specific ranking. The following subsections describe each of the OT-components in detail (the presentation draws on McCarthy 2002: 3-22).

\footnotetext{
${ }^{7}$ Other frameworks model the interaction differently: In Lexical Functional Grammar, syntactic constituents are linked to discourse functions like Topic and Focus (Bresnan 2001); in Principles-andParameters-style theories, the discourse notion is introduced via a corresponding phrase, such as Topic, Contrastive Topic or Focus, at the (preferably) left periphery (Rizzi 1997, Brody 1990). Also Dynamic Syntax accounts for interpretative effects with respect to discourse pragmatics (Marten, to appear).
} 


\section{Input, Generator (GEN), and candidates}

The two basic functions of the Generator GEN are to construct candidate output forms (which can be either words or sentences) and to specify a relation between candidate output forms and the input. In short, the candidate set produced by GEN contains output structures which are alternative realizations of the input. The important properties of GEN are universality and freedom of analysis. GEN is universal which means that the candidates for a given input are the same in every language. It obeys freedom of analysis as the candidates within the candidate set are very diverse. This freedom of GEN might only be restricted by primitive structural principles essential in every language. An example is the limitation to a specific alphabet of distinctive features (in phonology) or to some version of X-bar theory (in syntax).

In GEN there is no restriction on the size of the candidate set. It is assumed that GEN incorporates recursive and iterative operations. Therefore, every candidate set from every input is infinite. The economy in language that excludes repetition of meaningless elements is not imposed on GEN, but rather follows from constraint interaction.

Candidate comparison in analyses within OT are illustrated by means of tableaus. While discussing the constituting parts of an OT-analysis in this and the next section, an example tableau will be schematically filled by the input, candidates, constraints and evaluation. A tableau gives a clear view of some of the constraints, candidates and rankings that are crucial in selecting a candidate as optimal.

The example that is chosen to illustrate how OT-phonology works is syllabification in English and Arabic (example is taken from McCarthy 2002: 8; for work on syllabification in English within OT see e.g. Hammond 1999). Languages differ with respect to the syllabification of a consonant cluster like $b r$ (cf. English 'alge.bra' vs. Arabic jab.ri 'algebraic'). GEN produces competing candidates that differ along the dimension of the syllabification of the consonant cluster, leaving the choice of the right one to the languageparticular rankings in the constraint hierarchy $\mathrm{H}$.

In a tableau, the left upper cell is always reserved for the input. The leftmost column shows in rows the different candidates created by GEN, one of which is optimal. As GEN creates an infinite number of candidates, not all candidates are shown in the tableau but only those that are most relevant for the current analysis. This is schematized in tableau 1 , and specified for syllabification in tableau 2.

Tableau 1: Representation of input and candidates

\begin{tabular}{|c|c|}
\hline input & \\
\hline candidate a & \\
\hline candidate $b$ & \\
\hline candidate $\mathrm{c}$ & \\
\hline
\end{tabular}

Tableau 2: Syllabification: input and candidates for English and Arabic

\begin{tabular}{|c|c|}
\hline algebra/ jabri & \\
\hline a. alge.bra/ ja.bri & \\
\hline b. algeb.ra/ jab.ri & \\
\hline c. algebr.a/ jabr.i & \\
\hline
\end{tabular}




\section{Constraints (CON), constraint hierarchy (H), and Evaluator (EVAL)}

Output candidates, which are created by GEN, are then compared among each other by applying a hierarchy of violable constraints. Constraints encode restrictions on the output. They therefore assess the form of a candidate and its relationship to the input. Two basic types of constraints are distinguished in OT: faithfulness and markedness constraints. Faithfulness constraints require identity between the input and the output candidate. Markedness constraints favor certain structural configurations in the output candidate over others (e.g. syllables with onsets over syllables without onsets, or accusative objects over dative objects).

Constraints of both types are necessary: Without faithfulness constraints, all distinctions made by input forms would be reduced to some least-marked output. Without markedness constraints, there would be no way to account for languages differing systematically in the structure they permit. The interaction between faithfulness and markedness constraints forms the basis of an OT-analysis.

Apart from bare structural primitives which are implemented in GEN, all constraints in OT are violable. The basic assumption is that all constraints are universal and universally present in the grammar of all languages. They might be located in a constraint component CON in Universal Grammar. Differences between languages do not pose a problem for the assumption of constraint universality because of the violability of constraints.

The constraints relevant for the analysis of syllabification in English and Arabic are given in (20). They are all markedness constraints, i.e. they evaluate the structure of the output with respect to syllabification. As there is no information on syllabification present in the input, there are no faithfulness constraints on syllabification. Language-specific syllabification results from the language specific-ranking of these universal constraints.

Constraints for syllabification
a. ONSET
'Syllables have onsets.'
Violated for every onsetless syllable.
b. *COMPLEXONSET
'Onsets consist of one consonant.'
Violated once for every further consonant in the onset.
c. *CODA
'Syllables do not have codas.'
Violated once for every consonant in the coda.

The constraints in (20) are representative for the formulation of constraints in OT. Constraints often encode cross-linguistic tendencies, e.g. that syllables tend to have onsets cross-linguistically but disprefer codas. Exceptions from these tendencies can be accounted for through interaction of constraints.

Whereas the constraints themselves are simple and general, they may come into conflict with each other, and these conflicts are resolved through hierarchical ranking of constraints. Ranking consists of domination: of two constraints, either A dominates B or B dominates A. The effect of a certain constraint in a certain language is therefore determined by its ranking in relation to other constraints. 
The grammar of a language is a specific ranking of the set of universal constraints. Differences among languages are explained by language-particular rankings in OT. Candidates differ inevitably in performance on various constraints. Constraints can, in principle, be ranked in any order. Ranking of two constraints in a language is determined through a ranking argument, i.e. a 'proof' that one constraint dominates the other in the language-specific hierarchy (written $\mathrm{C}_{1} \gg \mathrm{C}_{2}$, whereby $\mathrm{C}_{x}$ refers to constraints).

In tableaus, constraints are given in the uppermost row in domination order from left to right. The individual cells show the violation marks $\left(^{*}\right)$ incurred by each candidate relative to each constraint. A fatal violation is marked by an exclamation mark. Cells that refer to irrelevant comparisons of constraints and candidates because of a fatal violation, are shaded in grey. The optimal candidate is indicated by the pointing finger. This is exemplified by discussing tableau 3 .

Tableau 3: Constraints, violations, winning candidate

\begin{tabular}{|ll||l|l|}
\hline input & C1 & C2 \\
\hline \hline a. & candidate a & & $*$ \\
\hline b. & candidate b & $* !$ & \\
\hline c. & candidate c & & $* * !$ \\
\hline
\end{tabular}

In tableau 3, $\mathrm{C} 1$ and $\mathrm{C} 2$ conflict in their evaluation of three candidates. $\mathrm{C} 1$ prefers candidate (a) and (c), whereas C2 prefers candidate (b). As candidate (a) is the observed output candidate, the conflict is resolved by ranking $\mathrm{C} 1$ above $\mathrm{C} 2$. Of two candidates the more optimal is the one that performs better on the highest-ranked constraint that distinguishes between them. Because candidate (c) violates $\mathrm{C} 2$ one time more often than candidate (a) does, candidate (a) is the winner, i.e. the most optimal output. The candidate that best satisfies or minimally violates the set of ranked constraints is considered the optimal output for a given input structure. Only the optimal structure is grammatical. Because constraints are violable, the output typically disobeys at least some of the lower-ranked constraints. This is also the case in tableau 3. The winning candidate (a) violates (the low-ranked) constraint $\mathrm{C} 2$.

The data of syllabification in English show that the output form that displays a complex onset emerges as the winner, when compared to to candidates that show no coda. Therefore, given the constraints in (20), *CODA must be ranked above *COMPLEXONSET. The analysis is exemplified in tableau 4. The ranking of the constraint ONSET cannot be assessed by the data presented in tableau 4. It is therefore left out.

Tableau 4: Syllabification in English

\begin{tabular}{|ll||l|l|}
\hline & algebra & $*$ CODA & *COMPLEXONSET \\
\hline \hline a. & alge.bra & & $*$ \\
\hline b. & algeb.ra & $* !$ & \\
\hline c. & algebr.a & $* ! *$ & \\
\hline
\end{tabular}

In Arabic, on the other hand, we find a different ranking, yielding a different syllabification in the winning candidate. Here, *CODA is ranked below *COMPLEXONSET and ONSET. Although the winning candidate violates the constraint *CODA by having /b/ 
in the coda of the first syllable, this violation is not fatal. The absolute ranking between *COMPLEXONSET and ONSET cannot be assessed by the data sample given in tableau 5 . This is indicated by the dotted line.

Tableau 5: Syllabification in Arabic

\begin{tabular}{|ll||ll|l|}
\hline \multicolumn{1}{|l||}{ jabri } & *COMPLEXONSET & $\vdots$ ONSET & $*$ CODA \\
\hline \hline a. & ja.bri & $*$ & $\vdots$ & \\
\hline b. & $*$ jab.ri & $*$ & $\vdots$ & $*$ \\
\hline c. & jabr.i & $* *$ & $\vdots *$ & $* *$ \\
\hline
\end{tabular}

The example shows that with three constraints that are relevant for syllabification crosslinguistically, the language-specific syllabification pattern of English and Arabic can be derived via re-ranking of the constraints.

\subsubsection{OT in syntax}

From the original work of Prince \& Smolensky (1993) the OT-framework has first been transferred to syntax in Grimshaw (1997), Pesetsky (1997), and Speas (1997). ${ }^{8}$ Among the problem first approached in OT-syntax was $d o$-support in English (see Speas 1995, Grimshaw 1997) which since then serves as a textbook example for the application of OT in syntax and is also used in the current section as a case study. Müller \& Sternefeld (2001) argue that Grimshaw (1997), Pesetsky (1998) and Legendre et al. (1998) are the three most influential analyses in optimality-theoretic syntax, and a majority of succeeding analyses within OT-syntax refers back to at least one of these works.

The main argument for transferring the theoretical framework of OT to syntax is that the idea of optimality rather than strict rules is prevalent in all areas of grammar. In their introduction Barbosa et al. (1998) give the Gricean conversational maxims (Grice 1975/1989) as an example for the principle of optimality in pragmatics. For example, according to the Gricean maxim of Quantity (see also section 2.4.1), the speaker must use the most relevant proposition in a given context. From a given set, the best proposition as measured by degree of relevance is chosen.

Furthermore, it has been argued that the principle of optimality is also present in Chomsky's treatment of do-support in English (Chomsky 1991). Speas (1995: 638-641) shows not only that the restrictions from Chomsky's analysis concerning do-support in English can be directly implemented into an optimality-theoretic analysis, but also that the terminology of violability and ordered restrictions is already inherent in Chomsky's analysis.

By making use of the theoretical framework developed for phonology, work in OTsyntax implements the principle of optimality in syntax. However, a number of problems arise in the process of this implementation. First, as the formal theory of OT is only a metatheory, it is used with different substantive theories of syntax, such as Government \& Binding Theory, Lexical Functional Grammar, and the Minimalist Program. Second, because of the diversity of the substantive theories and the complexity of the problems

\footnotetext{
${ }^{8}$ For an introduction to OT-syntax see Boersma et al. (2000), Müller (2000), Legendre (2001).
} 
tackeld, there is little consensus about the structure of the input and the candidate set. Third, just as in phonology, the critical question for every analysis remains how the constraints are motivated. These issues are addressed in more detail below.

\section{A case study of OT in syntax: $d o$-support in English}

Do-support in negation is obligatory in English if negation occurs above the main verb and no auxiliary is present, as in (21-a, b). In positive declarative sentences, $d o$-insertion is excluded, as shown in the examples in (21-c, d).
Do-support in English negation
a. *Mary not left.
b. Mary did not leave.
c. Mary left.
d. *Mary did leave. ${ }^{9}$

Consequently, $d o$ is possible only when it is necessary, i.e. when it is the only possibility to save the sentence. Do-insertion in negated declaratives in English represents one instantiation of a 'last-resort' phenomenon that Optimality Theory is especially successful at modeling.

The illustration of the optimality-theoretic analysis presented here follows Grimshaw (1997). Whereas Speas's (1995) objective is to translate the Chomskian analysis into an optimality-theoretic approach, Grimshaw (1997) proposes an own analysis that deviates in some points from Chomsky's original proposal. The difference between Grimshaw's and Chomsky's/Speas' analysis is that in the former the necessity of $d o$-insertion in negation is explained by case-requirements, whereas in the latter analysis it is explained by government of traces.

Grimshaw (1997) motivates the constraints in (22) for her analysis:

Constraints for $d o$-insertion
a. No LeXiCAl HeAD MOVEMENT (No-LEX-MVt)
'A lexical head cannot move.'
Violated whenever a lexical head has moved.
b. CASE MARKING (CASE)
'DPs must be Case-marked.'
Violated whenever a DP does not bear case.
c. SubJect (SUbJ) ment.'
Violated whenever sentences have no argument in subject position.
'Clauses have subjects.'/ 'The highest A-specifier must be filled by an argu-
d. FULL INTERPRETATION
'Lexical conceptual structure is parsed.'
Violated whenever there is lexical material in the output that is not present in the input.

\footnotetext{
${ }^{9}$ This example is possible when did is focused, which is outside the interest of the current problem.
} 
For the analysis, note has to be taken of the following assumptions that Grimshaw (1997) makes. First, sentence structure is not uniform: Sentences are minimally VPs (thereby following the VP-internal subject hypothesis (Larson 1988) which states that subjects are base-generated in Spec VP-position). However, GEN can create an theoretically infinite number of functional projections above the VP. Evaluation by the constraints will decide if the winning candidate contains additional functional structure.

Furthermore, Grimshaw (1997) assumes that 'not' is a head and projects its own functional phrase (NegP) above the VP. However, it is crucial to note that 'not' is not a head that has Case-assigning ability. Therefore, if the subject is in the specifier of the NegP, as in candidate (a) in tableau 6, CASE is violated. On the other hand, if the subject is in Spec VP, as in candidate (b), CASE is obeyed but SUBJ is violated (assuming that the specifier position is an A-position). Candidate (d) satisfies both SUBJ and CASE, but at the cost of a violation of the constraint NO-LEX-MVT since the main verb heads a nonlexical projection. Candidate (c) violates the constraint FULL-INTERPRETATION since it contains material in the output ( did) that did not exist in the input. However, as this constraint is ranked below the other constraints CASE, SUBJ, and NO-LEX-MVT, the violation is not fatal and candidate (c) emerges as winner, showing $d o$-insertion in negation. The reasoning is illustrated in tableau 6.

Tableau 6: $d o$-insertion under negation (Grimshaw 1997: 391, tableau 12)

\begin{tabular}{|c|c|c|c|c|c|}
\hline & Candidates & $\begin{array}{l}\sum^{-} \\
\sum_{1}^{1} \\
\dot{x} \\
1 \\
1 \\
0 \\
z \\
z\end{array}$ & $\sum_{0}^{\sqrt[n]{4}}$ & 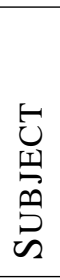 & 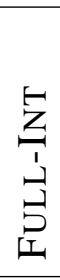 \\
\hline a. & {$\left[\right.$ NegP $\mathrm{John}_{i}$ not $\left[V_{V P} t_{i}\right.$ left $\left.]\right]$} & & $* !$ & & \\
\hline b. & {$[$ NegP $\operatorname{not}[V P$ John left] $]$} & & & $* !$ & \\
\hline c. & {$\left[{ }_{I P} \mathrm{John}_{i} \operatorname{did}\left[{ }_{N e g P} t_{i} \operatorname{not}\left[{ }_{V P} t_{i}\right.\right.\right.$ leave $\left.\left.]\right]\right]$} & & & & $*$ \\
\hline d. & {$\left[{ }_{I P} \mathrm{John}_{i} \operatorname{left}_{j}\left[{ }_{N e g P} t_{i} \operatorname{not}\left[{ }_{V P} t_{i} t_{j}\right]\right]\right]$} & $* !$ & & & \\
\hline
\end{tabular}

The constraint ranking shown in tableau 6 can also account for why in positive declaratives $d o$-insertion is not allowed. This is shown in tableau 7. Insertion of $d o$, as in candidate (d), violates the constraint FULL-INT, just as it did in the negated context. However, as the competing candidate (a) does not violate any of the constraints, the violation of FULL-INT becomes fatal. The other competing candidates in this tableau, namely (b) and (c) are string-identical with candidate (a). However, their syntactic structure is different, and the analysis proposed by Grimshaw judges their syntactic structure as non-optimal: in candidate (b), the subject DP remains without Case, as nominative case assignment is assumed to take place in the specifier of a finite head, i.e. either in the specifier of VP or IP. In (b), there is no finite head within the IP that could assign case to the subject. In candidate (c), the lexical head of the verb phrase has moved, which is banned by the high-ranked constraint No-LEX-MvT. 
Tableau 7: Lack of $d o$-insertion in positive declaratives (Grimshaw 1997)

\begin{tabular}{|ll||l|l|l|l|}
\hline \multicolumn{2}{|c|}{ Candidates } & NO-LEX-MVT & CASE & SUBJ & FULL-INT \\
\hline \hline a. & {$\left[{ }_{V P}\right.$ John left $]$} & & & & \\
\hline b. & {$\left[{ }_{I P} \mathrm{John}_{i}\left[V_{P} t_{i}\right.\right.$ left $\left.]\right]$} & & $* !$ & & \\
\hline c. & {$\left[{ }_{I P} \mathrm{John}_{i} \operatorname{left}_{j}\left[{ }_{V P} t_{i} t_{j}\right]\right]$} & $* !$ & & & \\
\hline d. & $\left[{ }_{I P} \mathrm{John}_{i} \operatorname{did}_{V P} t_{i}\right.$ leave $\left.]\right]$ & & & & $* !$ \\
\hline
\end{tabular}

After having demonstrated in this section how an OT-analysis in syntax works, the following three subsections will address basic aspects of the OT-analysis in more detail, namely the input, the competing candidates, and the constraints. Throughout these sections reference will be made to the analysis just presented.

\section{The input}

The function of the input is to determine the candidate set, since the candidates emitted by GEN bear a determinate relation to the input form. In OT-phonology, there is comparatively little controversy about the input. The input represents the underlying phonological representation. The input is needed in phonological analyses because it is referred to by faithfulness constraints that prohibit output candidates to deviate from specifications in the input.

For OT-syntax, different proposals have been made with respect to how the input should be structured. ${ }^{10}$ With respect to structured input of any kind, Archangeli \& Langendoen (1997: 214) raise the objection that it is the role of the constraints to evaluate the structures that can be associated with inputs. By structuring the input, the constraints are left with nothing to do except to check for faithfulness violations of input structures. Structure of the input still needs to leave non-trivial evaluations of output candidates for syntactic constraints to perform. Whereas it can be easily shown that the input cannot be totally unstructured, i.e. it cannot be a simple enumeration of lexical items (see Heck et al. 2002: 355), it is still discussed controversially how much structure is needed in the input.

Grimshaw (1997) proposes a partially structured input ${ }^{11}$ that consists of a predicateargument structure and specifications about tense and aspect. Crucially, functional categories are never part of the input, but can be freely generated by GEN. The analysis in section 1.5.2 has shown the consequences of these assumptions. The winning candidate in tableau 7 is the structure that consists only of a VP. According to Grimshaw (1997), nominative case assignment takes place in the VP. As there is no further need for functional projections, the slimmest and therefore most economic syntactic structure represents the optimal candidate.

Legendre et al. (1998) assume a highly structured input ${ }^{12}$. This means that besides syntactic structure also the logical form of an utterance is encoded in the input. For

\footnotetext{
${ }^{10}$ For an overview of issues pertaining to the input in OT-syntax see Archangeli \& Langendoen (1997: 200ff), Müller (2000: 14ff) and Heck et al. (2002).

${ }^{11}$ This term is adopted from Heck et al. 2002.

${ }^{12}$ Again, the term is taken from Heck et al. 2002.
} 
their analysis of $w h$-questions, Legendre et al. (1998) consequently assume that the input contains target scope positions of $w h$-phrases.

Heck et al. (2002), finally, argue that the input can be dispensed with in OT-syntax. They argue that in OT-syntax, in contrast to OT-phonology, the input is not referred to by faithfulness constraints. Seemingly existing faithfulness constraints in OT-syntax, such as FULL-INT, STAY and PARSE, can be reformulated as constraints on outputs.

The redefinition of FULL-INT, from (22-d), is spelled out as an example. Grimshaw (1997: 374) introduced FULL-INT in the analysis of $d o$-support in English to render $d o-$ insertion in positive declaratives non-optimal. This constraint requires that lexical information from the input is parsed in the output. It therefore makes crucial reference to the input and can be characterized as a faithfulness constraint, similar to the standard MAXIO in phonology that requires structure from the input to be present in the output. Heck et al. (2002: 364) argue that if $d o$ is not assumed to be present in the input, the same result can be reached by the redefinition of the constraint as in (23), which makes no reference to the input and is therefore no faithfulness constraint.

\section{FULL-INTERPRETATION \\ 'Expletives are not allowed.'}

The reason why according to Heck et al. (2002:372 ff) OT-syntax can do away with the input in contrast to OT-phonology, is that whereas syntax is a structure-preserving system, phonology is not.

The range of assumptions presented above show that in OT-syntax a widely accepted definition for the input is missing. Rather, where necessary, specifications are made and motivated. Where the structure of the input does not lead to different predictions concerning the optimal candidate, the input is often not further specified.

In the analysis proposed in chapter 4 of this thesis, I follow, on the one hand, Grimshaw (1997) in assuming a syntactically structured input. The input contains the verb as a lexical head with its argument structure and an assignment of lexical heads to its arguments. Thereby nominal constituents are encoded as subjects and objects in the input (Grimshaw 1997). On the other hand, constituents in the input may bear the morphosyntactic feature $F$ which indicates their discourse status as focused constituents (Grimshaw \& SamekLodovici 1998). I thereby follow Legendere et al. (1998) in assuming a specified logical form in the input as well. The reason why the morphosyntactic F-feature pertains to the logical form is that both its presence and its scope are relevant for the semantic interpretation with respect to alternatives (see section 1.2.3). Thereby, the F-feature closely resembles the wh-pronoun in Legendre et al.'s analysis (1998). A second reason for the need of morphosyntactic features in the input besides their influence on semantic interpretation is the observable interaction with syntax: A constituent bearing an F-feature cannot appear in subject position in Northern Sotho. This proposal will be discussed in detail in chapter 4 .

Closely related to the issue of the input is the candidate set, as GEN creates the set of competing candidates from the input. Assumptions about the input therefore have consequences for the resulting candidate set. This issue is addressed in the next subsection. 


\section{The candidates}

As GEN generates candidates on the basis of the input, assumptions about the input have consequences for the resulting candidate set. In phonology, the concept of Richness of the Base (ROTB, Prince \& Smolensky 1993) ensures that the structure of the input does not bias the analysis. ROTB says that there are no language-particular restrictions on the input, no linguistically significant generalizations about the lexicon, no principled lexical gaps, no lexical redundancy rules, no morpheme structure constraints, or similar devices (see McCarthy 2002: 70 and references therein).

As seen above, in OT-syntax the input is assumed to be structured in substantially different ways which results in different candidate sets for a given input. Grimshaw (1997: 376) assumes that the candidates are merely syntactic realizations of the input structure. She thereby implies non-distinct logical forms for all candidates. In the case study from section 1.5.2, the candidates in tableaus 6 and 7 all realize the same predicate-argument structure and all have the same logical form. Heck et al. (2002: 360) argue that in such an approach the concept of input is weakened: Though the logical form is not part of the input in Grimshaw's analysis (1997), the candidate set is defined with reference to properties which are not present in the input.

In Legendre's et al. (1998) approach the input is highly structured. Under the view that the logical form is part of the input, there will be candidates in the candidate set that are unfaithful to this aspect of the input, as unfaithful candidates are contained in any candidate set.

The proposal advanced by Heck et al. (2002), namely to dispense with the input in OT-syntax, meets the objection that the input is necessary to define the candidate set. For the generation of candidates, they therefore propose an input-independent definition of candidates, which might crucially require the sameness in logical form (Heck et al. 2002: footnote 16).

OT-syntax has received much criticism for the inconsistencies pertaining to the input and the resulting candidate set. The argument is that, as there is no consensus on the input and as the input guides the output, OT-analyses run the risk of becoming trivial by exploiting the strategy 'The input depends on the phenomenon under discussion'.

From the assumptions that I made above concerning the input, the following characteristics of the candidate set follow: The candidate set contains syntactic realizations of the given input. GEN produces unconstrained outputs that conform to X-bar theory but which can include e.g. additional functional structure. This additional functional structure is created to the left and to the right, which becomes important for left- and right-dislocation. GEN also generates functional heads that do not appear in the input (Grimshaw 1997). Just as GEN creates syntactic structure that diverges from the input, it also creates logical forms that are distinct from the input (next to logical forms which are faithful to the input). The reason is that faithfulness constraints do not only apply to the syntactic structure but also to the semantic structure (LF). Therefore, candidates can be unfaithful with respect to both parameters. 


\section{The constraints}

Constraints in OT are not merely solutions to language-particular problems. They are claims about Universal Grammar with rich typological consequences. The basic architecture of OT states that constraints are universal, violable and hierarchically ordered. Two basic types of constraints can be distinguished: faithfulness constraints and markedness constraints. Faithfulness constraints require identity between the input and the output, whereas markedness constraints evaluate the form of the output and favor certain structural configurations over others. Both types of constraints are needed in the evaluation of an input. Without faithfulness constraints, all distinctions made by input forms would be reduced to some least-marked output. Without markedness constraints, there would be no way to account for languages differing systematically in the structures they permit.

In phonology, some fairly specific faithfulness constraints have been argued to be needed, each of which militates against a particular kind of discrepancy in input and output. In syntax, no consensus on the form of faithfulness constraints has been arrived at, with Heck et al. (2002) even arguing against an input at all. The most basic faithfulness constraints in OT-phonology are MAX-IO and DEP-IO. They assign violation marks for every element that is present in the input but not in the output (DEP-IO) or vice versa (MAX-IO). An example of a faithfulness contraint in OT-syntax is the constraint FULLINTERPRETATION, as discussed above. Another recurrent example is the constraint STAY, given in (24).

$$
\begin{aligned}
& \text { STAY (Grimshaw 1997) } \\
& \text { 'Trace is not allowed.' } \\
& \text { Violated once for every trace. }
\end{aligned}
$$

A subtype of the constraint in (24) is NO-LEXICAL-MOVEMENT, which was used in the analysis of $d o$-support in English earlier this section. Both constraints compare the output to the input and assign a violation mark for every trace that is present in the output.

Markedness constraints are constraints that for their evaluation refer to the output only. Basically, a markedness constraint in OT is any constraint that assigns violation marks to a candidate based solely on its output structure (McCarthy 2002: 14). Thereby, the notion of markedness in OT differs from the Praguan School-concept of markedness, where markedness is about divergence from the neutral, natural, or most expected.

Whereas faithfulness constraints are unique to the framework of OT and are naturally limited in their formulation by relating the output to the input, the formulation of markedness constraints proves to be more intricated. Often, markedness constraints remind of ideas and approaches familiar from other linguistic theories. In the example of $d o$-support in English, the constraint CASE, (22-b), is reminiscent of the case requirement in Chomsky (1981). The constraint SUBJECT, (22-c), corresponds to the Extended Projection Principle (EPP, Chomsky 1982, 1995: Chapter 4), that requires sentences to have subjects. And the constraint FULL INTERPRETATION, (22-d), finds its counterpart in Chomsky (1986).

However, constraints in OT do not simply state what is forbidden and what is required in a language. As constraints are claims about universal grammar with typological consequences, there are certain rules for constraint formulation. 
First, descriptive universals are often found as constraints (McCarthy 2002: 40). The constraint SUBJECT is one such example. It has been observed cross-linguistically that sentences tend to have subjects. Formulating this observation as a violable constraint in OT, allows to account for the universal tendency, but at the same time also for exceptions to this tendency (by constraint interaction). The formal status (in form of constraints) of the otherwise vague notion of cross-linguistic tendency results in incorporating functional generalizations into OT. In theories stating inviolable constraints, the exceptions can only be captured by 'escape'-clauses.

Second, there is assumed to be internal structure in the universal constraint set CON (McCarthy 2002: 17) in the form of abstract formula for constructing constraints of a certain type, also termed constraint schemata. One example for a constraint schema is Align, a template for constraints that refer to the edges of constituents. Align will be discussed in more detail in the case study in section 1.5.3, and is also needed for the relation between syntactic and prosodic structure which is discussed in chapter 3 . Another example for a constraint schema is harmonic alignment, which goes from substantive universal scales to universally fixed constraint rankings. This constraint schema will be addressed in detail in section 4.3.

\section{OT at the interface}

The general architecture of OT and its successful application to both phonology and syntax suggest to apply this theoretical framework also to linguistic phenomena at interfaces of grammatical disciplines which deal with conflicting tendencies. Such interfaces are e.g. syntax interacting with different aspects of semantics, such as theta-hierachy or person hierarchy (Aissen 1999), or, which is of direct relevance for this thesis, information structure interacting with the prosody and the syntax of a language.

Aissen (1999) gives an example for the application of OT to a phenomenon at the interface of semantics/syntax. She proposes a formal treatment of Silverstein's (1976) association of semantic role with person/animacy. On a scale ranging from first and second person over various subcategories of third person (going from pronoun over human to inanimate), elements on the upper end are in the unmarked case associated with agents of transitive verbs according to Silverstein's claim. Elements of the lower end, i.e. inanimates, are associated with patients in the unmarked case. Aissen (1999) proposes to capture this insight by harmonically aligned prominence scales. She adopts prominence scales relating to person, semantic role and syntactic relation which have been proposed in previous literature, and brings them into alignment following the scheme of harmonic alignment (see also section 4.3).

The influence of information structure on prosody and syntax has been a topic of much research in recent years (e.g. Truckenbrodt 1995, Samek-Lodovici 2005). All studies carried out within the OT-framework uniformly assume syntactic structure in the input as well as a morphosyntactic F-feature that indicates the focused constituent (see e.g. Truckenbrodt 1995, Grimshaw \& Samek-Lodovici 1998, Samek-Lodovici 2005). Furthermore, syntactic and prosodic constraints evaluate the output. Crucially, an interface constraint evaluates the relation of prosody and focus. It is discussed controversially how the constraints established apply. Szendröi (2001) proposes that the syntactic and prosodic constraints apply in blocks, whereas Samek-Lodovici (2005) explicitly assumes that prosodic 
and syntactic constraints intermingle.

\subsubsection{A case study for OT at interfaces: Focus in English and Italian}

English, German, and the Romance languages have fairly similar intonational and syntactic properties. Both English and Italian are head-initial SVO languages where stress is rightmost in focus-neutral sentences. The parallel behavior in non-subject focus in these languages is exemplified in (25).

Context question: What happened?
a. English
[John has LAUGHED $]_{F}$
b. Italian
[Gianni ha RISO $]_{F}$
'John has laughed.'

The verb in the example in (25) is focused, which is indicated by the preceding context question. In both languages, it appears rightmost which is the position where it receives sentential accent.

Whereas focus on non-subjects behaves parallelly in languages like English and Italian, cross-linguistic differences emerge when considering subject focus. Focus on the subject in these languages is illustrated in (26). In the English example in (26-a), the subject is focused in its canonical preverbal position by means of a pitch accent. In Italian, the focused subject appears in clause-final position also bearing a pitch accent (26-b).

$$
\begin{aligned}
& \text { Context question: Who has laughed? } \\
& \text { a. English } \\
& \text { b. } \quad[\text { JOHN }]_{F} \text { has laughed. } \\
& \text { Halian } \\
& \text { 'JoHn laughed.' }
\end{aligned}
$$

\section{Prosodic approach to focus}

Focus in English is marked by a pitch accent on the focused constituent (Jackendoff 1972, Selkirk 1984). This is shown in both (25-a) and (26-a) where the verb and the subject bear a pitch accent when focused. No further syntactic changes are induced.

The characterization of focus in Italian is discussed more controversially in the literature. Purely syntactic accounts to focus in Italian, like Belletti \& Shlonsky (1995), posit a clause-final focus phrase or position into which the focused constituent has to be moved. Work by Zubizaretta (1994, 1998) and Cinque (1993) acknowledge the relation between prosody and focus in Italian: The position of clause-final focus is related to the position of main stress in these languages, which is likewise in clause-final position. Because the focused constituent needs to be stressed, it appears in the canonical position for stress.

Whereas purely syntactic analyses ignore the relation of stress and prominence that has been established for many European languages, and also overlook the fact that apart 
from subject focus, English and Italian share basic syntactic and prosodic features, these aspects can be captured in the approach proposed by Zubizaretta (1994, 1998). Three interacting aspects can be constituted within the expression of focus: the syntactic requirements of a language, the prosodic requirements of a language, and the necessity of a prominent focused constituent. Assuming that focused constituents must be stressed (Jackendoff 1972), languages like English obey syntactic requirements (SVO word order) rather than prosodic requirements (rightmost stress). In the case of subjects, this leads to in situ focusing by means of a pitch accent. Languages like Italian obey prosodic requirements (rightmost stress) rather than syntactic requirements. This leads to rightmost stress on a clause-final subject, thereby violating the canonical word order SVO.

The differences in weighing prosodic and syntactic requirements in order to resolve conflicts in the expression of focus have been captured by means of various parameters in the literature, e.g. Ladd (1996), [+/- plastic] in Vallduví \& Engdahl (1995), [+/- flexible syntax] in Van Valin (1999), and [+/- prosodic visibility] in Zubizaretta (1998). However, Samek-Lodovici (2005) argues that a framework as the Minimalist Program is not an adequate theory for conflict resolution in grammar. The core insights of Zubizaretta's work have been reanalysed in the OT-framework by Szendröi (2001) and Samek-Lodovici (2005) a.o. Within OT, the language-specific differences are seen as resulting from language-specific ranking of the prosodic, syntactic, and focus-related constraints involved.

The interaction of constraints in the expression of focus has first been modeled in OT in Truckenbrodt $(1995,1999)$ for prosodic phenomena in a variety of typologically different languages. Of direct relevance for the discussion here is that the relation between focus and prosody was captured by a constraint, which is given in (27).

Focus (Truckenbrodt 1995:11)

'For any $\mathrm{XP}_{f}$ and $\mathrm{YP}$ in the focus domain of $\mathrm{XP}_{f}, \mathrm{XP}_{f}$ is prosodically more prominent than YP.'

The constraint in (27) captures the generalization going back to Jackendoff (1972) that focused constituents bear a pitch accent in languages like English. Crucially however, the constraint does not directly link focus and accent placement, contrary to Jackendoff (1972). Rather the term prominence, which is used in the description of the constraint in (27), allows for cross-linguistic variation of prominence and thereby also for crosslinguistically different prosodic expressions of focus.

In developping an OT-account for focus in Italian and English, Samek-Lodovici (2005) refers back to the theoretical machinery for the focus-prosody interface established in Truckenbrodt $(1995,1999)$. He combines it with the syntactic constraints that are necessary to account for the differences of focus in English and Italian. The OT-analysis for focus in English and Italian is illustrated in the following two sections, presenting the analysis proposed in Samek-Lodovici (2005). Further OT-accounts of focus-syntax in other languages are Gutiérrez-Bravo (2002), Büring \& Gutiérrez-Bravo (2002) for English, Spanish and German; Büring (2001a, 2001b, 2004) for German; Szendröi (2001) for Italian, Samek-Lodovici (2005) for Italian, English, and French. Analyses have also been proposed for Bengali (Truckenbrodt 2002b, Selkirk 2004, Samek-Lodovici 2005). Apart from the languages investigated the analyses differ in the constraints used. 


\section{Focus in English}

The examples in (25) and (26) have shown that in English the focused constituent appears in its canonical syntactic position and bears a pitch accent. With respect to the three interacting tendencies, one can conclude that English obeys the requirement that the focused constituent is prominent, and the syntactic requirements that favor SVO word order. However, in order to follow these requirements it has, in certain environments like subject focus, to violate the prosodic requirement that stress is rightmost in English. In an optimality-theoretic account this is captured by the interface constraint and syntactic constraints dominating the prosodic constraints.

The interface constraint for the influence of focus on grammar has been presented in (27). The syntactic constraints for an account of focus in English have been introduced already and are repeated in (28) for convenience.

Syntactic constraints for focus in English

a. $\quad$ STAY ('No traces.')

b. SUBJ ('Clauses have subjects.')

These syntactic constraints can be regarded as fairly uncontroversial in syntactic OT-work, as has emerged from their discussion in section 1.5.2.

Constraints pertaining to prosodic structure have not been discussed so far. The analyses in Truckenbrodt $(1995,1999)$ and Samek-Lodovici (2005) follow the view that has emerged in the literature over the last twenty years (Selkirk 1984, 1995, Halle \& Vergnaud 1987, Hayes 1995 a.o.), that prosodic structure is organized into a hierarchy of prosodic constituents. At above-word-level, this prosodic hierarchy consists of Phonological Phrase (PP) ${ }^{13}$, the Intonation Phrase (IP), and the Utterance Phrase (UP) (see chapter 3 for cross-linguistic characteristics of these constituents). The constituent which is of interest here is the Intonation Phrase. In the representation of the bracketed grid (Halle \& Vergnaud 1987), which is adopted by Truckenbrodt $(1995,1999)$ and Samek-Lodovici (2005), round brackets indicate the boundaries of a prosodic constituent, whereas the head of each constituent is represented by a grid mark $\mathrm{x}$.

As shown by the example in (29), roughly each lexical item corresponds to a Phonological Word headed by the most prominent syllable. Phonological Words are parsed into Phonological Phrases headed by the most prominent Phonological Word (as the example sentence consists of only two words, these last two layers coincide in (29)). Phonological Phrases are in turn grouped into Intonation Phrases headed by the most prominent Phonological Phrase (again, this and the next higher level of Utterance Phrase coincide in (29)). The prosodic structure of the sentence in (25) and (26) therefore has the representation given in (29).

\footnotetext{
${ }^{13}$ The phrases relating to a specific layer of the Prosodic Hierarchy are given in capital letters.
} 


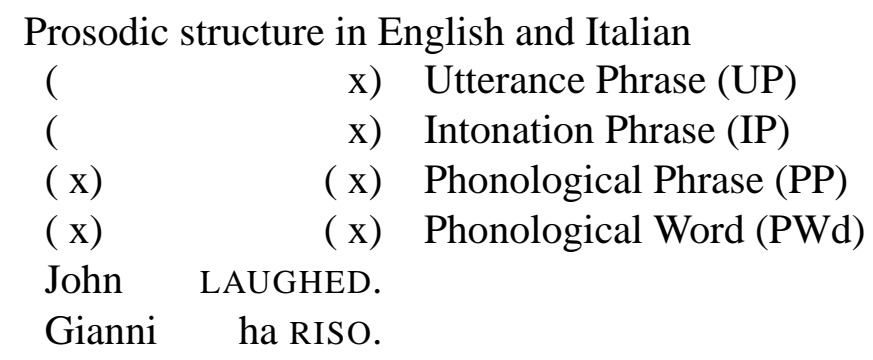

The size of the Phonological and Intonation Phrases is determined by constraints referring to the phonology-syntax interface, such as the ALIGN-constraints proposed in Selkirk $(1986,1995)$ or the WRAP-XP constraint in Truckenbrodt $(1995,1999)$. Those constraints have not been discussed here because they are of no direct relevance for the analysis. They will be introduced in detail in chapter 3 . However, the position of heads within the prosodic constituents is important. The position of heads in prosodic structure is subject to alignment constraints which, in English and Italian, require prosodic heads to occur rightmost (see also Prince 1983, Nespor \& Vogel 1986). Their formulation follows the format of alignment constraints in McCarthy \& Prince (1993). Alignment constraints demand that edges of constituents coincide. The constraint relevant for English and Italian in (30) e.g. says that every IP-head (i.e. the most prominent Phonological Phrase) is final in an Intonation Phrase.

Align (IP, R, Head (IP), R) (H-I)

'Align the right edge of every Intonation Phrase with its head.'

Violated once for every position separating the head from the right edge of the prosodic phrase.

Thereby, the appropriate ranking of the constraint in (30) can account for rightmost stress in English and Italian. ${ }^{14}$

In English, sentential stress matches the position of the focused constituent even if this means that main stress is not rightmost. This behavior can be accounted for by ranking the constraint FOCUS as well as the syntactic constraints above the prosodic constraints that require stress to occur rightmost in English. The analysis is exemplified in tableau 8 (adopted from Samek-Lodovici 2005: tableaus 12-14). The tableau is discussed in what follows.

Tableau 8: Subject focus in English

\begin{tabular}{|ll||l|l|l|}
\hline & focused subject & FOCUS & SUBJECT & H-I \\
\hline \hline a. & JOHN $_{F}$ laughed & & & $*$ \\
\hline b. & laughed $_{i}$ JOHN $_{F} t_{i}$ & & $* !$ & \\
\hline c. & $\operatorname{John~}_{F}$ LAUGHED & $* !$ & & \\
\hline
\end{tabular}

Candidate (a) shows canonical word order with the focused subject bearing a pitch accent. The pitch accent on the preverbal subject violates the constraint governing the position of prosodic heads. This is shown in (31).

\footnotetext{
${ }^{14}$ The alignment constraints referring to lower levels of the prosodic hierarchy have been left out for reasons of space and readability.
} 


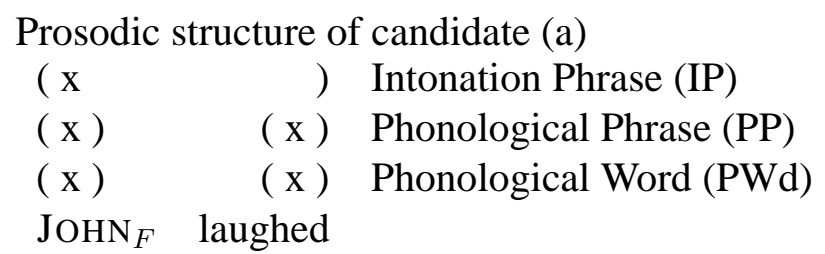

Candidate (a) obeys the canonical syntactic structure of English and the need for the focused constituent to be prominent. As the interface-constraint and the syntactic constraints are ranked above the prosodic constraint, and the competing candidates violate these higher-ranked constraints, the violation is not fatal and candidate (a) emerges as the winner.

Candidate (b) shows deviation from canonical word order in that the subject appears clause-finally. The clause-final subject bears a pitch accent. In candidate (b), both the interface constraint of stressing the focused constituent and the prosodic requirement of having the head of the Intonation Phrase rightmost in its phrase are met by placing the focused constituent in clause-final position where it receives prominence (see (32)).

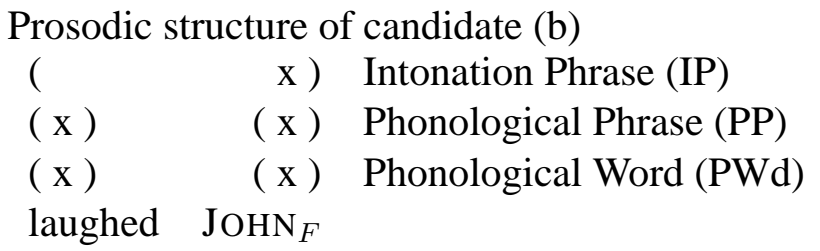

Candidate (b) crucially violates the syntactic constraint SUBJ, which requires every sentence to have a subject in SpecIP. As this constraint is ranked above the prosodic constraint in English, the violation incurred by candidate (b) is fatal.

Finally, candidate (c) shows canonical word order but with the pitch accent on the rightmost constituent, which is the discourse-old verb. Candidate (c) therefore meets both the syntactic requirement of SVO word order and the prosodic requirement of rightmost stress (see (33)).

$$
\begin{aligned}
& \text { Prosodic structure of candidate (c) } \\
& \left(\begin{array}{lll}
( & \text { x }) & \text { Intonation Phrase (IP) } \\
(\mathrm{x}) & (\mathrm{x}) & \text { Phonological Phrase (PP) } \\
(\mathrm{x}) & (\mathrm{x}) & \text { Phonological Word (PWd) } \\
\mathrm{John}_{F} & \text { LAUGHED }
\end{array}\right.
\end{aligned}
$$

Candidate (c) violates the interface constraint Focus because it is not the Phonological Phrase that contains the focused constituent that projects the head of the Intonation Phrase.

The observation that in English, a focused subject bears a pitch accent and appears in its canonical position thereby militating against rightmost stress, can be captured by the ranking given in (34) of the constraints involved.

$$
\begin{aligned}
& \text { Constraint ranking in English } \\
& \text { FOCUS, SUBJ/STAY } \gg \mathrm{H}-\mathrm{I}
\end{aligned}
$$

The following section illustrates how a re-ranking of these universal constraints can account for the expression of subject focus in Italian. 


\section{Focus in Italian}

The examples in (25) and (26) have shown that in Italian, the focused subject also bears a pitch accent, but does not appear in its canonical position. With respect to the three interacting tendencies, one can conclude that Italian obeys the interface requirement that the focused constituent is prominent, and the prosodic requirement that favors rightmost stress. The position of the focused constituent is matched to the clause-final prominent position even if this means that the canonical word order SVO is not maintained. In order to follow the interface and prosodic requirements, Italian has to violate the syntactic requirement that derives the canonical SVO word order in environments like subject focus. In an optimality-theoretic account this is captured by the interface constraint and prosodic constraints dominating the syntactic constraints. This is illustrated in tableau 9 (adopted from Samek-Lodovici 2005: tableaus 2-4).

Tableau 9: Subject focus in Italian

\begin{tabular}{|ll||l|l|l|}
\hline & focused subject & FOCUS & H-I & SUBJ \\
\hline \hline a. & ha riso GIANNI & & & $*$ \\
\hline b. & GIANNI $_{F}$ ha riso & & $* !$ & \\
\hline c. & Gianni $_{F}$ ha RISO & $* !$ & & \\
\hline
\end{tabular}

Candidate (a) shows the clause-final subject that bears the stress assigned to this position. (The prosodic structure of candidate (a) corresponds to (32).) It thereby satisfies the constraint that requires the focus of the sentence to be prominent as well as the prosodic requirement that stress be rightmost in Italian. However, the syntactic requirement of having a subject in SpecIP is violated. Because the other candidates violate higher-ranked constraints, the violation is not fatal, and candidate (a) emerges as winner.

Candidate (b) shows the sentence in canonical word order. The preverbal focused subject bears a pitch accent, as is the situation in English. (The prosodic structure of candidate (b) corresponds to (31).) Though this candidates satisfies the constraints on focus and syntax, it militates against rightmost stress. As this prosodic constraint is ranked above the syntactic constraint in Italian, the violation is fatal.

Candidate (c) shows the canonical structure in which the accent falls on the rightmost constituent, which is the non-focused verb. (The prosodic structure of candidate (c) corresponds to (33).) Although this candidate satisfies both the prosodic and syntactic requirement, it fails to render the focused constituent the most prominent constituent within the sentence. As the constraint FOCUS is also ranked above the syntactic constraint favoring a subject in Italian, the violation is fatal and candidate (c) is excluded from competition.

The observation that under focus, the subject in Italian moves rightward into a position where it can receive prominence, thereby militating against the canonical word order if necessary, can be captured by the ranking given in (35) of the constraints involved.

\section{Constraint ranking in Italian}

FOCUS, H-I $\gg$ SUBJ

In sum, the case study has demonstrated how OT can be applied to an interface phenomenon involving focus. The OT approach allows to capture both the similarities as 
well as the differences in the focus grammars of English and Italian.

English and Italian share certain properties concerning syntax (SVO word order) and prosody (rightmost stress). These similarities emerge from ranking the constraints that ultimately lead to SVO order and rightmost stress above constraints that derive other word orders and other stress patterns.

The requirement that focus needs stress leads to conflicts in the grammar of both English and Italian. It has been shown that OT models the different paths taken by these two languages by re-ranking of the universal constraints that pertain to prosodic and syntactic structure.

\subsubsection{Factorial typology}

The architecture of OT predicts that every permutation in the ordering of the constraints describes a possible human language. ${ }^{15}$ This is known as factorial typology (Prince \& Smolensky 1993). Therefore, every proposed constraint needs to be tested for its typological consequences, as it can engage in ranking permutations and therefore predicts typologically different languages. If these languages, however, do not exist among natural languages, the status of the proposed constraint is weakened.

An abstract example is given for a constraint set that is too rich in the typology it predicts. Even if such a constraint set works for a particular language, its overgenerating power (profligacy) requires further research. McCarthy (2002: 38f) gives the hypothetical tableau 10, with the constraints ranked as shown.

Tableau 10: Profligacy illustrated

\begin{tabular}{|l||c|c|c|c|}
\hline in & A & B & C & D \\
\hline \hline a. out1 & & & $*$ & $*$ \\
\hline b. out2 & $* !$ & $*$ & & \\
\hline c. out3 & & $* !$ & $*$ & \\
\hline
\end{tabular}

Through factorial typology the following inferences can be drawn, assuming that tableau 10 gives all the relevant information with respect to candidates and constraints:

Predictions by factorial typology

a. There is a language (the one shown in the tableau) where /in/ is mapped most harmonically to out 1 .

b. There is a language where /in/ is mapped most harmonically to out2 (if C dominates $\mathrm{A}$ and $\mathrm{B}$ ).

c. There is a language where /in/ is mapped most harmonically to out3 (if D dominates $\mathrm{B}$ and $\mathrm{A}$ dominates $\mathrm{C}$ ).

If no language of the predicted type (36-c) can be found among the languages of the world, the overgenerating constraint set needs to be reconsidered by either eliminating constraints or redefining existing ones so that they assign different violations. For the

\footnotetext{
${ }^{15}$ Not every permutation of the constraints necessarily gives an observably different language though.
} 
analysis in tableau 10 , the solution is to eliminate constraint $\mathrm{D}$, as it has no observable effect anyway.

The grammar of Northern Sotho is among the typological grammars that is predicted by the constraints presented in the preceding sections and provides an example for the type of resulting grammar that has not yet been reported before. First, the constraints motivated for the expression of focus in English and Italian, as discussed above in section 1.5.3, predict a language in which the constraint FoCUS is ranked below the constraints governing syntactic and prosodic well-formedness. As will be shown in section 3.8.1, Northern Sotho is of that language type, as focus is not expressed prosodically in the verbal and postverbal domain.

Second, based on the Northern Sotho data, a constraint is proposed in chapter 4 that relates to the interface between information structure and syntax. It will be shown that in Northern Sotho this constraint - that prohibits syntactic subjects to be F-marked - is ranked above the conflicting constraint SUBJ, that requires every sentence to have a syntactic subject. Because of factorial typology, the opposite ranking is predicted to be a human language as well, and indeed in languages like English or Chichewa we find that the constraint SUBJ is ranked above the interface constraint, resulting in an F-marked subject. The factorial typology and language variation with respect to this interface constraint is re-addressed in section 4.4 .

\subsubsection{OT in semantics}

In conservative analyses in OT-syntax, the evaluation of an input by means of syntactic constraints yields the optimization of a syntactic structure with respect to a semantic input. This is mirrored by the assumption discussed in section 1.5.2 that candidates in OT-syntax share the same logical form (Grimshaw 1997, Müller 2000).

Hendriks \& de Hoop (2001) argue that OT-syntax takes the perspective of the speaker who wants to express a certain thought optimally in a syntactic structure. OT semantics, on the other hand, takes the perspective of a hearer who is confronted with a certain syntactic structure and wants to interpret the structure optimally. ${ }^{16}$ In OT-semantics, the input is considered to be a well-formed syntactic structure whose theoretically infinite number of possible interpretations is evaluated. The constraints necessary for the interpretation can, in principle, be the same as for the evaluation of the syntactic structure. The difference between OT-syntax and OT- semantics lies in the nature of the input forms and candidates. In OT-syntax the candidates are syntactic structures, in OT-semantics the candidates are interpretations.

However, for certain phenomena it is standardly assumed that next to information about argument structure, semantic structure such as focus structure (Grimshaw \& SamekLodovici 1998) and scope considerations (Legendre et al. 1998) must be present in the input as well. Legendre et al. (1998) consequently argue that candidates differ both in syntactic and semantic structure, as GEN creates an infinite number of candidates. They admit that faithfulness constraints pertaining to semantic structure are often sufficiently high-ranked to have no effect on the grammar.

\footnotetext{
${ }^{16} \mathrm{~A}$ similar split of production and comprehension perspective can be found in OT phonology, see Boersma 1998 and subsequent work.
} 
Also Blutner (2000) argues that natural language interpretation has to consider both perspectives simultaneously, both the hearer and and the speaker perspective. He, too, bases this demand on the structure of GEN. He criticizes that if a unidirectional perspective is taken, certain interdependencies cannot be accounted for: In a unidirectional OT-syntax approach, interpretative preferences remain unaccounted, in a unidirectional OT-semantics approach, blocking effects remain unaccounted. Blutner (2000) therefore proposes a bidirectional variant of OT that considers both the form and function perspective.

The case of cleft sentences in Northern Sotho presents a case study for bi-directional OT. A brief introduction to the essentials of this approach will therefore be given in chapter 5, when the relevance of cleft sentences for the expression of focus in Northern Sotho is discussed. The following section now turns to the language under investigation in this thesis.

\subsection{The language Northern Sotho}

Northern Sotho is a Southern African Bantu language that belongs to the Sotho-Tswana family (S30 in Guthrie's classification (1948)). ${ }^{17}$ It is one of the eleven official languages of the Republic of South Africa and is spoken by approximately 3,840,000 speakers (1995 The Economist) in the northern most province (Limpopo Province) of South Africa. 'Northern Sotho' is a geographical term denoting the area where a specific variety of Sotho dialects is spoken (Louwrens et al. 1995). The boundary of the Northern Sotho area is an imaginary line stretching from Tshwane (Pretoria) ${ }^{18}$ through Middelburg, Groblersdal and Lydenburg to Sabie. From Sabie, the lines runs along the Sabie River and then north through the Bushbucksridge and Klaserie areas, across the Olifants River, then westwards as far as Makhado (Louis Trichardt), and northwards again as far as Musina (Messina). From there it stretches westwards to the Botswana border and then southwards through the Mokopane (Potgietersrus) district, through Bela Bela (Warmbaths) and back to Tshwane (Pretoria) (Louwrens et al. 1995).

The Northern Sotho speaking area is highlighted in lighter grey in the map in figure 1.

\footnotetext{
${ }^{17}$ I am well aware of the fact that the terms 'Bantu' and 'native speaker' have a pejorative meaning in South African English and that their use is considered offensive. In lack of alternative terminology that is precise and established enough I use these terms but distance myself from any negative connotations.

${ }^{18}$ The names in parentheses refer to the original city names. In the new South Africa (since 1994) many cities have been renamed.
} 
Figure 1: The Northern Sotho speaking area in South Africa

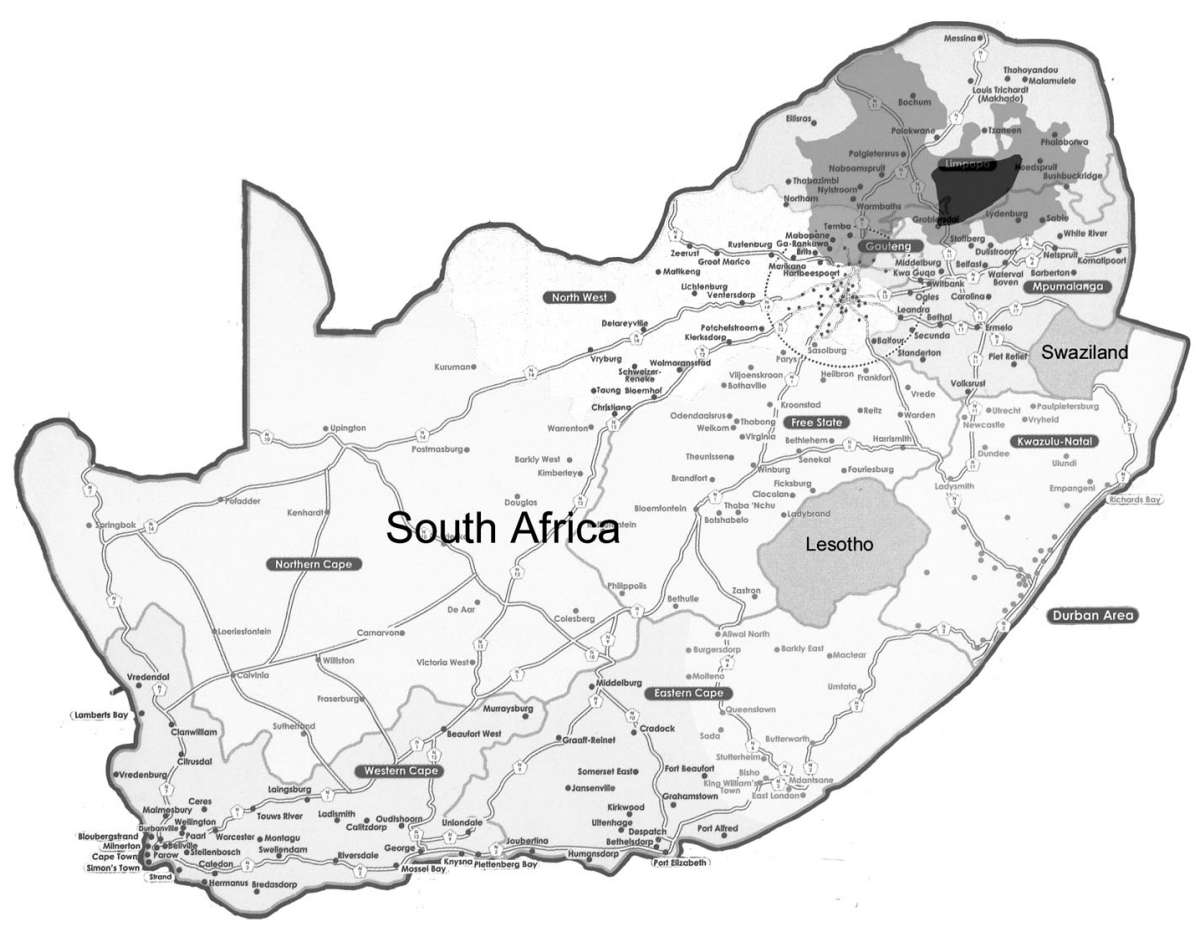

The Northern Sotho speaking area is known for its dialectal diversity. Van Wyk (1969) describes six Northern Sotho dialect clusters comprising approximately 25 dialects which show different influences from neighboring languages such as Venda, Tsonga, and Swazi. Among those dialects is Sepedi. It is the standardized dialect used for orthography and in education and also the dialect described in this thesis. It belongs to the central cluster (van Wyk 1969). The area in which the Sepedi dialect is spoken is according to Mokgokgong (1966) roughly located east of the Olifant River, within the triangle formed by Groblersdal in the South, Lebowakgomo in the North-West and Trichardtsdal in the North-East. The Sepedi speaking area is highlighted in darker grey in the map in figure 1.

\subsubsection{Linguistic studies on Northern Sotho}

The commented bibliography by Kosch (1993) provides a very detailed survey of the description and work on South African Bantu languages with special reference to the linguistic literature on Northern Sotho up to the date of publication. The current section is meant to pay tribute to at least some of the seminal work that has been done on Northern Sotho and furthermore to show that although a substantial body of work on Northern Sotho exists, there is little work investigating the expression of focus in this language. The selection of work is of course partly subjective.

The first authoritative grammar book on Northern Sotho appeared in 1876 and was compiled by Karl Endemann, a missionary from the Berlin Missionary Society. Before 
1876, the language Northern Sotho has received relatively little attention, though the description of other Bantu languages such as Zulu, Xhosa, Tswana and Southern Sotho was much more advanced (Kosch 1993: 14). It was due to the detailed description of Northern Sotho phonetics and phonology in Endemann's grammar, that Meinhof (1899) used Northern Sotho for the reconstruction of Ur-Bantu. K. Endemann $(1876,1901)$ and C. Endemann (1916) also ventured into the exploration of tone in Northern Sotho. The first dictionary indicating tone was edited by K. Endemann in 1911.

From around the 1930s, the situation concerning the grammatical description of Bantu languages improved in various respects. First, more detailed studies dealing with individual grammatical phenomena appeared, e.g. Endemann (1943), Schwellnus (1942), Trümpelmann (1942) for tonological and phonological aspects of Northern Sotho. Second, attention was paid to the dialectal variety of the Sotho speaking area, which was rather neglected in Endemann's studies, e.g. Tucker (1929, 1932), Ziervogel (1954), Mokgokgong (1966), van Wyk (1969). Third, the approach to the study of Bantu languages became more structured and theoretical.

One milestone in this respect was the publication of Doke's Textbook of Zulu Grammar in 1927 (reprinted a.o. in 1992) which had a great impact on South African Bantu linguistics. His main contribution was an approach to word division based on stress, and the classification of word categories. The Bantu word was identified based on phonetic/prosodic principles, i.e. by 'one main stress' (see also chapter 3 for stress in Bantu). Of all South African Bantu languages though, Northern Sotho seems to have been influenced the least by the Dokeian approach, although some grammars of the neighboring languages Southern Sotho (Doke \& Mofokeng 1957) and Tswana (Cole 1955) were based on this framework (Kosch 1993: 29). Ziervogel was one of the scholars who deviated from Dokes prosodic approach to the word in Bantu. His morphological approach to word division in Bantu is reflected in his grammar on Northern Sotho (Ziervogel et al. 1969 in English). Van Wyk (1958) investigated all existing approaches to the problem of word division and proposed an own model. As morphological aspects are not the topic of this thesis, the approaches of these three well-known scholars in Southern Bantu linguistics cannot be outlined here.

Some of the more specialized linguistic studies on Northern Sotho consider the influence of information structure on grammar. Unfortunately, some of the work are either unpublished Ph.D. theses or/and written in Afrikaans. Therefore, they do not present themselves to a wider audience. Among the studies pertaining to information structure in the widest sense are Louwrens (1979a, 1979b 1981a, 1981b, 1982, 1985) and Kosch (1988). Louwrens (1979a) investigates the information structural status of subjects and objects and thereby addresses the role of agreement. The main insights are published in subsequent articles (Louwrens 1981, 1982a). Louwrens (1979b) shows that interrogatives share the same syntactic restrictions as nouns which present new discourse information. Louwrens (1981b) treats pronominalization rules within a discourse-pragmatic approach. Kosch (1988) discusses the status of the so-called Present Tense - $a$ - in Northern Sotho. This morpheme, which only appears in the Present Tense under certain circumstances, has sometimes been brought into relation with focus marking on the verb.

The selective presentation in this section is meant to exemplify that a substantial body of work exists on the description of Northern Sotho. With respect to the grammatical 
expression of information structure, work has been done on agreement and verb morphology. The studies have been carried out using a functional approach, often collecting data from texts. Prosodic aspects of information structure have not yet been addressed at all. With respect to the existing studies, topic and emphasis have been established as the discourse notions that are relevant for the morphosyntax of Northern Sotho.

The thesis contributes to the description of Northern Sotho in that it provides systematic data on the expression of focus both in syntax and prosody. Further contributions of the thesis are with respect to the issue of clefts as focusing strategies (chapter 5), aspects of phrasal phonology (chapter 3), the syntactic status of the subject marker as well as the relevance of notion topic for the preverbal subject in Northern Sotho (both in chapter 4).

\subsection{Linguistic properties of Northern Sotho}

Northern Sotho shows linguistic properties that are common to Bantu languages: It is a tone language, it is an agglutinative language with basic SVO word order and has a rich noun class system as well as rich verb morphology. As tone, word order and agreement are important throughout the thesis, these linguistic properties will be presented in the following subsections.

\subsubsection{Tone}

Like most other Bantu languages, Northern Sotho is a tone language that uses changes in fundamental frequency in order to convey lexical and grammatical meaning. In accordance with other studies on Bantu languages, Northern Sotho is assumed to have a two tone system whereby only high tones are specified underlyingly and low tones are inserted by default. Therefore, only high tones are marked throughout the thesis. High tones are marked by acute. Underlying high tones are marked by underlining. The examples in (37) show the lexical and grammatical use of tones in Northern Sotho.
a. lexical minimal pairs (Ziervogel \& Mokgokgong 1961) lapá 'court-yard' lapa 'become tired' bóna '(to) see' bona 'they' thápo 'kernel' thapo 'rope' hlába 'illegitimate child' hlaba '(to) stab'
b. grammatical minimal pairs (Ziervogel 1969: 134f)

(i) Indicative re rútá 'we teach' ré rúta 'while we teach'

(ii) Subjunctive á rúte
Participal

Habitual

'he should praise' a rúte 'he praises habitually'

Tone is important in this study because its realization is influenced both by syntactic structure as well as by information structure. Early studies on Bantu languages already observed that the tonal shape of a word changes with its position in a sentence. Tone on a word in final position can be different from the tone of the same word in medial position. Chapter 3 investigates the role of tone in information structure in detail. 


\subsubsection{Basic word order}

Basic word order in Northern Sotho is SVOX (Heine 1976, Watters 1989). The inflected verb is the only obligatory element in the sentence. When subject and object NPs are present, the subject precedes the verb in canonical word order. The object appears postverbally, verb-adjacent. Local, temporal and modal adverbials follow the object, as illustrated in (38).

$$
\begin{aligned}
& \text { Mo-šemane o rekiš-itše bo-rotho maabane toropo-ng. } \\
& \text { CL1-boy CL1 sell-PST CL14-bread yesterday CL9.town-LOC } \\
& \text { 'The boy sold bread yesterday in town.' }{ }^{19}
\end{aligned}
$$

As can be seen in (38), the subject agrees with the verb. In Northern Sotho, subject agreement is obligatory, like in all Bantu languages. Concordial agreement with the object is optional. The subject can also follow the whole predicate, as shown in (39).

$$
\begin{aligned}
& \text { O rekiš-itše bo-rotho maabane toropo-ng, mo-šemane. } \\
& \text { CL1 sell-PST CL14-bread yesterday CL9.town-LOC CL1-boy } \\
& \text { Lit. 'He sold bread yesterday in town, the boy.' }
\end{aligned}
$$

Other word orders concerning the subject, verb, and object are ungrammatical. This is exemplified in (40).
a. *O rekišitše mošemane borotho.
b. *Borotho o rekišitse mošemane.

When the object marker is present, as in (41-a), all word orders of subject, verb, and object are possible, as shown in (41-b,c).
a. Mo-šemane o bo rekiš-itše bo-rotho.
CL1-boy CL1 CL14 sell-PST CL14-bread
b. O bo rekiš-itše mo-šemane borotho.
c. Borotho o bo rekiš-itše mo-šemane.

In showing free word order when the NP constituent is coreferred to on the verb, Northern Sotho behaves parallel to Chichewa, Setawana and other Bantu languages (Bresnan \& Mchombo 1987, Demuth \& Johnson 1989, Baker 2003). The variability in word order in those languages is closely tied to agreement, which will be discussed in the next section.

The reason why word order is important for this study is that information structure is one factor influencing word order in Northern Sotho. Chapter 2 comes back to information structure as an influencing factor on word order.

\subsubsection{Agreement}

Northern Sotho shows the defining characteristics of Bantu languages, namely the rich noun class system. Every noun belongs to one of 18 noun classes. The noun classes

\footnotetext{
${ }^{19}$ Northern Sotho, like Bantu languages in general, lacks an article. The translation therefore corresponds to the most probable translation.
} 
appear pair-wise whereby an even class number expresses the singular and an odd class number the plural. Class membership is indicated by a class prefix. The class prefix $n$ of class 9 often initiates severe sound changes. Table 1 shows the noun class prefixes and provides examples for the respective classes.

Table 1: Noun class prefixes in Northern Sotho (Ziervogel et al. 1969)

\begin{tabular}{|l|l|l|}
\hline noun class & noun class prefixes & Examples \\
\hline 1 & mo- & mo-nna 'man' \\
\hline 2 & ba- & ba-nna 'men' \\
\hline 3 & mo- & mo-lomo 'mouth' \\
\hline 4 & me- & me-lomo 'mouths' \\
\hline 5 & le- & le-getla 'shoulder' \\
\hline 6 & ma- & ma-getla 'shoulders' \\
\hline 7 & se- & se-lepe 'axe' \\
\hline 8 & di- & di-lepe 'axes' \\
\hline 9 & n- & mpša 'dog' \\
\hline 10 & di- & di-mpša 'dogs' \\
\hline 14 & bo- & bo-tho 'humanity' \\
\hline
\end{tabular}

Noun class membership is important not only for the marking of nouns, but also for agreement. Northern Sotho shows agreement in the nominal and in the verbal domain. In the nominal domain, the noun of a noun phrase agrees with its modifiers in the respective noun class features. Examples are given in (42) for different adjective formations.

(42) Noun adjective agreement in Northern Sotho (Ziervogel et al. 1969: 57f)
a. mo-tho yo a lokile-go
CL1-man DEM.CL1 CL1 be.good-REL
'a person who is good', 'a good person'
b. mo-šemane yo bo-hlale
CL1-boy DEM.CL1 CL14-wisdom
'a clever boy'
c. mo-tho o šele
CL1-man CL1 different
'a strange person'
d. mo-šemane wa ma-atla
CL1-boy POSS.CL1 CL6-strength
'a strong boy'

The examples in (42) show 'adjective' formation by a verb relative (42-a), by a nominal relative (42-b), by a enumerative relative (42-c), and by a possessive construction (42-d) (terminology taken from Ziervogel et al. 1969). All constructions have in common that the modifying expression agrees with the head noun in its noun class features, which is class 1 in all examples in (42).

Agreement in the verbal domain is expressed differently depending on the grammatical function of the constituent that triggers agreement. Subject and object agreement will 
be treated in turn.

\section{Subject agreement}

In active sentences in Northern Sotho, the constituent that bears the highest thematic role agrees with the verb and appears canonically in preverbal position. This constituent is referred to as grammatical or preverbal subject throughout this thesis. The subject agreement morphemes, that appear preceding the verb stem (also called subject markers in this thesis), are given in table 2 for Northern Sotho. The table shows that, except for class 1, 3, 6 , and 9, the noun class prefixes and the subject agreement markers are identical in their form. For the other classes, one can generalize that the morpheme-initial nasal is dropped.

Table 2: Subject agreement morphemes in Northern Sotho (Ziervogel et al. 1969)

\begin{tabular}{|l|l|l|}
\hline noun class & noun class prefixes & subject agreement \\
\hline $1 / 1 \mathrm{a}$ & mo- & o \\
\hline 2 & ba- & ba \\
\hline 3 & mo- & o \\
\hline 4 & me- & e \\
\hline 5 & le- & le \\
\hline 6 & ma- & a \\
\hline 7 & se- & se \\
\hline 8 & di- & di \\
\hline 9 & n- & e \\
\hline 10 & di- & di \\
\hline 14 & bo- & bo \\
\hline 15 & go- & go \\
\hline $16,17,18$ & go- & go \\
\hline
\end{tabular}

Examples for subject agreement on the verb are given in (43). The examples show that the morpheme preceding the verb agrees with the sentence initial subject in noun class features.
a. Mo-nna o ngwal-ela ba-sadi.
CL1-man CL1 write-APPL CL2-woman
'The man writes to the women.'
b. Ba-sadi ba ngwal-ela mo-nna.
CL2-woman CL2 write-APPL CL1-man
'The women are writing the man.'

All examples are given in Northern Sotho orthography. Northern Sotho orthography is disjunctive. Therefore the subject marker is written separately (disjunctive) from the verb (see Louwrens 1991 for an overview over Southern Bantu writing systems).

Concerning the syntactic structure of the subject in Bantu languages, the following three aspects are uncontroversial in the literature: First, the subject raises from an VPinternal position. Second, the verb moves from VP-internal position to the head-position 
of an inflectional phrase where information on tense, mood and aspect (TMA) are added or checked. Third, agreement between the verb and the subject is not established within the VP but within the higher functional projection that verb and subject have been moved to.

Because syntactic analyses have been proposed in different theoretical frameworks (Lexical Functional Grammar, Government \& Binding, Minimalist Program), the analyses differ in technical details, such as the theoretical motivation for both verb- and subjectmovement, or the denomination of the functional phrases involved (e.g. IP, AgrS, or TP).

In the following discussion, I will abstract away from these technical controversies and concentrate on the more substantial differences between the different approaches. On the one hand, the issue of the base position of the subject will be discussed, as it reoccurs throughout the thesis. On the other hand, the controversies concerning the subject's landing position and the status of the subject agreement morpheme are presented. There are three possible configurations for the subject and the agreement marker. I will present each of these in turn.

Base position The starting position of the subject is claimed to be VP-internally. Evidence for the raising of the subject from an VP-internal position comes from impersonal constructions. The term impersonal construction is used to refer to constructions that lack a grammatical subject NP and show invariable agreement on the verb. The examples in (44) illustrate the structure of impersonal constructions in Northern Sotho: the subject concord $g o$ is used and the logical subject appears in postverbal position. ${ }^{20}$

$$
\begin{aligned}
& \text { Northern Sotho } \\
& \text { a. Go fihla ba-eti. } \\
& \text { CL17 arrive CL2-guest } \\
& \text { 'There are guests arriving.' } \\
& \text { b. Go bina ba-sadi. } \\
& \text { CL17 dance CL2-woman } \\
& \text { 'There are women dancing.' } \\
& \text { c. Go soma ba-nna. } \\
& \text { CL17 work CL2-man } \\
& \text { 'There are men working.' }
\end{aligned}
$$

The postverbal constituent in constructions such as (44) will be referred to as subject in situ throughout the thesis. The use of the term subject is justified as the constituent still encodes the highest thematic role. (The term 'logical subject' is used throughout the thesis to refer to the constituent encoding the highest thematic role without any implications abouts it syntactic position.) The impersonal construction appears with both unaccusative and unergative intransitive verbs, as shown in the examples in (44-a, b), even with clearly agentive verbs as in (44-c). Thereby Northern Sotho shows an interesting difference to

\footnotetext{
${ }^{20}$ The subject concord $g o$ is transcribed as being class 17. It is important to note, however, that Northern Sotho does not have productive locative class agreement. Therefore, $g o$ is also referred to as classless prefix (Joubert, p.c.). Moreover, it is homonymous with the infinitive prefix of class 15. The transcription of go as class 17 is done following literature on the Southern Sotho and Tswana languages and in phonetic analogy to Bantu languages that do have productive locative class prefixes.
} 
locative inversion in Chichewa (Bresnan \& Kanerva 1989). Locative inversion is also a subject inversion construction but is only possible with unaccusative verbs in Chichewa. Northern Sotho is therein similar to the other Sotho languages (Demuth \& Mmusi 1997, Machobane 1995) and Shona (Harford 1983, 1990) that also allow inversion constructions with both classes of intransitive verbs.

Impersonal constructions have been excluded for transitive verbs in the Sotho languages by Demuth \& Mmusi (1997), Demuth (1990), du Plessis (1981) and Machobane (1995). ${ }^{21}$ However, for Kirundi (Ndayiragije 1999), Xhosa (du Plessis 1981, Visser 1985: 131) and Swati (Nhlanhla Thwala, p.c.), transitive expletive constructions are reported to be grammatical. Own research suggests that the impersonal construction might be possible with transitive verbs also in Northern Sotho, with the restriction that only transitive verbs taking [-human]-objects can occur in these constructions, as in (45-a). The impersonal construction is definitely excluded for transitive verbs taking two [+human]-objects, as in (45-b), and with ditransitive verbs, as in (45-c).

Transitive expletive construction in Northern Sotho
a. Go hlaba malome kgomo.
CL17 slaughter CL1.uncle CL9.cow
'The uncle is slaughtering the cow.'
b. *Go betha malome ngwana.
CL17 beat CL1.uncle CL1.child
Intended: 'The uncle is beating the child.'
c. *Go fa mo-nna mpša di-jo.
CL17 give CL1-man CL9.dog CL8-food
Intended: 'The man is giving food to the dog.'

However, as the judgements of the informants are not consistent, the matter has to await further research.

In impersonal constructions, as in (44), the subject has not raised to a higher position but remains in its VP-internal base-position. As the verb raises for independent reasons, namely to get TMA-features assigned, the resulting structure shows VS-word order. This is exemplified in (46).
a. Go fihla ba-eti.
CL17 arrive CL2-guest
'There are guests arriving.'

\footnotetext{
${ }^{21}$ According to Demuth \& Mmusi (1997) the impersonal construction does not appear with transitive verbs because this creates competition for a postverbal focus position. The issue of a syntactic focus position in Northern Sotho will be addressed in detail in chapter 2.
} 


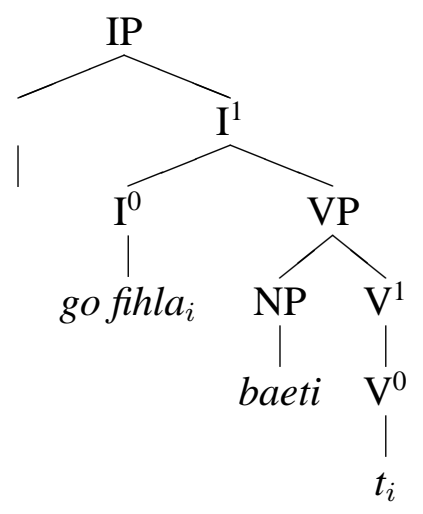

In impersonal constructions as in (46), the subject appears postverbally. As there is no element in SpecIP that the verb can agree with in noun class features, the verb bears class 17 agreement. In comparable constructions in other languages (Chichewa, Sotho), the postverbal subject does not show object properties, however: Neither can it be passivized, nor taken up by an object marker, nor extracted by relativization (see Bresnan \& Kanerva 1989, du Plessis 1981).

Landing position With respect to the subject's landing position and the grammatical status of the subject agreement morpheme, there are three possible configurations. A first syntactic configuration for agreement is one in which the subject agreement marker acts as a full NP and appears in subject position. The full subject NP, if present, is adjoined to a position higher in the tree. This configuration is illustrated in (47).

Anaphoric subject agreement I

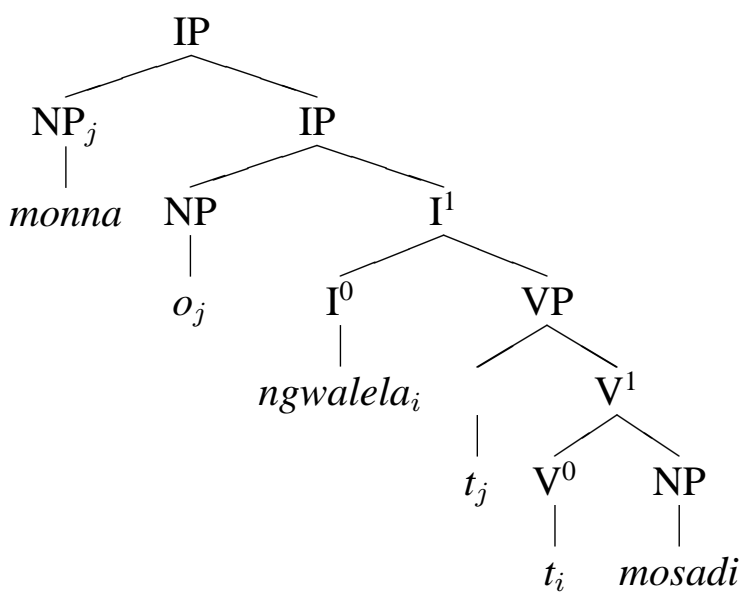

The configuration in (47) has been proposed by Demuth \& Johnson (1989). They argue that in Setawana (a language of the Sotho-Tswana family) the subject agreement marker always functions as a pronoun. Evidence comes from the optionality of the full subject NP, word order, non-locality effects, and the incompatibility of preverbal subjects with wh-words.

The two remaining syntactic configurations for subject agreement have in common that, in contrast to Demuth \& Johnson (1989), they consider the subject agreement marker 
as an incorporated pronoun into the verb stem. Incorporation is not only meant phonologically, but also syntactically. Phonologically, the subject agreement marker (though written separately in the Sotho languages) has been argued to form one unit with the following verb stem (see e.g. Myers 1985 for Shona). However, also syntactically, it is assumed that the agreement marker forms one unit with the following verb stem and is therefore located under $\mathrm{I}^{0}$ (or $\mathrm{T}^{0}, \operatorname{AgrS}^{0}$, depending on the analysis).

Therefore, in a second configuration the subject marker is considered part of the verbal inflection and therefore in $I^{0}$. Like in the first configuration illustrated in (47), the full subject NP, if present, is adjoined to the IP. Agreement between subject and verb is established via pro in SpecIP position. This syntactic configuration is illustrated in (48).

Anaphoric subject agreement II

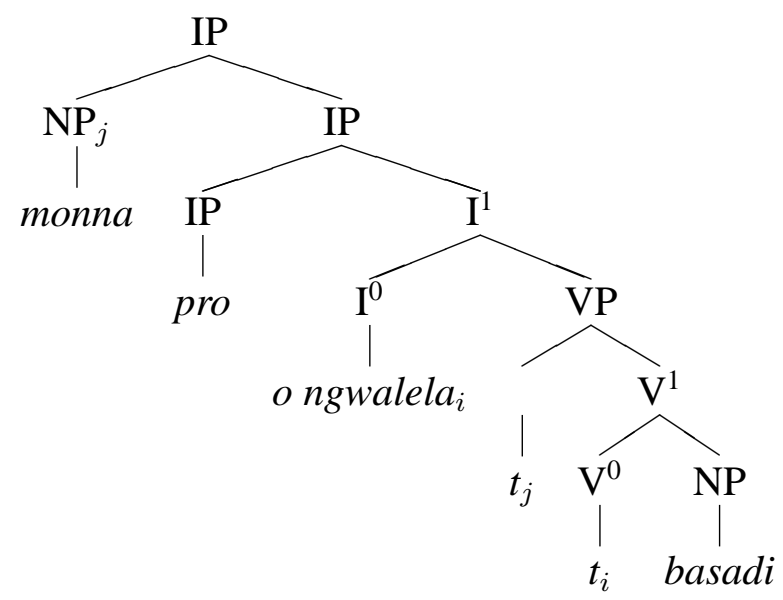

The configuration in (48) implies, just as the one in (47), that full subject NPs are always dislocated. In (48), however, the subject agreement marker does not fulfill the role of the grammatical subject but rather, the sentence is subjectless. The configuration equals prodrop phenomena in Romance languages where the full subject NP can also be missing and the verbal inflection takes over the duty of indicating anaphoric reference with a subject.

The view in (48) is advocated by Baker (2003), van der Spuy (1993), Visser (1985), and Sabel \& Zeller (to appear) for certain Bantu languages. For Kinande, a Bantu language spoken in the Democratic Republic of Congo, evidence for the syntactic dislocation of full subject NPs comes again from word order, incompatibility with wh-expressions, but also from specificity and scope considerations (Baker 2003). Data from word order in Kinande support Baker's claim that agreed-with subjects are dislocated and adjoined to the TP, as the subject appears at the left edge of the TP, as shown in (49-a), but not following the verb, as in (49-b).

(49) Word order in Kinande (Baker 2003: 112, 114)

a. Abakali ba-a-gula eritunda.

CL2.woman CL2-T-buy CL5.fruit

'The women bought a fruit.'

b. *A-gula omukali eritunda.

CL1-buy CL1.woman CL5.fruit

Intended: 'The woman bought a fruit.' 
Furthermore, wh-expressions in Kinande can be in postverbal object position, but not in the dislocated object position, as in (50-a). Baker (2003: 119) argues that for the same reason, namely syntactic dislocation, wh-expressions with agreed-with subjects are ungrammatical in Kinande, as shown in (50-b).

Wh-expressions in Kinande (Baker 2003: 112, 119)
a. *Ebihi, Kambale a-bi-gula?
CL8.what PROP.NAME CL1-CL8-buy
Intended: 'What did Kambale buy?'
b. *(Iyo)ndi a-gula eritunda?
who CL1-buy CL5.fruit
Intended: 'Who bought a fruit?'

With respect to scope and specificity, according to Cinque (1990, ch.2), dislocated NPs can have indefinite readings but they must be specific. Baker therefore concludes that dislocated NPs act like they have wide scope with respect to other quantified NPs (Baker 2003: 120). He shows that agreed-with subjects in Kinande have indeed wide scope with respect to other quantified NPs, similar to dislocated objects. A dislocated object taking wide scope with respect to the quantified subject is illustrated in (51-a). Similarly, (51-b) shows a subject that must take wide scope with respect to a quantified object.

Scope in Kinande (Baker 2003:120)

a. Eritunda, obuli mukali mo-a-li-gul-ire.

CL5.fruit every CL1.woman AFF-CL1-CL5-buy-EXT

'A fruit, every woman bought it.' (only one fruit bought)

b. Omukali a-gula obuli ritunda.

CL1.woman CL1-buy every fruit

'A (single) woman bought every fruit.'

Finally, Baker (2003: 118) shows that in Kinande, noun phrases lacking the initial augment vowel appear under the scope of negation and certain other operators as well as in object position, as shown by the augmentless object noun in (52-a). These forms are referred to as nonreferential NPs. However, they cannot appear neither as dislocated object, as in (52-b), nor as agreed-with subjects, as shown in (52-c).

(52) Nonreferential NPs in Kinande (Baker 2003: 111, 118)
a. Omukali mo-a-teta-gula ki-ndu.
CL1.woman AFF-CL1-NEG/PsT-buy CL7-thing
'The woman didn't buy anything.'
b. *(E)-ki-ndu, omukali mo-a-teta-ki-gula. (AUG)-CL7-thing CL1.woman AFF-CL1-NEG/PST-CL7-buy Intended: 'Anything, the woman didn't buy.'
c. *Mu-kali mo-a-teta-gula eritunda. CL1-woman AFF-CL1-NEG/PST-buy CL5.fruit Intended: 'No woman bought a fruit.'


Evidence from these four areas leads Baker (2003) to conclude that in Kinande, the subject is always syntactically dislocated.

A third and last configuration for subject agreement emerges from work by Bresnan \& Mchombo (1987). The authors claim that subject agreement in Chichewa, a Bantu language spoken in Malawi, is ambiguous between anaphoric agreement (as illustrated in (47) and (48)) and grammatical agreement. They argue that both kinds of agreement can be present in the same language. Grammatical agreement refers to the languagespecifically required agreement relation between a certain grammatical function (either subject or object) and the verb, which is expressed via a verbal affix. Anaphoric agreement refers to the relation of a morphologically bound pronoun to a discourse topic. Whereas evidence from word order, optionality of the full NP and non-locality effects indicate anaphoric agreement, the compatibility with $w h$-words in Chichewa (and also other languages such as Nsenga and Swahili (Marten p.c.)) indicates grammatical agreement of subject NP and verb.

Chichewa (Bresnan \& Mchombo 1987: 760, ex. (42))

a. (Kodí) chíyâni chi-ná-ónek-a?

QP CL7.what CL7-PST-happen-IND

'What happened?'

Because in Lexical Functional Grammar, an incorporated pronoun is linked anaphorically to an NP that bears the discourse-pragmatic function of topic, the compatibility with whwords excludes anaphoric reference because $w h$-words are considered inherently focused. $W h$-words and topic exclude each other. In those cases, namely when agreeing with a whword, the subject agreement marker acts as grammatical agreement (Bresnan \& Mchombo 1987). In a grammatical agreement relationship, the subject NP is inside the core clause, in contrast to anaphoric agreement where the full subject NP is outside the core clause. The translation of grammatical agreement into syntactic structure is done in (54).

Grammatical agreement

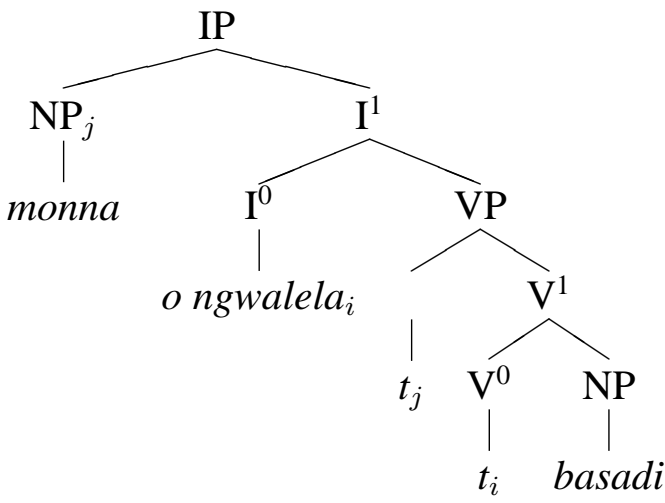

For the grammar of Northern Sotho, I adopt the wide-spread view illustrated in (48) and (54), that the subject agreement marker is part of the verbal inflection and therefore located in $\mathrm{I}^{0}$. With respect to the position of the full subject NP, evidence from word order, 
optionality and non-locality effects suggest that also in Northern Sotho the full subject NP is dislocated. ${ }^{22}$ The relevant data is given in (55).

Example (55-a) shows that the full subject NP can be left out. Example (55-b) shows that the subject NP can be freely positioned within the sentence. There can even be another constituent intervening between the subject and the verb. Lastly, example (55-c) shows that the subject NP can be moved out of its embedded clause and still be coreferrent with the subject marker.

a. Optionality

[Monna o dira eng?- 'What is the man doing?']

(i) Mo-nna o swiela le-bato. CL1-man CL1 sweep CL5-floor

(ii) O swiela lebato. '(The man,) he is sweeping the floor.'

b. Word order

(i) Mo-nna o swiela le-bato. CL1-man CL1 sweep CL5-floor

(ii) O swiela lebato, monna.

(iii) Monna, lehono, o swiela lebato. Lit.: 'The man, today, he is sweeping the floor.' ${ }^{23}$

c. Non-locality

(i) Ngwana kgoši e r-ile o swiela le-bato. CL1.child CL9.chief CL9 say-PST CL1 sweep CL5-floor Lit.: 'The child, the chief said, is sweeping the floor.'

However, I depart from the view advanced in Baker (2003) for Kinande and Demuth \& Johnson (1989) for Southern Sotho, that the subject is necessarily dislocated in Northern Sotho. Anticipating findings that are presented in great detail in chapter 4, I propose that under wide focus the subject is not dislocated and the subject marker expresses grammatical agreement in Northern Sotho.

Agreement under wide focus Under wide focus, the subject appears preverbally both with transitive verbs and with intransitive verbs. However, under wide focus it does not show properties of dislocated constituents. This means, it cannot be left out, as in (56-a), it appears in canonical preverbal position and cannot be re-ordered to the end of the sentence e.g., as in (56-b), and it can have a non-specific semantic interpretation, as in (56-c). ${ }^{24}$ Respective examples from chapter 4 are previewed in (56).

\footnotetext{
${ }^{22}$ In contrast to Kinande, there are no phonological consequences of left-dislocation in Northern Sotho, neither for the object nor for the subject, as will be shown in chapter 3 in detail.

${ }^{23}$ As with articles, cf. example (38), also for syntactic structures the most probable translations are given, unless marked by 'Lit.'.

${ }^{24}$ Further tests for the syntactic status of the subject cannot be applied, because for one, wh-expressions are not applicable to wide focus, and for the other, Northern Sotho lacks augmented forms that appear in Kinande.
} 
a. [Go diregang?- 'What is happening?']

*O ruta ngwana go bala buka.

CL1 teach CL1.child CL15 read CL9.book

Intended: 'A mother teaches a child to read a book.'

b. [Go diregang?- 'What is happening?']

*O ruta ngwana go bala buka, mma.

CL1 teach CL1.child CL15 read CL9.book CL1.mother

Intended: 'A mother teaches a child to read a book.'

c. [When reporting that my car was stolen]

Ma-hodu a utsw-itše koloi ya ka. CL6-thief CL6 steal-PST CL9.car CL9.POSS POSSPR.1

'Thieves stole my car.'

(Mojapelo 2003, in prep.)

Further evidence for the syntactic position of the subject under wide focus can be gathered from interpretational effects. Whereas dislocated subjects are argued to have a topic interpretation, chapter 4 shows in detail that not all preverbal subjects are topics. Preverbal subjects under wide focus are not topics. The view taken in this thesis is consequently that discourse-pragmatics are deterministic in providing evidence for the syntactic structure. This is contrary to the view advanced in Baker (2003):

"Phonological and/or pragmatic evidence is sometimes used to tell if an NP is dislocated. For example, dislocated NPs are sometimes set off from the rest of the clause by an intonation break, and they are sometimes associated with topic or contrastive focus interpretations. The Pronominal Argument Hypothesis is committed to there being cases of syntactic dislocation that do not have these nonsyntactic properties, however. (...) I show below that agreed-with objects in Kinande have these phonological and pragmatic characteristics of dislocation, but agreed-with subjects do not. All this implies that there are natural interconnections between the various components of language, but they are not fully deterministic." (Baker 2003: 130, footnote 8)

The view of unambiguous anaphoric agreement of the subject marker in Northern Sotho is questioned by the data presented in this thesis. Rather, the data provide evidence that wide focus is one context in which the subject agreement marker establishes grammatical agreement. Consequently, the occurrence of preverbal subjects under wide focus provides evidence from discourse-pragmatics for the ambiguous status of the subject marker between anaphoric and grammatical agreement and support Bresnan \& Mchombo's original analysis for Nothern Sotho as well. With respect to syntactic structure, the data provide evidence for the claim that at least in contexts of wide focus in Northern Sotho, the subject is in a position where it expresses direct agreement with the verb, i.e. in SpecTP. In how far this finding concerning the grammatical status of the subject marker is transferrable to other Bantu languages remains a topic of further research.

Whereas preverbal subjects agree obligatorily with the verb in all Bantu languages, there is more language-specific variation with respect to 'object agreement'. This will be addressed in the next section. 


\section{'Object agreement'}

A full object NP can agree with the verb, but need not. Variation in object marking is found with respect to animacity: In some languages the object marker is obligatory with [+human]-objects (e.g. in Makua, Stucky 1981) or occurs more frequently with them (e.g. in Swahili, Krifka 1995: 1407). Furthermore, there is variation with respect to the simultaneous appearance of both object marker and object NP (e.g. in Herero, Möhlig et al. 2002: 79) and the possibility of having both left- and right-dislocation in a language (e.g. in Kinande, Baker 2003). Subject and object marking have different characteristics in Bantu languages, one crucial difference being the optionality of object marking as opposed to subject marking.

In Northern Sotho, objects do not agree obligatorily with the verb, neither in certain persons nor with certain status' of animacity. Furthermore, an object marker can occur on the verb together with the co-occurring object NP. The object markers are given in table 3. Like the subject markers, they too, closely resemble noun class prefixes.

Table 3: Object markers in Northern Sotho (Ziervogel et al. 1969)

\begin{tabular}{|l|l|l|l|}
\hline noun class & noun class prefixes & subject agreement & object agreement \\
\hline 1 & mo- & o & mo \\
\hline 2 & ba- & ba & ba \\
\hline 3 & mo- & o & mo \\
\hline 4 & me- & e & e \\
\hline 5 & le- & le & le \\
\hline 6 & ma- & a & a \\
\hline 7 & se- & se & se \\
\hline 8 & di- & di & di \\
\hline 9 & n- & e & e \\
\hline 10 & di- & di & di \\
\hline 14 & bo- & bo & bo \\
\hline
\end{tabular}

Examples of object marking are given in (57). The examples in (57) show object marker and co-occuring object NP whereby the co-occurring NP appears in sentence-initial position in (57-a) and in sentence-final position in (57-b).

Object marking in Northern Sotho

a. Mo-rwalo ke a o rwala.

CL3-load 1 -A- CL3 carry

Lit. 'The load, I carry it.'

b. Ke mo nea ma-lekere malome.

1 CL1 give CL6-sweets CL1.uncle

Lit. 'I give him sweets, the uncle.'

Crucially, the object marker is not considered a grammatical agreement marker in the literature on Bantu languages, but rather a pronoun (Byarushengo, Hyman \& Tenenbaum 1976 for Haya, Wald 1979 for Swahili). It has been analysed as an object pronoun incorporated into the verb for Chichewa (Bresnan \& Mchombo 1987). This analysis has 
been followed in all recent work on Southern African Bantu languages (Baker 2003, Demuth 1989, Demuth \& Johnson 1989, van der Spuy 1993, Zeller 2004, Zeller \& Ngoboka 2005). Furthermore, it has been suggested early in the literature, that a full object constituent which co-occurs with an object marker is dislocated: it has been described as either 'outside the basic sentence unit' (Cole 1955: 427-444 on Tswana), 'being dissociated from the verb by the sentence boundary' (Louwrens 1985: 60 on Northern Sotho), or as following the 'basic communicative unit' (Kosch 1988:4 also on Northern Sotho).

Status of the object marker Evidence for the object marker as a pronoun comes from the optionality of the coreferent object NP, from word order and from tone. Bresnan \& Mchombo (1987) report for Chichewa that, first, if the object marker and a coreferred full object NP co-occur, the object can be left out without rendering the sentence ungrammatical. Second, whereas in simple transitive sentences, when there is no object marker on the verb, the word order is fixed in the sense that the object immediately follows the verb, there is free word order when the object marker is present. Third, the tone pattern that is realized on the verb when being followed by an object NP that has a coreferent object marker on the verb, resembles the tone pattern when the verb is phrase-final. As a consequence of analyzing the object marker as a full pronoun, it follows that object pronoun and its coreferent object NP cannot co-occur within the same core clause. The coreferent object NP is therefore analysed as being outside the core clause (Bresnan \& Mchombo 1987) or outside the VP (van der Spuy 1993).

The facts are parallel for Northern Sotho and the argumentation of Bresnan \& Mchombo (1987) is followed here in order to show that the object marker acts as an incorporated pronoun in Northern Sotho as well and that the full object NP is adjoined to the core clause. Evidence is cited from the optionality of the object NP, word order, and tone. Moreover, the Southern Bantu languages also provide evidence from verbal morphology for the position of the object NP. This will be taken up in the next subsection.

The data in (58) show that the presence of the coreferent object NP is only optional in Northern Sotho. The argument structure of the verb is satisfied by the appearance of the object marker alone. The full object NP might be added for discourse-pragmatic reasons (in the examples parentheses indicate optionality). The data in (58) furthermore show that in Northern Sotho, an object can be right-dislocated in contrast to languages like Kinande, where only left-dislocation is possible (Baker 2003).

Optionality of the object NP in Northern Sotho

a. Ke a o rwa:la (mo-rwa:lo).

1 -A- CL3 carry CL3-load

Lit. 'I carry it (, the load).'

b. Ke mo nea ma-leke:re (malo:me).

1 CL1 give CL6-sweets CL1.uncle

Lit. 'I give him sweets (, the uncle).'

When co-occuring with the object marker, the word order of the object NP is free. The data in (59) show that the coreferred object constituent can also appear in sentence-initial position, as in (59-a). Left-dislocation as in (59-a) is ruled out if the object marker does not co-occur with the object NP, as in (59-b). 
Left-dislocation in Northern Sotho

a. Le-ngwalo, ke le ngwad-ile. CL5-letter 1 CL5 write-PST Lit. 'The letter, I wrote it.'

b. *Le-ngwalo ke ngwad-ile. CL5-letter 1 write-PST

Similarly, the data in (60) show that the coreferred object NP cannot appear immediately postverbally if other VP-internal material is following. In the ditransitive structure in (60-a), the beneficiary object is coreferred with an object marker on the verb and appears in sentence-final position (instead of immediately postverbal). Its appearance in immediately postverbal position, as in (60-b), renders the structure ungrammatical. The same can be observed for the positioning of objects with respect to adverbs. The coreferred object NP can only occur following the adverb, as in (60-c), not between verb and adverb, as in (60-d).

(60) Word order with coreferred objects
a. O mo fa se-hlare, mo-kgalabje. CL1 CL1 give CL7-medicine CL1-old.man 'He gives the old man medicine.'
b. *O mo fa mo-kgalabje se-hlare.
CL1 CL1 give CL1-old.man CL7-medicine
c. Ke le ngwad-ile maabane le-ngwalo. 1 CL5 write-PST yesterday CL5-letter 'I wrote the letter yesterday.'
d. *Ke le ngwad-ile le-ngwalo maabane. 1 CL5 write-PST CL5-letter yesterday

With respect to tonal evidence, the data in (61) show that with the presence of the object marker also the tonal structure on the element which precedes the full object NP differs (see also Cole 1955 for Tswana). In (60-a), the underlying high tone from the initial syllable of the verb stem spreads onto the immediately right-adjacent syllable. This process of High Tone Spread (HTS) can be observed on words in phrase-medial position. In (60-b), the high tone from the verb stem initial syllable does not spread to the final syllable. The lack of HTS can be alluded to a phrase-final syllable.

(61) Tone in dislocation
a. Ke kw-élé mo-kgala:bje.
1 hear-PST CL1-old.man
'I heard the old man.'
b. Ke mo kw-é:le mo-kgala:bje.
1 CL1 hear-PST CL1-old.man
Lit. 'I heard him, the old man.'

For more details of the tonal processes as well as lengthening see chapter 3. Tonal facts have been interpreted as evidence for syntactic structure in Bresnan \& Mchombo (1987). 
In (61-a), verb and object are constituents of one syntactic phrase, the VP. In (61-b), the changes in tonal structure are induced by prosodic boundaries that coincide with syntactic boundaries. The verb and object are separated by the VP-boundary in (61-b).

Syntactic position of the dislocated constituent Data on obligatoriness of the full object NP, word order and tone give evidence for interpreting the object marker as an incorporated pronoun. Consequently, the coreferent object NP must be outside the core clause, as a pronoun cannot be coreferent with any constituent within the same clause. This view is reached at independently of the theoretical framework adhered to in the different studies cited.

Verbal structures containing adverbs give decisive evidence. The standard syntactic assumption is followed here, namely that adverbs are adjoined inside the verb phrase. As in Northern Sotho adverbs always follow objects, adverbs are adjoined to the highest verbal projection. Right-dislocated constituents differ from adverbs structurally in that they are adjoined to an even higher projection. Evidence for this claim comes from word order and tone. First, the word order of adverbs and right-dislocated NPs is not free. Right-dislocated elements always have to follow adverbs when those are internal to the core-clause. Second, between a right-dislocated element and its preceding constituent are salient suprasegmental differences (length and tonal changes). This is not the case between an adverb and its preceding element.

The following syntactic structure is proposed for right dislocation. Coreferred object NPs are outside the IP. They are adjoined to a higher projection of the IP. The syntactic structure is given in (62).

(62) a. (Mo-sadi) o e ngwa-dile maaba:ne le-ngwa:lo.

CL1-woman CL1 CL5 write-PST yesterday CL5-letter

Lit. 'The woman wrote it yesterday, the letter.'

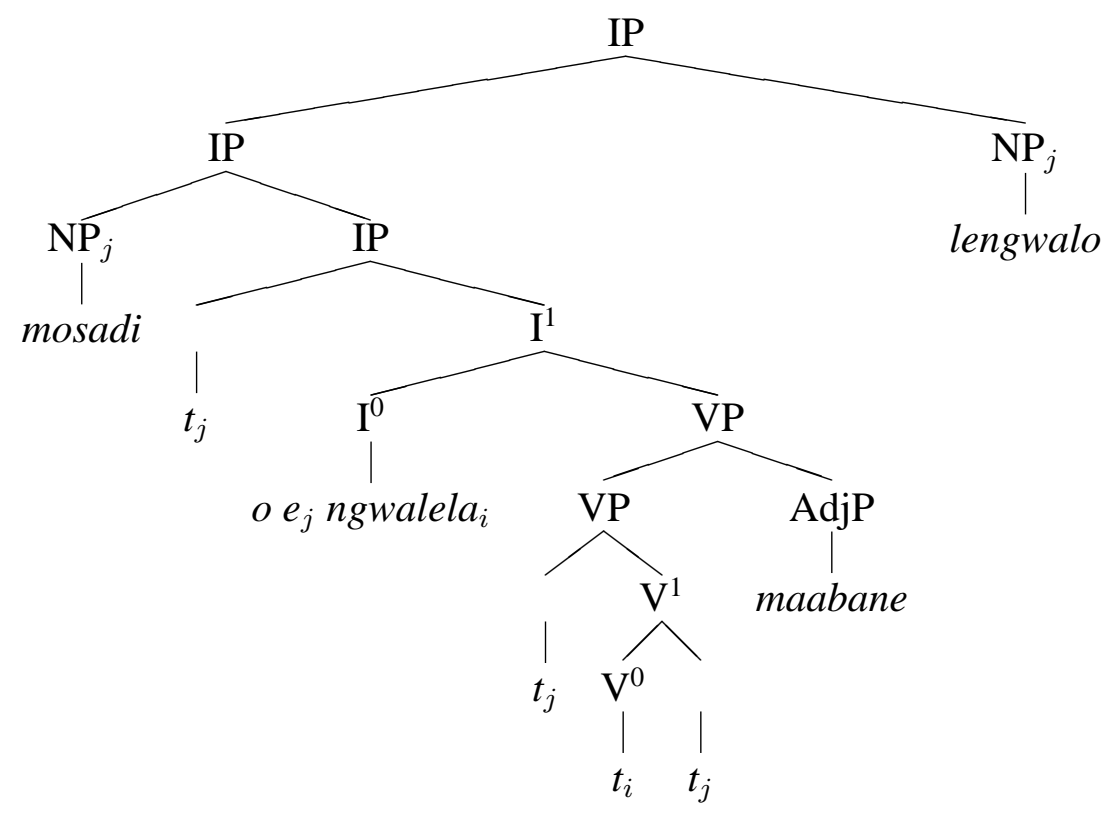


Syntactic structure of the object marker The theoretic approaches proposed in the literature differ, however, with respect to details of the pronoun incorporation. In the LFG-framework followed in Bresnan \& Mchombo (1987), the verb is taken from the lexicon containing the incorporated pronoun. The dislocated noun phrase is one direct constituent of the sentence besides the verb phrase and further topic NP as itself bears the discourse-functional role of topic. It is anaphorically linked to the incorporated object marker.

Two further proposals have been made in the literature concerning the syntactic structure of the object marker in Bantu. They differ in technical details, but are not necessarily incompatible (see Zeller 2004b, footnotes 2 and 16). On the one hand, according to Baker (2003), the object marker on the verb in Kinande represents object agreement. Its obligatory appearance in dislocation constructions is explained by the occurrence of null pronominal arguments (pro) in object position.

On the other hand, Zeller (2004b) in his work on left-dislocation in Zulu follows the proposal by Cecchetto (1999) made for clitic constructions in Italian. According to this proposal, the dislocated constituent originates from the specifier position of a 'big' DP whose head is the object marker. The object marker is considered a resumptive pronoun in this analysis as well. Zeller argues that the object marker in the head of the DP undergoes head movement and adjoins to $\mathrm{V}$ to be incorporated into the verbal morphology. The full nominal constituent moves from the specifier of 'big'-DP to either a sentence-initial position (left-dislocation) or to a right-peripheral landing site (right-dislocation).

Of relevance for the discussion in this thesis is foremost what is uncontroversial in the literature, namely that the object marker fulfills the role of the argument and that the full object NP is outside the core clause, which is assumed to be IP.

Subject and object agreement share the following properties: They depend on the discourse status of the agreeing constituent. They cannot appear when the agreeing constituent would be focused information. With respect to their syntax, both subject and object marker are considered pronominal markers. However, they differ in that only subject agreement but not object agreement can appear under wide focus in Northern Sotho. In this environment, it is argued that the subject marker expresses grammatical agreement on the verb. Objects never agree grammatically in Northern Sotho.

\subsubsection{Present Tense morpheme - $a$ -}

Northern Sotho shows a morphological alternation in the verbal paradigm in the Present Tense. This is similar to the situation in the other southeastern Bantu languages (Nguni, Venda, Tsonga, and Chopi, with the exception of Shona, for references see Güldemann 1996: 170). ${ }^{25}$ The alternation is illustrated by the data in (63).

\footnotetext{
${ }^{25}$ Other Southern Bantu languages, e.g. Mbala, Rwanda, Bemba, and Tonga, also show a morphological alternation in the Present Tense (see Güldemann 1996:165ff for an overview). An example is given in (i).
}

(i)

Kirundi (from Morimoto 2000: 126)

a. Abana ba-á-ra-nyoye amatá.

'Children drank milk.'

b. Abana ba-á-nyoye amatá.

'Children drank milk (not water).' 
Present Tense (from Louwrens 1985: 60)
a. Le-sogana le a ngwala.
CL5-young.man CL5 -A- write
'The young man writes.'
(long form/ disjunctive form)
b. Malome o tseba Se-sotho.
CL1.uncle CL1 know CL7-Sotho
'Uncle knows Sotho.'
(short form/ conjunctive form)

The example in (63-a) shows the verb in the Present Tense containing the -a-morpheme in the TMA-slot of the verbal template. The example in (63-b) shows the verb form not containing $-a-$. The distribution of the two allomorphs has been accounted for by different factors, among others syntax and information structure, and is still subject to research (see most recently Buell 2005). The syntactic approach will be presented below in detail, for the alternative approach relating to information structure and a comparison of both proposals see chapter 2 .

The alternating verb forms have been referred to by different terms in the literature, a.o. long vs. short (Doke 1927/1992) or disjunctive vs. conjunctive (Creissels 1996, Chebanne et al. 1997). In the example in (63), sentence (63-a) contains the so-called long or disjunctive form, whereas (63-b) contains the so-called short or conjunctive form. In contrast to other Bantu languages like Bemba (Givón 1975), the alternating verb forms in the Sotho family are characterized by the following properties:

(64) Characteristics of the disjunctive and conjunctive forms in Northern Sotho

-The alternating verb forms occur only in restricted tenses: only in the Present Tense.

-In the Present Tense the alternation is between $-a$ - and 0 .

-There are no alternations in negative and relative environments.

-There is no contrast with complements.

Text books (e.g. Ziervogel et al. 1969: 18) give as a rule of thumb that $-a$ - is inserted if the predicate appears at the end of a sentence (65-a,b). If an object, (65-c), or an adverb, (65-d) follows, $-a$ - is not inserted.

- $a$ - insertion in Northern Sotho
a. Mo-sadi
o a apea. / Mo-sadi
o a di apea.
CL1-woman CL1 -A- cook / CL1-woman CL1 -A- CL8 cook
'The woman is cooking (it).'

\footnotetext{
If the new information in the sentence is carried by the verb, the verb incorporates - $r a-$. If the new information is carried by the complement, -ra- does not appear (Kimyeni 1980: 217). Though there are similarities in the phenomenon (e.g. its connection to information structure, see chapter 2 for Northern Sotho), the differences e.g. with respect to the presence of the object marker, do not allow to simply extend van der Spuy's proposal (1993) to these languages as well.

In Nguni languages, the same alternation exists in the Perfect Tense between the suffix -ile and -e. See Doke (1954), van der Spuy (2003), Güldemann (1996), and most recently Buell (2005).
} 


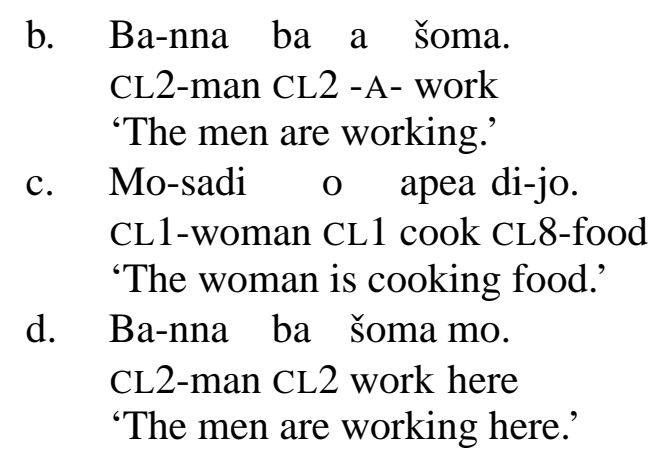

The description given in grammar books accounts for the ungrammaticality of the short form of the verb when there are no complements following, as in (66).

Ungrammatical forms in the Present Tense

a. *Mosadi o apea.

b. *Banna ba dira.

In the sentences in (66), the predicate is final in the sentence wherefore the insertion of $-a$ - is predicted. However, the surface description of grammars cannot account for the grammaticality of the examples given in (67).

(67) Occurrence of - $a$ - in non-final position
a. Mo-sadi o a di apea di-jo.
CL1-woman CL1 -A- CL8 cook CL8-food
Lit. 'The woman cooks it, the food.'
b. Ba-nna ba a šoma mo.
CL2-man CL2 -A- work here
'Men are working here.'
c. *Mo-sadi o di apea di-jo.

The object, not the predicate is at the end of the sentence in $(67-a, b)$. Therefore the presence of the Present Tense $-a$ - is surprising following the rule of thumb proposed in Ziervogel et al. (1969:18). The absence of $-a$ - even leads to ungrammaticality, as shown in $(67-c)$.

Syntactic approaches to the distribution have been proposed by van der Spuy (1993), Jokweni (1995), and most recently Buell (2005) for Nguni, and by Khoali (1991) and Louwrens (1985) for Sotho. Van der Spuy's (1993) approach for the Nguni languages will be followed here. As Sotho shows data comparable to Nguni, the same syntactic approach is extended to the alternation in the Present Tense in Sotho.

Van der Spuy (1993) claims that the long form of the Present Tense (and in the Nguni languages also the long form of the Perfect Tense) is a syntactic phrase-boundary marker (1993: 345) which appears when the verb is final in the IP. In the examples in (65), the verb meets van der Spuys generalization to be final in the IP vacuously. In (67-a,b), the verb is final in the syntactic IP (and therefore appears in the long form) when interpreting the presence of the object marker on the verb as evidence for the position of the object NP outside the syntactic IP. Being outside the syntactic IP explains further properties of the object NP such as its optionality, the resulting free word order, and prosodic changes on 
the verb (see preceding subsection for evidence for this claim). For adjuncts as in (67-b), van der Spuy (1993) assumes an analysis analogous to (67-a). The adjunct is outside the syntactic IP in (67-b), therefore the verb is final in the syntactic IP and surfaces in the long form.

The relation of the Present Tense morpheme $-a$ - to information structure is taken up again in chapter 2 .

After having outlaid the general linguistic characteristics of Northern Sotho, the following chapter turns to the syntactic expression of focus in this language. 


\section{Chapter 2}

\section{Syntax and focus in Northern Sotho}

\subsection{Introduction}

In discourse-configurational languages, "primary sentence articulation is motivated by discourse semantic, rather than theta role or case, considerations" (É Kiss 1995b: 3). Bantu languages have been shown to exhibit discourse-configurational characteristics. On the one hand, work by e.g. Morimoto (2000) discusses the relevance of the discourse notion 'topic' on word order and sentence structure in the Bantu languages Kirundi and Kinyarwanda. On the other hand, work by e.g Bergvall (1987a, b), Carstens (2005), and Sabel \& Zeller (to appear) investigates the influence of the discourse notion 'focus' on word order and sentence structure in the Bantu languages Kikuyu, Kilega, and Nguni respectively. Furthermore, also an immediately postverbal position has been shown to be relevant in the Grassfields Bantu language Aghem (Watters 1979, Hyman \& Watters 1984). These studies show that discourse notions influence word order and sentence structure in Bantu languages.

This chapter investigates syntactic reflexes of focus in Northern Sotho, a Bantu language spoken in South Africa. ${ }^{1}$ The definition of focus as a set of alternatives guides the elicitation of the data and ensures cross-linguistic comparability. The objective of this chapter is to introduce the relevant data that will be dealt with in this thesis, and more specifically to show that there is no grammatical marking of focus in Northern Sotho in the postverbal domain, neither syntactically nor morphologically. Focus is expressed strictly in situ. There are, nevertheless, reflexes of focus and information structure in Northern Sotho. These result from processes that target discourse-old constituents.

The chapter is structured as follows: In section 2.2, this chapter gives a systematic overview of the syntactic consequences of focus on the subject, the object, adverbials, modified constituents, and the verb in Northern Sotho. It emerges from the data that Northern Sotho shows a subject/non-subject asymmetry under focus. Whereas nonsubject constituents are focused in their base position, logical subjects appear either postverbally or in a cleft sentence, but crucially not in their canonical preverbal position. In section 2.3, the chapter explicitly investigates alternative positions for focused non-subjects with the result that focused constituents must not appear neither at the left periphery nor at the right periphery. Although there is no syntactic marking of focus in

\footnotetext{
${ }^{1}$ The notion of topic will be addressed in chapter 4 .
} 
Northern Sotho, information structure is mirrored in an utterance in that discourse-old constituents are subject to reduction or dislocation processes. These processes are illustrated in section 2.4 .

The reduction and dislocation processes presented in section 2.4 are of interest not only because they show the influence of information structure on grammar in Northern Sotho but also because their application leads to an increased occurrence of the focused constituent in clause-final position. However, both section 2.3 and 2.4 argue that there is no causal relation between final position and focus in Northern Sotho. Section 2.5 investigates the occurrence of Present Tense $-a$ - as a phenomenon along the same lines and shows that this verbal morpheme is no morphological marker of focus. Section 2.6 provides a conclusion.

\subsection{Syntactic reflexes of focus in Northern Sotho}

The following sections investigate how focus influences word order, agreement and syntactic structure in Northern Sotho. In accordance with section 1.2, focus is defined as indicating a set of alternatives. Focus is elicited in contexts of question/answer coherence, textual coherence, and expression of contrast, as motivated in section 1.2.

\subsubsection{Objects and adverbials}

An examination of focus-related contexts shows that objects and adverbials (i.e. nonsubjects) are focused in situ, i.e. in their canonical postverbal position. This is shown in (1) for questions and in (2) for answers displaying narrow focus, thereby establishing question/answer coherence. The object $w h$-word in (1-a) as well as the focused object in (2-a) appear in their basic position immediately after the verb. Also the local wh-word in (1-b) and the focused local adverb (2-b) surface as in basic word order, namely immediately following the object. The examples in $(1-c, d)$ are taken from semi-spontaneous speech collected by means of the questionnaire. They show a modal question word in the position immediately following the object.

(1) Non-subject questions in Northern Sotho

a. Mo-kgalabje o nyaka mang?
CL1-old.man CL1 look.for who
'Who is the old man looking for?'

b. Mo-kgalabje o nyaka ngaka kae?

CL1-old.man CL1 look.for CL9.doctor where

'Where is the old man looking for the doctor?'

c. O nagana gore mo-sadi yo o utsw-itše se-šupanako bjang?

2 think that CL1-woman DEM.CL1 CL1 steal-PST CL7-watch how

'How do you think that this woman stole the watch?'

(QUIS) 
d. Naa mo-sadi o rwala di-galase bjang ge a tloga ka QP CL1-woman CL1 carry CL10-glass how when CL1 leave PREP phapoši-ng?

CL9.room-LOC

'How did the woman carry the glasses when she left the room?'

(QUIS)

(2) Non-subject focus in Northern Sotho

a. Mo-kgalabje o nyaka $[\text { ngaka }]_{F}$.

CL1-old.man CL1 look.for CL9.doctor

'The old man is looking for THE DOCTOR.'

b. Mo-kgalabje o nyaka ngaka [toropo-ng $]_{F}$.

CL1-old.man CL1 look.for CL9.doctor CL9.town-LOC

'The old man is looking for the doctor IN TOWN.'

The data in (3) show contextual coherence with focus-sensitive particles. In German and English, accent placement marks the constituent that only associates with. Accent placement therefore influences the truth-value of an utterance which contains a focussensitive particle. The word fela is the Northern Sotho equivalent to English only. In (3-a), fela follows the object that it associates with. In (3-b), the reading is ambigious between the local adverb and the whole VP being in the scope of fela. (3-c) shows an example from semi-spontaneous speech. The context from which the utterance is taken is given in square brackets.

(3) Non-subjects and focus-sensitive particles
a. Mo-sadi o tliša $[\text { ba-na }]_{F}$ fela se-kolo-ng. CL1-woman CL1 bring CL2-children only CL7-school-LOC
'The woman only brings THE CHILDREN to school (not the teenagers).'
b. Mo-sadi o tliša ba-na [se-kolo-ng $]_{F}$ fela.
CL1-woman CL1 bring CL2-children CL7-school-LOC only
'The woman only brings the children TO SCHOOL (not to church).'
c. (i) [Ekaba Molatelo o na le di-monamonane le tšhese? 'Does Molatelo have chocolate and cheese?]
(ii) Aowa, Molatelo o na le [di-monamonane $]_{F}$ fela. No PROP.NAME CL1 be with CL10-sweets only 'No, Molatelo has only CHOCOLATE.'

(QUIS)

The data in (3) show that fela appears linearly after the focused constituent.

The data in (4) show further examples for textual coherence. In (4), however, the truth-value of the utterance is not influenced by the accent that indicates the focused constituent in languages like English and German. The examples are reproduced from Paul (1880). The first sentence in (4-a,b,c,d) establishes a discourse-context. The second sentence is lexically identical in all examples in (4). In Northern Sotho, no change in syntax (or morphology) reflects the different focus structures. (For predictions concerning the prosody of these utterances see chapter 3 ). 
(4) a. (i) Raisetja o rata go etela toropo e kgolo ya

PROP.NAME CL1 like CL15 visit CL9.town CL9 big POSS.CL9

Africa.

Africa

'Raisetja likes to visit big African cities.

(ii) $\mathrm{O}$ ya $[\text { Gauteng }]_{F}$ lehono.

CL1 go Gauteng today

'Today, he goes to JOHANNESBURG.' 2

b. (i) Raisetja o swanetše go ya Gauteng e sekgale.

PROP.NAME CL1 must CL15 go Gauteng CL9 far

'Raisetja soon needs to go to Johannesburg.

(ii) Ke kw-ele gore o ya Gauteng [lehono $]_{F}$.

1 hear-PST that CL1 go Gauteng today

'I heard that he goes to Johannesburg TODAY.'

c. (i) Raisetja o swanetše go ya Gauteng.

PROP.NAME CL1 need CL15 go Gauteng

'Raisetja needs to go to Johannesburg.'

(ii) $\mathrm{Ga}$ a rat-e go otlela se-fatanaga, bjale o ya Gauteng NEG CL1 like-NEG CL15 drive CL7-car now CL1 go Gauteng $[\mathrm{ka} \text { ma-oto }]_{F}$.

PREP CL6-foot

'He doesn't like driving, so he WALKS to Johannesburg.'

The data in (5) show an instantiation of the function of contrast. Focused negation is a case of correction. The element that the negation associates with is contrasted with another constituent of the same kind. The preverbal negation in the examples in (5) can have scope over either the object or the adverbial, as the continuation of the clause indicates.

(5) Focused negation with non-subjects

a. Mo-šemane ga se a rekiše [bo-rotho $]_{F}$ maabane, o rekišitše cl1-boy NEG NEG CL1 sell.PST CL14-bread yesterday CL1 sell.PST

[bupi $]_{F}$.

CL9.porridge

'The boy didn't sell BREAD yesterday, he sold PORRIDGE.'

b. Mo-šemane ga se a rekiše bo-rotho $[\text { maabane }]_{F}, o$ bo

cl1-boy NEg NEg CL1 sell.PST CL14-bread yesterday CL1 CL14 rekišitše $[\text { lehono }]_{F}$.

sell.PST today

'The boy didn't sell bread YESTERDAY, he sold it TODAY.'

The data in (6) provide examples for correction focus from the questionnaire which were elicited through semi-spontaneous interaction of two native speakers.

\footnotetext{
${ }^{2}$ In the Sotho languages, Johannesburg is referred to by Gauteng, which means 'Place of gold'.
} 
(6) Correction focus

a. (i) [Naa Masilo o na le diapola?

'Does Masilo have apples?']

(ii) Aowa, Masilo $\mathrm{o}$ na le $[\text { di-namune tše pedi }]_{F}$.

No PROP.NAME CL1 be with CL10-orange QUAL.CL10 two

'No, Masilo has TwO ORANGES.'

(QUIS)

b. (i) [Naa, Lesibe o na le katse?

'Does Lesibe have a cat?']

(ii) Aowa, o na le $[\text { mmutla }]_{F}$.

No CL1 be with CL3.hare

'No, he has a HARE.'

(QUIS)

The examples show that objects and adverbials appear in their canonical position in correction contexts, as triggered by focused negation (5) or direct contrast (6).

The data presented in this section have shown that non-subjects appear in their canonical position in focus contexts. The kind of focus, either new information focus or contrastive focus, does not influence the syntactic expression.

\subsubsection{Subjects}

For logical subjects, a differentiation has to be made between their base-position, which is VP-internally, i.e. postverbally (see section 1.7.3), and their canonical position, which is preverbally. In general, logical subjects can never be focused in their canonical, i.e. preverbal, position. In this respect, subjects and non-subjects show an asymmetric behavior in Northern Sotho. In contrast to Bantu languages like Chichewa (Bresnan \& Mchombo 1987, Downing et al. 2004), Nsenga and Swahili (Marten p.c.), an agreed-with subject that, when focused, appears either in preverbal or clause-final position, is ungrammatical in Northern Sotho. ${ }^{3}$ This is shown by means of questions in (7).

Ungrammatical subject questions

a. *Mang o nyaka ngaka?

who CL1 look.for CL9.doctor

Intended: 'Who is looking for the doctor?'

b. *O nyaka ngaka mang?

CL1 look.for CL9.doctor who

Intended: 'Who is looking for the doctor?'

The ban of focused subjects from preverbal position is the topic of chapter 4 .

Dependent on the valency of the verb, a logical subject can either be focused in situ, i.e. in its postverbal, VP-internal position, and/or by means of a cleft sentence. Both constructions will be dealt with in turn.

\footnotetext{
${ }^{3}$ Preverbal subject questions are only possible in echo-questions and in multiple questions (see also Demuth 1995, Machobane 2001).
} 


\section{Impersonal construction}

A focused logical subject cannot appear in its canonical preverbal position. Focused logical subjects of intransitive verbs can, however, appear in postverbal position immediately following the verb. ${ }^{4}$ These constructions are referred to as impersonal constructions (see also section 1.7.3). The term impersonal construction is used to refer to constructions that lack a grammatical subject and show invariable agreement of class 17 on the verb. In Northern Sotho, subjects of intransitive verbs can be questioned in the impersonal construction, as shown by the data in (8). The wh-word questioning the logical subject appears in postverbal position and the agreement marker of class 17 is shown on the verb.

Impersonal subject questions
a. Go fihla mang?
CL17 arrive who
'Who is arriving?'
b. Go bina bo-mang?
CL17 dance CL2b-who
'Who is dancing?'

The subject also appears in this position in other focus-related contexts. This is shown in $(9-\mathrm{a}, \mathrm{b})$ for negation and in $(9-\mathrm{c}, \mathrm{d})$ for association with fela- 'only'. In all examples, the subject appears postverbally, and impersonal agreement appears on the verb.

(9) Negation and focus-sensitive particles in the impersonal construction
a. Ga se go fihl-e mo-nna.
NEG NEG CL17 arrive-NEG CL1-man
'The man did not arrive.'
b. Ga se go bin-e ba-sadi.
NEG NEG CL17 dance-NEG CL2-woman
'The women did not dance.'
c. Go fihl-ile [mo-nna $]_{F}$ fela.
CL17 arrive-PST CL1-man only
'Only the man arrived.'
d. Go binne [ba-sadi $]_{F}$ fela.
CL17 dance.PST CL2-woman only
'Only women danced.'

An alternative structure to the impersonal construction is the cleft construction, which will be discussed in the next section.

\section{Cleft sentences}

Logical subjects can also be focused by means of a cleft structure. This structure is optional for logical subjects of intransitive verbs and obligatory for logical subjects of

\footnotetext{
${ }^{4}$ There seems to be variation as to whether languages allow this structure. In Bantu languages like Kinande wh-pronouns in postverbal position are in some instances "less than perfect" (Baker 2003: 119).
} 
transitive and ditransitive verbs. The optionality of cleft and impersonal construction is illustrated in (10) for intransitive verbs.
a. Go fihla mang?
CL17 arrive who
'Who is arriving?'
b. Ké mang a fihla-ng?
COP who CL1 arrive-REL
Lit. 'It is who that is arriving?'

The semantic interpretation of the cleft and the optionality of the two constructions in (10) will be addressed in chapter 5.

The use of clefts with transitive verbs is illustrated in the following examples with a variety of contexts. The data in (11) show question/answer pairs. When focused, the subject appears in a cleft construction. Evidence for the cleft construction does not only come from the use of high-toned ké in sentence-initial position but also from the change in the verbal morphology.

(11) Subject focus in questions and answers
a. Ké mang (yo) a nyaka-ng ngaka?
COP who DEM.CL1 CL1 look.for-REL CL9.doctor
'Who is looking for the doctor?'
b. Ké [mo-kgalabje $]_{F}$ (yo) a thokomela-ng ngaka.
COP CL1-old.man DEM.CL1 CL1 look.for-REL CL9.doctor
Lit. 'It is the old man who is looking after the doctor.'

High-toned ké is the copula and also appears in other copula-constructions in Northern Sotho. The use of a relative pronoun which agrees with the head noun in noun class features is optional in subject clefts (see also Kock 1997). With respect to verb morphology, the modifying clause shows the characteristics of relative clauses in Northern Sotho: the subject marker $a$ is used instead of $o$ for class 1 and furthermore -ng (or - go as a dialectal variant) is affixed onto the final vowel of the verb stem (for more details on relative clauses in Sotho languages see the description in Ziervogel et al. 1969, and the discussions in Demuth 1995, Mischke 1998, and Zeller 2004a a.o.).

When focus-sensitive particles have scope over the subject, a cleft construction is used, as shown in (12).

\section{Subject and focus-sensitive particle}
a. Ké $[\text { mo-sadi }]_{F}$ fela a tliša-ng ba-na se-kolo-ng.
COP CL1-woman only CL1 bring-REL CL2-child CL7-school-LOC
'Only THE WOMAN brings the children to school (not the man).'

Preverbal negation cannot have scope over the preverbal subject. In order to negate the subject, a cleft construction is necessary, as in (13), again indicated by a change in the subject marker and in verb morphology. 
Subject and focused negation

a. Ga se [mo-šemane $]_{F}$ yo a rekišsitše-ng bo-rotho

NEG COP CL1-boy DEM.CL1 CL1 sell-PST-REL CL14-bread maabane, ké $[\text { mo-kgalabje }]_{F}$. yesterday, COP CL1-old.man.

Lit. 'It wasn't the boy who sold bread yesterday, it was the old man.'

To sum up, subject and non-subject focus in Northern Sotho is expressed asymmetrically. Whereas non-subjects are focused in their canonical position, subjects must not be focused in their canonical preverbal position in Northern Sotho. Instead, they either appear in a cleft construction or in an impersonal construction. ${ }^{5}$

\subsubsection{Focus on modifiers}

The focused information in a sentence can also be the modification of a noun phrase. Focusing a modified noun follows the same asymmetry established in the preceding sections. A modified object is focused in situ, whereas a modified subject of a transitive verb is focused in a cleft sentence.

The data in (14) show question/answer coherence for modified objects. The questions in (14-i) show that the modifier question word is embedded in an expression in postverbal position. In the answers, in (14-ii), the modifier providing the new information also appears postverbally, embedded in a corresponding NP. Examples (14-c,d) are from speech elicited by means of the questionnaire.

(14) Modified objects in questions and answers
a.
(i)
O nyaka ngaka e-fe?/
O nyaka ngaka
ya
2 look.for CL9.doctor CL9-which/ 2 look.for CL9.doctor POSS.CL9
eng?
what
'Which doctor are you looking for?'
(ii) Ke nyaka [ngaka ya meno $_{F}$.
1 look.for CL9.doctor POSS.CL9 CL6.tooth
'I am looking for a DENTIST.'
b. (i) O rata le-tšoba le le-fe?
2 like CL5-flower QUAL.CL5 CL5-which
'Which flowers do you like?'
(ii) Ke rata le-tšoba le [le-hubedu $]_{F}$.
1 like CL5.flower QUAL.CL5 CL5-red
'I like RED flowers.'
c. (i) $[\mathrm{Naa}$, Molatelo o na le pherefere e serolwana?
QP PROP.NAME CL1 be with CL9.pepper QUAL.CL9 yellow
'Does Molatelo have a yellow pepper?']

\footnotetext{
${ }^{5} \mathrm{~A}$ further possibility of focusing an agent is, of course, by means of passive structures. Passive structures will not be treated separately here as they are considered to fall under in situ strategies.
} 
(ii) Aowa, Molatelo o na le pherefere e [tala $]_{F}$.

QP PROP.NAME CL1 be with CL9.pepper QUAL.CL9 green

'No, Molatelo has a GREEN pepper.'

d. (i) [Mo-nna o raloka ka di-kgwele tše kae?

(QUIS)

CL1-man CL1 play PREP CL10-ball QUAL.CL10 how.many

'With how many balls is the man playing?']

(ii) $\mathrm{O}$ raloka ka kgwele e [tee $]_{F}$.

CL1 play PREP CL9.ball QUAL.CL9 CL9.one

'He is playing with one ball.'

(QUIS)

The data in (15) show focused negation that targets modifiers in objects. Again, the data show that the focused modifier remains within its NP which appears in its canonical postverbal position.

(15) Focused negation with modified objects

a. Ga ke nyak-e ngaka ya $[\mathrm{kgale}]_{F}$, ke nyaka

NEG 1 look.for-NEG CL9.doctor POSS.CL9 CL9.old 1 look.for

ngaka ya $[\mathrm{moswa}]_{F}$.

CL9.doctor POSS.CL9 new

'I am not looking for an OLD doctor, I am looking for a YOUNG doctor.'

b. Ga ke rat-e ma-tšoba a [ma-hubedu $]_{F}$, ke rata

NEG 1 like-NEG CL6-flower QUAL.CL6 CL6-red 1 like

a $[\text { ma-serolwana }]_{F}$.

QUAL.CL6 CL6-yellow

'I don't like RED flowers, I like YELLOW ones.'

c. Ga ke a reka di-aparo tša [ma-rega $]_{F}$, ke rek-ile

NEG 1 NEG buy CL8-clothes POSS.CL8 CL6-winter 1 buy-PST

tša $\quad[\text { se-lemo }]_{F}$.

POSS.CL8 CL7-summer

'I didn't buy WINTER clothes, I bought SUMMER clothes.'

The data in (16) show modified objects with focus-sensitive particles. The data do not only show that the focused modifier remains in its canonical postverbal position following the modified noun, but also that the focus-sensitive particle follows it in linear order.

(16) Modified objects and focus-sensitive particles
a. Ke rata ma-tšoba a $[\text { ma-hubedu }]_{F}$ fela, e sego a
1 like CL6-flower QUAL.CL6 CL6-red only? NEG QUAL.CL6
$[\text { ma-serolwana }]_{F}$.
CL6-yellow
'I only like RED flowers, and not YELLOW ones.'

b. (i) $[\mathrm{Naa}$, Matome o na le pherefere e hubedu le QP PROP.NAME CL1 be with CL9.pepper QUAL.CL9 CL9.red and e tala?

'Does Matome have a red and a green pepper?'] 
(ii) Aowa, Matome o na le pherefere e $[\text { tala }]_{F}$ No PROP.NAME CL1 be with CL9.pepper QUAL.CL9 CL9.green fela. only 'No, Matome has only a GREEN pepper.'

(QUIS)

If, however, the focused modifier is part of the logical subject of the sentence, it appears in a cleft sentence. This is shown by the data in (17) for questions and answers. Again, the cleft sentence shows all characteristics of relative clauses in Northern Sotho.

(17) Modified subjects in questions/answers
a. (i) Ké ngaka e-fe yeo e hlahloba-go
COP CL9.doctor CL9-which DEM.CL9 CL9 examine-REL mo-setsana?
CL1-girl
'Which doctor is treating the girl?'
(ii) Ké ngaka ya $[\text { Se-sotho }]_{F}$ yeo e
COP CL9.doctor POSS.CL9 Cl7-Sotho DEM.CL9 CL9
hlahloba-go mo-setsana.
examine-REL CL1-girl
'The SOTHO doctor is treating the girl.'

b. (i) Ké mo-tho o-fe yo a ka kgona-go go reka

COP CL1-man CL1-which DEM.CL1 CL1 POT can-REL CL15 buy ntlo?

CL9.house

'Which person can afford to buy a house?'

(ii) Ké mo-tho yo a a $[\text { humile-go }]_{F}$ yo
Cop CL1-man DEM.CL1 CL1

kgona-go go reka ntlo.

can-REL CL15 buy CL9.house

'The rich person can afford to buy a house.'

c. Ké ngwana o-fe yo a ile-go a kgona go

COP CL1.child CL1-which DEM.CL1 CL1 go.PST-REL CL1 can CL15

bea le di-tamati?

return PREP CL10-tomato

'Which child went and was able to bring back tomatoes?'

d. Ké ba-tho ba ba-kae bao ba le-go

(QUIS)

COP CL2-man POSS.CL2 CL2-how.many DEM.CL2 CL2 be.PST-REL

kopano-ng?

CL9.meeting-LOC

'How many people were at the meeting?'

(QUIS)

The data in (18) show focused negation which targets the modifier of a logical subject. Again, the data show that the negated, modified subject NP cannot appear in its canonical preverbal position, but that it has to appear in a cleft sentence. 
(18) Focused negation with modified subjects
a. Ga se ngaka ya $[\text { Se-kgowa }]_{F}$ yeo e
NEG NEG CL9.doctor POSS.CL9 CL7-white.person DEM.CL9 CL9
hlahloba-go mo-setsana, eupša (ké ngaka) ya $[\text { Se-sotho }]_{F}$.
examine-REL CL1-girl but COP CL9.doctor CL9 CL7-Sotho
'Not the WESTERN doctor is treating the girl, but the SOTHO doctor.'
b. Ga se ba-šemane ba go [tšwafa] $]_{F}$ bao ba rata-go
NEG NeG CL2-boy POSS.CL2 CL15 be.lazy DEM.CL2 CL2 like-REL
mo-rutiši, eupša ké ba [bo-hlale $]_{F}$.
CL1-teacher but COP POSS.CL2 CL14-wise
'Not the LAZY boys like their teacher, but the CLEVER boys.'

The same observation applies to focus-sensitive particles that associate with the modifier of a logical subject, as shown in (19). The modified subject NP cannot appear in its canonical preverbal position but has to appear in a cleft sentence.

(19) Focus-sensitive particles with modified subjects
a. Ké ngaka ya [Se-sotho $]_{F}$ fela yeo e hlahloba-go
COP CL9.doctor POSS.CL9 CL7-Sotho only DEM.CL9 CL9 examine-REL mo-setsana.
CL1-girl
'Only the SOTHO doctor is treating the girl.' (not the western doctor)
b. Ké mo-tho yo a [humile-go] $]_{F}$ fela yo a ka
COP CL1-man DEM.CL1 CL1 be.rich-REL only DEM.CL1 CL1 POT
kgona-go go reka ntlo.
can-REL CL15 buy CL9.house
'Only the RICH person can afford to buy a house.' (not the average one)
c. Ké ba-šemane ba [bo-hlale] $]_{F}$ fela bao ba rata-go
COP CL2-boy POSS.CL2 CL14-wise only DEM.CL2 CL2 like-REL mo-rutiši wa bona.
CL1-teacher POSS.CL1 PRN.CL2
'Only the CLEVER boys like their teacher.' (not the lazy ones)

To sum up, the subject/object asymmetry also holds for modified constituents. Focused modification in objects appears with objects in their canonical position, modification of logical subjects appears in a cleft construction when focused.

\subsubsection{Focus on prepositions}

The notion of preposition is difficult to capture in Northern Sotho. There are few monomorphemic prepositions as known from English or German. Examples are given in (20-a). Locatives e.g. can also be expressed by a mere suffix $-n g$, as shown in (20-b). Furthermore, constructions using the possessive concord $g a$ or connective $l e$, as in (20-c), correspond to prepositional phrases in English. 
(20) 'Prepositions' in Northern Sotho (Ziervogel 1969: 27, 53)
a. (i) ka- 'by, with' (instrumental)
(ii) le - 'to, with' (associative)
(iii) ga - 'at' (locative)
b. (i) O tsena lapeng. - 'He goes into the yard.'
(ii) O tšwa lapeng. - 'He comes from the yard.'
(iii) O ya lapeng. - 'He goes to the yard.'
c. (i) godimo ga ntlo- 'on the house'
(ii) gare ga batho - 'between the people'
(iii) kgauswi le noka - 'near the river'

The example in (21) shows corrective focus on the locative. In the English translation, this corresponds to focus on the preposition. In Northern Sotho, the noun pele- 'front' is contrasted to morago- 'behind'. The focused element appears in its canonical postverbal position. The example has been elicited by means of drawings from the questionnaire.

(21) Focus on 'preposition'
a. Naa, mo-hlare o eme ka pele ga ntlo?
QP CL3-tree CL3 stand.PST PREP front PREP CL9.house
'Is the tree standing in front of the house?'
b. Aowa, mo-hlare o eme $[\mathrm{ka} \text { mo-rago ga }]_{F}$ ntlo.
No CL3-tree CL3 stand.PST PREP CL18-back PREP CL9.house

'No, the tree is standing BEHIND the house.'

(QUIS)

\subsubsection{Focus on the verb}

Focus on the verb comprises two different notions in languages like English and German. First, the lexical content of the verb can be questioned or focused, as shown in (22-a) for English. Second, the truth value of the verb can be questioned or focused (verum focus), as shown in (22-b).

(22) Verb focus in English
a. (i) What did you do with the cake?
(ii) I ATE it.
b. (i) You didn't eat the cake, did you?
(ii) Yes, I DID eat the cake.

The focus marking system of Aghem, a Grassfields Bantu language, allows to differentiate between these notions morphologically (Anderson 1979, Watters 1979). Sentence focus is shown in (23-a). Deviation from sentence focus is marked by the use of preverbal máa for verum focus, as shown in (23-b), or postverbal nó for focus on the lexical content of the verb, as in (23-c). 
(23) Verb focus in Aghem (Watters 1979: 166, ex. (18c), (18b), (21a))
a. fú kí mô ñìn á kí-'bé
rat SM PST run in compound
'The rat ran in the compound.'
b. fú kí máà ñ̀ìn rat SM PST/FOC run
'The rat DID run.' rat SM PST run FOC in compound
'The rat RAN [i.e. did not walk] inside the compound.'

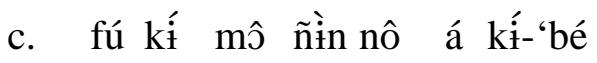

Another strategy for focus on the verb that is found in African languages, especially in the Kwa languages (e.g. Aboh 2004), is reduplication.

However, in Northern Sotho, both kinds of verb focus are expressed in situ. The data in (24) illustrate focus on the lexical content of the verb. The verb appears in its canonical position following the subject (if present).

(24) Verb focus in questions and answers
a. (i) $\quad[\mathrm{O}$ dira eng $\mathrm{ka}$ malome le ma-lekere?
2 do what PREP CL1.uncle and CL6-sweets
'What are you doing with the uncle and the sweets?']
(ii) Ke mo $[\text { nea }]_{F}$ ona.
1 CL1 give PRN.CL6
'I GIVE them to him.'
2 sing CL3-feast-LOC
'Are you singing at the party?']
b. (i) [O opela mo-nyanye-ng?
(ii) Aowa, ke [bina $]_{F}$ mo-nyanye-ng.
No 1 dance CL3-feast-LOC
'No, I am DANCING at the party.'
c. (i) $\quad[\mathrm{O}$ dir-ile eng polase-ng?
2 do-PST what CL9.farm-LOC
'What were you doing at the farm?']
(ii) $\operatorname{Ke}[\text { šom-ile }]_{F}$ (polase-ng).
1 work-PST CL9.farm-LOC
'I was WORKING (at the farm).

The examples in (25) show that verum focus is also expressed by leaving the verb in its canonical position. No verb morphology is added.

(25) Verum focus in questions and answers

a. (i) [O be o ile toropo-ng naa?

2 PST 2 go.PST CL9.town-LOC QP

'Did you go to town?']

(ii) Ee, ke be ke $[\text { ile }]_{F}$ toropo-ng.

yes 1 PST 1 go.PST CL9.town-LOC

'Yes, I went to town.' 


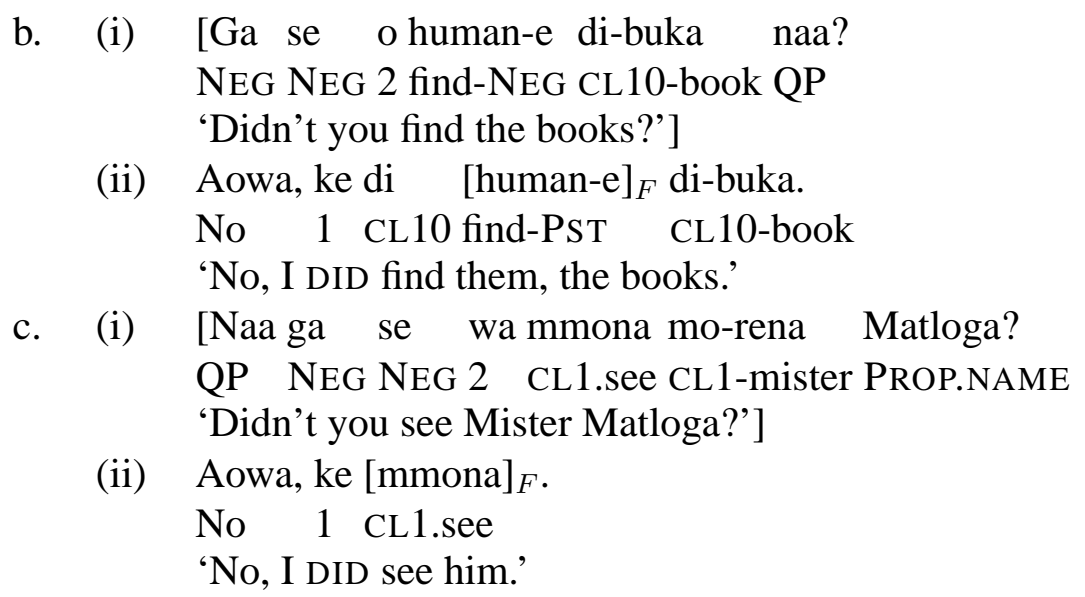

In the literature, the so-called Present Tense $-a$ - is discussed in connection with focus marking on the verb. However, as emerges from the examples in (24) and (25), it does not necessarily appear on the verb when the verb is in focus. For a discussion of Present Tense $-a$ - in Northern Sotho see the detailed discussion in section 2.5.

\subsubsection{Summary}

The current section presented data that show that in general, constituents are focused in situ in Northern Sotho. The focus contexts used for elicitation of the data were question/answer pairs, focused negation and focus-sensitive particles.

The examination of focus strategies used with subjects and non-subjects in Northern Sotho yielded the following three results. First, subjects of intransitive verbs and nonsubjects are focused in situ, i.e. in their base position (which is postverbally in the case of logical subjects). Second, logical subjects of transitive and ditransitive verbs cannot be focused in situ, i.e. postverbally, but only by means of a cleft structure. Third, whereas non-subjects can be focused in their canonical postverbal position, logical subjects can generally not be focused in their canonical, i.e. preverbal position.

The diverging behavior of different grammatical functions with respect to focus in canonical position has been referred to as subject/object asymmetry in the literature, and has also been reported for other African languages. Chapter 4 addresses this third result in detail by investigating information structural properties of the preverbal subject in Northern Sotho. Chapter 5 addresses syntactic restrictions within the VP in Northern Sotho and thereby provides an account for why with transitive verbs, the logical subject cannot appear postverbally.

The following section comes back to the first result and investigates if there are alternative focus positions in Northern Sotho next to the in situ option. This is interesting, as designated focus position have been reported for other Bantu languages.

\subsection{Alternative syntactic focus positions}

Some Bantu languages have been described as discourse-configurational in the literature, in the sense that information structure determines the primary sentence articulation. Mo- 
rimoto (2000) has shown that the status of topichood determines if a constituent acts as the grammatical subject in the Bantu languages Kirundi and Kinyarwanda. Downing et al. (2004) have claimed for the Bantu language Chichewa that information structure determines word order, as focused or otherwise prominent elements occur in sentence-initial position. In other studies, it has been proposed that a designated position is reserved for the focused element, either in left-peripheral, immediately postverbal or clause-final position.

This section investigates if for non-subjects such a designated syntactic focus position can be postulated for Northern Sotho in addition to the in situ variant presented in the preceding sections. Eventually, it argues that there is no designated focus position in Northern Sotho, not even as an alternative focus strategy.

\subsubsection{Left-peripheral focus position}

For Kilega, a Bantu language spoken in the Democratic Republic of Congo, a left peripheral position for $w h$-phrases has been reported, next to the familiar in situ option (Carstens 2005, referring back to Kinyalolo 1991). An example is given in (26), whereby (26-a) shows the in situ form, and (26-b) shows the variant with the wh-expression at the left periphery.

(26) Left-peripheral questions in Kilega (Carstens 2005: 220, ex. (1))
a. Bábo bíkulu b-á-kás-ílé mwámí bikí
CL2.that CL2.woman CL2-DV-give-PERF CL1.chief CL8.what mu-mwílo?
CL18-CL3.village
'What did those women give the chief in the village?'
b. Bikí bi-á-kás-ílé bábo bíkulu mwámí
CL8. what CL8-DV-give-PST CL2.that CL2.woman CL1.chief
mu-mwílo?
CL18-CL3.village
'What did those women give the chief in the village?'

When the object $w h$-phrase appears in the left periphery, as in (26-b), it agrees with the verb in noun class features. In referring back to the study by Nsuka (1982), Carstens (2005) reports that further 70 Bantu languages show a parallel pattern of word order and agreement, and in 34 other Bantu languages a "raised operator controls agreement on a right-adjacent element other than the verb" (Carstens 2005: 220).

Although the Kilega pattern is considered representative for Bantu languages in general, it is interesting to note, that this pattern is excluded for Northern Sotho. This is shown in the example in (27). Neither a left-peripheral object $w h$-word which does not agree with the following verb, as in (27-a), nor a left-peripheral object $w h$-word which does agree with the following verb, as in (27-b), is grammatical in Northern Sotho. 
Ungrammatical questions

a. *Mang le bona?
who 2.PL see
Intended: 'Who do you see?'
b. *Eng e reka mo-sadi?
what CL9 buy CL1-woman
Intended: 'What is the woman buying?'

For the Bantu languages Kikuyu and Kitharaka, another type of left-peripheral focus construction has been reported. The focused constituent appears in sentence initial position and is preceded by a focus particle. In contrast to Kilega, the preposed constituent does not show agreement with the verb. For Kikuyu, the left-peripheral focus construction, (28-b), is contrasted to the in situ construction in (28-a) (for Kitharaka see Muriungi, to appear).

Left-peripheral questions in Kikuyu (Schwarz 2003: 55)
a. Abdul a-ra-nyu-ir-e kee?
PROP.NAME SM-T-drink-AsP-FV what
b. ne-kee Abdul a-ra-nyu-ir-e?
FoC-what PROP.NAME SM-T-drink-AsP-FV
'What did Abdul drink?'

The construction in (28-b) is reminiscent of cleft constructions in this language. What is described as a focus particle is also used as the copula in certain cases. Moreover, tonal changes on the verb indicate that the verb form corresponds to verb forms which are used in subordinate clauses. However, Clements (1984a) and Schwarz (2003) argue convincingly that synchronically the construction in (28-b) must be considered a focus construction. Evidence for this claim comes from topicalization, multiple questions and locative focus (for a detailed discussion see Schwarz 2003: 77ff). Heine \& Reh (1984) argue that in African languages, focus constructions often developed out of cleft sentences.

Sabel \& Zeller (to appear) follow a similar approach for the Nguni languages, which are the southern neighbor of the Sotho languages. They assume an ex situ focus position in these languages which they claim is derived from declarative sentences via movement. An example is given in (29-a) for the in situ structure and in (29-b) for the ex situ alternative in Zulu.

Left-peripheral questions in Zulu (Sabel \& Zeller to appear, ex. (2))

a. U-bona ubani?

2-see what

b. Ng-ubani o-m-bona-yo?

COP-who 2-CL1-see-REL

'Who do you see?'

Like in Kikuyu, the focus particle in (29-b) is identical to the copula. The verb morphology mirrors that the verb form appears in a subordinate sentence. In addition, the subject marker on the subordinate verb shows characteristics of relative pronouns, and 
the fronted object is taken up by an object marker on the verb. In sum, synchronically the construction in (29-b) shows all properties of a cleft construction followed by a relative clause.

A transparent cleft construction as a focussing strategy similar to (29-b), is also found in Northern Sotho. Research has shown that its semantic meaning differs from in situ structures (a distinction of meaning with in and ex situ constructions has also been shown for Kitharaka (Muriungi, to appear)). Therefore, it is not considered an alternative to the in situ focusing strategy and will be dealt separately in chapter 5 .

To sum up, Northern Sotho does not show an alternative focus position at the left periphery, as has been reported for other Bantu languages. It emerged from the data in this chapter that focus only occurs postverbally in Northern Sotho. Therefore, the following two subsections investigate if a fixed focus position can be assumed in the postverbal domain.

\subsubsection{Immediately postverbal focus position}

For Aghem, a Western Grassfields Bantu language spoken in Cameroon, it has been shown that the discourse-new constituent appears in immediately postverbal position. The basic word order, as given in (30-a), changes from SVOX in order to accommodate the contrastively focused constituent or the $w h$-pronoun in immediately postverbal position. Data are given in (30-b) for subject focus and in (30-c) for focus on the applied object.

Focus in Aghem (Watters 1979: 152f, ex. (39a), (41a, b))
a. fúl á mò z’ọm nzàn â bà?tòm
friends SM PST sing Nzan for chief
'The friends sang Nzan for the chief.'
b. à mò $z^{\prime}$ ọm á-fín nzàn â bà?tòm
DS PST sing friends Nzan for chief
'The FRIENDS sang Nzan for the chief.'
c. fíl á mò z’ọm â bà?tóm nzàn
friends SM PST sing for chief Nzan
'The friends sang Nzan for the CHIEF.'

In their cross-linguistic overview of focus constructions, Drubig and Schaffar (2001) cite the Bantu language Kimatuumbi as a language with postverbal focus. The example is reproduced in (31).

(31) Postverbal focus in Kimatuumbi (Odden 1984: 291f)

Umukú akatae $[\text { kaámba }]_{F}$

Umuku 3s.cut rope

'Ukumu was cutting ROPE.'

The evidence for the focus position in Kimatuumbi based on the example in (31) is far from conclusive. Data from object focus in transitive verbs alone do not allow to draw conclusions regarding a focus position in the respective language. In the case of (31), postverbal, clause-final and sentence-final position coincide (which is, by the way, already 
implied in the rather vague terminology of 'final' position used by Drubig \& Schaffar 2001).

For the Sotho languages, Demuth \& Mmusi (1997) argue for an immediately postverbal focus position. They base their claim on inferences: In transitive sentences, a subject cannot appear postverbally (in an impersonal construction) as this creates competition of subject and object for the postverbal focus position.

For Northern Sotho, the data presented in section 2.2 have already shown that the focus position for non-subjects is not verb-adjacent, but really in situ. This was illustrated by means of double object constructions in which the position of a wh-word is dependent on the underlying structure, which is determined by aspects other than information structure (e.g. thematic hierarchies or person hierarchies) in Northern Sotho (see Hyman \& Duranti 1982, Demuth et al. 2005). The examples in (32) repeat the relevant data.

The example in (32-a) shows the basic order of two objects in double object constructions. The beneficiary precedes the patient. If one of the object constituents is questioned, it can only be questioned in situ, as shown in (32-b,d). The data in (32-c, e) show illicit structures where the $w h$-word does not appear in its underlying position. Example (32-f) is taken from the Northern Sotho corpus.

(32) Double object constructions in Northern Sotho
a. $\mathrm{O}$ fa mo-kgalabje se-hlare.
CL1 give CL1-old.man CL7-medicine
'He gives the old man medicine.'
b. O fa mo-kgalabje eng?
CL1 give CL1-old.man what
'What does he give the old man?'
c. *O fa eng mo-kgalabje?
CL1 give what CL1-old.man
'What does he bring the old man?'
d. O tliš-etša mang se-hlare?
CL1 bring-PST who CL7-medicine
'Whom does he bring medicine?'
e. *O tlišs-etša se-hlare mang?
CL1 bring-PST CL7-medicine who
'Whom does he bring the medicine?'
f. Ke tla bea mang mo-lato, Letau goba Lekgau?
1 FUT put.down who CL3-problem PROP.NAME or PROP.NAME
'Whom will I put the blame on, Letau or Lekgau?' (Corpus, B2001)

Ungrammatical examples emerge when the word order of object and adverbial is exchanged, as shown in (33) for temporal and locative adverbials.

Ungrammatical questions for non-subjects

a. *O bona neng mo-sadi?

2 see when CL1-woman

Intended: 'When do you see the woman?' 
b. *O hlakana kae le mo-kgalabje?

2 meet where PREP CL1-old.man

Intended: 'Where do you meet the old man?'

In sum, investigation of double object constructions show that there is no immediately postverbal focus position in Northern Sotho, not even as an alternative focus position.

\subsubsection{Clause-final focus position}

Cross-linguistically, focus often occurs in peripheral position. Focus in the left periphery was illustrated above. Work on Romance languages has shown that these languages display clause-final focus (Zubizaretta 1994, 1998, Belletti \& Shlonsky 1995, Frascarelli 2000, Samek-Lodovici 2005). The relevant data are given in (34), whereby the context questions are given in square brackets.

(34) Clause-final focus in Italian

a. (Samek-Lodovici 2005: 703, ex. (23))

(i) [What did you plant in the garden?]

(ii) Ho piantato in giardino un $[\mathrm{MELO}]_{F}$.

have.1SG planted in garden an apple.tree

'I planted an APPLE TREE in the garden.'

b. (Samek-Lodovici 2005: 703, ex. (22))

(i) [Who won the race?]

(ii) L' ha vinta $[\text { GIANNI }]_{F}$.

it has won John

'JOHN won it.'

c. (Samek-Lodovici 2005: 704, ex. (25))

(i) [Who has drunk the wine?]

(ii) Lo ha bevuto $[\mathrm{GIANNI}]_{F}$, il vino.

it has drunk John the wine

'John drank it, the wine.'

The focused constituent appears in final position even if the basic word order is otherwise, as shown in (34-a). The data in (34-b) show that if the subject is focused it appears postverbally in final position. The example in (34-c) is there to show that the crucial position is clause-final and not sentence-final, as right dislocated elements follow the focused constituent.

Also for the Bantu language Dzamba, a sentence-final focus position has been reported (Bokamba 1976). An example is given in (35), whereby (35-a) shows the normal SVO word order, and (35-b) shows sentence-final focus.

(35) Sentence-final focus in Dzamba (Bokamba 1976: 158, ex. (35b))
a. oPoso
a-tom-el-áki oMusa
mwenzi loome.
PROP.NAME sent-to/for PROP.NAME message today
'Poso sent Musa a message today.' 
b. oPoso a-tom-el-áki oMusa loome nde?

PROP.NAME sent-to/for PROP.NAME today what

'What did Poso send to Musa today?'

For Northern Sotho, it can be observed that the focused constituent often appears in clause-final position. This is due to the application of deletion, pronominalization and dislocation processes which target discourse-old constituent with the result that the focused constituent ends up clause-finally. These processes will be exemplified in more detail in section 2.4 of this chapter. A clause-final focus position is further suggested by the occurrence of the impersonal construction, which also places a narrowly focused logical subject in clause-final position. The data are repeated in (36) from section 2.2.

\section{Northern Sotho}

a. [Who is coming?]

b. Go tla [mo-n:na $]_{F}$.

CL17 come CL1-man

'There comes a MAN.'

Cases of right-dislocation in (37) show that the position must be clause-final, and not sentence-final.

a. [What do you give the uncle?]

Ke mo nea [ma-leke:re] $]_{F}$ malo:me.

1 CL1 give CL6-sweets CL1.uncle

Lit. 'I give him SWEETS, the uncle.'

Recent approaches to focus in Italian motivate the appearance of the focused constituent in clause-final position by the prosodic properties of this language (Cinque 1993, Zubizaretta 1998, Szendröi 2001, Samek-Lodovici 2005). Stress is rightmost in Italian. Consequently, if the focused constituent must be stressed (Jackendoff 1972, Selkirk 1984 a.o.), it has to appear in a position where it can receive prominence. (See also chapter 1 for a detailed treatment of focus in Italian within OT.)

Also in Northern Sotho, the clause-final position is a position of prominence. This can be argued for on the basis of both phonetics and phonology. Phonetically, the penultimate syllable of the clause-final word is lengthened, and duration is a correlate of accent also in intonation-only languages. Phonologically, Bantu languages show accentual properties in their tone systems. Culminativity, positional restrictions and tone/accent interactions are considered diagnostic of accentual tonal systems. For a detailed discussion see chapter 3 .

However, a postulation of a designated clause-final focus position in Northern Sotho cannot be upheld for a variety of reasons.

First, a focused verb might not always occur in clause-final position. With ditransitive verbs, morphosyntactic reduction of both discourse-old objects is excluded because of morphological restrictions on the verbal template which allow only one object marker in Northern Sotho. This is shown in (38). ${ }^{6}$

\footnotetext{
${ }^{6}$ Bantu languages vary with respect to how many object clitics are allowed. Whereas Swahili, Bemba, Chichewa, Nsenga, Swati, and Herero do not allow multiple object markers, Chaga, Haya, and Tswana allow more than one object marker to appear in the verbal template (overview taken from Marten et al.
} 


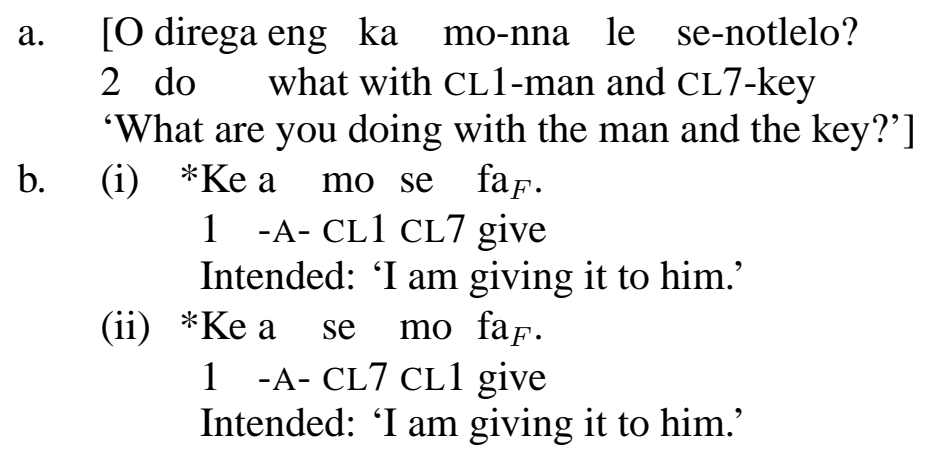

The strict SVO word order in Bantu languages does not allow movement of focused constituents into clause-final position with the objective to receive prominence there. This is shown by means of elicited data in (39-a) and (39-b), which correspond to the examples from Italian above. Consequently, we find focused constituents non-finally, as also the data from natural speech in (39-c, d, e) show.

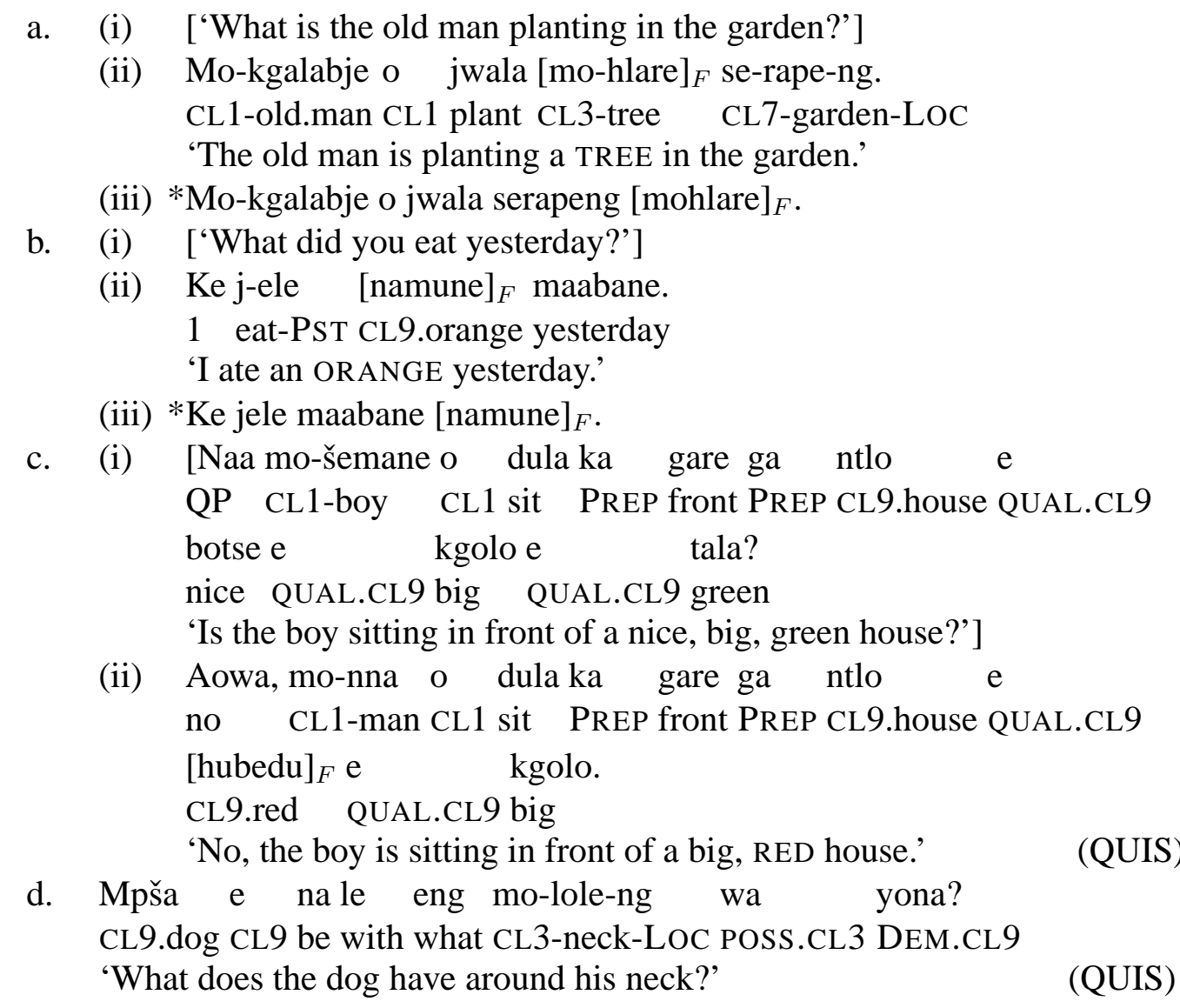

2005). Northern Sotho, though being closely related to Tswana, allows only one object marker in the verbal template. 
e. Mo-nna o swere mo-eta le hlapi gomme o [tšea $]_{F}$ CL1-man CL1 hold.PST CL3-bucket with CL9.fish then CL1 take hlapi o e fa mo-sadi.

CL9.fish CL1 CL9 give CL1-woman

'The man holds a bucket and a fish, then he TAKES the fish (and) gives it to the woman.'

(QUIS)

In the case of (39-e) there is no ambiguity if 'fish' were left out, as there would be in English, as 'bucket' and 'fish' belong to different noun classes in Northern Sotho.

Also the grammatical subject cannot be moved into clause-final position if focused. This is shown in (40).
[ 'Who is dancing?']
a. Go bina [ba-sadi $]_{F}$.
CL17 dance CL2-woman
'There are WOMEN dancing.'
b. *Ba bina $[\text { ba-sadi }]_{F}$.

Though the subject can appear postverbally in Northern Sotho in an impersonal construction, as illustrated in (40-a), movement of the subject into clause-final position is excluded, as shown in (40-b). That the construction in (40-b) is derived by movement can be seen from the agreement pattern on the verb. The logical subject does not agree with the verb in (40-a), hence class-17 agreement is displayed. In (40-b), the postposed subject does agree with the verb in noun class features.

In sum, morphological and syntactic requirements in Northern Sotho are stronger than the prosodic necessity to have the focused constituent in a position where it receives prominence. The examples presented in this subsection have shown that there is no evidence for a fixed clause-final focus position in Northern Sotho.

\subsubsection{Summary}

The data and discussion in this section have shown that there is no alternative syntactic position for focused non-subjects in Northern Sotho, neither at the left-periphery nor immediately postverbally nor clause-finally. A designated syntactic focus position for Northern Sotho therefore has to be rejected. Thereby, Northern Sotho differs from other Bantu languages like Kilega, Kikuyu, Aghem, Chichewa and Dzamba for which such a designated focus position has been described.

Consequently, the general claim that all Bantu languages are discourse-configurational languages cannot be upheld, as sentence articulation is primarily determined by morphological and syntactic requirements in Northern Sotho, not by focus, as has been shown in this section. These data are meant to show that there is no syntactic focus marking for non-subjects in Northern Sotho.

Although it is important to note that there is no designated focus position in Northern Sotho, it also important to understand why the immediately postverbal position or the clause-final position have been reported as designated syntactic positions for focused constituents in the literature on languages like Northern Sotho. The reason lies in the ob- 
servation that focused constituents often occur in one of these positions (an example from the literature has been given in (31) where these two notions even coincide). Importantly, however, focused constituents do not appear in these positions because of movement, as shown in this section, but because non-F-marked constituents underlie certain processes such as deletion, pronominalization, and dislocation.

The next section therefore presents the processes that lead focused constituents to occur in one of these postverbal positions. It also outlines how the processes can be accounted for in grammar without assuming that they apply with the objective to place the focused constituent in either immediately postverbal or clause-final position.

Moreover, although syntactic focus marking for non-subjects could not be established for Northern Sotho, this does not imply that there are no grammatical reflexes of information structure in a Northern Sotho utterance. The next section shows how non-F-marked elements are the target of (morpho-)syntactic processes that decode the information structure of an utterance in Northern Sotho.

\subsection{Grammatical reflexes of information structure}

The information structuring of an utterance has consequences for syntax, morphosyntax, and thereby also for morphology in Northern Sotho. However, it is not F-marking that triggers grammatical changes. Rather, constituents that are given in discourse are the target of (morpho-)syntactic processes, such as deletion, pronominalization, and dislocation.

The current section presents data on deletion, pronominalization, and dislocation in Northern Sotho. Although these processes often conspire to place the focused constituent in clause-final position, we have seen from the preceding section that the clause-final position is no designated focus position in Northern Sotho. Consequently, the occurrence of these processes cannot be accounted for by the need of the focused constituent to appear in this syntactic position where it receives prominence (as proposed for Italian). This section also outlines how the application of these processes can be accounted for by general pragmatic and discourse-pragmatic principles.

\subsubsection{Deletion and pronominalization}

\section{Deletion}

Deletion is a phonosyntactic process. Deletion occurs in syntactically and/or semantically identical structures and targets discourse-old constituents. In the following examples, the context question indicates the focus structure of the answer. Example (41-a) illustrates deletion of the discourse-old verb, (41-b) deletion of verb and adverbial, and (41-c) illustrates deletion of the adverbial only.

\section{Deletion}
a. (i) [O mema mang?
2 invite who
'Who do you invite?'] 


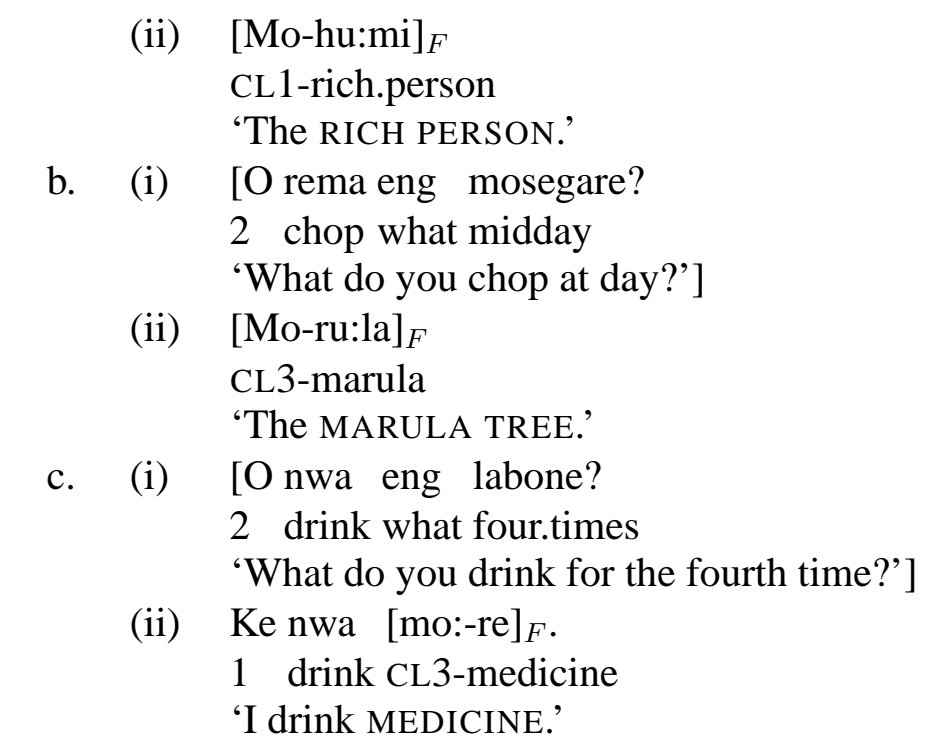

Deletion of postverbal discourse-old material results in the focused constituent being clause-final in the examples in (41). In the examples in (41-a, b) the focused constituent is the only constituent in the answer (term answer), therefore appearing automatically in clause-final position. Also in example (41-c), the focused constituent appears in clausefinal position.

\section{Pronominalization}

Pronominalization is considered a grammatical reflex of information structure as it applies to discourse-old objects. Pronominalization is a morphosyntactic process. It refers to the substitution of full NPs by pronouns. Whereas subjects and adjuncts can be deleted in Northern Sotho, object arguments cannot be deleted. They are pronominalized either as an object marker in the verbal template or by so-called absolute pronouns.

As the context question in (42-a) indicates, the object lee- 'egg' is given in discourse. However, an object cannot be deleted, as shown by the ungrammaticality of the example in (42-b). If an object is deleted, an object agreement marker of the respective class appears on the verb, as shown in (42-c). The object marker agrees with the object noun it refers to in noun class features.

\section{Pronominalization}

a. [O dir-ile eng ka le-e?

2 do-PST what with CL5-egg

'What are you doing with the egg?']

b. *Ke $[\mathrm{j} \text {-ele }]_{F}$.

1 eat-PST

c. Ke le: $[\text { jele }]_{F}$.

1 CL5 eat-PST

'I ATE it.'

Pronominalization of discourse-old objects results in positioning the focused constituent clause-finally in the example in (42). 
Further examples for object pronominalization are provided in (43). The examples show the substitution of the object by an object marker in transitive structures with new information focus, (43-a), substituting the beneficiary, (43-c), or patient argument, (43-d) in ditransitive structures, or the substitution of the object in transitive structures followed by a temporal adverbial (43-d). Examples (43-e, f) are taken from the questionnaire.

(43) Further examples of object pronominalization

a. (i) $\quad$ O dira eng ka mo-rwalo?

2 do what with CL3-load

'What are you doing with the load?']

(ii) Ke a o $[\text { rwa:la }]_{F}$.

1 -a- CL3 carry

'I CARRY it.'

b. (i) [O nea mang le-e?

2 give who CL5-egg

'Whom are you giving an egg?']

(ii) Ke le nea $[\text { na:re }]_{F}$.

1 CL5 give CL9.buffalo

'I am giving it to a BUFFALO.'

c. (i) [O nea malome eng?

2 give CL1.uncle what

'What do you give to the uncle?']

(ii) Ke mo nea [ma-leke:re $]_{F}$.

1 CL1 give CL6-sweets

'I give him SWEETS.'

d. (i) [O rema mo-rula neng?

2 chop CL3-marula when

'When do you chop the marula tree?']

(ii) Ke o rema [mose:gare $]_{F}$.

1 CL3 chop midday

'I chop it at MIDDAY.'

e. [Ke hwetša se-šupanako.] O se utswitše.

1 find CL7-watch 2 CL7 steal.PST

'I found the watch. You stole it.'

f. Mo-nna o swere mo-eta le hlapi gomme o tšea

CL1-man CL1 hold.PST CL3-bucket with CL9.fish and CL1 take

hlapi o e fa mo-sadi.

CL9.fish CL1 CL9 give CL1-woman

'The man is holding a bucket with a fish, then he takes the fish and gives it

to the woman.'

(QUIS)

Ditransitive structures are the context in which, contrary to what has been stated above, deletion of an argument is possible in Bantu languages. However, only the object bearing the thematic role of patient can be deleted, as shown in (44). 
(44) a. [O direga eng ka mo-nna le se-notlelo?]

2 do what with CL1-man and CL7-key

'What are you doing with the man and the key?'

b. (i) Ke a mo: $[\mathrm{fa}]_{F}$.

1 -A- CL1 give

Lit.: 'I GIVE him.'

(ii) $*$ Ke a se: $[\mathrm{fa}]_{F}$.

1 -A- CL7 give

Intended: 'I give it.'

The asymmetrical behavior of the two objects with respect to object deletion is related to the asymmetrical behavior of objects in double object constructions more generally (see Dryer 1986 for primary and secondary objects cross-linguistically). The phenomenon in (44) is related to 'indefinite object deletion' in other Bantu languages (Baker 1992). Baker (1992) and Alsina \& Mchombo (1993) show that an object can be deleted in instrumental constructions, but not in benefactive constructions. Also in the case of Northern Sotho, illustrated in (44), the theme but not the benefactive can be deleted. However, the issue of object deletion awaits further research.

Pronominalization and deletion of discourse-old constituents conspire to the frequent occurrence of focused constituents in clause-final position. This is the case in all the examples cited above. However, as has been shown in section 2.3.3, the occurrence of the focused constituents in clause-final position is by no means obligatory.

\section{Account}

The application of deletion and pronominalization can therefore not be motivated by the requirement that a focused constituents must appear in a syntactic position where it can receive prominence. Instead, it can independently be motivated by cognitive principles. The difference between deletion and pronominalizaion is guided by syntactic requirements. Arguments cannot be deleted as they thereby violate the subcategorization frame of the verb. However, the cognitive principles that apply to discourse-old adverbs and arguments are the same. They can be captured by the Gricean conversational maxims. ${ }^{7}$

The overview follows Marten's (2002) presentation of the development of Relevance Theory (Sperber \& Wilson 1995) that took the work of Grice as its historic antecedent. Grice (1975/1989: 26-27) proposes that some aspects of communication involve inference on the part of the hearer, so that, in addition to decoding the meaning of sentences, hearers derive implicatures in interpretation to establish the full meaning of an utterance. The inferential aspects of interpretation follow, according to Grice, from the assumption that certain conversational rules are being obeyed by speakers and hearers. In particular, Grice proposes that communication is governed by a co-operative principle, which instructs speakers as follows: 'Make your conversational contribution such as is required, at the stage at which it occurs, by the accepted purpose or direction of the talk exchange in

\footnotetext{
${ }^{7}$ As this is no thesis on discourse-pragmatics, the basic idea is solely sketched out. No space is devoted to criticsm of the Gricean approach and to further developments (a.o. Levinson 1983, Sperber \& Wilson 1995, Levinson 2000).
} 
which you are engaged' (Grice 1975/1989: $26^{8}$ ). The principle can be further specified by a number of rules, grouped under four 'maxims'. Grice proposes the following rules:

Grice's Maxims of Conversation

a. Maxims of quantity

(i) Make your contribution as informative as is required (for the current purpose of the exchange).

(ii) Do not make your contribution more informative than is required.

b. Maxims of quality

Supermaxim: Try to make your contribution one that is true. [...]

c. Maxim of relation

Be relevant.

d. Maxims of manner

Supermaxim: Be perspicuous. [...]

To illustrate one relevant maxim by means of an example, consider (46) where A addresses B who is passing by.

(46) Maxim of relation (Grewendorf et al. 1987)

A: 'I am running out of petrol.'

B: 'There is a petrol station around the corner.'

B would not be considered co-operative, if the petrol station were closed and s/he knew about it. In this case, B had violated the maxim of relation 'Be relevant'.

The maxims of conversations that relate to the deletion and pronominalization of discourse-old material in the establishment of linguistic meaning are the maxim of quantity (45-a) and maxim of relation (45-c). By reducing discourse-old information in an unambigious context, the contribution is as informative as required without providing unnecessary information, whereby the utterance is relevant. Grice (1975/1989: 26) points out potential problems in connection with the maxims. Of relevance here is his concession with respect to the second maxim. Overinformativeness could be viewed not as a violation of the co-operative principle but merely as a waste of time. He answers that

"such overinformativeness may be confusing in that it is liable to raise side issues; and there may also be an indirect effect, in that the hearers may be misled as a result of thinking that there is some particular point [emphasis $\mathrm{PG}]$ in the provision of the excess of information. However this may be, there is perhaps a different reason for doubt about the admission of this second maxim, namely that its effect will be secured by a later maxim, which concerns relevance."

(Grice 1975/1989: 26)

The maxims have been criticized for their vagueness and for the overlap between them (Sperber \& Wilson 1995). Furthermore, it remains unclear from the original formulation of the maxims which status they have in linguistic or cognitive theory, if they are learnt or innate, universal or culture-specific. Sperber \& Wilson argue further that inference

\footnotetext{
${ }^{8}$ The page numbers refer to the 1989 edition.
} 
plays a role not only in finding out what has been implied but also in establishing what has been said in the first place, i.e. inference is required even for the establishment of linguistic meaning, in addition to the establishment of inferences drawn from it. The role of inferential reasoning in the establishment of what has been said, as opposed to what has been implied, includes cases of ambiguity resolution and reference assignment where notably pronominal elements underdetermine their encoded content.

I leave it to the relevant fields of pragmatics to work out how deletion and pronominalization optimize an utterance with respect to speaker-hearer communication. The starting point has been sketched out in relating these two processes to discourse-pragmatics rather than the prosody-syntax interface. Therefore, deletion and pronominalization can be accounted for independently of focus syntax.

\subsubsection{Dislocation}

\section{Data}

Discourse-old constituents can be dislocated to the left and right sentence periphery in Northern Sotho. With arguments, the object marker obligatorily has to appear on the verb.

Constituents can be left-dislocated to sentence-initial position. Examples are given in (47-a) for a temporal adverbial and in (47-c) for an object. With objects, the object marker has to co-occur.

\section{Left-dislocation}

a. (i) $\quad[\mathrm{O}$ dira eng bjale?

2 do what now

'What are you doing now?']

(ii) Bjale, ke a: $[\text { nwa }]_{F}$.

now 1 -A-drink

'I am DRINKING now.'

b. Se-topo se o se lefa ka eng?

CL7-corpse CL7 2 CL7 pay PREP what

'What do you use to pay for this corpse?' (Lit. 'This corpse, you pay it with what?')

(corpus, D1821)

Left-dislocated constituents are discourse-old constituents. They cannot be new information. This is shown in (48) by means of the question and answer context.

a. [O nea mo-lamo namane neng?

2 give CL1-brother CL9.calf when

'When do you give the brother-in-law a calf?'

b. $*[\text { Mosegare }]_{F}$, ke mo nea namane.

midday $\quad 1$ CL1 give CL9.calf

That left-dislocated constituents must be known in discourse is also shown by means of example (49), where an absolute pronoun appears left-dislocated. Pronouns are by definition given in discourse. 
(49) Left-dislocated pronoun

Lehlakosana, lona o le fa mang?

PROP.NAME CL5.DEM 2 CL5 give who

'Lehlakosana, whom do you give it?'

(corpus, B0741)

Left-dislocation has frequently been discussed in the literature on Bantu languages (see e.g. Givón 1976, Morolong \& Hyman 1977, Wald 1979, Hyman \& Duranti 1982, Bresnan \& Mchombo 1987, Demuth \& Johnson 1989, Demuth 1989, van der Spuy 1993, Baker 2003, Zeller 2004b). Own research has shown that in Northern Sotho, left dislocation bears a special discourse meaning. Constituents occur at the left sentence-periphery which are emphasized, either as being contrasted (50-a), or noteworthy (50-b), or as setting a frame (50-c). Remember that emphasis has to be differentiated from focus, as focused constituents are not allowed in this position. Crucially, only discourse-old constituents can occur in the left sentence-periphery. Examples are given in (50).

(50) Left dislocation in Northern Sotho

a. Contrast

(i) Mosegare ngwana o dutše go-dimo go le-gogwa o midday CL1.child CL1 sit.PST CL16-above CL16 CL5-mat CL1 swere le-pidipidi. hold.PST CL5-duck

'During the day, the child sits on the mat and holds a duck.' (QUIS)

(ii) Bošego ngwana o dutše go-dimo go le-gogwa o evening CL1.child CL1 sit.PST CL16-above CL16 CL5-mat CL1 swere hlapi.

hold.PST CL9.fish

'In the evening, the child sits on the mat and holds a fish.'

b. Noteworthy

(i) La ka le-thabo ga ke tseb-e gore n-ka CL5.POSS 1PERSPR CL5-happiness NEg 1 know-Neg that 1-POT le lekantša le eng. [...]

CL5 compare with what

'My happiness, I don't know what I can compare it to.' (corpus, D3141)

(ii) Bjalo se-thunya o be a tlo se fi-wa ke kgoši. now CL7-gun 2 PROG 2 FUT CL7 give-PASS PREP CL9.chief Lit. 'Now, the gun, you will be given it by the chief.' (Makwala 1958: 11) 
c. Frame setting

(i) Ka ntlo-ng go na le ngwana wa mo-šemane. in house-LOC CL17 be with CL1.child POSS.CL1 CL1-boy 'In the house there is a boy.'

(QUIS)

(ii) Tšatši le le-ngwe mo-sadi a re a na le ba-na day CL5 CL5-other CL1-woman CL1 ? CL1 be with CL2-child ba gagwe ba ba-raro. [...] POSS.CL2 CL1.PERSPRN QUAL.CL2 CL2-three Lit. 'One day, there was a woman with three children.'

Next to left-dislocation also dislocation to the right sentence periphery is grammatical in Northern Sotho. Again, with dislocated objects, the object marker has to appear on the verb, as in (51-a) and (51-b).

a. (i) [O bala nonwane?

2 read CL9.story

'Are you reading a story?']

(ii) Aowa, ke a e [ngwa:la $]_{F}$, nonwa:ne.

no 1 -A- CL9 write CL9.story

Lit. 'No, I am WRITING it, the story.'

b. (i) [O rema mo-rula neng?

2 chop CL3-marula when

'When do you chop the marula tree?']

(ii) Ke o rema [mosega:re $]_{F}$, mo-ru:la.

1 CL3 chop midday CL3-marula

Lit. 'I chop it at MIDDAY, the marula tree.'

Right dislocation is similar to left dislocation in that the dislocated constituent crucially represents discourse-old information. This is shown by the ungrammaticality of the question in (52-b), in which the object marker is meant to be coreferent with the object question-word.
a. O nyaka mang?
2 look.for who
'Who are you looking for?'
b. *O mo nyaka mang?
2 CL1 look.for who

Right dislocation differs from left dislocation in its discourse-pragmatic meaning, however. According to Givón $(1975,1976)$, the right-dislocated constituent is interpreted as afterthought in English as well as the Bantu language Rwanda. This implies that the speaker first decides to use mere anaphoric pronominalization assuming that the hearer can retrieve the information which is already known from the previous discourse. Then, as an afterthought, the speaker adds the full information, "just in case" (Givón 1975: 197).

Examples for right dislocation from the Northern Sotho corpus are given in (53). 
Right dislocation in Northern Sotho
a. O di bots-wa ke mang tsona tseo?
2 CL10 tell-PASS PREP who CL10.PRN CL10.DEM
'Who told you those?'
(corpus, A0401)
b. Se ka rema mang se-letsw-ana sa magagane?
CL7 POT chop who CL7-axe-DiM CL7.Poss small
'Who can the small axe chop?'
(corpus, B0421)

Right dislocation occurs far less frequent than left dislocation in my translated sample of the Northern Sotho, and not at all in the data I collected by help of the questionnaire. Louwrens (1985: 60) points out that right dislocation is very rare in Northern Sotho. The rare occurrence in natural speech (in contrast to left dislocation) might be attributed to the very specific discourse function of right dislocation.

\section{Account}

The elicited examples of left dislocation in (47) and of right dislocation in (51) have in common that the focused constituent appears in clause-final position. For evidence for the syntactic position of the focused constituent see section 1.7.3. However, dislocation to the left and right sentence periphery can be argued to origin in parsing considerations rather than in the syntactic necessity to place the focused constituent in a designated, clause-final focus position.

Evidence for this approach comes from the observation that right and left dislocation appear to be universal in the languages of the world (Gundel 1988: 229). All languages in Gundel's survey of 30 languages have constructions which place topic, both old and new, at the beginning of a sentence, and all languages have at least one construction in which already established topics occur at the end. As there is apparently no language which has a construction whose primary function is to place new topics at the end of a sentence, she argues that this observation follows from two independent, and sometimes conflicting, principles. The principles are given in (54).

Gundel (1988: 229)
a. Given Before New Principle
'State what is given before what is new in relation to it.'
b. First Things First Principle
'Provide the most important information first.'

Already principle (54-a) could account for all cases of left dislocation as dislocated constituents are known in discourse. However, a principle as in (54-b) is needed not only in order to account for the occurrence of right dislocation, but also for the ordering of several given constituents. In right dislocation, the dislocated constituent is given. According to principle (54-a), this would qualify this constituent to occur initially. However, the speaker judges something else to be more important according to principle (54-b). Further, subjects are often discourse-old constituents and therefore compete with leftdislocated elements for the sentence-initial position. A principle as in (54-b) determines the order of several given constituents in that the more important one appears first. 
Gundel (1988: 236) speculates that the principles in (54) have a more general cognitive basis. Principle (54-a) ('Given Before New') is suggested to follow from Grice's maxim of manner (see (45-d)), in particular 'Be Orderly'. In this spirit, what is given is logically and conceptually prior to what is new in relation to it. The principle in (54-b) is meant to equal Givón's (1988) suggestion for principles governing word order, among them 'Attend first to the most urgent task'. The human tendency to order priorities temporarily from most important to least important is thereby captured. Givón (1988) argues that there are two factors which contribute to communicative task urgency: relative predictability and relative importance.

\subsubsection{Summary}

The current section has shown that deletion, pronominalization and dislocation apply to non-F-marked constituents. This section has also pointed out that these processes have the effect that the F-marked constituent appears in clause-final or immediately postverbal position. This explains why these positions have been argued to be focus positions. However, it has also been shown throughout the chapter, that these are no designated positions for focus in Northern Sotho. It has been sketched out how the application of the processes of deletion, pronominalization, and dislocation can be accounted for by general linguistic principles. ${ }^{9}$

The data discussed in this section have shown how the frequent occurrence of a constituent with a specific semantic interpretation in a specific syntactic position can lead to a misinterpretation of this syntactic position with the interpretable effect. To put differently, the frequent occurrence of a focused constituent in clause-final position can lead to a misinterpretation of the clause-final position as a focus position in Northern Sotho.

The next section investigates how the relation between the occurrence of the Present Tense morpheme $-a$ - and focus can be captured. This phenomenon will be shown to even go one step further in the misinterpretation: The distributional restriction of a verbal morpheme to the verb in clause-final position and the frequent occurrence of a focused constituent in clause-final position led to a misinterpretation of the morpheme to carry the interpretative effect.

\subsection{A note on the Present Tense morpheme - $a$ -}

A chapter on (morpho-)syntactic reflexes of focus on the grammar of a Southeastern Bantu language would be incomplete without a discussion of the Present Tense morpheme $a-$. Contrary to claims made in the literature, the Present Tense morpheme $-a$ - is not considered a focus marker that marks focus on the verb. Rather, the syntactic approach to the distribution of $-a$ - is followed, which has already been outlaid in section 1.7.4. Therefore, after presenting the information structural approach to the distribution of $-a$ in section 2.5.1, arguments will be given in favor of the syntactic approach in section

\footnotetext{
${ }^{9}$ The use of the impersonal construction, in which the focused logical subject appears clause-finally, remains unaccounted so far if it cannot be attributed to a prominent clause-final position. It will be discussed separately in chapter 4 .
} 
2.5.2. It is the relation between syntax and information structure that led to the claim that $-a$ - is a focus marker in the Sotho and Nguni languages. This relation has been the topic of this chapter. Its consequences for the distribution of $-a$ - will be discussed in section 2.5.3. By ending with the tendency of focused constituents to appear in clause-final position, the circle is closed to what has been presented above.

As mentioned before, like the other Southeastern Bantu languages Northern Sotho shows a morphological alternation in the verbal paradigm in the Present Tense. The alternation and its syntactic approach has been discussed in detail in section 1.7.4, and the reader is referred there for details of the alternation. It will only briefly be repeated here. The main focus in this subsection lies in its relation to information structure. The alternation is illustrated by the data in $(55-a, b)$.

Present Tense (from Louwrens 1985: 60)
a. Le-sogana le a ngwala.
CL5-young.man CL5 -A- write
'The young man writes.'
b. Malome o a se tseba Se-sotho.
CL1.uncle CL1 -A- CL7 know CL7-Sotho
'Uncle knows it, Sotho.'
c. Malome o tseba Se-sotho.
CL1.uncle CL1 know CL7-Sotho
'Uncle knows Sotho.'

Van der Spuy (1993) claims that the long form of the Present Tense in (55-a) is a syntactic phrase-boundary marker (1993: 345) which appears when the verb is final in the syntactic IP. In the examples in (55-a), the verb meets van der Spuy's generalization to be final in the syntactic IP vacuously as it is the only element in the sentence. In (55-b), the verb is final in the syntactic IP (and therefore appears in the long form) when interpreting the presence of the object marker on the verb as evidence for the position of the object NP outside the IP (see also section 1.7.3 for the pronominal status of the object marker). In (55-c), the verb is followed by an object within the verb phrase. Therefore, no Present Tense morpheme $-a$ - appears on the verb.

\subsubsection{Information structural approach to $-a-$}

Across Bantu languages verbal alternations similar to the one in (55) have been related to the information status of the constituents within the sentence (see e.g. Givón 1975, Hyman \& Watters 1984, Güldemann 1996). According to Givón (1975: 189) "an affix, most commonly associated with the tense-aspect-modality (TMA) prefixes on the verb, marks the scope of the assertion as to whether the verb is included [...] or excluded [...] from the new information." With respect to the rules governing the distribution of the alternating verb forms in the Southern Bantu languages, Givón (1975) and Kunene (1975) suggested for Nguni languages that the occurrence of $-a$ - is related to the information status of the constituents in the utterance. This proposal has been taken up repeatedly in the literature (Kosch 1988 for Northern Sotho, Güldemann 1996 for Zulu).

Based on the thorough discussion of Zulu pronouns and their role in discourse by 
Kunene (1975), Givón (1975) discusses the alternating verb forms in Zulu as a phenomena of overt morphological expression of scope contrasts. He summarizes that - $a$ - (in Zulu) is a VP-focus morpheme that, if present, leads to the interpretation of the verb as the only new information in the sentence. The verb form lacking $-y a$ - in the Present Tense indicates that the verb is not new information (complement focus in Givón's terminology). The view pertained in the literature is that $-y a$-indicates that the verb is the new information in the sentence, i.e. that complements are excluded from being new information (Güldemann 1996). Kosch (1988) claims that - $a$ - (in Northern Sotho) marks that a communicative unit ends with the verb. This generalization is supported by the examples in (56) from Xhosa (Nguni).

Xhosa (Jokweni 1995: 94, 78; emphasis provided by Jokweni)

a. bá-ya-fudúúka ngoLwésihláánu.

2-A-emigrate Friday

'They do emigrate on Friday.'

b. ba-yá-zaam ukú-lim úmbóóna.

CL2-YA-try CL15-cultivate maize

'They TRY to cultivate maize.'

c. ndi-ya-m-síík úmaam úziipho.

1-YA-CL1-cut mother nail

Lit. 'I CUT her, mother, nail.'

In the examples in (56), the verb form contains $-a$ - in the respective slot in the verbal template. The interpretation of the sentence is such that the verb is new information and therefore in focus. Comparable data can be compiled for Northern Sotho.

(57) Northern Sotho (from the production study (ch. 3); condition: natural speech)

a. (i) [O dira eng bjale?

2 do what now

'What are you doing now?']

(ii) Ke a $[\text { nwa }]_{F}$ bjale.

1 -A-drink now

'I am DRINKING now.'

b. (i) [O opela mo-nyanye-ng?

2 sing CL3-party-LOC

'Are you singing at the party?']

(ii) Aowa, ke a $[\text { bina }]_{F}$ (mo-nyanye-ng).

no 1 -A-dance CL3-party-LOC

'No, I am DANCING (at the party).'

c. (i) [O dira eng ka le-e lehono?

2 do what with CL5-egg today

'What are you doing with the egg today?']

(ii) Lehono ke a le $[\mathrm{ja}]_{F} . / \mathrm{Ke}$ a le: $[\mathrm{ja}]_{F}$, lehono.

today 1 -A-CL5 eat 1 -A-CL5 eat today

'Today, I am EATING it.' 
d. (i) $\quad$ O dira eng ka mo-rwalo?

2 do what with CL3-load

'What are you doing with the load?']

(ii) Ke a o $[\text { rwala }]_{F}$ (,mo-rwalo).

1 -A- CL3 carry CL3-load

'I am CARRYING it (the load).'

The data in (57) show by means of the preceding context question that the verb is the new information (57-a, c, d) or the corrected information (57-b). In all four cases, -A- appears on the verb. Whereas the first examples of the answers were given when asked for a natural answer to these questions, the alternatives (given as second sentences or in parentheses) were allowed as a further possibility on request. In these second utterances we see that the information following the verb is indeed discourse-old information. The data therefore support the 'focus-based approach' as outlined above, as the verb containing -A- in Northern Sotho indicates new information in the examples in (57).

The generalization that the long forms indicate the verb being new information in the sentence is one aspect of the recurrent properties that cooccur with the morphologically marked verb form. The list of differences between the alternating verb forms in table 4 is taken from Güldemann (2003: 328).

Table 4: Properties of alternating verb forms (Güldemann 2003: 328)

\begin{tabular}{|l|l|}
\hline Long form & Short form \\
\hline \hline $\begin{array}{l}\text { Postverbal constituent facultative, } \\
\text { verb can be the only constituent } \\
\text { and clause-final }\end{array}$ & $\begin{array}{l}\text { Postverbal constituent obligatory, } \\
\text { verb not the only constituent } \\
\text { and clause-final }\end{array}$ \\
\hline Postverbal material discourse-old & Postverbal material discourse-new, asserted \\
\hline $\begin{array}{l}\text { Complement anaphoric, definite, or generic; } \\
\text { verbal object concord possible }\end{array}$ & $\begin{array}{l}\text { Complement indefinite; } \\
\text { verbal object concord impossible }\end{array}$ \\
\hline Emphasis on positive truth value & Emphasis on postverbal constituent \\
\hline In polar questions and answers & In constituent questions and answers \\
\hline Only in asserted main clause & Formal counterpart in non-asserted clause \\
\hline Without formal negative counterpart & Formal negative counterpart \\
\hline $\begin{array}{l}\text { Predicate within the scope of focus, } \\
\text { complement/adjunct extrafocal }\end{array}$ & $\begin{array}{l}\text { Complement/adjunct within the scope of focus, } \\
\text { predicate extrafocal }\end{array}$ \\
\hline
\end{tabular}

\subsubsection{Against - $a$ - as a focus marker}

A purely focus-oriented approach towards the distribution of $-a$ - in Northern Sotho as outlined above raises four closely related issues:

First, it has to be stated that the relation between the presence of the long form and the information status of the verb as new information is unidirectional only. According to the literature, the presence of the long form indicates that the verb is new information. However, not every discourse-new verb in the Present Tense appears in the long form. Consider the example in (58). 
(58) a. Zulu (Kunene 1975: 181, ex. (29a))

(i) umfana u-nika indoda isinkwa

boy SM-give man bread

'The boy gives bread to the man.'

b. Northern Sotho

(i) [O direga eng?- 'What is happening?']

(ii) Ke ja namune.

1 eat CL9.orange

'I am eating an orange.'

(iii) *Ke a ja namune.

For the sentence in (58-a), Kunene (1975: 181) provides the context of an introductory sentence in a discourse, or an answer to a question such as 'What does the boy do?'. Through the context it becomes clear that the verb is new information in this context as it is part of a wider focus. However, it cannot appear in the long form, which would lead to ungrammaticality. The same can be shown for Northern Sotho in (58-b). The objection is not only valid for the verb under wide focus, but also for the verb under narrow focus. Examples are given in (59).

Northern Sotho

a. (i) [O opela mo-nyanye-ng?

2 sing CL3-party-LOC

'Are you singing at the party?']

(ii) Aowa, ke $[\text { bina }]_{F}$ mo-nyanye-ng.

no 1 dance CL3-party-LOC

'No, I am DANCING at the party.'

b. (i) [O dira eng ka namune?

do what with CL9.orange

'What are you doing with the orange?']

(ii) $\mathrm{Ke}[\mathrm{ja}]_{F}$ namune.

1 eat CL9.orange

'I am EATING the orange.'

c. Mo-nna o swere mo-eta le hlapi gomme o tšea

CL1-man CL1 hold.PST CL3-bucket and CL9.fish then CL1 take

hlapi o e fa mo-sadi.

CL9.fish CL1 CL9 give CL1-woman

'The man holds the pot and the fish, then he takes the fish, he gives it to the woman.'

(QUIS)

In all three examples in (59) the verb is narrowly focused. However, the long form is not used. Recall from section 2.4 that deletion, pronominalization or dislocation of discourseold material is not obligatory. Speakers can decide for various reasons to repeat discourseold material. In $(59-\mathrm{a}, \mathrm{b})$, it was requested to repeat discourse-old information as these data went into the production study reported in chapter 3, in example (59-c) discourse-old information (hlapi-'fish') was probably repeated to avoid ambiguity. Example (59-c) is taken from natural speech. 
Second, a focus-based approach also raises the question what information structural impact the short form, i.e. the form containing a zero morpheme, bears. On this point the view in the literature diverges. Whereas Givón (1975) and Güldemann (1996) generalize that the short from signals focus on the following constituent, Kosch (1988) formulates more carefully in proposing that the short form indicates that the informative unit does not end with the verb. Güldemann (2003) excludes all-new sentences (as the examples in (58)) from consideration as he concentrates on focus relations within the sentence and not within discourse. However, the examples in (59) show that the ungrammaticality of the short form can also arises with narrow focus on the verb. An analysis of the long form as a verbal focus marker or a focus morpheme (Givón 1975) can only mean that its presence marks focus on the verb. Nothing with respect to the information structuring of the sentence can be concluded from its absence.

Third, there is an asymmetry in the distribution of the long form depending on the valency of the verb. Whereas the short form is used in transitive structures (60-a), the long form is used with intransitive verbs in sentence-final position, as in example (60-b).

Northern Sotho

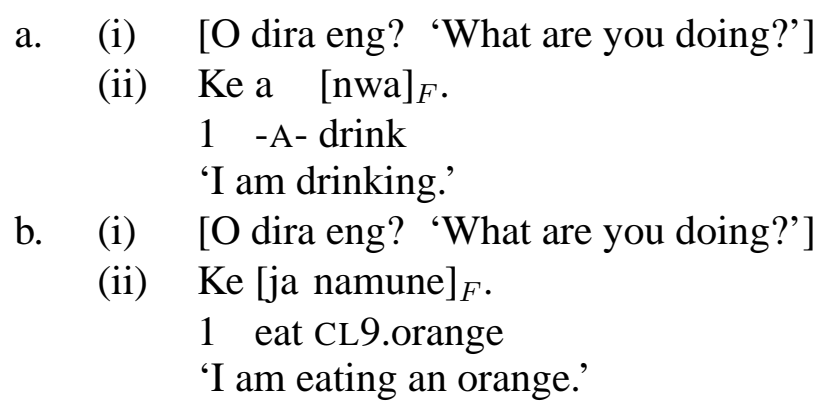

With intransitive verbs the use of the short form is excluded (61-a), as is the use of the long form with transitive verbs (61-b).
a. *Ke nwa.
b. *Ke a ja namune.

This asymmetry is undesired for the claim that the distribution of the short and long form is only dependent on the information structure of the sentence. The asymmetry displayed in (60) is a case of what Hyman \& Watters (1984: 243) call 'grammatical control of focus'. They observe that in most of the African languages that they treat in their article (all from the Niger-Congo family) the expression of focus is only partially controlled by pragmatics, i.e. the speaker determines the element(s) on which the grammar will express focus. For a large segment of the grammar of the respective languages they claim that focus marking is controlled by the grammar itself.

"The pattern is that there is a [+focus] and [-focus] form, and in some grammatical contexts the speaker has no choice but to use one or the other of these, regardless of what may actually be in focus according to pragmatic conditions."

Hyman \& Watters (1984: 243)

As an example they give the focus marker máà in Aghem, a Grassfields Bantu language. As Aghem does not allow máà to occur in relative clauses, the [-focus] form mo is thus 
required in relative clauses by the grammar. For the Southern Bantu languages, the concept of grammatical control of focus introduced by Hyman \& Watters (1984) means that the [-focus] form is used in (60-b) because in complement clauses the short form is excluded. This is necessary although the verb is focused. This line of argumentation already indicates the necessity of a syntactic approach to the distribution of the two alternating forms.

A final issue are (morpho-)syntactic changes that co-occur with the use of the long form. The object marker obligatorily appears on the verb in Northern Sotho when the long form is followed by an object, as shown in (62).

Northern Sotho

a. (i) [O dira eng ka namune?

2 do what with CL9.orange

'What are you doing with the orange?']

(ii) $\mathrm{Ke} \mathrm{a} \mathrm{e}[\mathrm{ja}]_{F}$, namune.

1 -A- CL9 eat CL9.orange

Lit. 'I am EATING it, the orange.'

b. (i) $\quad \mathrm{O}$ dira eng ka mo-rwalo?

2 do what with CL3-load

'What are you doing with the load?']

(ii) Ke a o $\left[\right.$ rwala $_{F}$, morwalo.

1 -A- CL3 carry CL3-load

Lit. 'I am CARRYING it, the load.'

Leaving out the object marker on the verb when the verb appears in the long form, leads to ungrammaticality in Northern Sotho, as is shown in (63).

\section{Northern Sotho}

a. *Ke a ja namune.

b. *Ke a rwala morwalo.

In sum, although the focus-based approach, which has been outlined in section 2.5.1, can account for information structural aspects in connection with the Present Tense morpheme $-a$ - in Northern Sotho, it cannot account neither for information structural meaning connected with the absence of $-a-$, nor for the asymmetry with transitive and intransitive verbs, nor for the morphosyntactic requirement regarding the object marker.

\subsubsection{The syntactic approach}

The syntactic approach to the distribution of the long and short form follows van der Spuy's (1993) account for Nguni and has been motivated for Northern Sotho in section 1.7.4. Van der Spuy (1993) proposes that the long form of the Present Tense is a syntactic phrase-boundary marker which appears when the verb is final in the syntactic IP. ${ }^{10}$ When the verb is followed by an object or adverb within the syntactic IP, the short form of the Present Tense is used in Nothern Sotho.

\footnotetext{
${ }^{10}$ See Buell (2005) for the most recent syntactic analysis of the alternation in Nguni.
} 
This approach to the distribution of $-a$ - in Northern Sotho can account for the shortcomings of the focus-based approach. The asymmetry in the distribution with respect to transitive and intransitive verbs falls out naturally, as only intransitive verbs are final in the syntactic IP, see (64-a) (unless an adverb is following, in which case the - $a$ - on the intransitive verb disappears as predicted, as in (64-b)). As transitive verbs require an object, the verb is never final in the syntactic IP, see (64-c) (unless the object is expressed by a pronoun in which case the verb is final in the IP and the $-a$ - surfaces as predicted, as in (64-d)).

(64) Northern Sotho (The index ${ }_{I P}$ refers to syntactic IP)
a. [Ke a nwa $]_{I P}$.
'I am drinking.'
b. $\quad[\text { Ke nwa bjale }]_{I P}$.
'I am drinking now.'
c. $[\text { Ke nwa meetse }]_{I P}$.
'I am drinking water.'
d. $\quad[\text { Ke a e nwa }]_{I P}$.
'I am drinking it.'

Apart from the asymmetry, also the presence of an object marker is captured by the syntactic generalization. The object marker has been argued to function as an incorporated pronoun (see section 1.7.3). As a pronoun cannot co-occur with its coindexed object NP within the same core clause, the full object constituent in examples as (65-a) has to be outside the core clause. Therefore, the verb is again final in the syntactic IP and the long form is used. If in ditransitive structures only one object is pronominalized, the short form is used because the second object still follows the verb within the syntactic IP. This is shown in (65-b).

$$
\begin{aligned}
& \text { a. }[\text { Ke a e ja }]_{I P}, \text { namune. } \\
& 1 \text {-A- CL9 eat CL9.orange } \\
& \text { Lit. 'I am eating it, the orange.' } \\
& \text { b. }[\text { Ke mo nea le-mao }]_{I P .} \\
& 1 \text { CL1 give CL5-needle } \\
& \text { 'I am giving him a needle.' }
\end{aligned}
$$

Though the syntactic approach can account for the shortcomings of the focus-based approach, it itself has a severe shortcoming: It does not address any information structural implications of the presence of $-a$ - in Northern Sotho. In taking both approaches together, one can hypothesize that the long form of the Present Tense is used when the verb is final in the syntactic IP. When the verb is final in the IP, it is in focus (either narrowly focused or part of a wider focus). This hypothesis will be discussed in the next section.

\subsubsection{Discussion: Relation between syntax and pragmatics}

The hypothesis which emerges when the generalizations of the focus-based and syntactic approach to the distribution of $-a$ - in Northern Sotho are taken together, resembles the 
generalization discussed above: the clause-final position is a focus position in Northern Sotho.

However, this chapter has shown that this is not the case in Northern Sotho as there never is movement into this position. Therefore, also discourse-old constituents can appear in this position. Not only does a narrowly focused verb not have to appear in clausefinal position obligatorily, these last subsections have also shown that a narrowly focused verb does not necessarily appear in the long form in the Present Tense. Sometimes it even must not appear in this form. The examples against an obligatory clause-final position are exactly the ones that show that the absence of $-a$ - on the verb does not always correspond to the verb being old-discourse information.

However, the correlation between focus and the presence of $-a-$, which is postulated in the literature, has been made on the same grounds as a potential claim of a clausefinal focus position in Northern Sotho can be made: There is the tendency for a focused constituent to appear in clause-final position. As clause-final verbs appear in the long form, there is a tendency observable in Northern Sotho that focused verbs appear in the long form. This tendency emerges because discourse-old constituents are often deleted, pronominalized or dislocated. As has been shown in section 2.4, these processes apply for focus-independent reasons. The same arguments hold for the insertion of the Present Tense morpheme - $a-$ : The insertion is not due to focus, but to independent reasons, namely syntactic ones.

This section has shown that the distribution of $-a$ - in the Present Tense in Northern Sotho can best be captured syntactically in that the long form appears when the verb is final in the IP. Because discourse-old constituents are often subject to deletion or dislocation, focused constituents often appear in clause-final position. However, neither syntactic marking nor the occurrence of $-a$ - in Northern Sotho are active focus marking strategies. Both can more adequately be characterized as grammatical reflexes of information structure in this language.

Questions for further research pertain to the diachronic origin of the Present Tense morpheme - $a$-. Güldemann (1996: 168) reports that the comparable morpheme $-a$ - in the Nguni languages is brought into relation with the verb kuya which means 'to go' in Nguni languages. He demands, however, that the phonologically acceptable hypothesis has to be furthermore motivated by semantic-functional considerations. Therefore, consensus about the function of this Present Tense morpheme seems necessary. When assuming a syntactic demarcation function of the Present Tense morpheme, at least in Sotho, a further question is what the functional necessity is to mark the verb as final in the syntactic IP.

\subsection{Conclusion}

This chapter dealt with the syntactic expression of focus in Northern Sotho. It emerged that constituents are focused differently according to the grammatical function they fulfill. Whereas non-subjects are focused in situ, subjects are focused by either a cleft structure or postverbally by an impersonal construction. This so-called subject/object asymmetry in focus contexts is not unique to Northern Sotho but has been reported for other languages within and outside Bantu as well (see e.g. Bokamba 1976 for Dzamba, Bergvall 1987 for Kikuyu, Demuth \& Johnson 1989 for Tswana, Sabel \& Zeller to appear for Nguni, 
Hartmann \& Zimmermann 2004, to appear a for the Chadic languages Tangale and Hausa respectively).

In not showing any syntactic focus marking of postverbal elements, Northern Sotho differs from Bantu languages like Kikuyu, Kilega, or Nguni for which focus marking at the left-periphery, at least as an additional alternative, has been claimed. It also differs from Bantu languages like Aghem for which an immediately postverbal focus position has been shown to exist.

Despite the absence of syntactic F-marking in the postverbal domain, the information structuring of an utterance is nevertheless reflected in an utterance in Northern Sotho. Deletion, pronominalization and dislocation of discourse-old constituents have been presented as processes that indirectly single out the focused constituent. Northern Sotho is no exception in showing processes that refer to non-F-marked constituents instead of F-marked constituents. As with grammatical F-marking, languages use means from different areas of grammar to mark non-F-marked constituents in discourse. Languages like English and German make use of prosodic means in deaccenting given material. Topic marking in Japanese is an example for morphological marking of discourse-old constituents.

The chapter has furthermore shown that there is no morphological marking of focus neither. In line with recent literature it has been argued that the presence of the morpheme $-a$ - on the verb is syntactically determined.

In sum, we can assert a lack of syntactic or morphological F-marking in the postverbal domain. This conclusion rises the question of the relevance of the notion of F-marking for the grammar of Northern Sotho. This chapter has shown that F-marking is of no direct relevance for the syntax of Northern Sotho as F-marking does not lead to a grammatical encoding. Cross-linguistically, the absence of syntactic focus marking is not unique. Also languages like English and German do not show obligatory syntactic focus marking.

For some languages, F-marking has been argued to be of indirect relevance. Scrambling in German is such a case. It has been argued that non-focal material that intervenes between the focus constituent and the verb is moved in order for the focused constituent to be target of the neutral sentence accent (e.g. Krifka 1998). In Catalan, discourse-old material is moved out of the core sentence (Vallduví \& Engdal 1996). For African languages, Bearth (1999) points out the importance of including indirect focus marking strategies in the investigation of information structure in African languages.

"Swahili, for example, makes extensive use of a type of word order permutation whereby focus effects, particularly on the verb, are obtained by moving postverbal constituents to the front, in topic position, and thereby defocusing them. It is not the focus constituent which undergoes movement, but the special focus effect is obtained by moving a non-focalised constituent out of its (unmarked) focus position."

(Bearth 1999: 129)

This section has shown that Northern Sotho does not dispose of indirect focus marking strategies. Though a tendency is observable to have the F-marked constituent in clausefinal position, this is by no means obligatory. Therefore, F-marking is of no indirect relevance for the grammar of Northern Sotho. 
The question remains if F-marking has any relevance at all. It is dispensable when characterizing the constituents that are target for the processes of morphosyntactic reduction and dislocation that have been discussed in this chapter. These constituents can also be captured by the notion Given as proposed by Schwarzschild (1999).

Before reaching at a conclusive answer with respect to the relevance of F-marking for the grammar of Northern Sotho, it needs to be investigated if F-marking has a relevance for prosody, as it has in English and German. This will be done in the next chapter for Northern Sotho. Furthermore, it needs to be investigated if the notion of F-marking is relevant in connection with restrictions on a focused, preverbal subject. This is the topic of chapter 4 . 


\section{Chapter 3}

\section{Prosody and focus in Northern Sotho}

\subsection{Introduction}

The preceding chapter has shown that there is no morphological or syntactic marking of focus in the verbal and postverbal domain in Northern Sotho. Though a tendency is observable for the focused constituent to appear in clause-final position, the appearance in clause-final position cannot be considered an obligatory means of syntactic marking of focus, as there is no movement into this position.

The current chapter has as its objective to investigate whether there is prosodic marking of focus in the verbal and postverbal domain in Northern Sotho. As was argued already in chapter 1 , syntactic reordering for reasons of information structuring has suprasegmental consequences in Northern Sotho. Consequently, Northern Sotho shows prosodic reflexes of information structure. The goal of this chapter is, however, to investigate if there is prosodic marking of postverbal in situ focus.

A wide-spread assumption in the literature on focus is that focus is marked somehow in a language. In light of the absence of morphological and syntactic marking, an investigation of prosodic marking can either support this assumption or provide evidence against its universality.

Furthermore, though the Bantu languages form the largest language family in Africa, consisting of approximately 500 languages, comparatively little research has been carried out on the prosodic expression of the information-structural categories topic and focus. The work presented in this chapter contributes to filling this gap in providing data on the prosodic expression of in situ focus in one of its languages. In applying experimental methodology that has been tested on Indo-European languages, this chapter provides new data that are comparable cross-linguistically.

The chapter is organized as follows: Section 3.2 and 3.3 introduce issues in Northern Sotho tonology and phonological phrasing respectively. This is necessary for three reasons: First, not much work has been done on Northern Sotho tonology (with the notable exception of the work by Lombard 1976 and Monareng 1992), let alone Prosodic Phonology. Second, there is rich microvariation in the tonology of Bantu languages, even among dialects of the same language. Third, an investigation of tonal issues in Northern Sotho lays the foundation for the study testing the influence of focus on prosodic phrasing, both with respect to the hypotheses formulated and to the choice of stimuli for the production 
and perception study. Insights about the tonal processes in Northern Sotho presented in this chapter have been gained by the study of existing literature on Northern Sotho and by work with native speakers. Thereby, not only the auditory impression but also acoustic measurements are taken as indicative for tonal structure.

The reader interested in the prosodic expression of focus only can skip these sections and start with section 3.4. Section 3.4 defines prosodic marking of focus. Therefore, in section 3.4.2 the expectation of suprasegmental marking of postverbal in situ focus in Northern Sotho is motivated by discussing the case of Chichewa in detail. Section 3.4.3 distinguishes prosodic marking of focus from prosodic reflexes of information structuring.

Section 3.5 presents the production study and section 3.6 the perception study which have been carried out to test the prosodic realization of in situ focus in Northern Sotho. Section 3.7 concludes the experimental part. Section 3.8 discusses the theoretical implications of the findings presented in this chapter.

The lack of prosodic focus marking in Northern Sotho, which emerged from the studies carried out (section 3.5 and 3.6), is going to be published in Zerbian (under review a). However, the current chapter provides a thorough introduction to Phrasal Phonology in Northern Sotho (section 3.2 and 3.3), a detailed description of the phonetic studies carried out (section 3.5 and 3.6), and a discussion of the results in light of the other findings reported in this thesis (section 3.8).

\subsection{Background}

There is quite a considerable amount of studies dealing with the tone systems of South African Bantu languages, starting with observations made by the missionaries. Detailed descriptions are available for tone at word-level in the Sotho family (Letele 1955, Khoali 1991, Lets'eng 1994 in Southern Sotho; Mmusi 1992, Chebanne et al. 1997 in Tswana), in the Nguni family (Khumalo 1987 in Zulu; Jokweni 1995, Cassimjee 1998, Cassimjee \& Kisseberth 1998 in Xhosa), in Shona (Myers 1985, 1995), in Venda (Cassimjee 1992), and in Tsonga (Kisseberth 1994). For Northern Sotho, I am only aware of three studies: Lombard (1976) is a detailed description of the tonology of the Sepedi dialect, Lombard (1979) investigates vowel length in Sepedi, and Monareng (1992) describes tonological processes in the Setswapo dialect of Northern Sotho. Zerbian (to appear) provides an overview of a word-related tonological process in Sotho varieties.

With respect to general characteristics of the Northern Sotho tone system, it displays the underlying two-tone system $(\mathrm{H}, \mathrm{L})$ common to many Bantu languages (Cole 1955, Doke 1954). In the verbal paradigm, verbs are classified into high- and low-toned verbs depending on the tone quality of the stem-initial vowel (Clements 1984b, Guthrie 19671971), as shown in (1). Low-toned verbs surface with all syllables low-toned, as shown in (1-a). In the case of high-toned verb stems, there is always a high tone on the first stem syllable, as in (1-b). It is assumed that this syllable is associated with a high tone underlyingly. Throughout this chapter high tones are marked by acute and underlying high tones are underlined. 
(1)

\begin{tabular}{|c|c|c|}
\hline & lasses in North & ern Sotho \\
\hline & go lwa & -'to fight' \\
\hline & go hlaba & - 'to stab' \\
\hline a. & go tlogela & -'to leave' \\
\hline & go dumediša & - 'to greet' \\
\hline & go fá & - 'to give' \\
\hline $\mathrm{b}$ & go ráta & - 'to love' \\
\hline & go bóláya & - 'to kill' \\
\hline & go khúrúmétša & - 'to cover' \\
\hline
\end{tabular}

The overall tonal pattern of a verb form in Sotho is not only determined by lexical association of a high tone to a tone bearing unit but also by principles governing tone spread and deletion.

Two phonological rules can be established for Northern Sotho that apply above the word-level. They are given in (2).

(2) Phonological rules above the word-level

a. Penultimate Lengthening (domain-edge rule)

b. Finality restriction (domain-edge rule)

The rules in (2) and their interaction with tonal rules will be illustrated in detail in the subsections to follow. If not indicated otherwise, the data for Northern Sotho are taken from my own elicitation work with five native speakers and represent the Sepedi dialect of Northern Sotho (for a map of the Sepedi speaking area see section 1.6).

\subsubsection{Penultimate lengthening}

Lengthening of the penultimate syllable at the end of utterances or even utterance-medially is a feature that is reported for many Bantu languages, independent of the fact if the language's phonological system contrasts between long and short vowels. However, it seems most wide-spread in Southern Bantu languages.

In Northern Sotho, vowel length is non-contrastive. Hence, it can be used without problems for prosodic purposes. The data in (3-a) show a verb (in i) and an object (in ii) that display a short vowel in penultimate syllable when being followed by a further constituent. A long vowel in penultimate syllable only appears when the word occurs in utterance-final position, shown in (3-b) for the verb in (i) and for the object in (ii). There are only a few idiosyncratic exceptions to this generalization (e.g. the first vowel in maabane- 'yesterday').
a. (i) Ke bóná gagóo:lo.
1 see well
'I am seeing well.'
(ii) Ke fá mo-rathó di-apa:ro.
1 give CL1-brother CL8-cloth
'I give the brother clothes.'


b. (i) Ke a bó:na.

1 -A- see

'I am seeing.'

(ii) Ke bóná mo-ra:thó.

1 see CL1-brother

'I am seeing the brother.'

The phonetic manifestation of penultimate lengthening is illustrated by data from three speakers in diagram 1. Each line in the diagram represents the respective values for one speaker (DE, Mak, MO). The data points represent the average duration for each vowel of two utterances of comparable SVO-structures, which are given in (4).
a. Ke mémá mo-hú:mi.
1 invite CL1-rich.man
'I invite the rich man.'
b. Ke rwálá mo-rwá:lo.
1 carry CL3-load
'I am carrying load.'

The utterances have been segmented according to the standards that will be set out in section 3.5.4 in detail. The software used was PRAAT (Boersma \& Weeninck 2005). A PRAAT script calculated the duration for the vowels. In order to allow comparability, the duration has been calculated as relative duration of the syllable in relation to the utterance. It emerges that the penultimate syllable is distinctively lengthened in comparison to the preceding syllables.

Diagram 1: Penultimate Lengthening in Sepedi

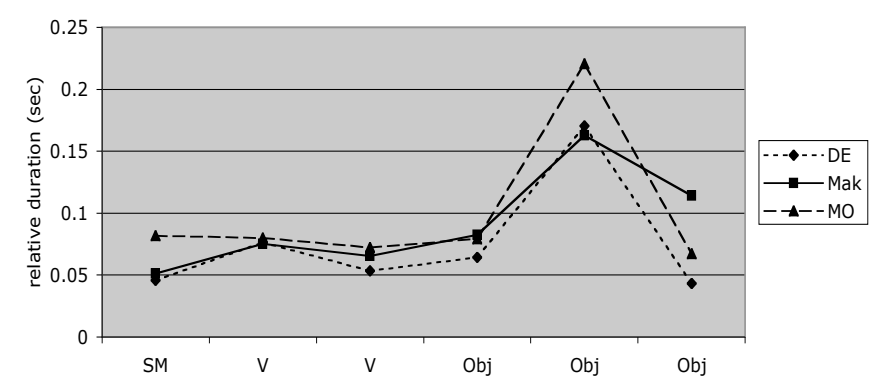

Length has been equaled with stress in early work by Doke (1927/1992) and has been used as an indicator of word-hood in Bantu languages. A morphological word consequently contains one main stress, i.e. a lengthened syllable. Length at word-level cannot be confirmed for Northern Sotho so far, neither in a preliminary study by Lombard (1979) nor in my own data (see diagram 1). In Northern Sotho, length reliably only occurs at prosodic boundaries above the word, but not at the penultimate syllable of every word. 


\subsubsection{Finality restriction}

Cross-linguistically, Nespor \& Vogel (1987) observe that the edges of prosodic domains are often subject to adjustment rules excluding the final syllable as being one of them. The restriction on domain-final syllables has been referred to as extrametricality (or extratonality for tonal processes). Also in Bantu languages it is a common observation that the domain-final syllable is exempt from phonological processes (Kisseberth \& Odden 2003: 64).

In Chichewa, high tones which are on phrase-final syllables are retracted to the preceding syllable (Kanerva 1990). In Northern Sotho, high tones which are underlyingly present on final syllables are realized on this syllable. This is shown in (5).

$$
\begin{aligned}
& \text { Northern Sotho } \\
& \text { ngwaná 'child' *ngwana } \\
& \text { a. morathó 'brother' *moratho } \\
& \text { b. go fá 'to give' *go fạ } \\
& \text { go lwá 'to fight' *go lwa }
\end{aligned}
$$

The realization of the underlying high tone on monosyllabic H-toned verbs, as in (5-b), therefore preserves the contrast between high- and low-toned verbs.

The activity of the finality restriction in Northern Sotho emerges in the interplay of tone spreading. Therefore, some background is necessary on the word-related process of high tone spread (HTS).

\section{High tone spread}

Mobility of high tones is one of the most fundamental phenomena of Bantu tonology (Kisseberth \& Odden 2003: 62). High tone spread (HTS) and high tone shift are instances of such tonal mobility: A high tone does not (only) surface on the syllable it is associated with underlyingly, but (also) on succeeding syllables. If the high tone surfaces only on one syllable, one speaks of tone shift, whereas tone spread refers to the situation where the high tone surfaces on all intervening syllables.

In contrast to the Nguni family which displays a rather homogeneous tone shift pattern (Peterson 1989, Downing 1990), the Sotho languages are heterogeneous with respect to tone spread. Research on HTS in Sotho varieties attributes the variation to two different types of HTS (Khoali 1991, Mmusi 1992, Monareng 1992, Cassimjee \& Kisseberth 1998): Bounded HTS spreads a high tone once to the immediately adjacent syllable, whereas unbounded HTS spreads a high tone to an unlimited number of syllables within a certain prosodic domain.

In the Sepedi dialect of Northern Sotho, high tone spread is a local process of tonal assimilation. This means that a high tone from an underlyingly high-toned syllable is spread only to the immediately right adjacent syllable (in the same word). This is shown in (6) (see also Lombard 1976). A high tone that is associated with the verb stem initial syllable spreads to the following syllable and only to this syllable. 
(6) High tone spread in verbs

a. Ke thúšśa mo-kgala:bje.

1 help CL1-old.man

'I am helping the old man.'

b. Ke šómá polase:-ng.

1 work CL9.farm-LOC

'I am working at the farm.'

In showing spread of high tones onto the immediately right-adjacent syllable, Northern Sotho groups with other Bantu languages such as Tswana (Chebanne et al. 1997), Chichewa (Kanerva 1990), Shona (Myers 1991), and Kikuyu (Clements 1984a) which show the same pattern.

The phonetic manifestation of high tone spread in Northern Sotho is illustrated by data from three speakers in diagram 2. As changes in fundamental frequency (F0) are the acoustic manifestation of tone, each line in the diagram represents the respective F0values for one speaker (DE, Mak, MO). MO is a male speaker wherefore the fundamental frequency for this speaker is considerably lower than for the other two (female) speakers. Each data point represents the F0-average of the two utterances of comparable SVOstructures, which were given in (4) and which are repeated in (7) for convenience.
a. Ke mémá mo-hú:mi.
1 invite CL1-rich.man
'I invite the rich man.'
b. Ke rwálá mo-rwá:lo.
1 carry CL3-load
'I am carrying load.'

The values that went into the calculation of the F0-average per speaker were likewise F0-averages that the PRAAT script ascertained for the respective syllable. All F0-values went into the calculation, i.e. there were no outliers. Diagram 2 shows the course of the fundamental frequency over the utterance. The disyllabic verbs used in the sentences are high-toned. For all speakers, we find a verbstem initial syllable that is slightly raised in pitch. The pitch contour continues to raise throughout the second syllable of the verb. After the verb, the pitch declines again.

Diagram 2: High tone spread (HTS) in Sepedi

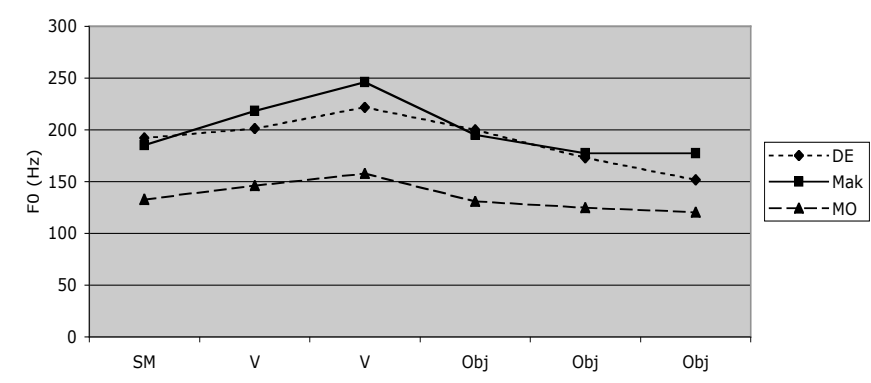

The raising of pitch which starts in the (underlyingly) high-toned verb stem initial syllable 
and continues throughout the immediately right-adjacent syllable, gives evidence for the claim of local HTS in Northern Sotho.

High Tone Spread does not only occur with verbs but also with nouns. This can be seen if nouns bearing a HL or LH tone pattern are extended by the low-toned diminuitive suffix -ana or -nyana (see also Monareng 1992, Khoali 1991: 32), as exemplified in (8).

$$
\begin{aligned}
& \text { High tone spread in nouns } \\
& \begin{array}{lll}
\text { a. kgomó } & \text { 'cow' kgomónyána } \\
\text { b. phíri } & \text { 'hyena' phíśána, phírínyana } \\
\text { c. moótlwa } & \text { 'thorn' moótlwányana }
\end{array}
\end{aligned}
$$

The domain in which HTS applies in Northern Sotho is restricted to the phonological word. That HTS does not occur across word boundaries, is illustrated by means of diagram 3. Average F0-values of two speakers are displayed from the utterances in (9).

\section{HTS at word-boundaries}

a. Ke fá mo-kgalabje di-apa:ro.

1 give CL1-old.man CL8-clothes

'I give the old man clothes.'

b. Ke fá kgarebe di-apa:ro.

1 give CL9.lady CL8-clothes

'I give the lady clothes.'

In both utterances in (9), a monosyllabic, high-toned verb is followed by an all low-toned object NP. Diagram 3 illustrates that the high tone of the verb syllable does not spread onto the following syllable, but rather falls on the syllable that represents the nominal prefix of the object.

Diagram 3: Absence of HTS across word boundaries

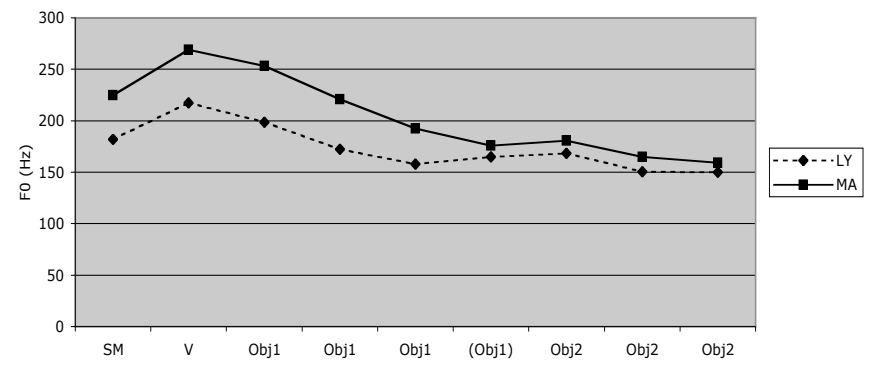

\section{Interaction with HTS}

Although being itself a word-related process, HTS interacts with the finality restriction, which is a phonological rule whose domain is larger than the prosodic word. The blocking of HTS is therefore a diagnostic for prosodic phrase boundaries.

The final syllable of a higher prosodic domain is exempt as a target for HTS. This is shown for verbs (10-a,) and nouns (10-c) respectively. In (10-a), the verbstem initial high tone of the verb spreads to the following syllable, as shown in diagram 2. However, this 
spreading is blocked in the examples in (10-b) where the verb appears final in the domain. (Note, that the penultimate syllable of the verb is also lengthened in this environment.)
a. (i) Ke thúšá mosáa:di.
'I help the woman.'
(ii) Ke šómá polase:ng.
'I am working at a farm.'
(iii) Ke bóná gagóo:lo.
'I see well.'
b. (i) Ke a thú:ša.
'I am helping.'
(ii) Ke a šó:ma.
'I am working.'
(iii) Ke a bó:na.
'I am seeing.'
c. mosá:di 'woman’ *mosá:dí

The blocking of HTS at domain edges is also depicted in diagram 2. The last three data points in 2 represent the three syllables of the object. The object carries a high tone on the second syllable, which is the nounstem initial syllable. The curve shows that F0 falls after this syllable (DE, MO) or remains at the same height (Mak), but does not raise as in the case of the verbal high tone.

Myers (1999) in his work on F0-alignment in Chichewa proposes a phonetic explanation for HTS which says that there is no tone spread but gradient patterns of F0 timing which are sensitive to vowel length and phrase-final position. According to this hypothesis, a high tone in an unlengthened syllable is expected to be realized with F0 rising through the high-toned syllable. The peak is only reached near the beginning of the next syllable (peak delay). In a lengthened penultimate syllable, however, an F0 peak is expected within such a syllable. He shows for Chichewa that this is indeed the case.

This phonetic explanation is attractive also for Northern Sotho, as the absence of HTS near domain boundaries falls out automatically due to the lengthened syllable. At domain edges, lengthening of the penultimate vowel occurs also in Northern Sotho. The late peak can be realized within the lengthened syllable and tone spread onto the following syllable does not take place.

However, a purely phonetic explanation for the process of HTS in Northern Sotho does not capture the observation that HTS does not take place across word-boundaries. The phonetic account predicts a higher pitch on any syllable following a short, high-toned syllable. Consequently, HTS can be motivated as a phonological process rather than a coarticulation phenomenon.

To summarize, penultimate lengthening and the absence of spread high tones give evidence for prosodic phrase edges in Northern Sotho. Section 3.3 deals with the determination of this prosodic domain. 


\subsubsection{OCP}

Another environment that influences the tonal realization not only of underlying high tones, but also of high tones that originate from high tone spread, is sequences of adjacent high tones. Cross-linguistically, many languages show an active restriction which disfavors adjacency of phonologically similar segments. The Obligatory Contour Principle (OCP, Leben 1973) states that adjacent identical elements are prohibited.

With respect to tone, the OCP disfavors adjacent high tones. High tones can be adjacent underlyingly (non-derived OCP violation) or they can be adjacent after tonal rules have been applied (derived OCP-violation). A sequence of two high tones is avoided by different strategies cross-linguistically (see Myers 1997 for an overview): Either, one of the tones is deleted or retracted away from the other. Or, both high tones are realized. In this case there is evidence that the two high tones nevertheless obey the OCP in that they are represented underlyingly with a single multiply-linked high tone, as in (11-b). The difference is illustrated in (11).

(11) Autosegmental representation of adjacent underlying high tones

a. OCP-violation

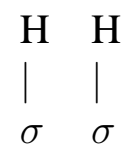

b. No OCP-violation

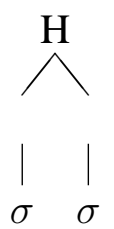

Moreover, processes that create a sequence as in (11-a) are blocked. A further option is to tolerate OCP-violations in the grammar and to use downstep between adjacent underlying high tones. By register lowering through downstep, the phonologically adjacent high tones are dissimilated phonetically. This is attested in Kishambaa where downstep appears both within words and within phrases (see Kisseberth \& Odden 2003).

Within the domain of the phonological word, Northern Sotho has an active OCPrestriction: Lombard (1976) reports that if three underlying high tones appear adjacent within the verbal domain, the middle high tone is changed into low. This is illustrated in (12) by means of a verb form used in subordinate clauses (indicated by the form of the subject marker and the verb ending).

(12) OCP-resolution within words (Lombard 1976: 26) (gore) $\underline{a}$ dí bóláye is realized as á di bóláye '(that) he has to kill them'

With respect to adjacent underlying high tones within a phrasal domain, the auditory impression and preliminary acoustic analysis support the view that adjacent high tones are downstepped in Northern Sotho. However, this observation is preliminary and requires 
further detailed investigation.

With respect to adjacent high tones that result from tonal processes, one can hypothesize from the data available that the OCP does not act as a rule blocker (McCarthy 1986): The application of the tonal rule of HTS within a word is not blocked even if this creates a violation of the OCP. This is illustrated by the sentence in (13). The sentence in (13) contains a high-toned verb that is followed by an object whose initial syllable is high-toned according to the dictionary (Ziervogel \& Mokgokong 1961).

$$
\begin{aligned}
& \text { Ke ngwálá nónwa:ne. } \\
& 1 \text { write CL9.folktale } \\
& \text { 'I am writing a folktale.' }
\end{aligned}
$$

Diagram 4 shows the pronunication of the sentence in (13) by four speakers. Again, MO is a male speaker wherefore the overall pitch is lower than for the other (female) speakers. In diagram 4, we find HTS within the verb just as in diagram 2, where the verb was followed by a low-toned syllable. Again, the high tone of the verbstem initial syllable raises through the following syllable. Crucially in this case, the noun initial syllable, which is assumed to be high underlyingly, is realized with a lower pitch. This is here interpreted as downstep.

\section{Diagram 4: HTS in OCP environments}

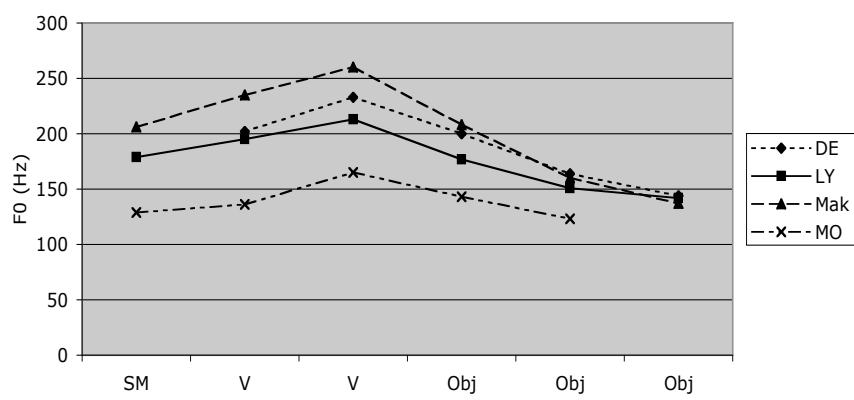

A clearer illustration of HTS followed by an initial high-toned syllable is presented in the case of the subject (see diagram 8). There, it clearly emerges that following high tones are downstepped.

The occurrence of HTS with the consequence of creating an OCP violation in Northern Sotho is contrary to what is found in Shona (Myers 1985, 1991), a neighboring Bantu language. In Shona, no HTS takes place in such an environment.

However, it needs to be repeated that with respect to the tonal behavior of two adjacent underlying high tones, the data available do not yet allow a precise analysis. ${ }^{1}$ Environments displaying or creating OCP-violations have been taken into consideration when designing the data set for the production study in order to test if focus is another factor that manipulates downdrift in Northern Sotho.

\footnotetext{
${ }^{1}$ The recorded corpus contains examples of such an environment. However, the adjacent high tones appear towards the end of the utterance where the pitch range available for tonal modulation is diminished due to declination. As the manipulation of declination/downdrift within and across phrases is an understudied topic in Bantu languages, the OCP context has to await further research in order to provide a detailed analysis of the tonal realization.
} 


\subsubsection{Summary}

The preceding section established the phonological cues to phrasing in Northern Sotho, namely the occurrence of penultimate lengthening and the application of the finality restriction that crucially interacts with HTS. A discussion of these facts is necessary for two reasons. For one, no work has yet been done on Phrasal Phonology in Northern Sotho. For the other, there is considerable variation found among the Bantu languages, not only with respect to the denomination and demarcation of the relevant prosodic domain but also with respect to the phonetic cues used.

Vowel length is a cue common to phrasing in Bantu languages, although there is variation in the principles determining its realization. In contrast to Northern Sotho, languages like Chi Mwi:ni and Kimatuumbi have long and short vowels underlyingly. In these languages, long vowels can only be realized in certain positions, otherwise they are shortened (Kisseberth \& Abasheikh 1974, Odden 1987). Languages like Chichewa, on the other hand, are reported to have lengthened vowels to different degrees, occurring at PPand IP-boundaries respectively (Kanerva 1990).

High Tone Spread does not only occur as a word-level process like in Northern Sotho, but also at the phrasal level, as reported for Tsonga and Chizigula (Kisseberth 1994, Kenstowicz \& Kisseberth 1990).

The realization of domain-final high tones is restricted by the finality restriction and the need to realize underlying high tones in Northern Sotho. Also more generally in Bantu languages, domain-final high tones are subject to positional conditions, though with different consequences. In Haya, LH-sequences in final position are realized as either HH or HL depending on the strength of the boundary (Byarushengo et al. 1976). In Chichewa, a final H is retracted, whereas a non-final H is doubled (Kanerva 1990).

Lastly, the realization of high tones that is suggested to be determined by adjacent high tones in Northern Sotho (OCP-environment), is crucially influenced by surrounding high tones in other Bantu languages as well: In Kinyambo, a high tone is deleted if the word that contains it is followed by another high-toned word within the same domain (Bickmore 1990). In Chichewa, succeeding high tones are downstepped if they occur in different phonological phrases (Downing et al. 2004: 183).

After a short introduction to phrasing in phonology, the following section discusses the prosodic domains which the phonological processes established for Northern Sotho give evidence for as well as the algorithm that is needed to derive this prosodic domain.

\subsection{Phonological Phrasing in Northern Sotho}

\subsubsection{Theoretical background}

\section{Relating prosodic structure to syntactic structure}

Syntactic structure influences prosodic structure. For Bantu languages, work on vowel length in Chi Mwi:ni (Kisseberth \& Abasheikh 1974), on tonal processes in Kimatuumbi (Odden 1987, see reanalysis in Truckenbrodt 1995) as well as on other languages (Bickmore 1990, Byarushengo et al. 1976, Hyman 1990, Jokweni 1995, Kanerva 1990, 
Kisseberth 1994, 2000, McHugh 1990, Odden 1995) has brought evidence for the proposal that certain phenomena, like tonal processes, are sensitive to prosodic domains, and that these prosodic domains stand in a certain relationship to syntactic domains. However, not much work has been done on Phrasal Phonology in Bantu languages of South Africa, as in general, prosody is often neglected in work on African languages (Creissels 1996, Bearth 1999). To my knowledge, the only study dealing with Phrasal Phonology at sentence level is Kisseberth (1994) on Tsonga and Jokweni's work on Xhosa (1995). A comprehensive study of phrase-related processes for the Sotho languages is therefore still lacking. The objective of this chapter is more modest, though. It is meant as an introduction into the issues at hand when eventually exploring the effect that focus has on the prosody in this language.

For Northern Sotho the influence of syntax on prosody has been observed as early as first descriptions of the language (e.g. Endemann 1876). The affect of prosodic structure is reflected in tonal changes and lengthening. The tonal pattern of a word changes with its position in the sentence. This is illustrated in (14), where the tone pattern of the verb changes from HL in (14-a) to HH in (14-b) depending on the presence of an object following the verb.

Northern Sotho
a. (i) Ke a thú:šsa.
'I am helping.'
(ii) Ke a šó:ma.
'I am working.'
(iii) Ke a bón:na.
'I am seeing.'
b. (i) Ke thúšá mosá:di.
(ii) Ke šómá polase:ng.
'I am working at a farm.'
(iii) Ke bóná gagó:llo.
'I see well.'

The linguistic subfield of Prosodic Phonology investigates the relation between prosodic processes and syntactic phrases. Odden (1987) in his work on the Bantu language Kimatuumbi develops an account of phrase-level phonology that refers to syntactic structure without invoking phrasal prosodic constituents (see also Kaisse 1985). The view of the phonology-syntax interface that is adopted here, is that prosodic structure acts as a mediator between phonological processes and syntactic structure (Nespor \& Vogel 1986, Selkirk 1980). This is captured in the Indirect Reference Hypothesis by Inkelas (1989), which is given in (15).

Indirect Reference Hypothesis (Inkelas 1989)

Phonological rules refer to only prosodic constituent structure.

Prosodic constituents are ordered in a hierarchy which is represented in (16). ${ }^{2}$

\footnotetext{
${ }^{2}$ In order to avoid terminological confusion I use capital letters for prosodic phrases that relate to a
} 


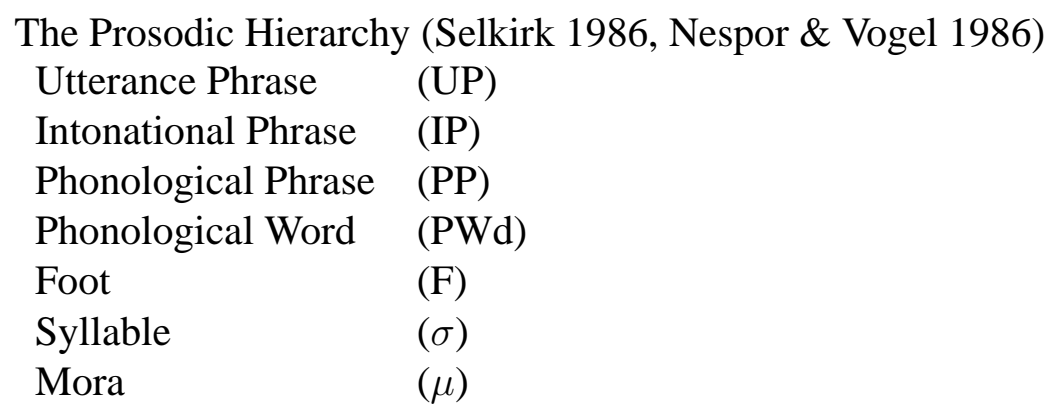

The prosodic constituent of Foot and Phonological Word denominate metrical domains in which stress is assigned at or near a domain edge. The view that is followed here is that also the prosodic domains above the word level serve as metrical domains in which stress is assigned at or near an edge (Nespor \& Vogel 1986, Hayes \& Lahiri 1991, Truckenbrodt 2006). This view is not uncontroversial for Bantu languages, both at word- and phrasal level, as Bantu languages do not show prominence directly. This issue will be taken up again below.

The phonological processes of penultimate lengthening and the finality restriction, which were discussed for Northern Sotho in the preceding section, apply above the wordlevel. I will therefore restrict the discussion to those domains in the following. Prosodic constituents above the word-level are defined with reference to syntactic structure. I follow the view pronounced in Truckenbrodt (1995) that it is Phonological Phrases (PP) that make reference to syntactic XPs such as Noun Phrases (NPs), Verb Phrases (VPs), and Adjective Phrases (APs). ${ }^{3}$ Intonation Phrases, in contrast, refer to prosodic constituents related to syntactic clauses.

Evidence for prosodic structure as a mediator between phonological processes and syntactic structure comes from the observation that the phonological phrases and the syntactic structure do not always match perfectly, but are influenced by economy considerations such as parameterized alignment constraints or WRAP, which are both discussed below.

\section{Phonological Phrases}

In order to account for the prosodic phrasing in a language on the basis of its syntactic structure, a phrasing algorithm has to be formulated which links the prosodic structure to the syntactic structure. Universal phrasing algorithms have been proposed in the literature, starting with the relation-based theory (Selkirk 1980, Nespor \& Vogel 1986, Hayes 1989). This algorithm for the derivation of phrases groups syntactic constituents into a prosodic constituent provided that they stand in a certain syntactic relationship. The relevant relationship is the head-complement configuration.

In the study of tone languages, it has been observed that phonological rules are sensitive to one edge of syntactic domains only (Clements 1978 for left edges in Ewe, Chen 1987 for right edges in Xiamen Chinese). Based on these insights and data from vowel length in the Bantu language Chi Mwi:ni, Selkirk (1986) proposes the end-based theory

specific layer (e.g. Phonological Phrase).

${ }^{3}$ Thereby, the Phonological Phrase (PP) subsumes what is termed 'Focus Phrase' in work by Kanerva (1990) and Downing (2002) for Chichewa. 
whose algorithm groups all words regardless of their syntactic relationship into a phrase until the edge of an $\mathrm{X}^{\max }$ constituent. This universal algorithm can account for crosslinguistic variation in that the relevant edge can be parameterized as left or right.

With the advent of Optimality Theory (Prince \& Smolensky 1993), the patterns of phrasing have been argued to be better understood when the syntax-prosody mapping is formalized in terms of ranked and violable constraints. Selkirk (1996) reformulates the edge-alignment approach in the format of Generalized Alignment (McCarthy \& Prince 1993). The constraints for aligning syntactic XPs with prosodic boundaries in order to derive prosodic domains following Selkirk (1996) read as in (17).

Edge alignment in OT (Selkirk 1996)

a. Align-XP,R: Align (XP, R; P, R)

'For each XP there is a $\mathrm{P}($ hrase) such that the right edge of $\mathrm{XP}$ coincides with the right edge of $P$.'

b. Align-XP,L: Align (XP, L; P, L)

'For each XP there is a $\mathrm{P}$ such that the left edge of XP coincides with the left edge of P.'

The alignment of syntactic XPs to Phonological Phrases is subject to the restriction that the alignment constraints only apply to lexical XPs to the exclusion of functional phrases. This is formulated in the Lexical Category Condition in (18).

Lexical Category Condition, LCC (Selkirk 1996, Truckenbrodt 1999)

Constraints relating syntactic and prosodic categories apply to lexical syntactic elements and their projection, but not to functional elements and their projection.

The Lexical Category Condition therefore captures the alignment of prosodic phrases with lexical categories such as NP, AP, or VP, but excludes alignment with functional phrases such as DP, IP, or CP and therefore also with functional elements such as pronouns.

In his work on phonological phrases and their relation to syntax, focus, and prominence, Truckenbrodt $(1995,1999)$ introduces the constraint WRAP-XP which is inspired by work by Hale \& Selkirk (1987) and which is given in (19).

$$
\begin{aligned}
& \text { WRAP-XP } \\
& \text { 'Each XP is contained in a phonological phrase.' }
\end{aligned}
$$

In contrast to the alignment constraints in (18), the constraint in (19) only ensures that every XP is contained in one Phonological Phrase (PP). One effect of the constraint in (19) is that it reduces prosodic structure. Truckenbrodt $(1995,1999)$ shows that the constraint in (19) exists besides edge alignment as proposed by Selkirk, and that its relation to the alignment constraints can explain the variation in phrasing found in several languages, including Kimatuumbi and Chichewa.

\section{Intonation Phrases}

Intonation Phrases are often excluded in the theory of the phonology-syntax interface as they are supposed to be subject to semantic well-formedness conditions rather than to 
conditions based on surface syntactic structure (Selkirk 1984: 5.4., Selkirk 1986: 385). It is still an open and "theoretically interesting question as to whether and how the formation of intonation phrases is sensitive to syntactic information" (Truckenbrodt 2005: 274). However, Intonation Phrases arguably show syntactic characteristics. According to Downing (1970), Intonation Phrases are co-extensive with root clauses whereby the root clause is a CP that is not embedded inside of a higher clause. Parenthetical material, which includes appositives and nonrestrictive relatives, is preceded and followed by Intonation Phrase breaks (Selkirk 1978, 1984, Nespor \& Vogel 1986). For English, this has been shown by the placement of (obligatory) pauses. Work on Italian supports this view because left- and right-dislocated topics form their own Intonation Phrase in Italian, which can be shown by the application of IP-specific phonological rules (Frascarelli 2000).

Observations such as the ones made by Downing (1970) for English and Frascarelli (2000) for Italian suggest a WRAP-constraint that applies at the level of the Intonation Phrase. This constraint is given in (20).

$$
\begin{aligned}
& \text { WRAP-CP (Truckenbrodt 2005) } \\
& \text { 'Each CP is contained in a single Intonation Phrase.' }
\end{aligned}
$$

This constraint yields a parse that wraps the $\mathrm{CP}$ into one Intonation Phrase. It is selfevident that, contrary to the WRAP-XP constraint, the WRAP-CP constraint is not subject to the Lexical Category Condition (LCC, (18)), as it explicitly refers to functional syntactic structure.

Truckenbrodt (2005) on his work on Intonation Phrase boundaries in German argues that the universal theory of edge-alignment proposed by Selkirk (1996) is to be extended to the relation between clauses and Intonation Phrases. Parallel to the ALIGN-XP constraint in (17), he proposes the ALIGN-CP constraint in (21).

Align-CP = ALIGN(CP, R; I, R), following Truckenbrodt (2005)

'The right edge of a $\mathrm{CP}$ must coincide with the right edge of an intonation phrase.'

Based on the phenomenon of upstep in German, Truckenbrodt (2005) motivates the constraint in (21) for German. Upstep (a process similar to reset, but which appears clausefinally instead of clause-initially) occurs at the right edge of an Intonation Phrase and is therefore a diagnostics for IP-boundaries in German. A right edge of an Intonation Phrase is found at the right edge of clauses, including embedded clauses, as shown in (22-a-c). However, indication for an IP-boundary is not found preceding medial left edges of clauses, as in (22-c, d). The word containing the upstepped syllable is marked by bold capitals in the examples.

IP-boundaries in German (Truckenbrodt 2005)

a. [Die Lola und die Manu wollen der Lena im November MARONEN geben $]_{C P}$ [und der Werner will der Hannelore das Leinen weben. $]_{C P}$ 'Lola and Manu want to give chestnuts to Lena in November, and Werner wants to weave linen for Hannelore.' 
b. [[Dass die Lehrerin dem Lehrer eine WARNUNG geben will $]_{C P}$ hat die Hannelore gewundert. $]_{C P}$

'That the (female) teacher wants to give the teacher a warning, surprised Hannelore.'

c. [Die Lola hat dem Mann, [der einem Maurer einen LöWEN gemalt hat $]_{C P}$, ein Lob gegeben. $]_{C P}$

'Lola paid the man who drew a lion for the bricklayer a compliment .'

d. [Der Werner hat dem Maler gesagt, [dass er der Lola das Weben zeigen will. $\left.]_{C P}\right]_{C P}$

(no upstep)

'Werner told the bricklayer that he wants to show Lola how to weave.'

The asymmetry of edge alignment in the phrasing of embedded clauses cannot be captured by a symmetric constraint such as WRAP-CP in (20). Only alignment constraints as (21), which are parameterized for one specific edge, render the observable asymmetric phrasing.

\subsubsection{Describing the domain}

For Northern Sotho, penultimate lengthening and the interaction of the finality restriction and high tone spread allow a description of the syntactic domain to which these processes refer to.

\section{Transitive structures}

The phonological rules indicate that in basic word order (SVO) the verb is phrased together with postverbal elements into one prosodic domain. The data in (23) show that the verb is not followed by a phrase-boundary. The spread of the verb stem-initial syllable to the succeeding syllable (HTS) and the absence of lengthening on the penultimate syllable of the verb are indicative of this analysis. Consequently, the verb and following constituents form one unit. This holds irrespective of the syntactic status of the following constituent. In (23-a) it is an object that is phrased together with the verb, in (23-b, c) it is an adverb. ${ }^{4}$

(23) Phrasing in transitive structures in Northern Sotho
a. (ke thúšá mo-sá:di) $)_{I P}$
1 help CL1-woman
'I am helping the woman.'
b. (ke šómá polase:-ng) $)_{I P}$
1 work CL9.farm-LOC
'I am working at the farm.'
c. (ke bóná gagóo:lo) $)_{I P}$
1 see well
'I am seeing well.'

\footnotetext{
${ }^{4}$ Admittedly, the adjunct status of the locative in (23-b) might be more controversial than that of the modal in (23-c). However, I did not find any evidence for a phrase-boundary between the verb and a following constituent in normal declarative structure.
} 
A conjoint phrasing for the verb and the following object, as in (23-a), has been reported for all Bantu languages cited in this section. Also cross-linguistically, it is not surprising to find a (syntactically and) prosodically close relationship between the verb and the following object.

Especially noteworthy, therefore, seems the similar, prosodically close relationship between the verb and a following adverb in Northern Sotho, as in (23-b,c). The following diagrams illustrate the similar prosodic behavior of immediately postverbal constituents independent of their grammatical function. Penultimate lengthening and high tone spread are again taken as diagnostic. The utterances in (24) have been investigated for this purpose.
a. Verb-object sequence
(i) Ke mémá mo-hú:mi.
1 invite CL1-rich.man
'I invite the rich man.'
(ii) Ke rwálá mo-rwá:lo.
1 carry CL3-load
'I am carrying load.'
b. Verb-adverb sequence
(i) Ke bíná mo-nyánye:-ng.
1 dance CL3-party-LOC
'I am dancing at the party.'
(ii) Ke bóá mo-lále:-ng.
1 return CL3-old.field-LOC
'I am returning from the field.'

Note that (24-a) and (24-b) differ in the number of syllables, as the locative suffix in (24-b) is syllabic. This is mirrored in the diagrams below, but does not influence the finding. As in diagram 2, the disyllabic verb used in the sentences is high-toned.

Diagram 5 shows the course of the fundamental frequency over an utterance for two speakers of Sepedi. For each speaker, the dotted line represents the verb-object sequence, (24-a), and the solid line represents the verb-adverb sequence, (24-b). The values represent the average $\mathrm{F} 0$ of the vowels from two comparable utterances each. With respect to F0, we find a parallel contour in verb-object and verb-adverb sequences. The pitch starts rising on the verbstem initial syllable and continues through the second syllable of the verb stem. ${ }^{5}$ After the high-toned verb, the pitch drops on the object or adverb.

Diagram 5: F0 in verb-object/adverb sequences
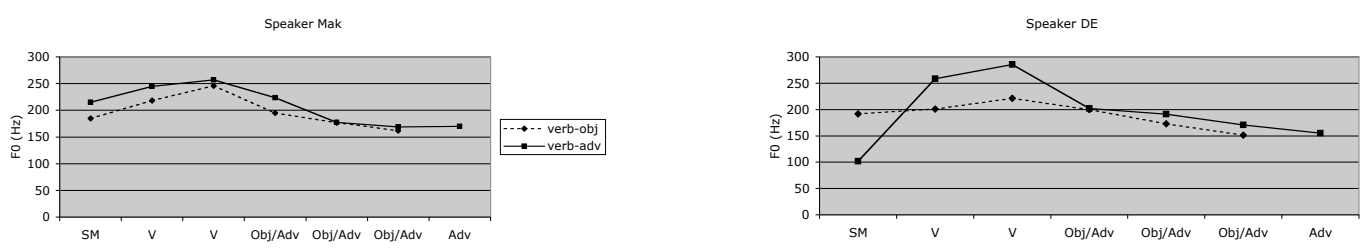

\footnotetext{
${ }^{5}$ Differences in the realization of the vowel that forms part of the subject marker ke have different origins and can be neglected here.
} 
With respect to the raised overall pitch of the verb in the verb-adverb sequence for speaker DE, I have not found it reported for any other Bantu language that the realized overall pitch height of the verb depends on the grammatical function of the constituent that follows. The raised overall contour for verb-adverb sequences needs more investigation in order to safely conclude that it is an artifact due to the small number of utterances that went into the calculation of the average.

Diagram 6 shows the average duration of the syllables taken from the same utterances. In order to allow comparability, the duration has been calculated as relative duration of the syllable in relation to the utterance. The only syllable that emerges as distinctively lengthened in comparison to the other syllables is the penultimate syllable, both in the verb-object and in the verb-adverb sequence. No significant differences emerge on the second and third syllable that belong to the verb.

Diagram 6: Duration in verb-object/adverb sequences
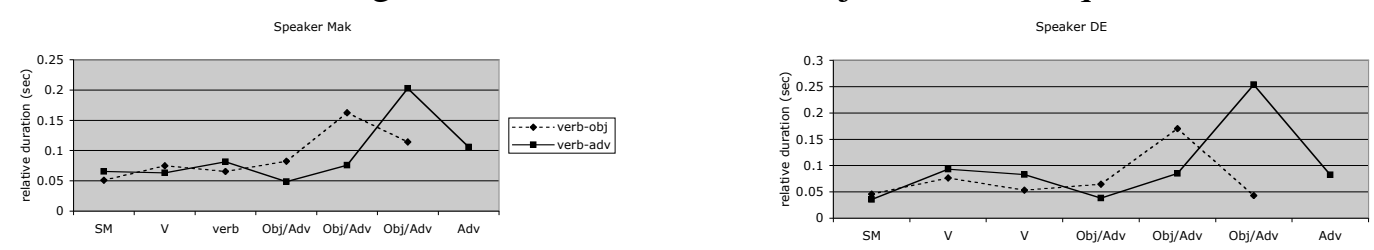

A parallel behavior with respect to the phrasing of verb-adverb sequences has been reported for Kinyambo (Bickmore 1990). Also in Kinyambo, a verb is phrased together with the succeeding constituent independent of its grammatical function.

\section{Ditransitive structures}

In a more complex postverbal structure, as in (25), there is no indication for phrase boundaries either, as is shown in (25-a) for double object constructions, in (25-b) for object-temporal adverbial sequences, in (25-c) for object-local adverbial sequences, and in (25-d) for object-modal adverbial sequences. In all examples in (25), the absence of lengthening on the penultimate syllable of the first postverbal constituent as well as high tone spread from the medial to the final syllable of the first object (thereby showing the phrase-medial pattern) suggest that there is no phrase-break intervening between the first and second postverbal constituent.

(25) Phrasing in ditransitive structures in Northern Sotho
a. Ke fá mo-góló di-apa:ro.
1 give CL1-brother CL8-clothes
'I give the brother clothes.'
b. Ke bóná mo-sádí mo-séga:ré.
1 see CL1-woman CL3-midday
'I see the woman at midday.'
c. Ke bóná mo-lámó toropo:-ng.
1 see CL1-brother.in.law CL9.town-LOC
'I see the brother-in-law in town.'


d. Ke bóná malómé ku:du.

I see CL1.uncle much

'I see the uncle a lot.'

The auditory impression of HTS from the medial to the final syllable of the first object is illustrated by the average F0-value from the two utterances in (26), pronounced by two speakers.
a. Ke fá mo-góló di-apa:ro.
1 give CL1-brother CL8-clothes
'I give the brother clothes.'
b. Ke fá mo-sádí di-apa:ro.
1 give CL1-woman CL8-clothes
'I give the woman clothes.'

Diagram 7 shows that on the final syllable following the medial, underlyingly high-toned syllable of the first object, the pitch does not fall as expected according to normal downdrift, but creates a slight plateau instead. This manipulation of downdrift is interpreted as evidence for HTS within the immediately postverbal object.

\section{Diagram 7: HTS phrase-medially}

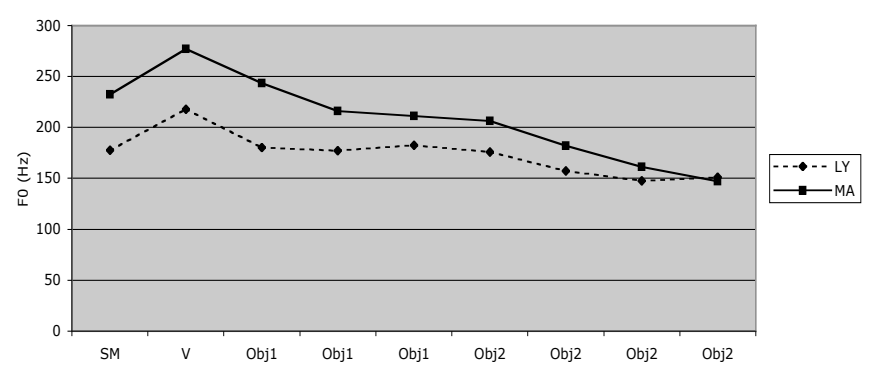

The phrasing of two objects into one prosodic constituents has also been reported for Chichewa (Kanerva 1990), Kinyambo (Bickmore 1990) and Haya (Byarushengo et al. 1976). That the phrasal incorporation extends to all postverbal constituents independent of their grammatical functions, i.e. also to postverbal object-adverb sequences, has also been reported for Kinyambo (Bickmore 1990).

\section{Subject}

The lack of penultimate lengthening on the preverbal subject and the occurrence of HTS suggests that no phrase boundary follows the subject in Northern Sotho, as otherwise the finality restriction would have applied and made the subject-final syllable exempt from tone spread.

The occurrence of HTS is illustrated by the single values and the average F0-value for the utterances in (27) pronounced by one speaker. 
Phrasing of subjects in Northern Sotho

a. (mo-lámó !ó tla gạ:e) $)_{I P}$

CL1-brother CL1 come CL9.home

'The brother is coming home.'

whereby the subject ranges over malóme-'uncle', molámo- 'brother-in-law', morwédi- 'daughter' and mosádi- 'woman'

As shown in diagram 8, the high tone of the subject spreads onto the following syllable as indicated by the raised F0-value. The subject marker is high-toned. Its absolute F0-value is lower than that of the preceding subject, which suggests a downstep (marked by an exclamation mark in (27)). The subject marker spreads its high tone onto the following toneless verb, creating an F0-plateau. The occurrence of HTS is expected because subject marker and verb can be argued to form one phonological word. The high tone on the following locative noun phrase is also at a lower pitch level, again suggesting downstep of adjacent high tones.

Diagram 8: Phrasing of the subject: HTS phrase-medially

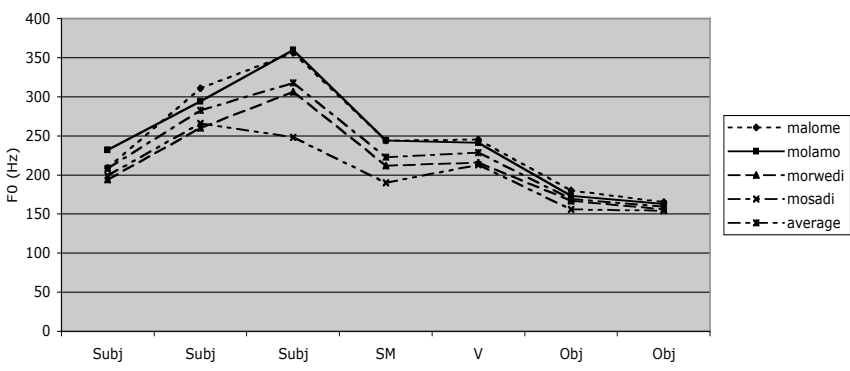

When the subject is a full noun phrase, the absence of lengthening on the penultimate syllable of the subject and the occurrence of high tone spread on the subject constituent suggests that the subject is phrased together with the verb into one prosodic constituent. Further indication for this analysis is the presence of downstep on the high-toned subject marker which follows the subject constituent in basic word order. A pause after the subject is only optional.

The phrasing of the subject within a separate prosodic domain in Northern Sotho deviates from what is found in Chichewa (Kanerva 1990), Tsonga (Kisseberth 1994), and Chi Mwi:ni (Kisseberth \& Abasheikh 1974) a.o., where the subject is phrased separately from the verb.

\section{Right-dislocated elements}

Right dislocation structures show prosodic differences to SVO structures. The sentences in (28) repeat examples for right-dislocated objects in (28-a) and adverbials in (28-b).

a. (i) (ke a mo thú:ša $)_{I P}$ (mo-kgala:bje) $)_{I P}$

1 -A- CL1 help CL1-old.man

Lit. 'I am helping him, the old man.' 


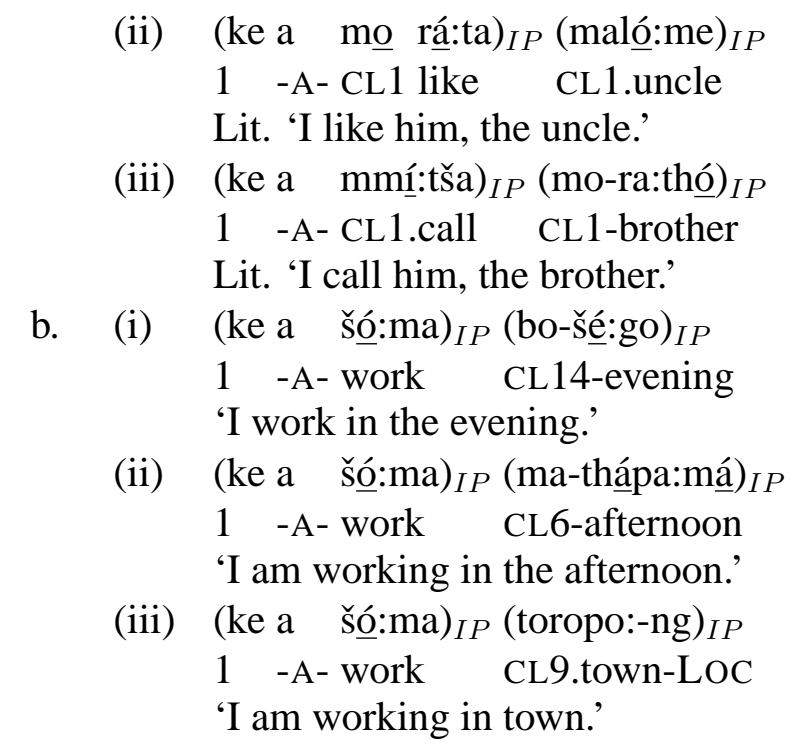

Apart from the obvious changes in syntax (insertion of object marker and Present Tense $-a$-, see chapter 1), the following prosodic changes can be observed: There is a pause before the right-dislocated object or adverbial, accompanied by a lengthened penultimate syllable on the verb. ${ }^{6}$

Apart from pause and lengthening, there is a systematic tonal distinction between basic word order and right dislocation. The verb does not show the HH tonal pattern but rather shows a HL tone pattern. This provides evidence for the analysis that the verb is followed by a phrase boundary. It is exactly the phrase boundary to which the nonfinality restriction is sensitive to. Thereby the final syllable of the verb is exempt from spreading and surfaces with a low tone rather than with a high tone. Comparable behavior has been observed for Chichewa (Bresnan \& Mchombo 1987) and has been evaluated as evidence for the syntactic structure.

In Northern Sotho, the same observations apply for right-dislocated subjects. ${ }^{7}$ Intonationally, there is again an optional pause before the right-dislocated subject accompanied by a lengthened penultimate syllable on the preceding constituent, which is a verb in (29-a) and an object in (29-b). Furthermore, HTS does not occur on the constituent preceding the dislocated subject. This observation can be explained by the application of the finality restriction in this environment.

Right dislocation of the subject in Northern Sotho
a. Ó a šó:ma mo:-nna.
CL1 -A- work CL1-man
Lit. 'He is working, the man.'
b. Bá thúšśá maló:me, ba-kgala:bje.
CL2 help CL1.uncle CL2-old.man
Lit. 'They help the uncle, the old men.'

\footnotetext{
${ }^{6}$ Pause and degree of lengthening seem to be subject to variation. Some speakers do not pause and do not lengthen the utterance-internal penultimate syllable as much as the utterance-final. The variation might be influenced by speech tempo and idiolect.
} 
The phrasing of right-dislocated constituents as separate from the rest of the clause in Northern Sotho is found for other Bantu languages like Chichewa (Kanerva 1990) and Haya (Byarushengo et al. 1976) as well.

\section{Left-dislocated elements}

With respect to left-dislocated elements, the absence of lengthening and the occurrence of HTS to the word-final syllable of the preposed constituent suggests that there is no separation of the left-dislocated constituent from the following subject. This has been reported for Southern Sotho (Khoali 1991: 68, ex. (66)) and is also true for Northern Sotho, as shown in (30).

Left dislocation in Northern Sotho
a. (mo-sádí ke a mmó:na) $)_{I P}$
CL1-woman 1 -A- CL1.see
Lit. 'The woman, I see her.'
b. (malómé ke a mmó:na) $I P$
CL1.uncle 1 -A- CL1.see
Lit. 'The uncle, I see him.'
c. (bošégó ke a šó:ma) $)_{I P}$
CL14-evening 1 -A- work
Lit. 'In the evening, I am working.'

The data in (30) show that there is no phrase-boundary before a left-dislocated constituent. There is further evidence that preverbal constituents are treated alike, independent of their syntactic structure. Northern Sotho shows the lexically identical structures given in (31).
Ambiguous structures (only underlying tones are given)
a. Ba-sádi, bá a bá thú:ša.
CL2-woman CL2 -a- CL2 help
'The women are helping them.'
b. Ba-sádi, bá a bá thú:ša. CL2-woman CL2 -A- CL2 help
'They are helping the women.'

In the example in (31-a), the noun phrase basadi is the subject of the sentence that agrees with the verb, in (31-b) it is a preposed object that also agrees with the verb. These ambiguous sentences can be construed productively. In order for them to be appropriate, they need a specific discourse context. This is given in (32).

\footnotetext{
${ }^{7}$ These findings on the phrasing of the right-dislocated subject are in contrast to Khoali (1991: 61) who reports no separate phrase boundary for right-dislocated subjects in Southern Sotho.

(i) Right-dislocated subjects in Southern Sotho (Khoali 1991: 61)

a. E rátá ho biná póódi.

CL9 like CL15 sing CL9.goat

Lit. 'It likes to sing, the goat.'
} 
(32) Ambiguous structures

a. (i) Context: 'What are the women doing to the men?' ('men' = ba-nna, class 2)

(ii) Ba-sadi $_{i} \quad \mathrm{ba}_{i}$ a $\mathrm{ba}_{j}$ thuša.

CL2-woman CL2 -A- CL2 help

'The women are helping them.'

b. (i) Context: 'What are the men doing to THE WOMEN?' (not to the children)

(ii) Ba-sadi $_{i} \quad \mathrm{ba}_{j}$ a $\mathrm{ba}_{i}$ thuša.

CL2-woman CL2 -A- CL2 help

'They are helping the women.'

The pronunciation of these sentences in the contexts given in (32) was recorded from three native speakers and played back to other native speakers with the task to assign each of the sentences one of the meanings. The perception task was carried out in order to test if subject constituents, (32-a), and left-dislocated objects, (32-b), are indeed not differentiated suprasegmentally, as suggested by the auditory impression transcribed above. The informants' judgments suggest that preposed constituents are indeed not differentiated prosodically independent of their syntactic status. The prosodic realization of the structures is shown in (33-a). When informants became aware of the difference between the sentences while producing them, they sometimes used different prosody. However, this alternative prosody was perceived as a third syntactic structure by other informants. The alternative structure is given in (33-b).
a. Ba-sádí, bá a ba thú:ša.
'The women are helping them.', 'They are helping the women.'
b. Ba-sáa(:)di, bá a bạ thú:ša.
CL2-woman CL2 -A- CL2 help
'Women! They are helping them.'

The preverbal constituent in sentence (33-b) shows a vocative.

The phrasing of left-dislocated elements together with following constituents is different from what has been reported for languages like Chichewa (Kanerva 1990), Chi Mwi:ni (Kisseberth \& Abasheikh 1974), Tsonga (Kisseberth 1994) and Chizigula (Kenstowicz \& Kisseberth 1990, though only for preposed objects). However, also for Haya (Byarushengo et al. 1976) and for adverbs in Chizigula (Kenstowicz \& Kisseberth 1990), the phrasal incorporation of left-dislocated elements has been observed.

\section{Summary}

The domain to which the phonological processes in (2) give evidence in Northern Sotho is bigger than the phonological word, as both penultimate lengthening and the finality restriction do not occur at the edge of every phonological word. The domain in question also extends a maximal projection, since both penultimate lengthening and the finality restriction do not occur at the edge of every maximal projection, but include e.g. both the direct object and the indirect object. However, the prosodic domain is not as big as a whole sentence, as right-dislocated constituents are phrased separately. 
Again, variation is found across Bantu languages with respect to the phrasing of the syntactic constellations treated here. Table 5 summarizes the generalizations that can be drawn from the literature. ${ }^{8}$

Table 5: Phrasing in Bantu languages

\begin{tabular}{|l|l|}
\hline \hline (S) (VO) & (SVO) \\
\hline Chi Mwi:ni, Tsonga, Chichewa & Haya, Northern Sotho, Kinyambo \\
\hline \hline$(\mathbf{V})(\mathbf{O})$ & $(\mathbf{V O})$ \\
\hline- & $\begin{array}{l}\text { Chi Mwi:ni, Tsonga, } \\
\text { Chichewa, Northern Sotho, Kinyambo }\end{array}$ \\
\hline \hline (VO) (O) & (VOO) \\
\hline Chi Mwi:ni, Kimatuumbi & $\begin{array}{l}\text { Chichewa, Haya, Northern Sotho, } \\
\text { Kinyambo }\end{array}$ \\
\hline \hline (SM OM V) (O) & (SM OM V O) \\
\hline Haya, Chichewa, & - \\
Northern Sotho, Kinyambo & \\
\hline \hline (XP) (S V) & (XP S V ) \\
\hline Tsonga, Chichewa, Chi Mwi:ni, Chizigula & Haya, Northern Sotho, Chizigula \\
\hline
\end{tabular}

The following generalizations can be drawn from table 5: Whereas there is variation with respect to the phrasing of preverbal constituents and VP-internal postverbal constituents, all languages behave similarly with respect to the phrasing of VO-sequences and rightdislocated objects. Whereas the former sequence is always contained within one prosodic phrase, the latter is always separated by a phrase-boundary.

There is no consensus as to which domain the boundaries cited above refer to. The studies on Chi Mwi:ni (Kisseberth \& Abasheikh 1974) and Haya (Byarushengo et al. 1976) do not designate the prosodic constituent, as they appear before work by Selkirk (1980, 1986) and Nespor \& Vogel (1986) established the Prosodic Hierarchy. Working within the framework of Optimal Domain Theory (ODT), the work on Tsonga (Kisseberth 1994) names the domains according to the processes that refer to it. Further work is needed to investigate in how far they can be related to the Prosodic Hierarchy. The original work on Kimatuumbi (Odden 1987) does not relate the phonological processes to prosodic constituents, but relates them directly to syntactic structure. However, the re-analysis in Truckenbrodt $(1995,1999)$ has argued both for Kimatuumbi and Chichewa to relate the prosodic constituent in question to the Phonological Phrase. Also the work on Kinyambo (Bickmore 1990) relates the domains in question to the Phonological Phrase, although this meets some conceptual problems that will be discussed below. In the work on Chizigula (Kenstowicz \& Kisseberth 1990), the domain is not named, but it is the only prosodic domain above word-level that is discussed in the study.

\footnotetext{
${ }^{8}$ The references are the following: Kisseberth \& Abasheikh (1974) for Chi Mwi:ni, Kisseberth (1994) for Tsonga, Byarushengo et al. (1976) for Haya, Kanerva (1990) for Chichewa, Truckenbrodt (1995) for Kimatuumbi, Kenstowicz \& Kisseberth (1990) for Chizigula, Bickmore (1990) for Kinyambo.

${ }^{10}$ Preposed objects are phrased separately.

${ }^{10}$ Preposed adverbials are phrased together with the following sentence.
} 
The 'wide' phrasing in Northern Sotho and Haya (two languages that, by the way, behave similarly with respect to phrasing) could be argued to refer to a level of phrasing higher than the 'narrow' phrasing found in the other languages. However, as illustrated earlier in this chapter, no evidence for smaller phrases could be found in Northern Sotho. The following section will discuss to which constituent the established processes refer to in Northern Sotho by evaluating cross-linguistic characteristics of the phrases in question.

\subsubsection{Determining the constituent}

As mentioned in section 3.3.1, there are three prosodic levels in the Prosodic Hierarchy (Selkirk 1980, 1986, Nespor \& Vogel 1986) that are above the Phonological Word and that are therefore of relevance for the question to what prosodic constituent the suprasegmental rules in Northern Sotho relate to: the Phonological Phrase (PP), the Intonation Phrase (IP), or the Utterance Phrase (UP). The Utterance Phrase is excluded as domain in question for the phonological rules in (2), as the data in have shown that the domain can be smaller than the utterance.

The last section has shown that the relevant prosodic domain is by far larger than a morphosyntactic XP. This is an argument against analyzing the relevant prosodic domain as the Phonological Phrase, because Phonological Phrases are argued to be co-extensive with lexical syntactic XPs. This objection is valid for any work grouping a string of more than two syntactic XPs into one Phonological Phrase (e.g. Jokweni 1995 for Xhosa; Truckenbrodt 1995, 1999 for Chichewa; Bickmore 1990 for Kinyambo). It has been argued in the literature, however, that there are instances where two syntactic XPs are indeed phrased together. The constraint WRAP-XP introduced in section 3.3.1 has exactly the effect of phrasing a sequence of two XPs into one prosodic phrase. The constraint is repeated in (34).

WRAP-XP (Truckenbrodt 1995: 9)

'Each syntactic XP must be contained in a Phonological Phrase.'

In applying (34) to the syntactic VP, the constraint captures the observation that in Chichewa for example, two postverbal objects in a ditransitive construction are phrased into one Phonological Phrase. However, even a constraint like WRAP-XP cannot capture the phrasing observed in Northern Sotho, even if it allows the Phonological Phrase to contain more than one maximal syntactic projection. This is for two reasons: On the one hand, because of its definition, the constraint in (34) does not capture the phrasal incorporation of adjoined phrases. On the other hand, its economy effect of phrase reduction is limited to lexical syntactic phrases and crucially does not extend to functional syntactic phrases. The two arguments will be briefly outlined in turn.

In Northern Sotho, not only objects in ditransitive constructions are phrased into one phrase, but also adverbs are phrased together with the verb, as shown in (24). Syntactically, adverbs are assumed to be adjoined to the VP as they are not complements of the verb. The question therefore arises which of the two VP-nodes in an adjunction structure is relevant for the constraint in (34): the higher node containing the adverb, or the lower node, containing only the complements of the respective verb? In answering this question, I follow Truckenbrodt's argumentation $(1995,1999)$ that WRAP-XP is defined as making 
reference to syntactic categories and not to syntactic segments. Thereby, this constraint behaves like constraints referring to the syntax-phonology mapping more generally. In an adjunction structure, each VP node represents a syntactic segment. The category VP dominates all and only the material dominated by both its VP segments, hence the material under the lowest VP node. Consequently, the constraint in (34) makes reference to the lower VP node only, and VP-adjuncts are not captured by it. This prediction is contrary to the phrasing facts observed in Northern Sotho.

Furthermore, the constraint WRAP-XP in (34) has been argued to be subject to the Lexical Category Condition in (18), which states that mapping constraints only apply to lexical syntactic phrases. Therefore, the phrasal incorporation of the subject in Northern Sotho cannot be accounted for by the WRAP-constraint in (34), because the preverbal subject, being in SpecIP, is within a functional syntactic phrase. Consequently, the Phonological Phrase is not the relevant prosodic domain in Northern Sotho.

Instead, the data from Northern Sotho strongly suggest that there is an affinity of the domain in question with the root clause. Early work on English argued that root clauses, but not embedded clauses, are separated by obligatory pauses. Pauses have been interpreted as suprasegmental cues to Intonation Phrase boundaries (Downing 1970, Nespor $\&$ Vogel 1986). Also the edges of parentheticals and appositive relative clauses are pronounced with pauses, and are therefore also argued to relate to Intonation Phrases. The fact that the preverbal subject is phrased together with the verb and the separate phrasing of right-dislocated constituents in Northern Sotho fulfills the requirements for Intonation Phrases. Therefore, in the next section the phrasing algorithm will be derived relating syntactic structure to Intonation Phrases.

Data concerning phonetic cues to Intonation Phrases in Bantu are available from work on the languages Haya and Chichewa. In Haya, as in English, obligatory pauses can be related to domains of Intonation Phrases (Byarushengo et al. 1976). In Chichewa, intonational boundary tones, IP-final lengthening (which occurs at a differing degree from PP-final lengthening) and downdrift within IPs, or rather reset at IP-boundaries, indicate edges of Intonation Phrases (Kanerva 1990: 140).

There are two aspects that are noteworthy when relating the phonological processes to Intonation phrases in Northern Sotho. First, it is interesting to note, that the same phonological processes such as tone sandhi and lengthening obviously make reference to different prosodic domains within the same language family (Bantu). That the same process can refer to different layers of the prosodic hierarchy in different languages, has emerged from the literature. One example is the boundary tone which is argued to appear at Intermediate and Intonation Phrase boundaries in English but not at Accentual Phrase boundaries. In Japanese, a boundary tone also appears at Accentual Phrase boundaries (Beckman \& Pierrehumbert 1986). Another example is the process of reset which is argued to appear at phrase boundaries that are aligned to XPs in Japanese (Selkirk \& Tateishi 1991, Phonological Phrases in Truckenbrodt's (1999) terminology), but at Intonation Phrase boundaries in German (Truckenbrodt 2005). ${ }^{11}$ Microvariation within a language family in what concerns the determination of prosodic domains both in size and hierarchical layer consequently remains a topic for further research.

A second issue is that, though the described domain meets cross-linguistic character-

\footnotetext{
${ }^{11}$ I thank Hubert Truckenbrodt for pointing out these examples to me.
} 
istics of Intonation Phrases, this means that up to now, no evidence has been found for the occurrence of Phonological Phrases in Northern Sotho. The lack of Phonological Phrases that are subject to phonological rules challenges the Strict Layering Hypothesis, which is given in (35).

Strict Layering Hypothesis (Selkirk 1984)

A prosodic constituent of rank $n$ is immediately dominated by a single constituent of rank $n+1$.

The hypothesis in (35) states that a prosodic constituent is contained in the next-higher constituent of the prosodic hierarchy. This means that a prosodic word, which shows a systematic relation to morphosyntactic words without being identical to them, is contained in a Phonological Phrase, which then is contained in an Intonation Phrase. If no evidence can be collected for the presence of the Phonological Phrase in Northern Sotho by way of phonological rules that refer to this constituent, the Strict Layering Hypothesis in (35) is challenged. Solutions are either to consider the hypothesis in (35) a generalization that can be violated, or maintain its universality and assume an abstract and empty level of Phonological Phrases in Northern Sotho. The consequences of these alternatives still need to be explored.

\subsubsection{Phrasing algorithm}

In the preceding section it has been argued that the prosodic domain to which the established phonological processes refer to is the Intonation Phrase in Northern Sotho. It has also been pointed out that the Intonation Phrase roughly relates to the root clause. This section comes back to the determination of the Intonation Phrase through syntax.

Two constraints have been introduced in section 3.3.1 that account for the insertion of Intonation Phrase boundaries in languages like English and German. These constraints are ALIGN-CP and WRAP-CP (following Truckenbrodt 2005). For Northern Sotho, the constraint from the ALIGN-family can account for the observable phrasing, which is given in $(36) .{ }^{12}$

Align (synIP, R; prosIP, R) ${ }^{13}$

'Every syntactic IP is right-aligned with a prosodic Intonation Phrase.'

\footnotetext{
${ }^{12}$ The constraint proposed in (36) resembles the one proposed in Downing $(2002,(12))$ for phonological phrasing in Haya.
}

(i) Align R (pause, IP)

'Align each pause with the right edge of IP.'

The placement of pauses in Haya roughly corresponds to syntactic CP-boundaries (Downing 2002). Although the constraint proposed in (36) is similar to (i) in its underlying idea, namely that the basic alignmentmechanism is extended to the prosodic IP-level, it differs from it in crucial aspects. The constraint proposed here follows work by Truckenbrodt (1995) and Selkirk (2004) in that first, it aligns prosodic boundaries with syntactic constituents according to universal constraints. Downing's constraint in the notation in (i) aligns prosodic cues to prosodic phrase boundaries. And second, as a consequence of this, it leaves the languagespecific realization of prosodic boundaries to a separate domain. Downing's constraint implements the language-specific prosodic cue in the formulation of the constraint. 
The constraint ALIGN-IP instead of ALIGN-CP is proposed here for reasons of consistency: Throughout the thesis the view has been followed that there is no evidence for a $\mathrm{CP}-l e v e l$ in matrix clauses in Bantu languages. It remains an empirical question of further research also in languages like German (see Truckenbrodt 2005) which functional phrase edge triggers Intonation Phrase boundaries, either CP, IP, TP, or vP.

The phrasing of root clauses into one prosodic constituent is trivially derived by the constraint in (36).

Basic word order

a. (ke thúšá mo-sáa:di) $)_{\text {prosIP }}$

1 help CL1-woman

'I am helping the woman.'

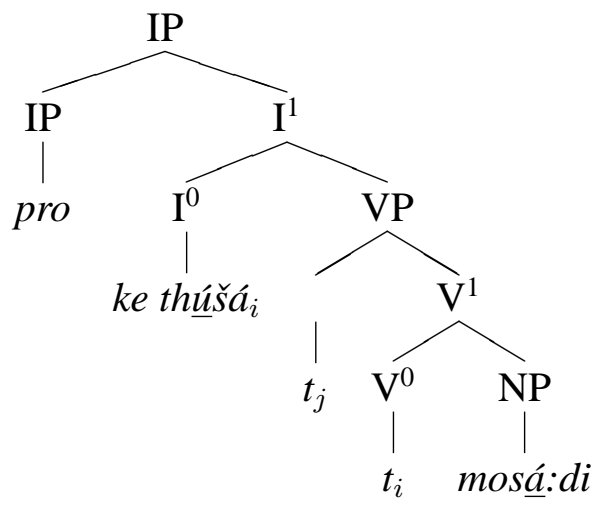

The phrasing algorithm in (36) aligns the right edge of the syntactic IP with the right edge of a prosodic IP. Left prosIP-boundaries are inserted by default. The phrasing of the whole sentence into one prosodic IP is the observed result.

After the determination of the prosodic domain by the algorithm in (36), the phonological rules that refer to this domain apply. The rule of penultimate lengthening is a domain-edge rule and in accord with this applies at the right edges of prosodic Intonation Phrases. Consequently, the penultimate syllable of the final word in the syntactic IP is lengthened. The finality restriction, which also applies at the right edges of Intonation Phrases, makes the final syllable of the prosodic IP extratonal. Therefore, the high tone from the noun stem does not spread onto the following syllable. However, the high tone from the verbstem initial syllable spreads onto the following syllable.

The constraint in (36) also derives the separate phrasing of right-dislocated constituents. Following Bresnan \& Mchombo (1987), object constituents that co-occur with an object marker on the verb are assumed to be outside the VP. ${ }^{14}$ The object constituent is therefore claimed to be right-adjoined to the IP. This is illustrated in (38). As the phrasing algorithm in (36) aligns the right edge of a syntactic IP with the right edge of a prosodic IP, one Intonation Phrase boundary is inserted following the verb, and a second one following the dislocated object.

\footnotetext{
${ }^{13}$ In order to avoid confusion, syntactic IPs will be marked as synIP and prosodic IPs as prosIP where necessary.

${ }^{14}$ For a discussion see also chapter 1 and 2. Evidence for this syntactic assumption comes from the optionality of the object NP, word order restrictions and tonal evidence. Northern Sotho furthermore provides morphological evidence (insertion of $-a$ - in the Present Tense) that supports this view.
} 
Right dislocation

a. (Ke a mo thú:ša $)_{\text {prosIP }}$ (mo-sá:di) $)_{\text {prosIP }}$
1 -a- CL1 help CL1-woman

Lit. 'I am helping her, the woman.'

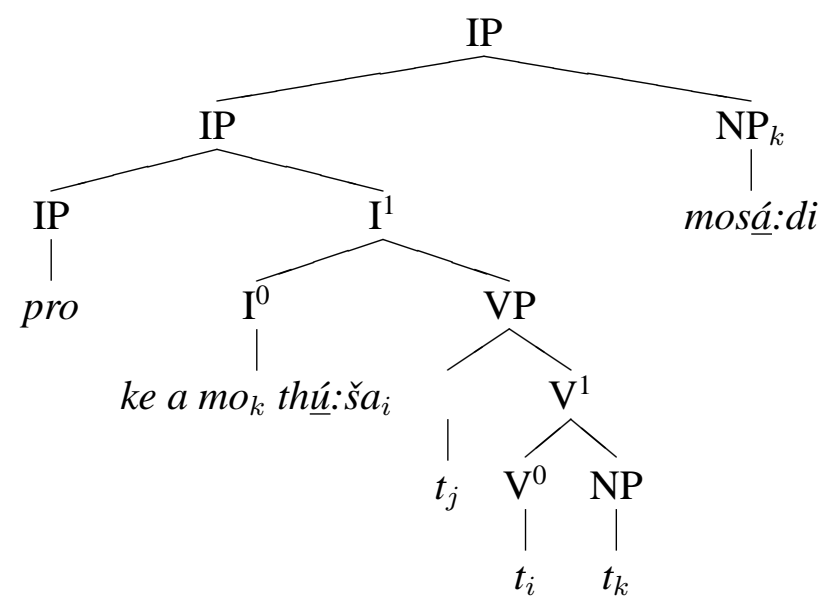

After the determination of the prosodic domain by the algorithm in (36), the phonological rules that refer to this domain apply. The rule of penultimate lengthening applies at the right edge of both prosodic IPs in (38). Consequently, the penultimate syllables of both the verb and the right-dislocated NP are lengthened. The tonal rule of HTS does not apply, neither within the verb nor within the noun, because the final syllable of both the verb and the noun fall under the finality restriction which applies at the edge of the IP. In neither case does the underlying high tone spread.

As the phrasing algorithm in (36) aligns right edges of prosodic and syntactic phrases, it makes the prediction that preverbal constituents are phrased together with the following constituents into one prosodic phrase. The prediction is made independently of the syntactic structure of the preverbal constituent. The algorithm in (36) therefore predicts that both preverbal subject NPs as well as left-dislocated constituents are phrased together with the following verb. This prediction is borne out by the data. As shown in diagram 8 and (30), both preverbal subjects and preverbal objects are phrased together with the rest of the clause.

Phrasing in Northern Sotho is therefore asymmetric in that right-dislocated constituents, but not left-dislocated constituents, appear in a separate prosodic domain. This pattern can be captured by specifying the alignment constraint to align right edges of syntactic IPs only, thereby deriving asymmetric phrasing. Next to German, Northern Sotho thereby provides further evidence for the necessity of alignment constraints at the level of Intonation Phrases.

The data on the phrasing of left-dislocated elements in Northern Sotho also give evidence for the necessity of separate prosodic structure next to syntactic structure more generally, because these two structures do not coincide. The Intonation Phrase in Northern Sotho does not coincide with the root clause. Left-dislocated constituents do not form part of the root clause and are separated from it intonationally in languages like English and German. Note that prosodic structure therefore does not provide evidence for the syntactic position of the subject in Northern Sotho (see discussion in chapters 1 and 4). 


\subsubsection{Prominence in Bantu}

The preceding sections have shown that the phonological rules make reference to the Intonation Phrase in Northern Sotho. In section 3.3.1, it has been stated that the view is followed here that higher constituents of the Prosodic Hierarchy, such as Phonological Phrase and Intonation Phrase, are also metrical domains in which prominence is assigned. This section discusses how Intonation Phrases in Northern Sotho display prominence. Starting with Doke (1927/1992), and taken up in recent work like Truckenbrodt (1995, 1999) and Samek-Lodovici (2005), length has been interpreted as prominence or stress in Bantu languages. See also the detailed overview in Downing (2004) concerning prominence in Bantu and African languages more generally.

\section{Phonetic evidence}

In intonation-only languages ${ }^{15}$ like English, German and Italian, prominence, e.g. focus, is expressed through sentential accent. The phonetic correlate of sentential accent is F0-movement (pitch accent) in intonation-only languages. Odden (1999: 192) summarizes that the most reliable acoustic correlate of stress in Bantu tone languages is greater duration. It can be argued that F0-movement and duration are not arbitrary acoustic parameters, but that both are acoustic variants of an abstract notion of prominence. This view will be motivated in this section.

With respect to pitch accent, it is straight-forward that the F0-movement is an acoustic parameter of prominence because of the direct correlation between focused constituent and pitch accent in intonation-only languages like English and German: The focused constituent bears a pitch accent (Jackendoff 1972, Selkirk 1995, and many others).

With respect to duration, word-level stress in intonation-only languages supports the view that length is a parameter of prominence. The phonetic correlates of word-level stress in languages like English and German are duration, F0, intensity and the distribution of intensity levels in the spectrum (see Heuven \& Sluijter 1996, Sluijter 1995). Studies on the perception and production of word-level stress in German have shown that duration is the most reliable phonetic cue to word-level stress in this language (Dogil \& Williams 1999, Jessen et al. 1995). As the stressed syllable of a word is the most prominent syllable within the word-domain, duration qualifies as an acoustic parameter of an abstract notion of prominence. Word-level stress and sentence-level stress interact in intonation-only languages in the sense that sentential accent is realized on the stressed syllable of a word. This relation supports considering F0-movement and duration as two aspects of the same thing, namely prominence. Ladd (1996: 48) discusses the view that is sometimes held in the literature that lexical stress (=word-level stress) is only a phonological abstraction, and the 'stressed' syllable of a word is simply the place where actual sentence-level prominence occurs if the word is prominent in a sentence.

If duration and changes in fundamental frequency are regarded acoustic correlates of prominence, then the use of F0-changes in German and English and the use of duration in Bantu languages, such as Northern Sotho, can be considered serving the same purpose from a phonetic perspective. The use of duration as an acoustic cue to prominence can be

\footnotetext{
${ }^{15}$ The term is adopted from Gussenhoven (2004: 12) and refers to languages without lexical tone.
} 
motivated by the fact that Bantu languages already use changes in fundamental frequency to indicate lexical and grammatical meaning. However, this reasoning does not apply to all tone languages, since a careful phonetic study on Chinese has shown that in a tone language F0 can indeed be modulated under focus (Xu 1999).

\section{Phonological evidence}

Apart from the phonetic motivation to consider the lengthened penultimate syllable prominent, accentual properties of Bantu languages serve as further evidence for stress in Bantu languages. The discussion of phonological evidence for prominence follows the detailed overview in Downing (1996, 2003).

The role of accent in tonology has been an issue in Bantu tonology since the 1970s, when McCawley $(1970,1978)$ characterized some Bantu languages as accentual tone languages. Accentual tone languages are languages that combine features of pitch-accent and 'pure' tone languages.

One word about the conception of stress and/or accent in Bantu tonology. Since McCawley's proposal of tone languages with accentual properties, the conception of accent has undergone striking changes in Bantu tonology (see Downing 1996: 114f for an overview). In the latest proposal before Optimality Theory, accent is redefined as metrical prominence (Goldsmith 1987, Goldsmith et al. 1989). In accentual languages, high tones and metrical prominence can interact. It should be noted, however, that although metrical structures were originally devised to explain stress patterns, metrical prominence is not equivalent to stress as known from intonation-only languages. While stress is one of the possible surface realizations of prominence, a metrically prominent syllable is defined phonologically as one which is associated with a certain hierarchical position in an abstract metrical constituent structure (Goldsmith 1987). The phonology of a given language will determine whether a metrically prominent position correlates with stress or high pitch or vowel length - or with no surface feature whatsoever in some cases.

According to McCawley (1970, 1978), pitch-accent languages and tone languages differ both in their underlying representations and in their rules. With respect to the underlying representation, tone in pitch accent languages is contrastive on every morpheme, whereas tone in tone languages is contrastive on every syllable. Therefore, in pitch-accent languages, underlying representations only need to indicate which syllable, if any, contributes an accent. With respect to phonological rules, rules in pitch-accent languages can act at long distance and apply to yield at most one accent per domain, whereas in tone languages, tonal rules may only target immediately adjacent syllables and can spread tones. This is illustrated below.

As the data in (39-a) are meant to illustrate, the only tonal contrast for verb stems in Xhosa, as in other Bantu languages (Greenberg 1948, Guthrie 1967-71), is between low-toned stems (in (i)) and high-toned stems (in (ii)). This is because only the initial syllable of verb stems contrasts for tone in Bantu languages (Kisseberth \& Odden 2003). Consequently, it needs only be specified underlyingly which syllable contributes the high tone, instead of specifying for every syllable which tone value it contributes. Furthermore, in (39-b), the verb stem high tone surfaces either on the penultimate or antepenultimate syllable of the verb stem (which is the third morpheme in the examples in (39-b)), although it is arguably the stem initial syllable that contributes the high tone. This process 
of tone shift serves as an example for an accentual rule that can act at long distance. It does not necessarily target the immediate syllable, but can show its influence over several intervening syllables.

Pitch accent properties

a. Xhosa verb - accentual representation (Cassimjee \& Kisseberth 1998: 77, $85)$

(i) ndi-ya-caciisa ndi-ya-xoleela si-ya-moneela 'I am explaining' 'I forgive'

(ii) ndi-ya-sebéénza 'we are waiting for' si-ya-sebénzeela 'I am working' ni-ya-nyinnyithékiisa 'we are working for' 'you (pl.) are making slippery'

b. Tone Shift in Xhosa - accentual rule (Cassimjee \& Kisseberth 1998: 85)

$$
\begin{array}{ll}
\text { ndi-ya-sebéénza } & \text { 'I am working' } \\
\text { si-ya-sebénzeela } & \text { 'we are working for' } \\
\text { ni-ya-nyinnyithékiisa } & \text { 'you (pl.) are making slippery' }
\end{array}
$$

In non-accentual tone languages, on the other hand, underlying representations must indicate tone for every syllable, as illustrated by the data in (40). The noun stem system of Kikuyu, (40-a), shows properties of a tonal system. ${ }^{16}$ In a two-tone system in which every syllable needs to be specified for its tonal value, eight tonal patterns are expected for three-syllabic noun stems. In Kikuyu, seven out of these eight possible patterns are attested, as shown in (40-a). With respect to phonological rules, rules in tone languages may only target immediately adjacent syllables and can spread tones. The rule of high tone spread in Emakhuwa, (40-b), illustrates a rule with tonal properties. Similarly to Northern Sotho, tone spread targets the syllable immediately adjacent to the one bearing the tone which triggers the rule.

(40) Tonal properties

a. Kikuyu noun (McCawley 1978: 127) - tonal representation

HHH hénéré 'slab'

HHL náúrò 'person with shaved head'

HLH tínòrí 'large boy not circumcised with his age-mates'

HLL

LHH rèméré 'way of cultivating'

LHL bàríitì 'anger'

LLH bòòbòòtó 'downpour'

LLL bèrèdì 'leaf-shaped spear'

b. Tone Spread in Emakhuwa (Cheng \& Kisseberth 1979) - tonal rule

inúpá... 'house'

nrérémélá ... 'eel'

nthóndóro... 'a long rope'

\footnotetext{
${ }^{16}$ Generally, verb stems in Bantu only show a contrast between high and low (or toneless) stems. Noun stems in Proto-Bantu had more tonal contrasts (Guthrie 1967-71), which have been preserved in a number of Bantu languages, a.o. Kikuyu.
} 
As already suggested by the examples in (39) and (40), Bantu languages combine characteristics of pitch-accent languages in what concerns (mostly) the underlying representation, with features of tone languages in what concerns the phonological rules (McCawley 1970, 1978, Downing 2003).

Taking together McCawley's pioneering work, subsequent studies on accentual tone languages (e.g. Hyman 1977, Odden 1988, 1999) and further work on stress-accent languages, Downing (2003) states the following properties as diagnostic of accentual tonal systems:
Accentual tonal systems
a. Culminativity
One main stress occurs in a particular domain.
b. Positional restriction
Stress demarcates major morpheme edges, i.e. stress is peripheral.
c. Tone-(stress) accent interaction
Stress conditions the location of high tones $(\mathrm{H})$.

Downing (2003) shows data from Xhosa and Chichewa that illustrate the accentual properties of these languages, both at word- and sentence-level.

At word-level, it is uncontroversial that Bantu languages show accentual properties in some areas of the tonal grammar. With respect to culminativity, in Xhosa only one $\mathrm{H}$ tone is found per verb stem in many tenses. Also the process of tone shift, illustrated in (39-b), leads to culminativity. As Kenstowicz (1993), Cassimjee \& Kisseberth (1998) and Kisseberth \& Odden (2003) show, tone shift is related to the process of tone spread which is illustrated by the Emakhuwa data in (40-b). Tone shift results instead of spread when only the rightmost syllable in the tone spread domain bears a $\mathrm{H}$ tone instead of all intervening syllables as well. Kenstowicz (1993) argues that the delinking, which accounts for tone shift, is best explained with the culminativity effect of stress accent.

With respect to positional restrictions, the data in (39-b) show that $\mathrm{H}$ tones in Xhosa occur at word edges, i.e. either on the penultimate or the antepenultimate, even though the syllable contributing the $\mathrm{H}$ tone can be several syllables away. Downing (2003) interprets the data in the sense that positional restrictions on the location of $\mathrm{H}$ tones make syllables at the right edge of the word prominent in a fashion analogous to stress-accent.

With respect to tone-accent interaction, Downing (2003) argues that it is the phrasal stress on the penultima (i.e. lengthened penultimate according to Doke 1954) that conditions the antepenultima as a target for $\mathrm{H}$ tone shift, as seen in (39). This can be shown by data in which the verb occurs phrase-medially, i.e. where the penultimate is not stressed, and where a $\mathrm{H}$ tone shifts to the penultimate. The relevant data are given in (42), cited from Downing (2003). ${ }^{17}$

\footnotetext{
${ }^{17}$ In the case of Xhosa, high tones therefore avoid the stressed syllable. Though the stress-accent interaction is clear, Downing (2003: 65) points out that more research is necessary to understand why high tones sometimes avoid stressed syllables (as in Xhosa) and sometimes are attracted to them (as in Chichewa).
} 


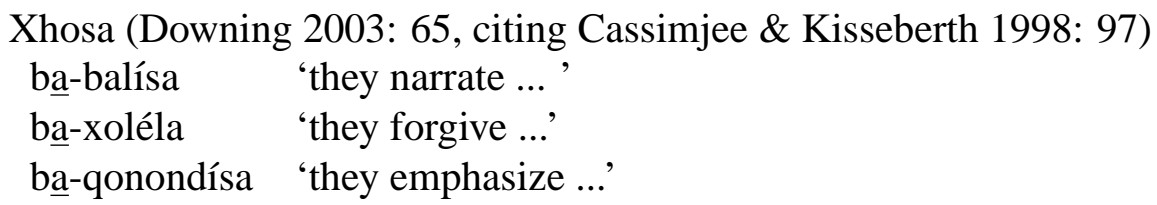

In Bantu languages stress at word-level has no direct phonetic correlate but is an abstract notion of metrical prominence. For stress at phrasal level, Downing (2003) follows Doke (1954) in interpreting the lengthened penultimate syllable as evidence for stress. Downing (2003) discusses analogies between sentential accent assignment in languages like English and phrase accent assignment in languages like Chichewa and Xhosa, and concludes:

\begin{abstract}
"Phonological phrase alignment in Chichewa and Xhosa is highly reminiscent of English sentential accent assignment [...]. Both PPs and sentential accent are cues to focus. Both target phrase-final position under broad focus and obligatorily retract to an element earlier in the phrase if it has narrow focus. The final element of the PP is assigned stress and conditions tone, properties also shared by sentential accent." (Downing 2003: 71)
\end{abstract}

One crucial difference, however, between sentential accent in English and phrasal stress in Chichewa, that only recently received attention, is the lack of culminativity in the latter (Downing 2003). As Downing (2003) points out, in the Bantu languages that use prominence for the indication of focus, the focused element is detected by paradigmatic comparison with the unmarked structure, not by syntagmatic prominence.

Properties of Bantu tone systems provide evidence for an accentual nature of these systems and allow therefore to draw a parallel to other accent systems. Through this parallel the notion of prominence can be motivated for Bantu languages as well.

However, not all Bantu languages meet the characteristics of accentual tone systems. Bantu languages that have been claimed to display pitch accent systems are Xhosa (Goldsmith et al. 1989), Luganda, Safwa, Kinga, Hibena, Kikerewe (Odden 1988), and Chichewa (Downing 2003) among others. Other Bantu languages, like Makua, Kimatuumbi and Kuria (Odden 1988) have been shown to have tonal properties. Generally, both Hyman (1989) and Odden (1999) regard the necessity of accent in Bantu languages with skepticism, partly due to the existence of tonal spreading processes in many Bantu languages that can only be analysed in terms of tones not stress. A closer examination of the Northern Sotho tone system shows that also Northern Sotho lacks accentual properties in its tone system.

With respect to culminativity, Northern Sotho is in line with all other Bantu languages that verbs have at most one high tone underlyingly. However, nouns can have more than one high tone underlyingly and therefore violate the principle of culminativity. Examples are given in (43).

(43) Non-culminativity in nouns in Northern Sotho
a. moségaré 'midday'
b. mathápamá 'afternoon'
c. gósasá 'in the morning' 
It remains to be investigated if the occurrence of two high tones in the examples in (43) can be ascribed to the morphological complexity of these nouns.

With respect to positional restrictions, Northern Sotho shows an asymmetry in the verb and noun tone system. Whereas the high tone in verbs is restricted to word-edges (it is realized on the stem initial syllable), the high tone in nouns can occur on every syllable. Examples are given in (44).

(44) Tonal properties of nouns in Northern Sotho (Ziervogel \& Mokgokong 1969)
a. HL púdi - 'goat'
b. LH kgomó $\quad$ - 'cow'
ngwaná - 'child'
c. LLH morathó - 'younger brother'
d. LHL mosádi - 'woman'
e. HLH gósasá - 'in the morning'
f. HLL phínere - 'winner'
nónwane - 'folktale'

With respect to the third parameter, namely tone-stress interaction, Northern Sotho shows that there is no preference for the high tone to align with the stressed (lengthened) syllable in nouns. In the Sepedi dialect of Northern Sotho (as well as in Setswana and Southern Sotho), HTS is strictly local to the right-adjacent syllable ${ }^{18}$ and therefore does not target a metrically stressed syllable at the right edge of the prosodic constituent. Examples has been given in preceding sections and are also given in (45) for another language of the Sotho family.

$$
\begin{aligned}
& \text { HTS in Sesotho (Mmusi 1992: 40, 63) } \\
& \text { a. go ágísa:nya 'to live in harmony' } \\
& \text { go khúrúmele:tsa 'to cover for' } \\
& \text { b. ó á le:ma 'he is ploughing' } \\
& \text { ó á leba:la 'he is forgetting' } \\
& \text { ó á kgorome:tsa 'he is pushing' }
\end{aligned}
$$

Although the high tone is not attracted to the prominent syllable in the data in (45), this does not necessarily contradict an accentual approach. One can argue that in (45), the high tone is simply realized on the underlying syllable, expressing faithfulness to the underlying form. An alternative analysis for bounded spread as in (45) also involves metrical structure, though at a different prosodic layer. According to this view (e.g. Bickmore 2003), high tones are spread within the binary foot which is constructed with the underlyingly high-toned syllable as the strong syllable.

The existence of the finality restriction has also been interpreted as evidence for accentual structure. Comparable restrictions are not found for segmental processes such as vowel harmony e.g., but only for accent in that a final syllable might not be accented.

\footnotetext{
${ }^{18}$ In two Northern Sotho dialects, the high tone aligns with the stressed (lengthened) syllable (see Monareng 1992 and Zerbian, to appear).
} 
To sum up, some arguments can be raised that contradict accentual aspects of the tone system in Northern Sotho, as e.g. the lack of clearly accentual characteristics at the word-level. Nevertheless, the assignment of lengthening at phrase-edges, the presence of the finality restriction and the nature of the phonetic cue involved speak in favor of prominence in Northern Sotho.

\title{
Assigning prominence
}

Work on intonation in European languages like English, German or Italian has brought evidence for the generalization that each syntactic XP must contain phrasal stress at the level of the Phonological Phrase. The last of these phrasal stresses is strengthened on the level of the Intonation Phrase. The former generalization is captured by the constraint in (46).

\author{
STRESS-XP (Truckenbrodt 1995, 2006) \\ 'Each XP must contain a phrasal stress.' (where 'phrasal stress' is the head of a \\ phonological phrase)
}

The second generalization, namely that the last of the phrasal stresses is enforced at the level of IP, is captured by the constraint in (47), following work by Nespor \& Vogel (1986) and Truckenbrodt $(1995,2006)$.

\section{H-I: Align (IP, R, Head(IP), R)}

'Align the right boundary of every intonational phrase with its head.'

The constraint in (47) accounts for edge-most prominence within the Intonation Phrase and captures the rightmost stress observable in languages like English, German and Italian because of its specification to the right edge.

As argued for in detail in the preceding section, the assignment of lengthening at phrase edges, the presence of the finality restriction and the phonetic cue involved speak in favor of prominence in Northern Sotho. Also in Northern Sotho, prominence is rightmost in the clause, i.e. the penultimate syllable of a clause is lengthened. As the clause-final position corresponds to the final position within a prosodic IP, prominence is rightmost in the prosodic IP. The data therefore suggest to follow the analysis proposed above, in that the constraint in (47) accounts for the observable pattern.

The constraint in (47) will be taken to be crucial for prominence assignment in Northern Sotho. In its regular allocation of lengthening to the penultimate syllable in a phrase, the Northern Sotho intonation system can be characterized as one in which sentential pitch is typically associated with a particular syllable of a phrase rather than a word. The location of the syllable to be made prominent is determined with reference to the phrase boundary. The pure regularity in the assignment of prominence in Northern Sotho is illustrated by the fact that any grammatical category can be assigned prominence, not only verbs and nouns, but also functional categories such as pronouns, as in (48-a), or even to semantically empty marker of syntactic structure, as in (48-b). 

a. Ke a mo: $[\mathrm{fa}]_{F}$.
1 -A- CL1 give
'I give (it) to him.'
b. Ke a: ja.
1 -A- eat
'I am eating.'

Furthermore, the regularity in stress assignment also accounts for the lack of culminativity across utterances in the case of right dislocation, as length is assigned to the penultimate syllable at every syntactic IP-edge.

The following confinement applies to what has just been argued: The necessity of a constraint like (46) cannot be meaningfully tested for Northern Sotho, as so far no evidence for a level of the Phonological Phrase could be gathered. The apparent lack of the Phonological Phrase-level in Northern Sotho remains an issue for further research at this point, as it also violates the Strict Layering Hypothesis that has been mentioned in (35).

Let us assume for now that there is an abstract level of Phonological Phrase to which stress is assigned according to (46), but to which (to my knowledge) no phonological rules of Northern Sotho make reference to.

\subsubsection{Summary}

This section has shown the phonological processes which are relevant at phrasal level in Northern Sotho. These are penultimate lengthening and the finality restriction which manifests itself in the blocking of HTS. Arguments have been discussed to analyse the relevant prosodic domain as the Intonation Phrase. It has been argued that the phrasing in Northern Sotho can be accounted for by a phrasing algorithm that aligns the right edge of the syntactic IP with the right edge of the prosodic IP. Furthermore, this section has argued for the lengthened penultimate syllable to be interpreted as prominent in Northern Sotho. Thereby, it follows earlier claims made for these languages which are based on phonetic evidence as well as accentual properties of the language's tone system.

Issues of further research with respect to phrasing of Northern Sotho are the investigation of further syntactic configurations which include syntactic IP-boundaries, such as conjoined (syntactic) IPs, preposed clauses and embedded relative clauses. Furthermore, it seems interesting to investigate if there is reset at IP-boundaries, similarly to what has been reported for German (Truckenbrodt 2005). Thereby, a potential systematic relation between prosodic cues and prosodic boundaries would be explored. The proposal made in this section should, of course, be extended to languages such as Haya, Kinyambo, Tsonga, and Chizigula, whose phrasing shares certain properties with Northern Sotho.

With this background on tonal and suprasegmental processes in Northern Sotho, the next section turns to the question how phrasing is exploited for the marking of focus in other Bantu languages. It motivates the detailed study on the prosodic expression of focus in Northern Sotho by reviewing the literature with respect to how Bantu tone languages make use of suprasegmental means in order to express pragmatic information. 


\subsection{Influence of focus on prosody}

\subsubsection{Introduction}

The description of the influence of focus on syntax in chapter 2 has shown that in Northern Sotho only subjects show a syntactic reflex of focus. They appear postverbally or in a cleft construction, dependent on the valency of the verb. Focused non-subject constituents appear in situ in their canonical postverbal position, as shown in (49-a). Furthermore, it has been described that a tendency can be observed to delete or pronominalize constituents that are given in discourse, as in (49-b) with respect to the object pronoun.

Postverbal object focus

a. (i) O thúša máng?

2 help who

'Who do you help?'

(ii) Ke thúǔá [mo-gó:lo] $]_{F}$.

1 help CL1-brother

'I help the BROTHER.'

b. (i) O thúušá mo-gólo néng?

2 help CL1-brother when

'When do you help the brother?'

(ii) Ke mo thúšá [mo-séga:rée $]_{F}$.

1 CL1 help CL3-midday

'I help him DURING THE DAY.'

Furthermore, it has been reported in chapter 2 that morphosyntactic reduction or deletion is by no means obligatory in Northern Sotho. Therefore, minimal pairs emerge when discourse-old constituents are not reduced morphosyntactically, as in (50-a-ii) and (50-b-ii).

Syntactic minimal pairs in Northern Sotho

a. (i) O thúšá mo-gólo néng?

2 help CL1-brother when

'When do you help the brother?'

(ii) Ke thúšśa mo-góló [mo-ségaré $]_{F}$.

1 help CL1-brother CL3-midday

'I help the brother DURING THE DAY.'

b. (i) O thúšá máng mo-ségaré?

2 help who CL3-midday

'Who do you help during the day?'

(ii) Ke thúusáa [mo-góló] $]_{F}$ mo-ségaré.

1 help CL1-brother CL3-midday

'I help THE BROTHER during the day.'

The question arises if the focused constituent is marked prosodically in minimal pairs like the two answers in (50). I refer back to chapter 1 for a general definition of grammatical marking of focus. Prosodic marking of focus in a language entails a rule that assigns an 
F-marked constituent a specific prosodic 'feature'.

English and German are familiar examples for languages that show prosodic F-marking. Pitch is used to differentiate between the equivalent sentences in (51), which differ in the information status of their constituents alone (Selkirk 1995). In (51), capitals are used to indicate an $\mathrm{H}^{*} \mathrm{~L}$ pitch accent that signals focus.

Syntactic minimal pairs in English

a. Peter ate pizza [YESTERDAY $]_{F}$.

b. Peter ate $[\mathrm{PIZZA}]_{F}$ yesterday.

The occurrence of the pitch accent can be considered prosodic F-marking as it is closely tied to the focused constituent. Generally speaking, in these languages the F-marked constituent bears a pitch accent whereby the actual placement of the pitch accent within the focused constituent is determined by a variety of factors (such as syntax and discoursestatus of constituents within the focused phrase).

Though pitch accent as the prosodic correlate is probably the best known example of prosodic marking of focus (the one that is best investigated it is without doubt), pitch accent is by no means the universal prosodic cue to focus. Detailed work on Bengali (Hayes and Lahiri 1991) has suggested that it is not pitch accent that is informative for the information structure of the sentence, but rather phonological phrasing which entails intonational changes. Examples for prosodic marking of focus are given in (52) (repeated from chapter 1, Selkirk 2004).

$$
\begin{aligned}
& \text { Cross-linguistic prosodic means of focus-marking } \\
& \text { •appearance of special tonal morpheme } \\
& \text { •appearance of default pitch accent } \\
& \text { •demarcation by a prosodic phrase edge } \\
& \text { •presence of main stress of a prosodic phrase } \\
& \text { •appearance in a higher pitch range } \\
& \text { •vowel length under main phrasal stress }
\end{aligned}
$$

The general path taken by Truckenbrodt $(1995,1999)$ and also used in Selkirk (2004) is that there is a relation between focus-marked syntactic constituents on the one hand and prosodic prominence on the other hand. All the predictable prosodic properties related to focus which are given in (52) are claimed to be derived as a consequence of phonological markedness constraints on the relation between prosodic prominence and other aspects of phonological representation. The Focus Prominence Theory (named as such in Selkirk 2004) is meant to provide an account of the diverse phonological properties that are associated with focus cross-linguistically, but also to explain the observed generalizations about focus projection and focus-related prominence within the sentence.

\subsubsection{Prosody in tone languages}

With respect to tone languages, it is discussed controversially in how far intonation, i.e. suprasegmental means in general, is used to convey discourse-pragmatic meaning. Work 
on Chinese has shown that at least some tone languages make use of intonation in addition to syntactic means in order to mark focus (Xu 1999, Xu 2004). With respect to African tone languages, studies on Eastern Bantu languages and on one Southern Bantu language have shown that focus is marked prosodically in these languages (Hyman 1990 for Kinande, Kanerva 1990 and Downing et al. 2004 for Chichewa, Jokweni 1995 for Xhosa). However, the focused constituent is not marked through pitch accent as familiar from intonation languages like English and German, but rather by changes in phonological phrasing. Focus in these languages therefore has an effect on phonological phrasing, in that further phrase boundaries are inserted ('boundary narrowing', Hyman 1999).

The examples in (53) from Chichewa illustrate this point. Among the cues to phonological phrase boundaries in Chichewa are the lack of high tones on phrase-final vowels and lengthened vowels in the penultimate syllable of phrase-final words (see Kanerva 1990 for more details on the phonological processes that motivate Phonological Phrases in Chichewa). Phonological Phrase boundaries are indicated by parentheses, focus structure is indicated by brackets. Under wide focus (as controlled for by questions), the entire VP is a single Phonological Phrase, as shown in (53-a). The same phrasing is observed for narrow focus on the sentence-final prepositional phrase in (53-b). Narrowing the focus within the sentence, as to the object in (53-c) or to the verb in (53-d), results in an increase of Phonological Phrase boundaries.

Focus phrasing in Chichewa (Kanerva 1990: 98)
a. (i) 'What did he do?'
(ii) ([anaményá nyu ${ }^{\mathrm{m}}$ bá ${ }^{\mathrm{n}}$ dí mwála $\left.]_{F}\right)_{P P}$
he.hit house with stone
'He hit the house with a stone.'
b. (i) 'What did he hit the house with?'
(ii) (anaményá nyu ${ }^{\mathrm{m}}$ bá $\left.\left[{ }^{\mathrm{n}} \text { dí mwáála }\right]_{F}\right)_{P P}$
c. (i) 'What did he hit with the rock?'
(ii) (anaményá [nyuúm $\left.\left.{ }^{\mathrm{m}} \mathrm{ba}\right]_{F}\right)_{P P}\left({ }^{\mathrm{n}} \text { dí mwáála }\right)_{P P}$
d. (i) 'What did he do to the house with the rock?'
(ii) $\left([\text { anaméenya }]_{F}\right)_{P P}\left(\text { nyuúm }{ }^{\mathrm{m}} \mathrm{ba}\right)_{P P}\left({ }^{\mathrm{n}} \text { dí mwáála }\right)_{P P}$

The data in (53) show that the focused constituent is followed by a Phonological Phrase boundary. Downing et al. (2004) describe the disruption of downdrift and pauses as a further phonetic cue to focus in Chichewa. For further details of the analysis concerning the phrasing of post-focal constituents see Kanerva (1990) and the re-analysis in Truckenbrodt $(1995,1999)$. For comparable expression of focus by suprasegmental means in Xhosa see Jokweni (1995) and the re-analysis in Zerbian (2004b).

Apart from cross-linguistic comparison with neighboring and related Bantu languages, there are two further sources of evidence that suggest suprasegmental expression of focus in Northern Sotho as well. First, intonation is used for conveying discourse-pragmatic meaning in Northern Sotho. Changes in pitch and length on the penultimate syllable distinguish declaratives from yes/no-questions in Northern Sotho and Southern Bantu languages more general (Poulos \& Louwrens 1994: 374, Jones et al. 2001a,b in a detailed phonetic study on Xhosa), as shown in (54). Independent of the lexical tone patterns of the words used in an utterance, the yes/no-question is pronounced at a higher overall 
pitch, as indicated by the arrow, and lacks the lengthened penultima.

Intonation in yes/no-questions
a. $\quad$ O dumediša di-kgarebe?
I 2 greet CL10-lady
'Are you greeting the ladies?'
b. Ee, ke dumediša di-kgare:be.
yes 1 greet CL10-lady
'Yes, I am greeting the ladies.'

Also, a non-lexical high tone on the ultimate syllable of a clause indicates continuation, as shown in (55). Though the clause-final word lefasetere is all low-toned, a high tone is pronounced on its final syllable if it is followed by a coordinated clause.

\section{Continuation rise}
a. Kgarebe e tswalela le-fasetere $H \%$ mo-kgalabje o bula le-mati . CL9.lady CL9 close CL5-window I CL1-old.man CL1 open CL5-door 'The lady closes the window, (and) the old man opens the door.'

Second, prosodic phrasing in Northern Sotho is by no means fixed. Factors such as syntactic structure (but also constituent size and branchingness) have been reported to influence phrasing in the Sotho languages (Khoali 1991). A prosodic consequence of right dislocation, discussed in chapter 2 , is that 'afterthought'-constituents are intonationally set off from the preceding nuclear clause. This is illustrated in (56), where '-' in (56-b) indicates pause.

(56) Prosodic reflexes of information structure
a. (i) Who are you helping?
(ii) (Ke thúšá mo-sá::di) ${ }_{I P}$
1 help CL1-woman
'I am helping the woman.'
b. (i) What are you doing to the woman?
(ii) (Ke a mo thú:ša $)_{I P}-(\text { mo-sá:di })_{I P}$
1 -A- CL1 help - CL1-woman
Lit. 'I am helping her, the woman.'

In comparing (56-a) to (56-b), right-dislocated elements induce a change in the tonal pattern on the preceding verb, as well as additional lengthening of the penultimate vowel of the verb. Furthermore, the verb is followed by a pause. However, the presence of the object marker on the verb in the example in (56-b) supports the view that the structure in (56-b) is determined syntactically and that the resulting intonational changes follow from the syntactic structure. The example in (56-b) therefore does not constitute a case that is of interest for the investigation in this chapter. This chapter investigates prosody as a means for the marking of focus independent of syntax. Nevertheless, intonational changes as in (56-b) deserve further research, as they are a prosodic reflex of information structure.

Variation in phrasing and intonational changes for conveying discourse-pragmatic 
meaning justify the hypothesis that suprasegmental means also play a role in postverbal in situ focus in Northern Sotho. If there is prosodic marking of focus in Northern Sotho, it is expected that suprasegmental changes can be observed, either concerning the realization of underlying tone patterns, realization of length, or overall register height.

\subsubsection{Expectation}

It has been reported for other Bantu languages that a prosodic phrase boundary is inserted to the right of the focused element (Jokweni 1995 for Xhosa, Kanerva 1990 for Chichewa). The expected phrasing differences under focus in Northern Sotho, following the existing body of research, are illustrated in (57), together with the resulting suprasegmental differences that follow from it. Only right (phonological) IP-boundaries are indicated in the examples. The sentence in (57) has the tonological structure that allows HTS to occur from the verb stem initial syllable to the verb stem final vowel. VP-focus and object focus result in 'wide phrasing', i.e. a phrase boundary is inserted after the object, as shown in (57-a,b). Therefore, HTS can occur on the verb. The final syllable of the object is lengthened as it appears in phrase-final position. The high tone on the noun cannot spread to the clause-final syllable as the finality restriction rules out a derived $\mathrm{H}$ tone on a phrase-final syllable. Under verb focus, as in (57-c), a phrase boundary is predicted after the focused verb. This results in lengthening of the penultimate syllable of the verb (in addition to the penultimate syllable of the object which is also in phrase-final position), and in blocking of HTS on the verb because of the finality restriction.

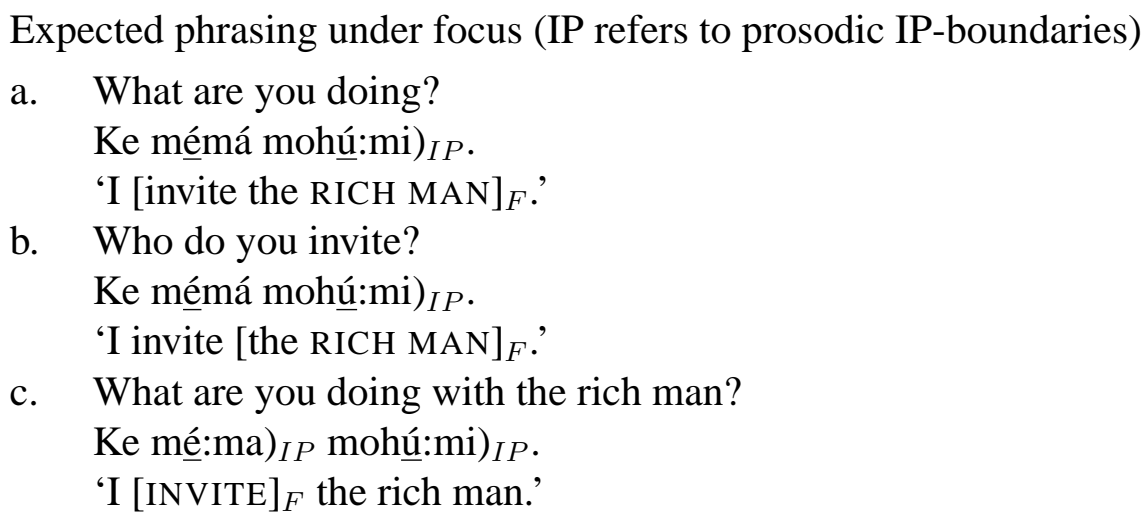

Based on the phrase-related tonological processes in Northern Sotho, a production and perception experiment has been carried out in order to determine if focus has an effect on phrasing in this language. The tonal processes described in these subsections determine the choice of the stimuli. Question/answer pairs determine the focus structure of the utterances. The design of experiment as well as the results are described in the next subsection. 


\subsection{Production study}

\subsubsection{Aim}

As in situ focus with non-subjects generates syntactic minimal pairs, the production and perception study described in this subsection aims at investigating if in situ focus is marked prosodically in Northern Sotho.

\subsubsection{Procedure}

In order to establish if there are prosodic differences between structures with VP, verb, object or adverb in situ focus, a production study was carried out with native speakers of Northern Sotho. Northern Sotho sentence pairs with different focus structures (VP, verb, object, and adverb focus) were recorded. The individual pairs consist of a trigger sentence and a target sentence. The trigger sentence is a question that determines the focus structure of the corresponding answer, the target sentence. For instance, the question $O$ dira eng? 'What are you doing?' determines that the answer will contain a VP-focus. Thereby, this study follows the underlying assumption first used in Paul (1880) and applied in experimental set ups by Gussenhoven (1983b), Oppenrieder (1989), Uhmann (1991), Birch \& Clifton (1995), Xu (1999) among others, that the focus of an utterance is controlled by a preceding question.

(58) Control for focus: Question/answer pairs match in their information structure When do you work? I work [during the day $]_{F}$.

In linguistic research, spontaneous speech is preferred to read speech. It has been reported that the intonation is not natural if subjects are asked to read a sentence, but subjects are 'reading what it says' (Gussenhoven 1983b, referring back to Brazil et al. 1980: 83). Therefore, the experiment was designed in such a way to prevent reading.

Five pairs of native speakers were involved in the experiment, being questioner and respondent respectively. Cards were prepared for the presentation of the questions and answers. The questioner read a fully spelled-out question from his/her card. The respondent was only given the missing information on his/her card and was asked to respond to the question in a natural way, making use of the information that is provided on the card. Nevertheless, the respondent was instructed to answer in a full sentence, therefore repeating all constituents even if discourse-old. Though this is not the most natural answer (discourse-old constituents are often reduced or deleted (see chapter 2)), this elicitation method is justified by the need for a controlled set-up. The focus in-situ construction with discourse-old material which is not reduced morphosyntactically occurs too rarely in running speech to allow systematic phonetic analysis ('Zipfian' problem).

The production study aimed at providing 69 question/answer pairs where the answers were of the form Ke rema morula mosegare.- 'I chop the marula tree at midday'. The question/answer pairs that were recorded can be found in the appendix. In addition, 12 sentences were filler question/answer pairs. The total number of recorded sentences for 
each speaker was $81 .{ }^{19}$

The target sentences were randomly mixed with regard to focus structure in order to prevent repetitive effects. The total set of question/answer pairs was divided into four blocks of 26 items each. In between blocks, the speakers were given a break. Eight native speakers of Sotho languages participated in the experiment. The five speakers who provided the target sentences were all speakers of the Sepedi dialect of Northern Sotho. The recordings were done in an office at the University of South Africa (UNISA) with an analogue tape recorder using a Sennheiser microphone. The recordings were digitized and converted into wav-files, which were then analysed using PRAAT.

\subsubsection{Material}

The target answers differed along two dimensions. They differed in the scope of the focus induced by the preceding question (VP-focus: 'What are you doing?', object focus: 'What do you chop at midday?', adverb focus: 'When do you chop the marula tree?', verb focus: 'What do you do with the marula tree at midday?'). This variation served the purpose to check whether a difference in focus structure resulted in a difference in prosodic structure.

The second variation concerned the tonal pattern of the verb and postverbal constituents. As research on other Bantu languages like Xhosa and Chichewa has shown, the suprasegmental means which can be expected to be used to express focus in these languages are related to tonal processes and length. The target sentences were chosen in such a way that a maximal suprasegmental contrast, i.e. not only in length which is independent of tone, but also in tonological processes could be observed if these were the means also used in Northern Sotho to communicate differences in information structure. Two tonal environments were tested. The first environment is one were HTS is affected by potential phrase boundaries that are inserted by focus. In this environment, a disyllabic high-toned verb is followed by nouns whose initial syllable is low-toned. Therefore a perceivable difference in the occurrence or non-occurrence of HTS would be predicted. The second environment is one in which OCP violations occur. Additional phrase boundaries due to focus could lead to a different resolution of the OCP-clash compared to environments without focus-induced boundaries.

For investigations of phenomena related to fundamental frequency there are furthermore independent phonetic restrictions on the use of segmental material in the target utterances. As fundamental frequency is the correlate of tone and intonation, the segmental make-up of target words or sentences has to assure that changes in fundamental frequency are indeed related to extra-phonetic facts like discourse-pragmatics. Obstruents (stops and fricatives), however, interrupt and disturb the contour of the fundamental frequency by their inherent phonetic properties. The disturbance of the fundamental frequency reveals itself in higher F0 onsets after voiceless obstruents. These disturbances are not grammatical but purely phonetic. The interruption of the fundamental frequency

\footnotetext{
${ }^{19}$ Originally, the study was designed to provide 92 question/answer pairs. Out of these, 13 question/answer pairs tested contrastive focus on the verb. They did not yield different results, but will not be taken into further consideration in this study. Also, three sets of question/answer pairs yielding a total of ten target sentences (all showing potential OCP-violations) had to be excluded as they were rejected by at least some subjects. The remaining corpus thus consisted of 69 question/answer pairs.
} 
can be a crucial factor in the investigation carried out here. Therefore, the target sentences were constructed in such a way that they contain sonorants only.

The use of sonorants was important for a second reason as well: It has been shown that there are differences in pitch peak alignment in long and short vowels. In long vowels, the pitch peak occurs at the end of the vowel. In short vowels, the pitch reaches its peak at the end of a following consonant. If this consonant is an obstruent, the pitch peak is cut off because obstruents do not have fundamental frequency. This observation has been made for Dutch (Ladd et al. 2000) and for German. The Bantu languages Chichewa and Kinyarwanda have also been reported to show a peak delay, in that the F0 peak caused by a high tone is only reached at the beginning of the following syllable (Myers 1999, 2003). As in Northern Sotho all vowels are short, there is a potential for late pitch peak alignment into the following consonant.

\subsubsection{Prosodic analysis}

A first impressionistic auditory analysis of the recordings shows prosodic differences in pronunciation only for some speakers and some sentences. Suprasegmental differences between utterances manifested themselves in pauses before or after the focused constituent, differences in pitch height on or after the focused constituent, and differences in the duration of constituents. Apparently, the existing differences between utterances in different focus structures are not related to one suprasegmental cue only. Moreover, suprasegmental cues are not always linked to the constituent in focus in an expected way, but also appear on elements not in focus.

Therefore, in a first step, a sample of the recorded data was made subject to a prosodic analysis. The aim was to investigate not only if the different focus structures were produced differently within one speaker, but also if the same focus structure was produced alike across different speakers. The basic SVO/SVAdv structure was chosen to be made subject to analysis. The reason for the decision in favor of basic SVO/SVAdv structures as compared to structures in which two constituents follow the verb, is that, if there is prosodic expression of focus, it will most clearly emerge within short sentences. In short sentences, the register size at disposal for pitch manipulations is wider ithan in long sentences. The respective sentences from the corpus are given in (59).

Sentences of prosodic analysis (underlying tones indicated only)

a. (i) Ke méma mo-húmi.

1 invite CL1-rich.man

'I invite the rich man.'

(ii) Ke rwála mo-rwálo.

1 carry CL3-load

'I am carrying load.'

b. (i) Ke bína mo-nyánye-ng.

1 dance CL3-party-LOC

'I am dancing at the party.'

(ii) Ke bóa mo-lále-ng.

1 return CL3-old.field-LOC

'I am returning from the field.' 
Though the sets are different with respect to the grammatical function of the postverbal constituent, they are identical in their phrasal and tonal make-up. It has been shown in diagrams 5 and 6 that objects and adverbs are phrased parallel in Northern Sotho. This insight is exploited here.

Moreover, all sentences in (59) contain a high-toned disyllabic verb and a following constituent that has a low-toned nominal prefix but bears a high tone on the noun stem initial syllable. This tonal environment allows HTS to occur on the verb and has been chosen for analysis for various reasons: First, the predictions based on previous research are more precise for this environment. The manipulation of downdrift that is expected in OCP contexts is less well studied (notable exception: Downing et al. 2004). Second, it has been shown that high tones are indeed manipulated at IP-boundaries in Northern Sotho. Third, the realization of high tones under focus has been reported for other Bantu languages as well. The fourth reason is a practical one. The rejection of three question/answer sets by at least some subjects led to the situation that there are not enough comparable utterances for SVO structures in the OCP context.

Although the sentences in (59-a) differ from those in (59-b) in the absolute number of syllables (remember that the locative suffix $-n g$ in (59-b) is syllabic), this difference is not crucial as the syllables of interest are the two syllables of the verb and the following nominal prefix, as laid out in the section 3.4.3.

The sounds of these utterances were segmented according to the standards laid out in the following section.

\section{Measurements}

Two phonetic parameters were measured: pitch height and duration. These two parameters are phonetic correlates of stress in intonation-only languages. ${ }^{20}$ The tonal and durational changes that are expected under phrasing differences in Bantu tone languages will also be captured by these parameters. Changes in tonal structures due to HTS or upstep will result in differences in F0, changes in penultimate lengthening due to the insertion of prosodic boundaries after focused constituents will result in longer duration of vowels. The data were segmented and labeled as follows (see Ladefoged 2001, 2003).

The target sentences contained vowels, sonorants $(/ \mathrm{m} /, / \mathrm{n} /)$, the lateral $/ 1 /$, the glides $/ \mathrm{j} /(<\mathrm{y}>)$ and $/ \mathrm{w} /$, as well as $/ \mathrm{r} /, / \mathrm{h} /$ and $<\mathrm{b}>$. The duration of vowels was measured at the positive zero crossing when the second and third formant were clearly established. Nasals were determined because of the formant around $200 \mathrm{~Hz}$ and formants around 2000-2500 $\mathrm{Hz}$ (though with lower amplitude). Often the sharp discontinuity after a vowel when lips come together or when the tongue comes up to contact the roof of the mouth, was taken as indicator for the begin of the nasal. Like nasals, the lateral also shows a formant near the base line and a formant with lower amplitude around 1000-2000 Hz. As the lateral formants have distinct locations from those of the neighboring vowels, the abrupt break

\footnotetext{
${ }^{20}$ Intensity is a further parameter of stress. In this study, intensity is left out for two reasons: first, it is the parameter that indicates stress least reliably in intonation-only languages. Second, it is the parameter that is the most sensitive to changes in the recording surrounding such as distance to the microphone and background noises that might lead the subject to speak louder. As these parameters were not controlled for (flexible distance to the microphone and no sound-proof box), it is expected that deviation in intensity values might not alone be attributed to focus.
} 
in the signal was taken as an indicator for the beginning of the lateral. Glides are difficult to separate from following vowels as they do not represent a separate sound but, as their name suggests, rather a transition into the following vowel. Therefore, /w/ and /j/ have been labeled as ending where vowel formants became stable. In Northern Sotho, $<\mathrm{r}>$ is pronounced as a trill and is therefore clearly discernible in the spectrograms. For $/ \mathrm{h} /$, noise in high frequencies was taken as an indicator of its beginning and end. Between vowels, the first two noisy formants of $/ \mathrm{h} /$ are especially prevalent. In Northern Sotho, $\langle\mathrm{b}\rangle$ is articulated as a voiced bilabial fricative, which means that it is discernible by the noise that accompanies the pronunciation of a fricative.

The recorded data were segmented and labeled into words and vowels using the annotation tools in PRAAT. A script extracted average F0 and duration for the vowels.

\section{Results}

In the following diagrams, the F0/duration values for each individual are represented in a plot. The three horizontal lines correspond to the three different focus conditions: VP focus, object focus and verb focus. The values indicated in the diagrams are average values of the respective segment over the four utterances indicated in (59). Thereby, the following comments need to be made:

Fundamental frequency is influenced by the preceding sound. Sometimes, no F0-value could be calculated for the vowel following the plosive of the subject marker. Along the same lines, it was sometimes impossible to calculate a F0-value for the final vowel of an utterance. It is made explicit when less than three values went into the calculation of the F0-values of the first and last syllable.

Because of the unequal number of syllables in (59-a) and (59-b), the fifth value in the diagrams is only calculated for the examples in (59-b) and therefore represents the average of two utterances only. The penultima and last syllable of all examples have been calculated together. This is especially important for the duration measurement, as the penultima is the lengthened syllable.

The duration values represent relative duration of the segments. Because of the unequal number of syllables in (59-a) and (59-b), the absolute duration of the segment has been divided by the absolute time of the whole utterance in order to account for differences which are not only induced by utterance length but by speech tempo etc.

Fundamental frequency In diagram 9, the F0 average for each vowel in the three different focus conditions is given for each of the five subjects separately. They are discussed below. 
Diagram 9: F0 in different focus conditions

Speaker DE
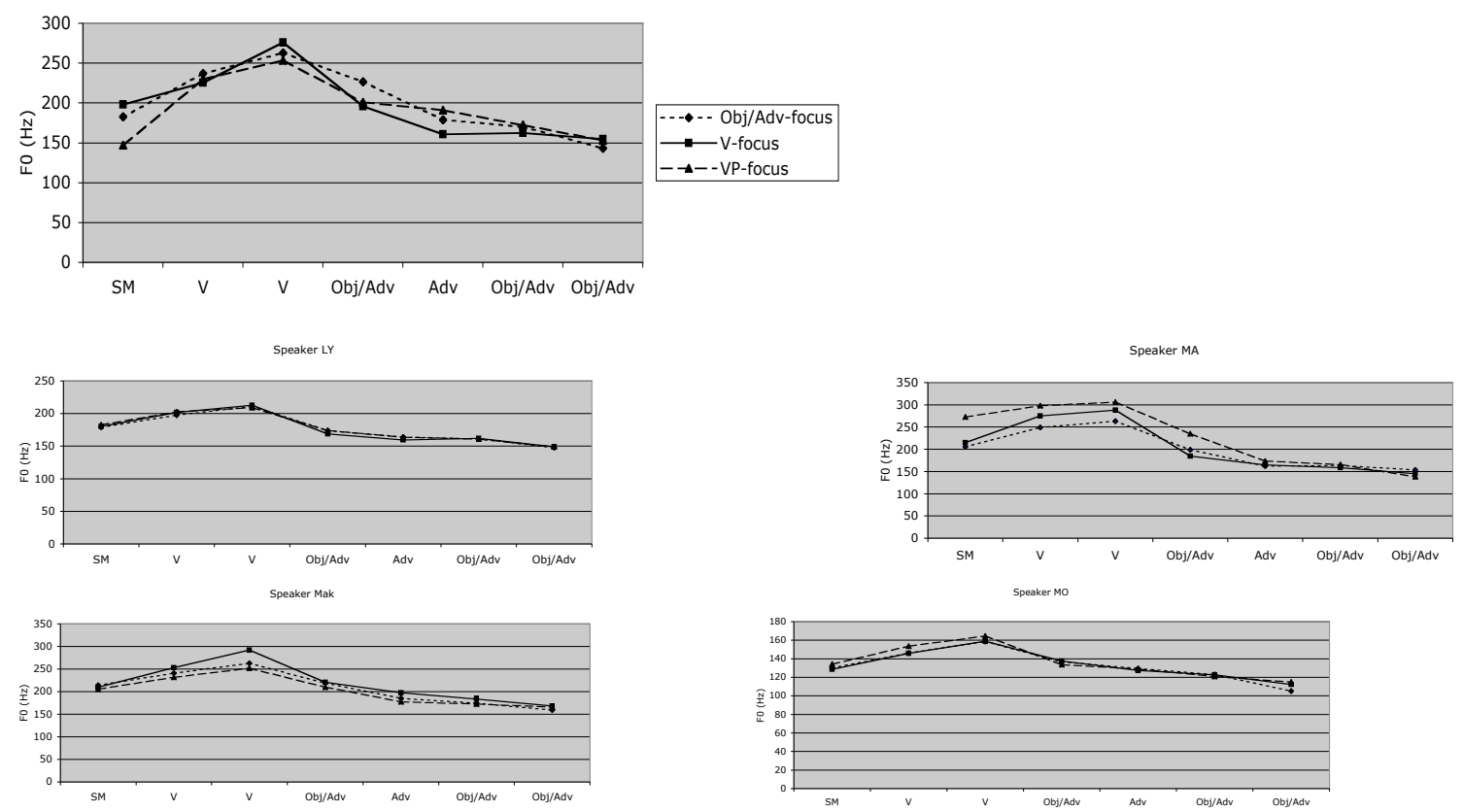

On the x-axis, the vowels of the different constituents in the utterance are displayed. The second and third value correspond to the verb, the fourth till final value correspond to the object or locative adverbial. The first value refers to the vowel of the personal pronoun $(k e)$. On the $\mathrm{y}$-axis, the average F0-value is given in Hertz. Four speakers are female. The fifth speaker is male wherefore the lines occur in a lower pitch range. The dashed line represents VP-focus, the continuous line represents focus on the verb, and the dotted line indicates focus on the object or local adverbial.

Again, the general tonal information emerges from the diagrams. The verb bears a high tone on the stem initial syllable underlyingly. The peak of F0 is only reached in the second syllable of the verb. After the F0 peak in the second syllable of the verb, F0 drops again.

The stem initial syllable, i.e. the second syllable of the noun, is transcribed in the examples as bearing a high tone. This is motivated by the tonal realization the noun receives if it is pronounced in isolation. Within the sentence, as in diagram 9, no F0 peak is visible. This is due to declination which narrows the pitch range available to speakers towards the end of the utterance.

In the speech of LY, MA, Mak and MO, we find a nearly perfect overlap in what concerns the F0 for all three focus conditions. F0 raises in the verb due to HTS and falls smoothly towards the end of the sentence.

Only the speech of DE shows some variation. Variation is found with respect to the F0-value on the first syllable. Contrary to all other target vowels, it follows the voiceless plosive [k]. In section 3.5.3, it has been pointed out that consonants such as plosives and fricatives influence the F0-value of the following vowel. Therefore, and also because its duration is sometimes very short, the F0-values calculated for this segment have to be treated with care. 
More interestingly, a slightly higher F0 can be found for the initial syllable of the object when it is in focus. Also, a slight raised pitch and a lower initial syllable of the object can be found when the verb is in focus, which results in a sharper fall in pitch. Though the differences are only slight, it is nevertheless important to follow up on these differences, as the second phenomenon, namely the sharper fall after a focused verb, has been reported as a focus strategy in Chichewa (Downing et al. 2004). Under the term 'anti-accent', Downing et al. (2004: 177) describe that in Chichewa, the focused element is "made prominent by raising the pitch enough to make the following elements relatively much lower in pitch".

However, what we do not find is a pitch accent on the focused constituent. The diagram shows that F0 falls towards the end of the sentence (due to declination) also if the object is the focused constituent. Judging from the pitch accent distribution in intonationonly languages like English and German, if focus were expressed by pitch accent in Northern Sotho as well, one would expect to find some reversal of the trend in the condition of object focus.

In addition to the lack of evidence for the use of a pitch accent to indicate focus, it is interesting to note that tone sandhi do not emerge as a consequence of different focus conditions either. Against expectation, no speaker shows a fall of F0 on the second syllable of the verb, as predicted if focus inserted a phrase boundary that blocks the application of high tone spread (HTS).

Also a third option reported for tone languages, namely the raising of the overall pitch register, is not mirrored in the diagrams 9.

The preliminary conclusion is that focus is indicated neither by pitch accent nor by tone sandhi in Northern Sotho. The perception study presented in 3.6 checks this preliminary conclusion, and also checks if the slightly sharper fall after a focused verb in the speech of DE is interpreted as a focus strategy, parallel to the 'anti-accent' described in Downing et al. (2004) for Chichewa. 
Duration In diagram 10, the duration of each vowel over the three different focus conditions is given for all five subjects separately.

Diagram 10: Duration in different focus conditions

Speaker DE
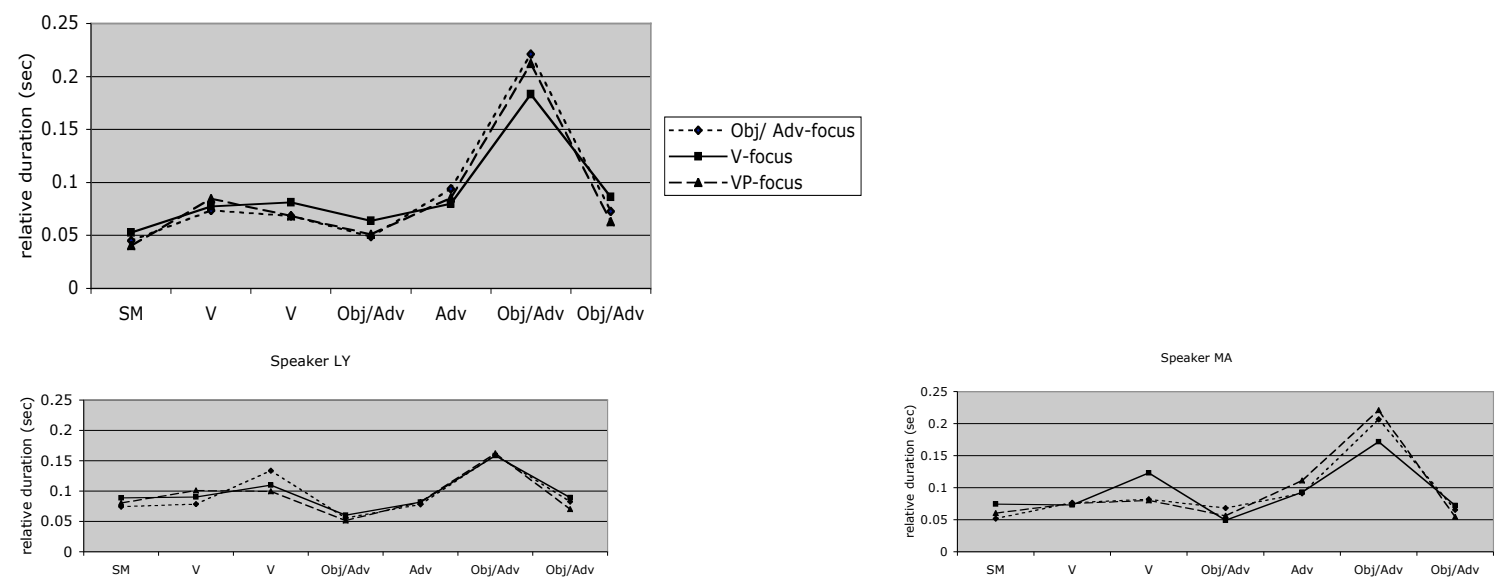

Speaker Mak
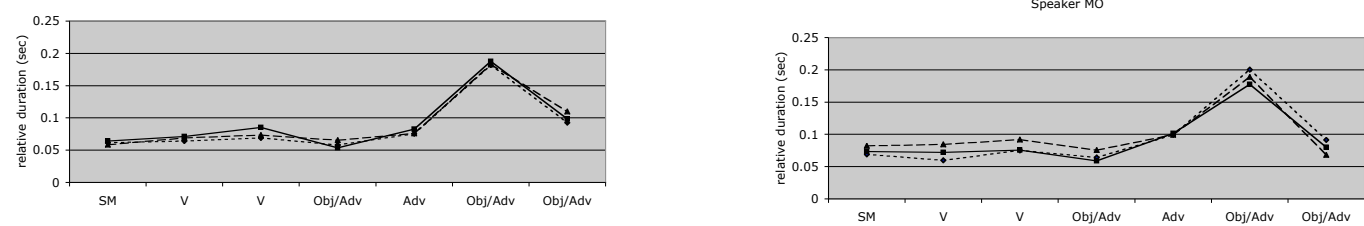

Again, on the $\mathrm{x}$-axis the vowels of the different constituents of the utterance are displayed. Each line represents the average values within one focus condition. On the y-axis, the relative duration of the segments is given in seconds.

A quite homogeneous picture emerges for all five speakers in all focus conditions. The speech of DE, Mak, and MO again shows a nearly perfect overlap with respect to duration in different focus conditions. The lengthening of the vowel in the penultimate syllable is clearly discernible in diagram 10.

In the speech of LY and MA, we find a slightly lengthened verb final syllable. However, the implication of this observation with respect to the encoding of information structure is doubtful. First, the increase in duration is not as expected in the penultimate syllable of the focused constituent and also is not as high as the lengthened penultimate syllable of the sentence. Second, the lengthening of the final syllable is not restricted to one focus condition. It occurs with verb focus in the speech of MA, but with object focus in the speech of LY.

Again, the preliminary conclusion from a phonetic investigation of the production data suggests no prosodic expression of focus through lengthening. However, the lengthening of the verb final syllable, though slight, might be significant enough for native speakers to serve as an indicator for the focused constituent in the utterance. 


\subsubsection{Summary}

The production study allowed to compile a Northern Sotho data corpus which contained segmentally well-suited data with controlled focus structures by five native speakers. A first impressionistic auditory analysis of the data showed for some sentences differences in the prosodic realization of different focus structures. However, there are no systematic differences and the differences do not occur with all speakers. A systematic quantitative analysis supported the impression: No phonetic cues are used to encode the focused constituent.

However, in order to test if the minor phonetic differences have linguistic relevance and also in order to check if other phonetic cues than duration and fundamental frequency are used and thereby escaped the analysis so far, a perception study was carried out. The study is the topic of the next section.

\subsection{Perception study}

\subsubsection{Aim}

For any acoustic contrast to be described by the grammar and to be explained by linguistic theory it needs to fulfill two requirements:
a. it needs to be there
b. it needs to be a linguistic contrast.

The first restriction seems trivial. If something is not there it cannot be described by grammar nor can it be explained by theory. However, there are various examples in linguistics that treat entities as part of grammar which are not present and can be inferred only indirectly, if at all (e.g. pro, traces, zero-morphemes etc). The second requirement captures the need for something to be of linguistic importance rather than of paralinguistic.

The impressionistic acoustic analysis of the production data from different focus structures revealed two things: In one part of the data, there is a (slight) perceptible suprasegmental difference between utterances recorded in different focus structures. In the other part of the data, there is no such perceptible difference in the signal. The prosodic analysis revealed that there are no significant differences between different focus structures if tested for common stress-related parameters like pitch peak and duration. The goal of the perception experiment was therefore twofold: It needs to be investigated if there are prosodic cues in all data that enable native speakers of Northern Sotho to identify instances of in situ focus (60-a). These prosodic cues might be very subtle so that they have escaped an impressionistic acoustic analysis of the data. And they might differ from the stress-related phonetic correlates that were investigated in section 3.5.4. Second, it needs to be established if the existing suprasegmental differences are indeed related to differences in focus structure of the utterances. This addresses the aspect in (60-b), namely if the difference is of a linguistic nature.

The literature provides examples that show the need to double-check acoustic measurements for their perceptual or interpretative value. One example has been reported by B. Ladd at a workshop on experimental prosody in Leipzig (Oct. 2004). In the Ameri- 
can ToBi transcription corpus there is one example ('A friend of mine works for NASA') where a measured pitch accent is not pitch prominence. Furthermore, Ladd \& Morton (1997) report the result that differently perceived intonation contours might not represent different grammatical meanings.

In order to test if there are acoustic differences perceivable to native speakers of Northern Sotho and if these differences are linguistic in nature, a perception study was conducted to establish distinct categories in diverging focus structures. Perception tests for focus structures have been carried out by Gussenhoven (1983b), Oppenrieder (1989), Jannedy (2002) for focus structures in sentences and by Swerts et al. (2002) for focus structures in NPs. The recordings done for compiling the production data were played back to native speakers in order to test if there are perceivable prosodic differences in the pairs that sound identical, and if prosodic differences in the non-identical pairs can be recognized to be related to information structure.

\subsubsection{Pre-test}

In a pre-test of the perception experiment (carried out in August 2004), subjects were auditorily confronted with answers to different questions only and were asked to indicate in which sentence a pre-determined word was especially emphasized or focused. The task is illustrated in (61).

(61) Pre-test: In which of these sentences is 'polaseng' more prominent?

a. Ke tla be ke šoma [polaseng] $]_{F}$.

b. Ke tla be ke [šoma $]_{F}$ polaseng.

It emerged that asking for an intuitive notion of prominence in the recorded target sentences posed a problem for the listeners. This task did not yield any results. None of the speakers could identify the focused constituent in the utterances correctly with this set up. Not only did they sometimes not identify the sentence with the underlyingly correct focus structure, they also overgenerated and allowed too many structures to signal focus on a specific constituent.

One frequent comment was that it is difficult to identify a prominent constituent in the sentences if they all display the same word order. Indeed, word order is reported to convey emphasis in Northern Sotho (Louwrens p.c.). A preposed constituent is considered emphasized. However, as shown in section 2.3.1, the sentence-initial position is crucially not for focused constituents as defined in this thesis. Rather, the sentence-initial position can mark discourse-old constituents as noteworthy. Emphasis of the sentence initial position therefore corresponds to saliency rather than F-marking. Because of these confusions with respect to terminology, it was chosen to ask for appropriateness judgments in the perception task.

\subsubsection{Procedure}

The target sentences obtained through the recordings were used in the perception experiment. The perception study asked for appropriateness judgments in the following way: 
Subjects were presented with an identical question followed by two differing answers in direct comparison. The task is illustrated in (62).

(62) Task: Which of these question/answer pairs matches best?
a. (i) O tla be o šoma kae?
2 FUt PRog 2 work where
'Where will you be working?'
(ii) Ke tla be ke šoma [polase-ng] $]_{F}$.
1 FUT PROG 1 work CL9.farm-LOC
'I will be working ON THE FARM.'
b. (i) O tla be o šoma kae?
(ii) Ke tla be ke [šoma $]_{F}$ polaseng.
'I will be WORKING on the farm.'

As indicated in (62) by the English equivalent, one of the answers is the original answer to the question (in (62) it is answer (a)). The second answer is taken from another focus context (i.e. it was originally the answer to a different question, in (62) the answer in (b) is taken from the question 'What will you be doing on the farm?'). The question/answer pairs are presented auditorily using the PRAAT experiment mask. Each answer is presented with the question immediately preceding it. The subject could only listen once to every question/answer-pair. After having listened to the question/answer pair, the subject was asked to choose which of the two alternative answers was more appropriate in the context given by the preceding question. Subjects had to decide between the first and the second question/answer pair. After they had made their decision, they immediately heard the next question/answer pair. The study data were divided into four blocks, allowing a short break after every quarter of the items.

\subsubsection{Material}

Two perception studies were carried out. Study 1 contained utterances with slight, but perceptible suprasegmental differences. Four lexically different contexts were used from three different speakers. Study 2 contained utterances with no perceptible difference. Three lexically different contexts were used from three speakers. The sentences chosen for study 1 are given in (63), the sentences chosen for study 2 are given in (64).

(63) Study 1 (only underlying tones indicated)
a. Ke néa náre le:é. (DE)
'I give the buffalo an egg.'
b. Ke néa molámo lemá:o. (DE)
'I give the uncle a needle.'
c. Ke nyálwa labón:ne. (MA)
'I marry for the fourth time.'
d. Ke rwála morwáa:lo. (MO)
'I carry load.'


The suprasegmental differences that were realized in the utterances in (63) are the following: In (63-b), the speaker pronounced a pause preceding one of the objects, when it was in focus. Furthermore, the verb was pronounced with a higher pitch when in focus which also applies to (63-d). The constituents following the focused verb were realized with a downstepped pitch height in $(63-\mathrm{a}, \mathrm{c})$.

The pronunciations of the sentences in (64) did not show any perceptible suprasegmental differences.

$$
\begin{aligned}
& \text { Study } 2 \text { (only underlying tones indicated) } \\
& \text { a. Ke jáa namú:ne. (DE) } \\
& \text { 'I eat an orange.' } \\
& \text { b. Ke réma morúla moséga:rée. (MA) } \\
& \quad \text { 'I chop the marula tree at midday.' } \\
& \text { c. Ke fá mmá hé:mpe. (MO) } \\
& \text { 'I give mother a shirt.' }
\end{aligned}
$$

The question/answer quadruples for the perception study were prepared in such a way that the three/four underlying sets were taken from different speakers. Furthermore, questions are asked by a person different from the answer giver in order to make the listening less monotonous. Also, the question poser differed within sets to make the task more lively and also to include many different speakers. As the speakers overlapped with the listeners, the intent was to reduce the amount that a speaker might have to listen to his/her own voice. The same person asked the questions in the different ordering conditions $(\mathrm{a} / \mathrm{b})$ as well as within the same focus condition. For the different focus conditions a different person was chosen to ask the questions. The speech of one subject was included as questioner whose speech was not taken into consideration for the production data, as he originates from a different geographical area.

Recall from the production procedure that every sentence was recorded with new information focus on all constituents and additionally with VP focus. In the perception study, every focus structure in the target sentence was checked against all possible constituent questions. The study only concentrated on narrow focus, therefore neither sentence focus nor VP-focus was considered, the reason being that the subjects were forced to decide between the two question/answer pairs presented. Based on languages like German, VP-focus coincides prosodically with object focus in simple transitive sentences. In the experimental set up used here, there would be no correct choice in terms of which of the two question/answer pairs is the correct one. Furthermore, as the correct answer is always either pair 1 or pair 2, no quadruples are taken into the study where none is the correct answer or both are the correct answers.

One quadruple consists of two questions and two answers. Every quadruple was presented twice showing the answers in different orders to account for the ordering effect, i.e. the tendency observed in test persons to judge the second of two alternatives better (Ladd \& Morton 1997, Schiefer \& Batliner 1991). The two possibilities of one quadruple (due to ordering effect) are repeated four times in order to get the chance effect if there are indeed no prosodic cues to focus.

The question/answer pairs were given in random order, with a separate test experiment to familiarize the subject with the task, the voices, and the speed of the experiment. Even- 
tually, study 1 contained 128 question/answer quadruples that were asked to be judged with respect to their appropriateness, whereas study 2 contained 112 question/answer quadruples. Four subjects participated in each of the perception studies.

The expectation for the perception study is that the speaker chooses one of the two alternative answers as more appropriate if there are meaningful prosodic differences in the realization of various in situ foci. The set up in terms of minimal answer pairs was chosen in order to focus the listener's attention on possible subtle differences in the realisation of different focus structures.

\subsubsection{Results}

The responses from the perception study were recorded by the experiment software and evaluated as to if the preferences correspond to the 'correct', underlying answer. The results for each study are reported in the following two subsections.

\section{Study 1}

Study 1 contained question/answer pairs with a perceptible difference in prosody. They are repeated in (65).

(65) Study 1 (only underlying tones indicated)
a. Ke néa náre le:é. (DE)
'I give the buffalo an egg.'
b. Ke néa molámo lemáa:o. (DE)
'I give the uncle a needle.'
c. Ke nyálwa labón:ne. (MA)
'I marry for the fourth time.'
d. Ke rwála morwáa:lo. (MO)
'I carry load.'

Table 6: Overall performance in study 1

\begin{tabular}{|l|l|l|l|l|}
\hline subject & LY & MA & MO & Mak \\
\hline \hline total & $58 / 128$ & $62 / 128$ & $71 / 128$ & $67 / 128$ \\
\hline percent & $45,31 \%$ & $48,44 \%$ & $55,47 \%$ & $52,34 \%$ \\
\hline
\end{tabular}

The above table shows that the responses are distributed according to chance. However, as the four utterances that are contained in the study and which had to be judged with respect to their appropriateness, stem from different speakers and also because different prosodic cues are used, a separate evaluation of the items is given below. It emerges that the responses are distributed according to chance for all utterances. 
Table 7: Performance according to item

\begin{tabular}{|ll|l|l|l|l|}
\hline Item (65) & & LY & MA & MO & Mak \\
\hline \hline (a) & total & $21 / 48$ & $25 / 48$ & $27 / 48$ & $24 / 48$ \\
& percent & $43,75 \%$ & $52,08 \%$ & $56,25 \%$ & $50 \%$ \\
\hline (b) & total & $23 / 48$ & $21 / 48$ & $26 / 48$ & $27 / 48$ \\
& percent & $47,92 \%$ & $43,75 \%$ & $54,17 \%$ & $56,25 \%$ \\
\hline (c) & total & $8 / 16$ & $8 / 16$ & $9 / 16$ & $7 / 16$ \\
& percent & $50 \%$ & $50 \%$ & $56,25 \%$ & $43,75 \%$ \\
\hline (d) & total & $7 / 16$ & $8 / 16$ & $9 / 16$ & $9 / 16$ \\
& percent & $43,75 \%$ & $50 \%$ & $56,25 \%$ & $56,25 \%$ \\
\hline
\end{tabular}

Table 7 shows that for the separate items the correct responses are also very much distributed according to chance. This means that the slight prosodic differences in the utterances do not correlate to a phonetic cue that is employed by the speaker and interpreted by the listener as being related to information structure.

A closer examination of the responses within the single items reveal that the pause before the focused object in (65), sentence (b) is not interpreted with respect to focus but is generally rejected. Also in (65), sentence (c), downstep after the focused verb is not taken as a cue to focus structure. Though two subjects perform exceptionally well on the condition where the downstepped answer is the correct answer, they choose this answer also when it is not the appropriate one. This reveals a general preference for the downstepped answer. The distribution of the responses furthermore show ordering effects. Whereas one subject predominantly chooses the second answer, another nearly always chooses the first answer.

The results of study 1 show that the existing prosodic differences are not related to the focus structure of an utterance.

\section{Study 2}

Study 2 contained utterances without any obvious prosodic changes. The items are repeated (66).

(66) Study 2 (only underlying tones are indicated)

a. Ke já namú:ne. (DE)

'I eat an orange.'

b. Ke réma morúla moséga:ré. (MA)

'I chop the marula tree at midday.'

c. Ke fá mmá hé:mpe. (MO)

'I give mother a shirt.'

Table 8: Overall performance in study 2

\begin{tabular}{|l|l|l|l|l|}
\hline subject & Mak & MO & PA & SI \\
\hline \hline total & $59 / 112$ & $53 / 112$ & $56 / 112$ & $51 / 112$ \\
\hline percent & $52,68 \%$ & $47,32 \%$ & $50 \%$ & $45,54 \%$ \\
\hline
\end{tabular}


Again, the responses are distributed according to chance. The following tables show the total number of correct responses according to individual items.

Table 9: Performance according to item

\begin{tabular}{|c|c|c|c|c|c|}
\hline \multicolumn{2}{|c|}{ Item (66) } & Mak & MO & PA & SI \\
\hline \multirow[t]{2}{*}{ (a) } & total & $6 / 16$ & $6 / 16$ & $10 / 16$ & $8 / 16$ \\
\hline & percent & $37,5 \%$ & $37,5 \%$ & $62,5 \%$ & $50 \%$ \\
\hline \multirow[t]{2}{*}{ (b) } & total & $25 / 48$ & $23 / 48$ & $22 / 48$ & $20 / 48$ \\
\hline & percent & $52,08 \%$ & $47,91 \%$ & $45,83 \%$ & $41,66 \%$ \\
\hline \multirow[t]{2}{*}{ (c) } & total & $27 / 48$ & $24 / 48$ & $24 / 48$ & $23 / 48$ \\
\hline & percent & $56,25 \%$ & $50 \%$ & $50 \%$ & $47,91 \%$ \\
\hline
\end{tabular}

The results from study 2 show that the utterances with no perceptible differences do not contain subtle prosodic cues that could be related to focus structure by native speakers.

The studies show that in one part of the recorded data there are no prosodic cues to focus (study 2). In the other part of the data, where there are slight perceptible differences, these differences cannot be related to differences in focus structure (study 1). The differences recorded rather reflect paralinguistic shades in meaning, as the subjects' comments reveal.

\subsubsection{Summary}

The perception study described in the preceding section has shown that although there are slight prosodic differences in the production data, these differences are not exploited by native speakers to draw inferences about the information structuring of the sentence. The suprasegmental differences in the production data are not systematic and this is reflected in the results of the perception study: The answers regarding the comparison of certain prosodic structures indicate general preferences independent of the focus structure of the utterance, e.g. that no pauses between constituents are preferred. Checking the differences in the production data therefore did not hint towards hidden prosodic cues that are exploited for the interpretation of the information structuring of the sentence.

\subsection{Summary of the experimental part}

The experimental part had as its objective to test if there is a prosodic expression of focus in Northern Sotho when the focused constituent does not appear clause-finally and is followed by discourse-old material. Based on existing studies on Chichewa and Xhosa, changes in the realization of the tonal pattern or lengthening of penultimate syllables were expected. Northern Sotho tonology shows characteristics which are comparable to Chichewa and Xhosa and which lead one to expect prosodic changes under focus also in Northern Sotho.

A production study tested if Northern Sotho native speakers produce prosodic differences which are correlated to diverging focus structures. Target sentences were prepared in such a way to allow tonal as well as durational differences to occur. Question/answer 
pairs that were controlled for different focus conditions were recorded from five native speakers. A phonetic analysis of the data with respect to fundamental frequency and duration showed no systematic prosodic expression of focus, and slight differences only for some speakers. A follow-up perception study showed that the existing prosodic differences were not interpreted with respect to focus. Neither did any other prosodic cue emerge as prosodically relevant for the encoding of focus in Northern Sotho.

The conclusion drawn from these production/perception studies is that in syntactically identical sentences there is no suprasegmental marking of focus in Northern Sotho. The study therefore showed that in Northern Sotho in contrast to Chichewa and Xhosa focus does not affect phrasing. Differences in production of diverging underlying information structures can only be attributed to idiolects or differences in speech tempo, but they cannot be regarded as language-inherent functional means of marking focus.

\subsection{Conclusion and discussion}

This chapter has investigated the prosodic expression of postverbal in situ focus in Northern Sotho. This was motivated firstly, by the controversy in how far tone languages use intonation in order to convey discourse-pragmatic meaning, secondly because related Bantu languages do exploit suprasegmental means to convey the information structuring of the sentence, and thirdly, because Northern Sotho itself makes use of intonation to indicate questions and continuation. The results of a production study show reflexes of suprasegmental changes under focus for only some speakers. A follow-up perception study showed that the production data did not contain any systematic cue for listeners to make inferences about the focused constituent. Consequently, somehow surprisingly considering the literature on Chichewa, in Northern Sotho there is no prosodic marking of focused constituents that appear in situ. This result raises two questions.

First, even though is known from the literature that pitch accent is not a universal cue to focus, there is still the assumption that focused constituents are generally made prominent, if not through pitch accent than by other prosodic means (Selkirk 2004, Truckenbrodt 1995, 1999; see also chapter 1). The study reported in this chapter has shown that Northern Sotho has no prosodic means whatsoever to mark a focused constituent as focused when it appears in situ. How can the absence of prosodic focus marking be accounted for? This question is dealt with in section 3.8.1 by comparing the expression of focus in Northern Sotho to the expression of focus in English and Italian. This discussion shows that Northern Sotho actually is a language type that is predicted by the factorial typology of the constraints proposed in chapter 1 .

Second, it is widely-assumed in the literature that focus is marked somehow in a language. Prosody might be the predominant cue as in language like English and German. However, in some languages prosody plays only a minor role or does not play any role whatsoever in focus marking because morphology or syntax are taking over this role. This is the case in Wolof, where morphology is the predominant cue to focus (Rialland \& Robert 2001), or in Hungarian, where word order is the prevalent means of focus marking (É. Kiss 1998). As has been shown in this and the preceding chapter, Northern Sotho uses neither prosodic nor morphological nor syntactic means for indicating focus in the postverbal domain. The question is discussed in section 3.8.2 what consequences for a 
theory of focus the total absence of grammatical focus marking in the postverbal domain has.

\subsubsection{Prominence-focus correspondence}

The absence of pitch accents for focus marking in Northern Sotho is not surprising, as the same has been found in pitch-accent languages like Swedish, Serbo-Croation, and Japanese (see Selkirk 1995: 553 for references). Also in tone languages no pitch accents are reported. Here it is other suprasegmental means such as tone sandhi and length which are induced by the same discourse-pragmatic factor focus. The simultaneous use of boundary intonation in Northern Sotho, such as continuation rise, with the absence of focus intonation is no contradiction: It has been shown that boundary tones are exploited cross-linguistically (Selkirk 1995: 553). Languages as diverse as Chinese, Japanese, Serbo-Croation, Hungarian, and Igbo employ sentence-final boundary tones to distinguish assertions from questions.

However, the production and perception study has shown that there are no prosodic means whatsoever available in the grammar of Northern Sotho for marking in situ focus in the verbal and postverbal domain. The data rather suggest that in Northern Sotho there is no requirement inherent to grammar to highlight the focused constituent prosodically. It therefore differs from languages like Italian and English where this requirement influences the grammatical expression of sentences.

The absence of prosodic marking is problematic for the approaches to focus prominence proposed in Selkirk (1995) and Truckenbrodt (1995), as both models require a prosodic expression of focus. According to Selkirk (1995), either phonological phrasing or prominence must cue focus, whereas according to Truckenbrodt (1995) focus is universally linked to prominence (see Frota 2000: $375 \mathrm{ff}$ for discussion).

However, the formulation of these requirements by means of rankable and violable constraints (as already proposed by Truckenbrodt 1995), also captures the absence of prosodic marking. The argument will be developed following the analysis for focus in Italian and English as proposed by Samek-Lodovici (2005) and already discussed in chapter 1 .

It has been shown that for subject focus, English keeps its canonical word order and places a pitch accent on the focused subject, thereby violating the general rule of rightmost stress in English. Italian, on the other hand, preserves rightmost stress but places the focused constituent in non-canonical clause-final position. Both languages deviate from their canonical linguistic properties in order to assign the focused constituent sentential prominence. The constraints proposed in the OT-framework to capture this languagespecific behavior are repeated in (67).

(67) Constraints for focus in English and Italian

a. Interface-constraint: FOCUS (following Truckenbrodt 1995)

'For any $\mathrm{XP}_{f}$ and $\mathrm{YP}$ in the focus domain of $\mathrm{XP}_{f}, \mathrm{XP}_{f}$ is prosodically more prominent than YP.'

b. Syntactic constraints: SubJECT / STAY

'Clauses have subjects.' / 'No traces.' 
c. Prosodic constraints: H-I: ALIGN (IP, R, Head (IP), R)

'Align the right edge of every Intonation Phrase with its head.'

The respective rankings of these constraints for Italian and English are repeated in (68). For a detailed discussion the reader is referred to chapter 1.

$$
\begin{aligned}
& \text { Ranking in English and Italian } \\
& \text { a. English } \\
& \text { bOCUS, SUBJ/ STAY } \gg \mathrm{H}-\mathrm{I} \\
& \text { b. Italian } \\
& \text { FOCUS, H-I } \gg \mathrm{SUBJ} / \mathrm{STAY}
\end{aligned}
$$

Although English and Italian differ in the grammatical areas that allow flexibility to meet the correspondence between prominence and focus, both languages have in common that the focused constituent emerges as maximally prominent. In Northern Sotho, however, there is no interaction between prominence and focus. Chapter 2 has shown that focused constituents do not obligatorily appear in clause-final position, which has been argued to be prominent in Northern Sotho just as it is in Italian. The present chapter has shown that although length can be considered prominence, focused constituents are not lengthened when appearing in situ nor are they marked otherwise by suprasegmental means. These observations are evidence for the claim that prominence in Northern Sotho as displayed by the lengthened penultimate is independent of focus.

Within an OT-framework the absence of any prosodic marking under focus data can consequently be accounted for by re-ranking: The corresponding FOCUS-constraint is ranked low relative to syntactic and prosodic constraints. Syntactic and prosodic constraints therefore shape and determine utterances in Northern Sotho. The ranking in Northern Sotho is shown in (69).

$$
\begin{aligned}
& \text { Ranking in Northern Sotho } \\
& \text { prosodic constraints (H-I), syntactic constraints (STAY) } \gg \text { FOCUS }
\end{aligned}
$$

Prosodic requirements that favor right-most lengthening, as well as syntactic requirements that favor SVO word order, are ranked above a constraint that wants the focused constituent to be most prominent. The result of this ranking order is that focus remains

\begin{tabular}{|c|c|c|c|c|}
\hline \multicolumn{2}{|r|}{ focused verb } & $\mathrm{H}-\mathrm{I}$ & STAY & FOCUS \\
\hline a. & ke [mémá] $]_{F}$ mohú:mi) $)_{I P}$ & & & F \\
\hline b. & ke [mé:ma] $]_{F}$ mohumi) $)_{I P}$ & $* !$ & & \\
\hline c. & ke mohumi $\left._{i}[\text { mé:ma }]_{F} t_{i}\right)_{I P}$ & & $* !$ & \\
\hline
\end{tabular}
without any grammatical reflex. The resulting analysis is exemplified in tableau 11 by means of the transitive structure in (70), which shows a focused verb.

[O direga eng ka mohumi?]

Ke [mémá] ${ }_{F}$ mohú:mi.

Tableau 11: Focus in Northern Sotho 
Tableau 11 shows the three competing structures. Candidate (a) shows the Northern Sotho structure in which stress appears finally in the canonical structure. Though this configuration violates the constraint demanding the focused constituent to be prominent, the violation is not fatal as the constraint FocUs is low-ranked. Candidate (b) shows a configuration in which the stress appears not rightmost but on the constituent in focus. This is comparable to subject focus in English. However, this candidates violates the prosodic constraint demanding rightmost stress and as this is ranked above the constraint FocUS in Northern Sotho, the violation is fatal. Finally, candidate (c) corresponds to Italian in that prominence is kept rightmost, but the canonical word order is changed. Again, as the syntactic constraints are ranked above the constraint FocUS in Northern Sotho, the violation is fatal and the candidate is excluded from the competition.

Given the typological consequences that OT-constraints have (factorial typology, see section 1.5.4), the existence of a language that does not mark focus prosodically is not surprising. As OT-constraints are violable and ordered, a language is allowed to occur in which the constraint FOCUS is ranked below prosodic and syntactic constraints. Italian and English constitute other examples of the free rankability of constraints: In Italian, prosodic constraints are ranked above the constraint FocUS which is ranked above syntactic constraints. In English, syntactic constraints are ranked above the constraint FocUS which is ranked above prosodic constraints. Hence, every permutation in the ordering of the constraints involved describes a possible and attested human language.

Although factorial typologies may account for certain language types, they do not provide further explanations for why, in this case, there is no prosodic expression of focus. One can only speculate if this connected to the apparent absence of rules that refer to the layer of Phonological Phrases. For languages like English and German, it has been established that focus crucially influences phrasal stress, i.e. the Phonological Phraselevel (see also Truckenbrodt, to appear). Also work on Chichewa has shown that the demarcation of Phonological Phrases is crucially influenced by focus considerations in this language (Kanerva 1990, Downing et al. 2004). If also in Northern Sotho focus is manipulated by e.g. insertion of Phonological Phrases but the language lacks rules that refer to this layer, than the changes in prosodic structure due to focus do not manifest themselves in the language. However, this remains speculative and has to await further research.

In order to account for the lack of prosodic expression of focus, Frota (2000: 374) proposes the Split Focus Effects model. According to this model, languages may follow one of two possible routes. In Route A, focus is marked syntactically. Languages that take this route are Hungarian, Korean, and Basque. In the absence of morphosyntactic means of focus marking, other languages such as English and European Portuguese use prosodic prominence to mark the focused constituent.

Frota's model is ahead of both Selkirk's and Truckenbrodt's approaches because it covers syntactic focus marking as well. With respect to Northern Sotho, Frota's model of Split Focus Effects can capture the lack of prosodic reflexes of focus. At the same time, however, it also predicts syntactic or morphological marking of focus. Chapter 2 has shown that these means are absent as well. The absence of any grammatical F-marking in the postverbal domain in Northern Sotho is not only problematic for all the approaches mentioned here, but rises more generally the question of the relevance of F-marking for 
the grammar of Northern Sotho. This will be discussed in the next section.

\subsubsection{Lack of focus marking: Areas for further research}

The data from Northern Sotho raise the question about the universality of grammatical focus marking in grammar. They show that neither the presence of prosodic marking for focus nor the unambiguous coding of focus through syntax or morphology is universal. Recent studies on other African languages have shown that Northern Sotho is not unique in this respect: also for Wolof (though with morphological focus marking instead, see Rialland \& Robert 2001), Hausa and Tangale no prosodic marking of focus (in additional absence of syntactic marking) has been found (Hartmann \& Zimmermann 2004, to appear a). Nevertheless, it remains an empirical question how widespread the total absence of grammatical focus marking is among the languages of the world.

The absence of obligatory grammatical expression of focus with objects and adverbials poses a problem for focus theories that assume that focus must be marked grammatically in order to indicate alternatives. However, there is no a-priori reason why focus must be marked grammatically. The data can be equally well handled if context is considered for disambiguation too. This is necessary in focus theories anyway as there are regularly focus ambiguities in what concerns sentence-, IP-, and VP-focus in languages like English and German. The data from Northern Sotho suggest that context is used in all instances of focus in order to resolve focus ambiguities, unless discourse-old constituents are marked as such. Consequently, a theory of context-based interpretation has to account for focus interpretation in Northern Sotho.

Just to remind the reader, lack of grammatical F-marking in Northern Sotho does not imply that the language lacks grammatical means of indicating the focused constituent. For example, Northern Sotho uses deletion, pronominalization and dislocation of discourse-old constituents, as has been shown in chapter 2. Neither does the lack of prosodic marking of postverbal in situ focus mean that Northern Sotho does not show any prosodic reflexes of information structuring. For example, a right-dislocated discourseold constituent is set off from the sentence by an optional pause, preboundary lengthening and tone sandhi. However, the necessity of an object marker on the verb when being dislocated shows that the prosodic changes are dependent on the syntactic structure and not a means on their own.

Hartmann \& Zimmermann (to appear a), who discuss the theoretical implications of the lack of grammatical focus marking in Hausa, suggest that Hausa is among the languages that do not require obligatory F-marking in grammar. This characterization is reminiscent of the distinction between obligatory and non-obligatory focus-marking systems in Heine \& Reh (1983). This distinction was first proposed with respect to morphological F-marking but seems to be applicable more widely also with respect to prosodic and syntactic focus marking.

This view comes close to arguing that focus does not exist as a grammatical category in the grammar of Northern Sotho, an hypothesis that would be reflected by the lack of formal F-features. The lack of direct or indirect relevance for the F-feature in syntax has been discussed in chapter 2. The current chapter has shown that F-marking has no influence on prosody either. However, as will be discussed in the next chapter, F-marking is 
nevertheless crucial in Northern Sotho and therefore needed as a morphosyntactic feature.

The next chapter returns to F-marking on the logical subject and discusses an area where the relevance of F-marking manifests itself. For the syntax of the logical subjec only F-marking makes the right prediction concerning the occurrence of a grammatical subject. 


\section{Chapter 4}

\section{The preverbal position in Northern Sotho}

\subsection{Introduction}

Chapter 2 and 3 have shown that non-subjects, i.e. objects, adverbs, and verbs, are neither syntactically nor prosodically marked for focus in Northern Sotho. The data presented in chapter 2 have shown that a focused logical subject appears either in a cleft construction or in a so-called impersonal construction, i.e. postverbally. This chapter returns to the grammatical consequences of F-marking on the logical subject in Northern Sotho and investigates why subjects cannot be focused in their canonical preverbal position. The need for a cleft construction with focused logical subjects of transitive verbs is the topic of the following chapter.

Before discussing the discourse-pragmatic properties of the subject in Northern Sotho, terminological issues concerning the term 'subject' are repeated (see also section 1.7.3). Consider the sentences in (1).

(1) Subject in Bantu
a. Mo-nna o ngwala le-ngwalo.
CL1-man CL1 write CL5-letter
'The man is writing a letter.'
b. Go fihla mo-nna.
CL17 arrive CL1-man
Lit. 'There arrives a man.'

The sentences in (1) illustrate two different uses of the term 'subject'. In (1-a), the noun monna has the following properties: It is selected by the verb and bears the highest thematic role, it appears preverbally, and it agrees with the verb in noun class features. A constituent that shows these grammatical properties is referred to as the grammatical subject, or the preverbal subject. In general, the discussion in this thesis is restricted to active sentences.

In (1-b), the noun monna has the following properties: It is also selected by the verb and bears the highest thematic role, but it appears postverbally and does not agree with the verb in noun class features. A constituent that displays these grammatical properties is 
referred to as the postverbal subject or subject in situ. The term 'logical subject' refers to the constituent bearing the highest thematic role without reference to its syntactic position.

The data on subject focus in Northern Sotho are repeated in (2) for convenience. Logical subjects are focused by either a cleft construction or an impersonal construction. This is illustrated in (2) by means of questions. For intransitive verbs, both impersonal construction and cleft construction can be used, as shown in (2-a) and (2-b). The impersonal construction in (2-a) is characterized by class 17 -agreement on the verb and the postverbal appearance of the logical subject. The cleft construction in (2-b) is characterized by the high-toned copula ké and relative clause morphology on the verb. For transitive and ditransitive verbs, the cleft construction is the only available option, as shown in (2-c, d). Impersonal constructions are excluded. ${ }^{1}$

(2) Subject questions in Northern Sotho
a. Go fihla mang?
CL17 arrive who
'Who is arriving?'
b. Ké mang a fihla-ng?
COP who CL1 arrive-REL
'Who is arriving?'
c. Ké mang (yo) a nyaka-ng ngaka?
COP who RELPRN.CL1 CL1 look.for-REL CL9.doctor
'Who is looking for the doctor?'
d. Ké mang (yo) a fa-ng mpša di-jo?
CoP who DEM.CL1 CL1 give-REL CL9.dog CL8-food
'Who is giving the dog food?'

The use of the cleft and/or the impersonal construction for a focused subject suggests a syntactic marking of subject focus in Northern Sotho (see e.g. Hartmann \& Zimmermann, to appear a, for Hausa). Grammatical focus marking is by definition predictable in that a focused constituent always displays the grammatical feature that is used for focus marking, be it a morpheme, pitch accent, or a certain syntactic structure. Both the optionality of cleft and in situ structure as well as the restriction to certain grammatical functions violate such a correspondence. Therefore, 'focus marking' in Northern Sotho differs from syntactic focus marking in e.g. Hungarian where constituents are moved into a preverbal focus position independent of their grammatical function.

The optionality between cleft and impersonal construction with subjects will be dealt with in chapter 5 . The current chapter investigates why logical subjects can apparently be focused in situ (i.e. postverbally), but not in their canonical preverbal position. The exclusion of a focused logical subject in preverbal position is argued to be restricted by information structure, as F-marked constituents do not appear in this position.

In the literature, this generalization has been accounted for differently: One account explains the ungrammaticality of focused preverbal subjects by functional principles in

\footnotetext{
${ }^{1}$ It will be shown in chapter 5 that the syntactic difference in focus structures for subjects, namely between cleft and impersonal construction, does not correspond to a semantic difference. Both alternatives can be used as the 'normal', unmarked focusing strategy. Moreover, the exclusion of impersonal constructions for transitive verbs is also topic of chapter 5.
} 
that the preverbal subject must be a topic in Bantu languages. Another account explains the ungrammaticality of preverbal focused subjects by syntactic principles in that subject movement would result in improper movement under focus.

In this thesis, the functional approach is followed and the ungrammaticality of the focused preverbal subject is explained by discourse-pragmatic restrictions on the preverbal subject position. Thereby, the view is adopted that information structure influences syntax. However, the approach proposed here differs from existing functional approaches in that the restriction for the preverbal subject is not related to topichood, but to F-marking instead.

In section 4.2, this chapter reviews the functional approaches that relate the subject to the discourse-pragmatic function of topic in Bantu. Furthermore, it tests the topic properties of the subject in Northern Sotho and comes to the conclusion that, although the subject is often a topic in this language, this is not obligatorily the case. The only valid generalization about the preverbal subject in Northern Sotho is that is must not be F-marked.

In section 4.3, the chapter shows how the influence of information structure on syntax can be modeled in OT. Thereby, it compares the OT-analysis proposed here to the syntactic account proposed in the literature in order to show that the crucial difference does not lie in the basic syntactic assumptions, which are parallel in both approaches, but solely in the way that information structure interacts with syntax.

Therefore, in section 4.3.1, the chapter derives the relevant interface constraint that accounts for the interaction of syntax and information structure. The constraint follows the constraint schema of harmonic alignment that has been introduced in chapter 1 . The grammatical relation scale and the focus scale are harmonically aligned in order to derive the constraint that bans F-marked subjects.

In section 4.3.2, the chapter derives in detail how this constraint accounts for the asymmetry in focusing logical subjects and non-subjects that is observable in Northern Sotho.

The emergence of the cleft structure for subject focus with transitive verbs will be dealt with separately in chapter 5, where the role of cleft sentences in the grammar of Northern Sotho is investigated more generally.

A treatment of the subject/object asymmetry in Northern Sotho within Optimality Theory is going to be published in Zerbian (under review b). Consequently, Zerbian (under review b) outlines the discussion in section 4.2 as well as the basic idea of constraints at the syntax-pragmatics interface in section 4.3. However, in the course of writing the thesis evidence has been collected that the preverbal subject is not necessarily a topic in Northern Sotho (section 4.1), a crucial insight that is missing in Zerbian (under review b), together with the explicit derivation of the constraint proposed by harmonic alignment. Furthermore, the current chapter is, of course, in general more detailed than the paper.

\subsection{Discourse-pragmatic role of the subject}

Grammatical functions such as object and subject differ in their linguistic characteristics. Subjects e.g. tend to be more restricted cross-linguistically or underlie special rules. An 
example for differences in syntactic behavior is question formation in English where doinsertion takes place with objects, but not with subjects. An example from prosody is the projection of accents in English where the projection of a pitch accent from an object onto the whole sentence is possible, but not from a subject. ${ }^{2}$ Subjects also differ from objects in other non-syntactic aspects of grammar. For example, subjects often encode agents in the languages of the world whereas objects prototypically encode patients. With respect to discourse-pragmatics, subjects tend to be topics (Chafe 1976, Keenan 1976 and many others), whereas objects tend to be (part of the) focus (Lambrecht 1994).

This section investigates the discourse-pragmatic characteristics of the preverbal subject in Northern Sotho in comparison to Bantu languages more generally.

\subsubsection{Subjects in Southern Bantu}

The generalization that grammatical subjects tend to be topics holds cross-linguistically, and is found for Bantu languages specifically in Givón (1976). The importance of the observation that subjects are topics for the grammar of Northern Sotho has been acknowledged by Louwrens (1979a, 1981, 1991). In functional and generative approaches the incompatibility of narrowly focused subjects in their canonical preverbal position has been attributed to their discourse-pragmatic properties. Subjects in Bantu languages, and in particular in (Northern) Sotho, are regarded topics (Givón 1976, Louwrens 1979a, Demuth \& Johnson 1989, Bresnan \& Mchombo 1987, Sabel \& Zeller 2004).

The sources cited use different definitions of the term topic. Givón (1976: 152f) uses the term topic both in its meaning as old information and as topic of discussion. Bresnan \& Mchombo (1987: 746) refer to work by Givón (1976), Chafe (1976) and Wald (1979), and define the TOPIC constituent in Lexical-Functional Grammar (LFG) as the constituent under discussion, whether previously mentioned or assumed in discourse. Demuth \& Johnson (1989) in following the work of Bresnan \& Mchombo (1987) also adopt their definition of topic. Louwrens (1979a) adopts the definition of old information.

All these approaches have in common that they refer to the topic as old discourse information that has been under discussion (explicitly or implicitly) or has been mentioned before. Evidence for this claim comes from different areas: diachronic evidence, (morpho-)syntactic evidence, and textual evidence. Further evidence comes from inversion structures, such as locative inversion and subject-object reversal. The evidence will be reviewed in the following subsections.

\section{Diachronic evidence}

The preverbal subject agrees obligatorily with the verb in Bantu languages. Development of agreement can therefore provide evidence for synchronic characteristics of subjects. A functional view on agreement relates the obligatoriness of subject agreement to its historical origin and claims that, although the agreement markers are fully grammaticalized from a synchronic point of view, they kept their discourse-pragmatic meaning. It is a 'widely accepted scenario for the development of agreement systems' (Schadeberg, p.c.) that they evolve from a topic construction, in which a full (morphologically unreduced) pronoun is

\footnotetext{
${ }^{2}$ Thetic sentences form a systematic exception to this generalization.
} 
used to refer anaphorically to the topic NP (stage I in (3)). The anaphoric pronoun is then reduced to a clitic-like element, though still retaining the pronominal content (stage II). As illustrated in stage III, it is then further reduced to a morphologically dependent affix - resulting in a loss of pronominal content - to a mere agreement marker (Givón 1976, going back to at least Boas 1911). The course of diachronic development according to Givón (1976) is illustrated in (3).

$$
\begin{aligned}
& \text { Diachronic development of agreement } \\
& \begin{array}{llll}
\text { I Topic Pronoun II } & \text { Clitic pronoun } & \text { III } & \text { Subject Agreement } \\
\text { The man, he came. } & \text { The man he-came. } & \text { The man he-came. } \\
\text { TOP PRO } & \text { TOP PRO } & \text { SUBJ AGR }
\end{array}
\end{aligned}
$$

In the transition from stage II to III, the reduction of the full topic pronoun to a mere agreement marker has happened, but the preceding NP has still retained its discourse function, namely being topic. This is the state of development a language like Northern Sotho is assumed to be in: There is obligatory, thus grammaticalized, subject agreement on the verb, whereby the subject itself always represents topical information.

\section{Morpho-syntactic evidence}

Bresnan \& Mchombo (1987) argue in their paper on agreement in Chichewa that the subject agreement marker is ambiguous in this language between anaphoric and grammatical agreement. They argue that the subject agreement marker can fulfill the function of an incorporated pronoun (just as the object marker can). Therefore, if a full subject constituent is present, this might be linked anaphorically to the incorporated pronoun and is then restricted to bearing the topic role.

Evidence for the claim that the incorporated subject marker acts as the argument of the verb comes from the optionality of the full subject NP, and from non-locality effects. When the verb is the only constituent in the sentence, the subject agreement marker appears on the verb and functions as an incorporated pronoun. This is shown in (4).

Optionality of subject

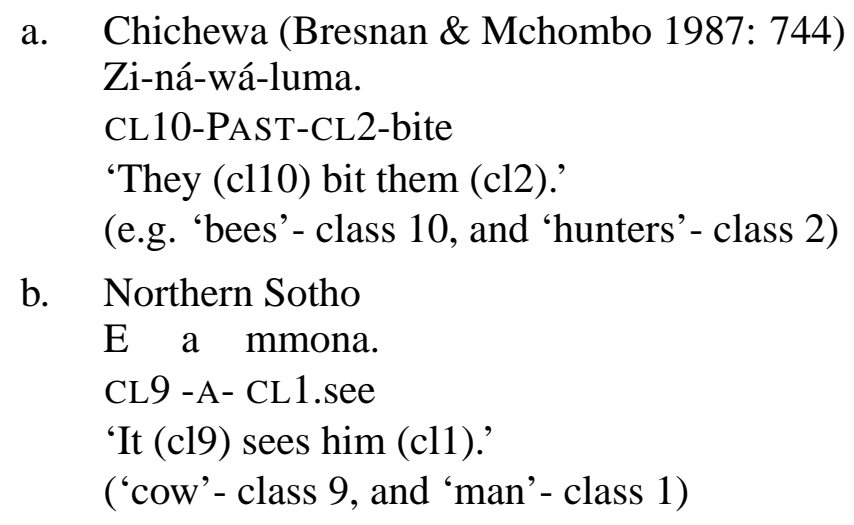

Furthermore, if the subject marker functions as an incorporated pronoun and the subject NP is linked anaphorically to it, one expects to find the subject NP non-adjacent to the verb. Non-locality effects can indeed be observed with the subject NP in both Chichewa 
and Northern Sotho. This is illustrated in (5), where the subject of the embedded clause is extracted and appears in sentence-initial position.

(5) Non-locality effects with the subject

a. $\quad$ Chichewa (Bresnan \& Mchombo 1987: 756)

Mkángó uwu, alenje a-ku-gáníza kutí ú-ma-fúná

CL3.lion this CL2.hunters CL2-PRES-think that CL3-HAB-want

ku-gúmúla nyumbá yá mfûmu.

INF-pull.down house of chief

Lit. 'This lion, the hunters think that it wants to pull down the chief's house.'

b. Northern Sotho

Malome, kgoši e re o swanetše go hlaba kgomo.

CL1.uncle CL9.chief CL9 say CL1 must.PST CL15 slaughter CL9.cow

Kgoši e re malome o swanetše go hlaba kgomo.

Lit. 'The uncle, the chief says, must slaughter the cow.'

The examples in (5) show that the subject agreement marker can establish non-local reference to the subject NP, both in Chichewa and Northern Sotho. In the LFG-approach that Bresnan \& Mchombo (1987) adopt, anaphoric reference can only be made to a topic constituent.

\section{Subject inversion structures}

The occurrence of inversion structures in Bantu languages has been interpreted as evidence for the topichood of the grammatical subject. In inversion structures, the logical subject appears postverbally and does not agree with the verb. The impersonal construction in Northern Sotho is one type of subject inversion structure. Other inversion structures are locative inversion (Bresnan \& Kanerva 1989 for Chichewa), subject-objectreversal (Kimenyi 1980 for Kinyarwanda) and transitive expletive constructions (Ndayiragije 1999 for Kirundi). Examples are given in (6-a,b,c) respectively.

In locative inversion in Chichewa, in (6-a), a locative constituent precedes the verb and agrees with it in locative noun class features. In subject-object-reversal in Kinyarwanda, as in (6-b), a logical object precedes the verbs and agrees with it in noun class features. In the transitive expletive construction in Kirundi in (6-c), both object and subject appear postverbally. The object immediately follows the verb and the logical subject appears in sentence-final position. The verb shows a default agreement (glossed as LOC in Ndayiragije 1999). In all inversion structures in (6), the logical subject appears following the verb.

(6) Subject inversion structures in Bantu languages

a. Locative inversion in Chichewa (Bresnan \& Kanerva 1989: 36)

Pa-m-chenga p-a-im-a nkhandwe.

CL16-CL3-sand CL16-PERF-stand-IND CL9.fox

'On the sand is standing a fox.' 
b. Subject-object-reversal in Kinyarwanda

(i) Umuhuungu a-ra-soma igitabo.

CL1.boy CL1-PRES-read CL7.book

'The boy is reading the book.'

(ii) Igitabo ki-soma umuhuungu.

CL7.book CL7-read CL1.boy

Lit.: 'The book is reading the boy.'

('The book is being read by the boy.')

c. Transitive impersonal construction in Kirundi (Ndayiragije 1999)

Ha-á-nyoye amatá abana.

LOC-PST-drink:PERF milk children

'Children (not parents) drank milk.'

With respect to the discourse-pragmatic meaning of inversion structures, it has been reported in the literature that impersonal constructions are used for presentational focus (a.o. Bresnan \& Kanerva 1989, Demuth \& Mmusi 1997, Harford 1990). Alternatively, the constructions can also indicate narrow focus on the subject (Bresnan \& Kanerva 1989, Morimoto 2000, Ndayiragije 1999). The argument goes that when being new discourseinformation, the logical subject cannot appear in its preverbal position as this position is tied to the notion of topic. It therefore appears in postverbal position. Because of the topic-prominence that these languages display, other topical constituents can appear in the preverbal topic position. In Chichewa, this is possible with topical locatives, in Kinyarwanda even with topical (logical) objects. Those constituents display formal subject properties, such as agreement on the verb.

Northern Sotho, however, does not allow any other constituent than the logical subject in preverbal position (see Baker 1992 and Zerbian 2004a for arguments against locative inversion in Sotho). The preverbal position in Northern Sotho is exclusively reserved for constituents bearing the highest thematic role.

\section{Textual evidence}

Evidence from text passages has been taken as evidence to show that a preverbal subject in Northern Sotho is old information (Louwrens 1979a). It has been decided to review Louwrens' work in detail as it pertains directly to Northern Sotho. Louwrens argues that the information status of the subject is old information. He uses text sequences showing three constellations: co-referentiality, situational givenness (bridging inference), and world knowledge. The following examples illustrate these points.

In (7-a), the underlined noun phrase is introduced into the text as discourse-new information in postverbal position. When it is taken up again later in the text, as in (7-b), it appears in preverbal position as it is old-discourse information.

(7) from Ramaila (1960: 127), cited following Louwrens (1979a: 46)

Angelo ke seteišene sa setimela mo gare ga Germiston le Boksburg. Gona fao ke mo gwa go namela (a) mokgalabje wa Mosotho e šetše e le mantšiboa a mokibelo. [...] Ka baka leo go bonala gore (b) mokgalabje o ile a botoga a potlakile ge a etšwa mo baneng ba gagwe. 
'Angelo is a train station between Germiston and Boksburg. One Saturday evening, an old Sotho man went there. [...] Therefore, the old man was in a hurry when he left from his children's place.'

Givenness in discourse arises not only from what has been explicitly mentioned before, as in the example in (7), but also implicitly, through the situation. Louwrens (1979a: 47) provides the example in (8), that follows within the same text as (7).

(8) from Ramaila (1960: 127), cited following Louwrens (1979a: 47)

Ge a šetše a dutše gabotse ka mo kgaolong ya ba "sekene", ya ba gona radithekete a tsenago go tlo botšiša dithekete.

'When he was sitting comfortably in the second class compartment, the conductor came to check the tickets.'

Raditheke- 'conductor' has not been explicitly mentioned in the preceding text. Nevertheless, it appears in the preverbal position that according to Louwrens is reserved for discourse-old information. This can be captured by considering raditheke discourse-old by situational givenness (Afrikaans 'situasionele gegewens'). The train that has been the local setting of the preceding discourse, made the conductor a logical discourse referent and therefore discourse-old.

Louwrens (1979a) claims that discourse referents are also treated as given information when they can be assumed to be world knowledge, without having been explicitly mentioned in the discourse or having been evoked through the situation. A textual example that supports the relevance of this generalization for Northern Sotho is given in (9).

from Kgatle (1972: 1), cited following Louwrens (1979a: 48)

Letšatši le diketše. Go na kwala diphefo tša marega tše di tšutlatšutlago. Mahlare a ewa dihlareng. Matšoba a naga a hlobotše botala, bose le lethabo tša selemo. [...] Dibota le digodi di hwile melodi.

'The sun went down. Only the winterwinds are audible. The leaves are falling from the trees.

underlineThe flowers on the fields have lost their beauty of the summer. [...] The birds and hawks are quiet.'

The underlined subjects appear in preverbal position though they have not been mentioned explicitly in the preceding discourse. Louwrens proposes that by presenting the subjects preverbally, the author assumes that the reader is familiar with this setting because of his knowledge of the world.

Further textual examples that show that a preverbal subject is discourse-old information, can be found at the beginning of stories or in stage directions, as shown in (10). Here, the context makes clear that the logical subject is not known to the hearer, and it can be seen from (10) that the subject does not appear preverbally. 
(10) Text beginnings and stage directions

a. Go be go na le di-nonyana le di-phukubje tš-eo di CL17 be.PST CL17 be with CL10-bird and CL10-jackal CL10-REL CL10 be-go di dula le-šoke-ng. was-REL CL10 live CL5-wilderness-LOC

'There were birds and jackals that lived in the wilderness.' (Matabane 1998)

b. Go tsena Matalebele.

CL17 enter PROP.NAME

'Matalebele enters.'

(Makwala 1958)

The use of impersonal constructions at the beginning of stories, as in (10-a), or in stage directions, as in (10-b), supports the claim that grammatical subjects, i.e. preverbal constituents that agree with the verb, are discourse-old. As in the beginning of stories all information is new, no grammatical subject is employed.

Although data from texts support the claim that the preverbal subject is discourse-old information, there are the usual disadvantages with textual evidence. Though the examples in (7), (8), and (9) show that the subject can be discourse-old information, and the example in (10) shows that the postverbal subject can encode discourse-new information, texts do not provide negative evidence. Though valuable information can be retrieved from an investigation of texts, at the same time texts do not provide negative evidence. In this case this means that texts can never show that the preverbal subject obligatorily has to be discourse-old information, neither that no discourse-old subject can appear postverbally. These data can only be gained from the elicitation of controlled contexts. Therefore, the next section systematically tests topic properties of the preverbal subject in Northern Sotho.

\subsubsection{Testing topic properties in Northern Sotho}

The preceding section has shown that in the literature, the grammatical function subject has been equalled with the discourse-pragmatic function topic in Bantu languages in general, and in Northern Sotho specifically. Thereby the term topic refers to two different aspects: either to information known in the discourse (Louwrens 1979a), or to the topic of the sentence (Givón 1976 and work thereafter). These notions of topic are also known as familiarity topic and aboutness topic respectively. The literature on the information structural status of the subject in Bantu languages therefore constitutes a case in which the same terminology has been used to refer to different things.

The objective of this subsection is to investigate the properties of preverbal subjects in Northern Sotho with respect to both familiarity and aboutness topic in order to ascertain which of the two notions is relevant in accounting for the distribution of the preverbal subject. It uses data gained from elicitation. Again, a context question controls the information status of the constituent under consideration. The data bring to light that the preverbal subject in Northern Sotho does not show properties pertaining to neither of these topic definitions. 


\section{Familiarity topic}

At the discourse-level or intersentential level, the term topic is often used to refer to given information (von Heusinger 1999, see also section 1.2.2). Louwrens (1979a) claims that this is the relevant notion that characterizes the preverbal subject in Northern Sotho. The view that the preverbal subject is discourse-old information is also held by Givón (1976) and subsequent work.

Given information is retrievable from the context and can therefore be left out. If the generalization holds that the preverbal subject in Northern Sotho is given information at the discourse-level, it is predicted that it can be left out. This is shown in the data in (11). The context question specifies 'the man' as the referent whose actions are inquired about. In the answer, this nominal NP can be repeated, as in (11-a), or be left out, as in (11-b).
Monna o dira eng?- 'What is the man doing?'
a. Mo-nna o swiela le-bati.
CL1-man CL1 sweep CL5-floor
'The man is sweeping the floor.'
b. O swiela lebati.

The grammaticality of (11-b) shows that the preverbal subject is given information in this context as it has been mentioned immediately before. That the subject can be dropped, is expected, as Northern Sotho shows the characteristics of a pro-drop language.

However, not all logical subjects which are given by discourse can appear in preverbal subject position. This is illustrated by the data in (12). In (12-a-c), the subject is given in discourse by having been mentioned before explicitly as alternatives to the question. Nevertheless, the questioned constituent appears in a cleft sentence in the answer. Data comparable to the ones elicited in (12-a) can also be found in natural speech taken from the questionnaire, as in (12-b). The example in (12-d) shows that also givenness by worldknowledge does not obligatorily lead to a preverbal occurrence of the subject.

a. (i) Ké mang a bala-ng puku, Masilo goba Molatelo? COP who CL1 read-REL CL9.book PROP.NAME or PROP.NAME 'Who is reading the book, Masilo or Molatelo?'

(ii) Ké Masilo a bala-ng puku. COP PROP.NAME CL1 read-REL CL9.book 'MASILO is reading the book.'

b. (i) Ké mang a bula-ng le-tsikanope ka morago ga COP who CL1 open-REL CL5-window PREP after PREP kopano - monna goba mosadi? CL9.meeting man or woman 'Who opens the window after the meeting - the man or the woman?' (QUIS)

(ii) Ké mo-nna a bula-ng le-tsikanope ka morago ga COP CL1-man CL1 open-REL CL5-window PREP after PREP kopano. CL9.meeting 'The MAN opens the window after the meeting.' 
c. (i) Ké mang a rata-ng mma wa Karabo?

COP who CL1 like-REL CL1.mother CL1.POSS PROP.NAME

'Who likes Karabo's mother?'

(ii) Ké Karabo a rata-ng mma wa

COP PROP.NAME CL1 like-REL CL1.mother CL1.POSS

gagwe.

CL1.POSS.PR

'KARABO likes his mother.'

d. (i) Ké mang a bop-ile-ng le-fase le le-godimo?

COP who CL1 create-PST-REL CL5-ground and CL5-above 'Who created heaven and earth?'

(ii) Ké mo-dimo yo a bop-ile-ng le-fase le COP CL1-god DEM.CL1 CL1 create-PST-REL CL5-ground and le-godimo.

CL5-above

'GoD created heaven and earth.'

A preverbal occurrence of the subject in the cases of (12) is excluded, as the negative evidence from elicitation shows. This is given in (13).
a. $*[\text { Masilo }]_{F}$ o bala puku.
PROP.NAME CL1 read CL9.book
Intended: 'MASILO is reading the book.'
b. $*[$ Karabo $]]_{F}$ o rata mma wa gagwe.
PROP.NAME CL1 like CL1.mother CL1.POSS CL1.POSSPRN
Intended: 'KARABO likes his mother.'
c. $*[$ Mo-dimo $]]_{F} \mathrm{O}$ bop-ile le-fase le le-godimo.
CL1-god CL1 create-PST CL5-ground and CL5-above
Intended: 'GoD created heaven and earth.'

It can be concluded from the data in (12) and (13) that a focused logical subject, even if contextually given, does not appear preverbally.

Summary The examples in this subsection have tested if givenness is the decisive characteristics for the preverbal subject in Northern Sotho. The questions in (12) confront the addressee with explicitely mentioned alternatives.

The data show that the logical subject cannot appear in preverbal position if it is contrasted to other possible referents. Consequently, givenness is no sufficient condition for subjects in Northern Sotho. However, the contexts used conform to the definition of focus as a set of alternatives. Thus, the restriction on the preverbal subject that emerges from the data in this subsection can be captured by F-marking: The preverbal subject must not be F-marked.

The interpretatory effect, namely that subjects often represent given information in discourse, emerges indirectly from F-marking. F-marked constituents often (but crucially not exclusively!) refer to discourse-new constituents, whereas discourse-old constituents are often not F-marked. However, the cases in (12) constitute one example where a 
discourse-old constituent is F-marked. ${ }^{3}$

The notion of F-marking also captures the distribution of preverbal subjects in the examples cited in Louwrens' work (1979a), which has been presented in detail above. The preverbal appearance of the subject in the cases of situational givenness and world knowledge (see (8) and (9)) can be captured by arguing that these subjects are not Fmarked. Such a generalization is preferrable to the one used in Louwrens' (1979a), as the latter runs the risk of becoming circular when arguing that an author indicates that the description is known to the reader, only because of the preverbal appearance of subjects.

In sum, formulating a discourse-pragmatic restriction on subjects making use of a topic definition that refers to old information cannot be maintained for Northern Sotho. The subject in Northern Sotho is not necessarily a topic at discourse-level.

\section{Aboutness topic}

At the sentential level or intrasentential level, the term topic is used to refer to aboutness topics (Kuno 1972, Reinhart 1981), going back to early work on sentence structure (e.g. von Gabelentz 1891). A constituent that bears the label of aboutness topic, denotes what the rest of the sentence is about. The term topic for the preverbal subject in Bantu has been used in this interpretation in work by a.o. Givón (1976), Bresnan \& Mchombo (1987), Demuth \& Mmusi (1997).

There are certain grammatical restrictions on constituents that can act as aboutness topics. They are grounded in semantic considerations (certain operators and definiteness) and discourse considerations (thetic sentences and wide focus). These aspects will be tested in the following subsections in order to investigate if aboutness topic is the relevant notion for the preverbal subject in Northern Sotho.

Operators A test for aboutness topics is the occurrence of certain operators. Noun phrases containing operators like 'no one' and 'about' cannot function as aboutness topics. The data in (14) show that these operators do not appear in preverbal position in Northern Sotho.

a. Ga go na mo-tho yo a dumediša-ng mo-rutiši. NEG CL17 be CL1-person DEM.CL1 CL1 greet-REL CL1-teacher Lit. 'There is not a person who is greeting the teacher.', 'No one is greeting the teacher.'

b. Ga go mang a tseba-go gore mo-lato ké eng. NEG CL17 who CL1 know-REL that CL3-problem COP what Lit. 'There is not who that knows that the problem is what.', 'Nobody knows what the problem is.' (corpus, B721)

c. [...] eupša e fo ba polobolo yeo go se go mang a [...] but CL9 still only CL9.talk CL9.DEM CL17 NEG CL17 who CL1 ka kgona-go go e fa le-ina. POT be.able-REL CL15 CL9 give CL5-name Lit. '...it is just a talk which no one can give name to.' (corpus, B1181)

\footnotetext{
${ }^{3}$ For the opposite case in which a discourse-new element is not F-marked see examples under wide focus in the next section.
} 
d. Ké ba-ithuti ba e-ka-bago ba ba-raro ba ba COP CL2-student CL2 about QUAL.CL2 CL2-three DEM.CL2 CL2 be-go ba dir-ile mo-šomo wa gae.

PST-REL CL2 do-PST CL3-work POSS.CL3 home

Lit. 'It is students that can be three that had done their homework.' 'About three students had done their homework.'

(answering the question: 'How did your class go yesterday?')

The data in (14) show that if the subject of the sentence is an operator like 'no one' or contains an operator like 'about', it does not appear in its canonical preverbal position, but in a cleft sentence instead. ${ }^{4}$

The data in (15) show that the operator 'about' can indeed occur in an in situ structure which suggests that the incompatibility in (14-d) is because of the syntactic function it fulfills in this case. Also, the occurrence of the negation structure with constituents in situ, as in (15-b), suggests an incompatibility of 'no one' and the preverbal position.

a. [Ke bana ba bakae bao ba bego ba le mo?- 'How many children were here?']

Ga ke gopole botse, eupša ke bone ba-na e-ka-rego ba

NEG 1 remember.NEg well but 1 see.PST CL2-child about CL2

ba-hlano.

CL2-five

'I don't remember well, but I saw about five.'

b. Mo-rutiši ga a dumediše mo-tho.

CL1-teacher NEG CL1 greet.NEG CL1-person

Lit. 'The teacher is not greeting a person.', 'The teacher doesn't greet anyone.'

In both structures in (15), the operators under consideration have scope over the object. In both cases, the constituent they have scope over appears in its in situ position.

The data in (14) and (15) show that certain operators are ungrammatical in preverbal subject position. These operators correspond to the constituents that have been argued to be excluded as aboutness topics for semantic reasons. Consequently, the incompatibility of these operators in preverbal position supports an aboutness topic interpretation for this position and therefore for the preverbal subject in Northern Sotho.

${ }^{4}$ The subject containing an 'about'-expression can also appear in preverbal position as in (i).

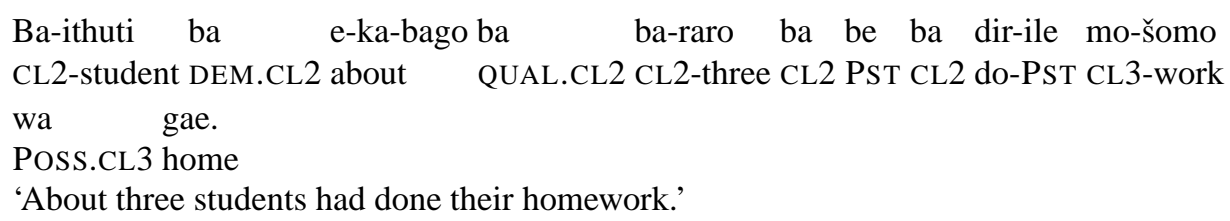

However, the fact that the cleft construction is also natural in this context is interpreted here as pointing towards a tendency of not having the structure containing 'about' in preverbal position. Nothing crucial hinges on this assumption. 
Thetic sentences Thetic sentences do not have topics (Kuroda 1972, Sasse 1987). Contrary to categorical sentences which name an entity and make a statement about it (cf. aboutness topic), thetic sentences lack this bipartite structure and are logically unstructured. Thetic sentences express an event or a situation or state. A typical example is the sentence 'It is raining.'. Impersonal constructions lack on overt subject and are therefore prototypical examples of thetic sentences. Sentences having a grammatical subject, on the other hand, are always taken to constitute examples of categorical sentences (Sasse 1987: 513) (but see counterexamples from Northern Sotho). Japanese is an example for a language that has the thetic/categorical distinction implemented in its grammar (Kuroda 1972). The distribution of the particles $w a$ and $g a$ depends on the interpetation of the sentence. According to Kuroda (1972), if an entity is marked by the particle wa (also called topic marker, Kuno 1972), the sentence is to be interpreted as categorical. Otherwise the grammatical subject is marked by $g a$ and the sentence is thetic.

Cross-linguistically, thetic sentences differ from categorical statements in word order and intonation (Sasse 1987). The sentences in (16) have been categorized as thetic sentences in German, based on intonation. In contrast to bipartite structures in which the verb bears the sentence accent, in (16) it is the subject that bears an accent . The grammatical subject in these sentences does not act as topic, as thetic sentence do not show the topic-comment structure.
Thetic sentences in German
a. Die Polizei kommt. The POLICE arrives.
b. Die SonNE geht auf. 'The SUN rises.'
c. Meine SCHWESTER ist gestorben. 'My SISTER died.'

The accent placement on the subject instead of the verb, as would be predicted by general accent placement rules, gives evidence for the non-bipartite structure of these sentence. The prediction concerning Northern Sotho therefore is, that if the subject is a topic in Northern Sotho, the syntactic subject position has to remain empty in thetic sentences. The data in (17) show sentences from Northern Sotho that correspond to the sentences in (16).

(17) Thetic sentences in Northern Sotho

a. Ke bone kotsi e direga maabane kgauswi le gagešu. Monna o be a rapaletše tseleng. Batho ba be ba eme ba lebeletše. Amalantshe e ile ya tla. Banna ba amalantshe ba ile ba thuša monna yoo, gomme ba mo rwalela bookelong. 'I saw an accident close to my home yesterday. A man was lying on the street. People stood and watched. An ambulance came. The ambulance men took care of the man and took him to the hospital.'

b. Go fapana le nageng ya Germany, matšatši a na le botelele bja go lekana ka Afrika-Borwa. Letšatši le hlaba ka 6 a.m. Mathapama letšatši le dikela ka 5 p.m. Ga go na phapano e kaalo magareng ga dihla ge go etla go botelele bja letšatši. 
'In contrast to Germany, in South Africa days always have the same length. The sun rises at $6 \mathrm{a} . \mathrm{m}$. In the evening the sun sets at 5 p.m. There is not much difference between the different seasons in what concerns the length of the day.'

c. Ke be ke le gae bošego bja go feta ka lebeletše TV. Mogala o ile wa lla. E be ele mma. ${ }^{5} \mathrm{O}$ rile 'Mogolo wa gago o hlokofetše.' Ke ile ka lla gomme ka gopola go ya gae gabomma ka yona nako yeo.

'I was at home last night watching TV. The telephone rang. My mother was on the phone. She said: 'Your sister died.' I cried and decided to go home to my mother's place immediately.'

In all the sentences in (17), the subject appears preverbally. The native speakers I worked with prefer the sentence displaying canonical word order to the impersonal construction. The occurrence of the subject in preverbal subject position in thetic sentences contradicts an obligatory aboutness topic interpretation of preverbal subjects in Northern Sotho.

Definiteness Another test for aboutness topics is definiteness. Indefinites and nonspecific NPs cannot be aboutness topics. If preverbal subjects in Northern Sotho were indeed aboutness topics, then no indefinite or non-specific NPs can appear in preverbal position.

In some languages, definiteness is grammaticalized in the distribution of the definite and indefinite article. Like Bantu languages in general, Northern Sotho does not have articles. It neither has pre-prefixes which serve a similar goal in other Bantu languages (Meinhof 1948:68f, Hyman \& Katamba 1993), for example in Dzamba (Bokamba 1971). Neither have the subject and object markers in Northern Sotho been reported to fulfill this function, e.g. Doke (1955: 9) reports that in Zulu only definite subjects agree with the verb. Only context can serve as an indicator for definiteness and specificity in Northern Sotho. Mojapelo (2003, in prep.) shows that subjects are not necessarily definite and specific in Northern Sotho. The examples in (18) are grammatical and felicitous.

a. [When reporting that my car was stolen]

Ma-hodu a utsw-itše koloi ya ka.

CL6-thief CL6 steal-PST CL9.car CL9.POSS PERSPR.1

'Thieves stole my car.'

b. [Possible responses to a cry from outside]

(i) Ngwana o a hwa mo ntle!

CL1.child CL1 -A- die LOC outside

'A child is dying outside.'

${ }^{5}$ Thanks to Daniel Schmidt for directing my attention to this sentence.

(i)
$E$ be e le mma.
CL9 PST CL9 with CL1.mother
Lit. 'There was with mother.'

The logical subject appears postverbally and does not agree with the verb. The verb shows agreement with class 9 , in contrast to the impersonal constructions discussed so far, where the verb shows agreement with class 17 . This example is the only construction of this kind in my corpus so far and needs further research. 

(ii) Mo-tho o bolaya ngwana mo ntle.
CL1-person CL1 kill CL1.child LOC outside
'Someone is killing a child outside.'

The context makes clear that at sentential level, the subjects are indefinite and nonspecific. The lack of definiteness/specificity effects contradicts an aboutness-analysis of the preverbal subject in Northern Sotho as indefinites and non-specific NPs do appear in preverbal subject position. ${ }^{6}$

Wide focus Further evidence against an obligatory aboutness topic interpretation of the preverbal subject in Northern Sotho comes from its occurrence under wide focus. This aspect is closely related to the aspect of definiteness and thetic sentences discussed above. A thetic reading, i.e. a logically unstructured statement which expresses an event or situation, can be evoked systematically by all-new questions. Kuno (1972: 298) introduces the term 'neutral descriptions' for sentences which do not contain any discoursepragmatically presupposed material and which are typically found after expressions such as 'Oh look!' or 'What happened then?' (termed 'all-new utterances' in Schmerling 1976). Kuno's characterization and the information concerning the distribution of 'neutral descriptive' sentences conform well to thetic sentences as described in Kuroda (1972). Therefore, under wide focus, it cannot be maintained that the predicate makes a statement about the subject of the sentence. Rather, the whole sentence serves as making a statement about a situation. Utterances appearing in all-new contexts or elicited by questions such as Molato ke eng?- 'What's up?' or Go direga eng?- 'What is happening?' show that a logical subject can appear in its canonical preverbal position. ${ }^{7}$ The data in (19) are taken from Mojapelo (2003), and represent examples that are uttered in an all-new context.

\footnotetext{
${ }^{6}$ Northern Sotho does not show definiteness or specificty effects in contexts where they occur in English. One example are impersonal constructions. The English sentence in (i-a) is ungrammatical in which a definite subject appears in postverbal position. However, the Northern Sotho the counterpart in (i-b) is grammatical, see also (10-b).
}

$$
\begin{aligned}
& \text { a. *There is sleeping John in the bed. } \\
& \text { b. Go robala Karabo mo mpte-ng. } \\
& \text { CL17 sleep PROP.NAME PREP CL9.bed-LOC } \\
& \text { Lit. 'There is sleeping Karabo in the bed.' }
\end{aligned}
$$

More work needs to be done on definiteness in Northern Sotho to find out if it behaves parallely to English and if therefore the same tests relating to definiteness and specificity can be applied to test for properties of topics (see Mojapelo in prep.).

${ }^{7}$ Also in multiple questions a focused subject can appear in its canonical preverbal position. Examples are given in (i).
(i) a. 1)
Mang o fa mma eng? who CL1 give CL1.mother what 'Who gives mother what?'
2) $[\text { Malome }]_{F} \mathrm{O}$ fa mma $[\mathrm{mpho}]_{F}$. CL1.uncle CL1 give CL1.mother CL9.gift 'The uncle gives mother a gift.'
b. 1) Ké mang a fa-ng mma eng? COP who CL1 give-REL CL1.mother what 'Who gives mother what?' 
a. [When reporting that my car was stolen]

Ma-hodu a utswitše koloi ya ka. CL6-thief CL6 steal.PST CL9.car CL9.POSS PERSPR.1

'Thieves stole my car.'

b. [Possible responses to a cry from outside]

(i) Ngwana o a hwa mo ntle!

CL1.child CL1 -A- die LOC outside

'A child is dying outside.'

(ii) Mo-tho o bolaya ngwana mo ntle.

CL1-person CL1 kill CL1.child LOC outside

Lit. 'Someone is killing a child outside.'/ 'Someone is beating a child.'

c. Stage directions

Le-rumo le ja mo-tho, go tuka mo-llo wa di-thunya.

CL5-spear CL5 eat CL1-person CL17 burn CL3-fire CL3.POSS CL8-gun

'A spear kills a person, there is gunfire burning.'

Makwala (1997)

In (19), the logical subjects appear in preverbal position and agree with the verb. Examples like in (19) can be elicited systematically by all-new contexts. The data in (20) show examples in which the logical subject is part of a larger focus domain and appears preverbally. The data have been elicited in the interaction of two native speakers by means of pictures from the questionnaire. The preceding question or instruction is indicated by the context in square brackets.

a. [Go diregang?- 'What is happening?']

(i) Le-sea le robetše.

CL5-baby CL5 sleep.PST

'A baby is sleeping.'

(QUIS)

(ii) Mma o ruta ngwana go bala buka.

CL1.mother CL1 teach CL1.child CL15 read CL9.book

'A mother teaches a child to read a book.'

(QUIS)

b. [Hlaloša seo o se bonang!- 'Describe what you see!']

(i) Matome o na le ma-gapu a ma-raro

PROP.NAME CL1 be with CL6-watermelon QUAL.CL6 CL6-three gomme Lesiba o na le ma-gapu a

and PROP.NAME CL1 have be with CL6-watermelon

ma-ne

QUAL.CL6 CL6-four

'Matome has three water melons whereas Lesiba has four.' (QUIS)

2) Ké malome a fa-ng mma mpho.

COP CL1.uncle CL1 give-REL CL1.mother CL9.gift

'The uncle gives mother a gift.'

However, with multiple questions also cleft structures are possible as shown in (i-b). Multiple questions will not be addressed here. See Haida (in prep.) for issues pertaining to multiple questions. 
(ii) Ngwana o nametše karikana ya di-tonki gomme CL1.child CL1 climb.PST CL9.wagon CL9 CL10-donkey and ka thoko go eme mo-nna.

PREP next CL17 stand.PST CL1-man

'A child is sitting on a donkey waggon while next to it is standing a man.'

(QUIS)

c. [Go direga eng mo?- 'What is happening here?']

(i) Mo-sadi le mo-nna ba a atl-ana.

CL1-woman and CL1-man CL2 -A- kiss-REC

'A woman and a man are kissing each other.'

(QUIS)

(ii) Katse e a rutha.

CL9.cat CL9-A- swim

'A cat is swimming.'

(QUIS)

(iii) Mo-nna o rema kota.

CL1-man CL1 chop CL9.wood

'A man is chopping wood.'

In all the examples in (20), both the preceding question and the fact that the corresponding picture that had to be described has been shown for the first time, indicates that the following sentence contains only new information. When being part of a wide focus, a discourse-new logical subject can appear in preverbal position. Further examples come from the opening sentences of descriptions of scenarios, elicited by means of short video sequences contained in the questionnaire.

Description of scenarios

a. Mo-nna o tšwa ka ntlo-ng a swere mo-eta [...]. CL1-man CL1 leave PREP CL9.house-LOC CL1 hold.PST CL3-pot

'A man leaves a house, he carries a bucket [...]'

b. Ngwana wa mo-setsana o dutše godimo ga mo-ngatse ka CL1.child POSS.CL1 CL1-girl CL1 sit above PREP CL3-hat PREP fase ga mo-hlare. [...]

under PREP CL3-tree

'A girl is sitting on top of a hat under a tree.'

Also in opening sentences when describing a scene, the logical subject can appear in preverbal position in Northern Sotho. However, also the appearance of the logical subject in an impersonal construction when discourse-new, appears in the corpus and is given in (22).

$$
\begin{aligned}
& \text { Go tšwelela mo-sadi gomme o lebantšha mo-nna [...] } \\
& \text { CL17 appear CL1-woman and CL1 place.opposite CL1-man } \\
& \text { 'There appears a woman, she places herself opposite the man.' }
\end{aligned}
$$

In contrast to French (cf. Sasse 1987), however, it is ungrammatical in Northern Sotho to place the logical subject in a cleft construction when it is not the focused constituents itself, but only part of a larger focus. This is illustrated in (23). The data are taken from elicitation, as negative evidence does not appear in any text collection that is based on 
natural speech.
a. [Go diregile eng?- 'What is happening?']
(i) $[\text { Mo-nna o bo-etše gae }]_{F}$
CL1-man CL1 return-PST home
'The man came back home.'
(ii) *Ké monna (yo) a boetšeng gae.

b. [Go diregile eng ka namune?- 'What happened to the orange?']
(i) $[\text { Mo-nna o e jele }]_{F}$
CL1-man CL1 CL9 eat.PST
'A man ate it.'
(ii) *Ké monna yo a e jeleng.

Summary The preceding section has investigated if the appearance of a logical subject in preverbal position in Northern Sotho is restricted to subjects which are interpreted as aboutness topics. It has emerged from the data that the ungrammaticality of certain operators in preverbal position supports such an analysis. However, the occurrence of a preverbal subject in thetic sentences and under wide focus contradicts the aboutness topic restriction for preverbal subjects, as cross-linguistically these contexts are argued to lack a sentence topic. Also the occurrence of subjects in preverbal position that must be interpreted as indefinite and non-specific, contradict an aboutness topic analysis.

This thesis has argued that the valid characterization of the preverbal position in Northern Sotho with respect to its information structural status is that preverbal subjects must not be F-marked. This generalization does not make the wrong predictions concerning the data presented in this section. Neither under wide focus nor in thetic sentences is a logical subject F-marked. Consequently, it can appear in the preverbal position.

With respect to definiteness, F-marking can freely combine with definite or indefinite readings, just like with discourse status of old and new, as discussed in connection with familiarity topics. Therefore, the generalization that preverbal subjects must not be F-marked does not make any predictions about the interpretation with respect to definiteness. It only predicts that F-marked definite or indefinite subjects must not appear in preverbal position.

If the relevance of the notion of aboutness topic is discarded for the grammar of Northern Sotho, the ungrammaticality of certain operators in preverbal position remains unaccounted for. Remember that the notion of aboutness topic made the right prediction with respect to the occurrence of 'no one' and the occurrence of constituents containing 'about' in preverbal position.

For negation, there are two possible alternative explanations that will be briefly sketched out. One approach is to argue that negation is F-marked. An intrinsic morphosyntactic focus, $[+\mathrm{F}]$, has been assumed for negation in the literature on Bantu languages (Hyman \& Watters 1984, Hyman 1999), given its marked semantic status. This intrinsic morphosyntactic $[+\mathrm{F}]$ represents a "secondary focus" which is not semantically interpreted but acts in the grammar. Another explanation might lie in restrictions about the scope of verb negation. Verb negation can only have scope over what follows, but not over a preceding 
subject. Consequently, the sentence in (24) negates the predicate, but is not identical to 'No one eats an orange.'.

$$
\begin{aligned}
& \text { Mo-tho ga a j-e namune. } \\
& \text { CL1-person NEG CL1 eat-NEG CL9.orange } \\
& \text { 'Someone does not eat an orange.' }
\end{aligned}
$$

As there is no determiner negation in Northern Sotho, the only way of negating a logical subject is letting it occur in a construction where it appears postverbally. A cleft structure is such a construction. Obviously, the account for the lack of preverbal negation remains an area of further research. As for the occurrence of operators such as about, their complex syntactic structure qualifies them as a research area in its own rights.

In sum, the data presented contradict an obligatory aboutness topic interpretation of the preverbal subject in Northern Sotho.

\subsubsection{Summary}

The two preceding sections have shown that the preverbal subject in Northern Sotho is neither a familiarity nor an aboutness topic. The generalization that can be drawn from the data in Northern Sotho is that the preverbal subject must not be narrowly focused. Thereby it is shown that the discourse-pragmatic dichotomy of given/new or topic/focus that is often used in information structural research in Bantu languages cannot account for the data in Northern Sotho. How these notions intersect, is illustrated by table 10 .

Table 10: Subject and discourse status in Northern Sotho

\begin{tabular}{|l|l|l|}
\hline syntactic position & information structural context & discourse-status \\
\hline \hline preverbal & focus on non-subject & old information \\
\hline preverbal & wide focus & new information \\
\hline cleft, postverbal & narrow focus on subject & new information \\
\hline
\end{tabular}

In equalling the preverbal position with a familiarity or aboutness topic, the appearance of preverbal subjects under wide focus in Northern Sotho is not captured. The old/new dichotomy (Givón 1976, Louwrens 1979a, Bresnan \& Mchombo 1987) can therefore not account for the data. The difference between narrow and wide focus can be captured by F-marking, in that only narrowly focused subjects are F-marked.

This finding has implications for the preverbal subject position in Northern Sotho, both with respect to its interpretation as well as with respect to its syntactic structure. First, it should have become clear that SpecIP, the position in which the subject generates agreement with the verb, is not a topic position, but is restricted to constituents bearing the highest thematic role. The restriction to constituents with the highest thematic role instead of topics can explain the absence of any inversion structures in Northern Sotho in which another constituent than the subject appears preverbally and expresses agreement with the verb. For other Bantu languages, inversion structures have been reported that place either a locative or a logical object in the position of a grammatical subject if it is the topic of the sentence. The subject position is claimed to be a topic position in these languages. This has been argued for locative inversion in Chichewa by Bresnan \& Kanerva (1989) and for 
subject/object reversal in Kinyarwanda and Kirundi by Morimoto (2000). Northern Sotho, however, does not show any of these structures (see Baker 1992 and Zerbian 2004a for arguments against locative inversion in Sotho). The preverbal position in Northern Sotho is exclusively reserved for constituents bearing the highest thematic role.

The detachment of the grammatical function of subject from the discourse notion topic has implications for the syntactic position of the preverbal subject constituent and the syntactic status of the agreement marker. In section 1.7.3 it has been discussed that the equation of subject with topic has been interpreted as evidence for its syntactic status as obligatorily dislocated constituent (see Demuth \& Johnson 1989 for Sesotho, Baker 2003 for Kinande). Accordingly, the subject marker has been analysed as marking anaphoric agreement. Taking discourse-pragmatic interpretation as indicative for syntactic structure, however, the data presented in this chapter have shown that under wide focus and in thetic sentences, the subject constituent cannot be considered dislocated. Consequently, these contexts provide further evidence for the status of grammatical agreement of the subject marker in Northern Sotho (next to the context of wh-questions in Chichewa, Bresnan \& Mchombo 1987).

The next section presents how the generalization that preverbal subjects must not be F-marked can be derived in a grammar without stipulating it. The mechanism for the derivation of this generalization is taken from the inventory of schemata for constraint formulation within Optimality Theory (OT).

\subsection{Influence of information structure on syntax}

The view taken in this thesis is that information structure directly influences syntax. Evidence for this view comes from the observation that in Northern Sotho, F-marking prevents a logical subject to appear in preverbal position. A subject/non-subject asymmetry as the one in Northern Sotho has also been described for other Bantu languages such as Kinyarwanda (Kimenyi 1980), Dzamba (Bokamba 1976), Kitharaka (Muriungi, to appear), and the Nguni languages (Sabel \& Zeller, to appear). Sabel \& Zeller (to appear) capture the asymmetry by the generalization in (25).

*wh-in Spec TP

They acknowledge the functional explanation for the generalization in (25) which is based on the incompatibility of $w h$-phrases and topic. However, they criticize that a functional account of (25) predicts that $w h$-phrases are banned from SpecTP in all languages. They are right in their criticism that the prediction that all languages show a ban of wh-phrases in subject position can easily be falsified. English is such a language. Therefore, Sabel \& Zeller (to appear) argue that (25) must be a parameterized property of SpecTP. However,

"[I]t is not clear how the fact that (25) is a parameterized property of SpecTP can be captured in this approach." (Sabel \& Zeller, to appear: 5)

This section will show how a 'parameterization' of the functional account can be modeled and implemented in grammar by means of an Optimality-theoretic approach through (re)ranking of the syntax-pragmatics interface constraint. 
First, the relevant interface constraint is motivated and derived in section 4.3.1. The constraint schema used is harmonic alignment. The ban of focused constituents from preverbal position can be captured by aligning the grammatical function scale and the prominence scale. Contrary to existing work, this section argues for a differentiation of the prominence scale into a focus and a topic scale.

Then, the influence of information structure is modeled in section 4.3.2, making use of the constraint motivated in the preceding section. By a systematic comparison to the syntactic account by Sabel \& Zeller (to appear), this section shows that the approach proposed here does not diverge from Principles \& Parameter-style theories in its basic syntactic assumptions but only in the role information structure plays.

Throughout the following sections it will become clear that the OT-approach goes beyond sole modelling of parameterization. First, it assigns information structure an active role in shaping syntax, a view that is maintained not only for discourse-configurational languages in which a certain position is reserved for the focused constituent, but also for e.g. German (Büring 2000). In Principles \& Parameter-style approaches, information structure finds its way into syntax via syntactic phrases (Topic Phrase or Focus Phrase, see e.g. Rizzi 1997, Brody 1990). The direct influence that discourse-pragmatics has on syntax in an OT-approach has an empirical advantage over an approach that assumes the mediation of discourse-pragmatically motivated syntactic phrases: In Northern Sotho, there is no evidence neither for a fixed Focus Phrase nor for a Topic Phrase that contains the subject (see chapter 2 against a fixed Focus Phrase, and the preceding sections against an obligatory topic interpretation of the preverbal subject).

Second, because constraints in OT have to fulfill certain requirements with respect to their formal format, the interface constraint proposed here is not in danger of expressing a mere stipulation as a parameterization parameter is.

Finally, the framework of OT allows to model the interaction of syntax and information structure, or form and function more generally. This aspect will be taken up in chapter 5 .

As mentioned already in the introduction to this chapter, the idea to capture the ban of focused subjects from preverbal position within Optimality Theory is going to be published in Zerbian (under review b). The following sections differ from the paper in both exposition and the actual constraint postulated.

\subsubsection{The interface constraint}

This section derives the constraint that mediates between information structure and syntax in Northern Sotho (and possibly in other languages as well) and that captures the generalization in (25).

First, the constraint schema of harmonic alignment will be introduced. By relating to an approved schema for the formulation of the relevant constraint, the objection common to OT-analyses is replied to, namely that the constraint merely describes the observable facts and is stipulated. Then, the alignment of the two prominence scales which are involved will be technically derived. As a consequence it falls out automatically that it is with respect to the subject, and not the object, that there exists a restriction which is related to information structure. Then, the assumed split into a topic and a focus scale is 
motivated. Thereby, it emerges that through harmonic alignment of those two scales, the relation between F-marking and topichood can be derived, which makes it clear why in the literature the preverbal subject is often characterized as a topic in Bantu languages.

\section{Harmonic alignment}

Language is full of natural scales, with one end more prominent, in an abstract sense, than the other. These prominence scales are inferred orderings of linguistic objects. Examples for prominence scales can be found in any area of grammar: the sonority scale on which vowels are more prominent than liquids, which are more prominent than nasals; the person scale on which the first person is more prominent than the second which is more prominent than the third; or the grammatical relation scale on which the subject is more prominent than the object and the accusative is more prominent than the dative and so on.

Two natural linguistic scales can be combined to derive a harmony scale on which a linguistic element combining properties from the two scales is more harmonic than a linguistic element combining different properties from the same scales. Harmonic alignment of prominence scales thereby establishes a preferred correlation between two distinct but related dimensions. Harmonic alignment of prominence scales is introduced in Prince \& Smolensky (1993: Chapter 6,8).

Harmonic alignment is defined as in (26) (following Prince \& Smolensky 1993: 136):

\section{Harmonic alignment}

Given a binary dimension $\mathrm{D}_{1}$, with a scale $\mathrm{X}>\mathrm{Y}$ and another dimension $\mathrm{D}_{2}$ with a scale $\mathrm{a}>\mathrm{b} \ldots>\mathrm{z}$, the harmonic alignment of $\mathrm{D}_{1}$ and $\mathrm{D}_{2}$ is the following pair of harmony scales:
a. $\mathrm{H}_{x}=\mathrm{X} / \mathrm{a}>\mathrm{X} / \mathrm{b}>\ldots>\mathrm{X} / \mathrm{z}$
b. $\quad \mathrm{H}_{y}=\mathrm{Y} / \mathrm{z}>\ldots .>\mathrm{Y} / \mathrm{b}>\mathrm{Y} / \mathrm{a}$
The constraint alignment is the following pair of constraint hierarchies:
c. $\quad \mathrm{C}_{x}=* \mathrm{X} / \mathrm{z} \gg \ldots \gg * \mathrm{X} / \mathrm{b} \gg * \mathrm{X} / \mathrm{a}$
d. $\quad \mathrm{C}_{y}=* \mathrm{Y} / \mathrm{a} \gg * \mathrm{Y} / \mathrm{b} \gg \ldots * \mathrm{Y} / \mathrm{z}$

Sonority preferences in different syllable positions will serve as an example for the technical definition in (26) (from McCarthy 2002: 22). The syllable-position prominence scale, given in (27-a), can be combined with the sonority scale, given in (27-b), to form two harmony scales. These are given in $(27-\mathrm{c}, \mathrm{d})$.
Harmonic alignment
a. syllable position: Nucleus $>$ Onset
b. $\quad$ sonority: vowel $>$ liquid $>$ nasal $>$ fricative $>$ stop
c. harmony scale I: Nucleus/vowel $>$ Nucleus/liquid $>\ldots$
d. harmony scale II: Onset/stop $>$ Onset/fricative $>\ldots$

Following the schema in (26), harmony scales are derived by aligning the most prominent element from a binary scale with the elements of the second scale, starting with the most prominent one, and by aligning the least prominent element from the binary scale with the elements of the second scale starting with the least prominent one. For the use in an 
OT-framework, these harmony scales are transformed by contraposition into universally fixed constraint hierarchies, given in $(28-a, b)$.

Constraint hierarchy from harmonic alignment

a. constraint hierarchy I: ... $\gg *$ NUCLEUS/LIQUID $\gg *$ NUCLEUS/VOWEL

b. constraint hierarchy II: ... \*ONSET/FRICATIVE $\gg *$ ONSET/STOP

Both constraint hierarchies in $(28-a, b)$ have important empirical consequences: the nucleus hierarchy accounts for the implicational universal that some languages have only vowel nuclei (Italian) and some have both liquid and vowel nuclei (English, German), but no language has only liquid nuclei; the effect of the onset hierarchy can be observed in early acquisition, when many children avoid nasal or liquid onsets.

\section{Interface between information structure and syntax}

The constraint that captures the generalization that F-marked logical subjects must not appear in preverbal position will be derived in this section by harmonically aligning the respective scales.

The generalization suggests that the prominence scales involved are on the one hand the grammatical relation scale, consisting of at least subject and object, and on the other hand a discourse prominence scale, referring to F-marked and non-F-marked. The two prominence scales, which are part of universal grammar, are given in (29) (for a literature review and discussion of the discourse prominence scale see next subsection).

$$
\begin{aligned}
& \text { Prominence scales } \\
& \text { a. Relational scale: Subject }>\text { Non-subject }\left(D_{1}\right) \\
& \text { b. } \quad \text { Focus scale: Non-F-marked }>\text { F-marked }\left(D_{2}\right)
\end{aligned}
$$

Two natural linguistic scales as the ones in (29) can be combined to form two harmony scales by aligning their most and least prominent elements. By aligning the scales in (29), the harmony scales in (30) are reached at.

Harmony scales

a. $\quad \mathrm{H}_{\text {subject }}=$ Subject/Non-F-marked $>$ Subject/F-marked

b. $\quad \mathrm{H}_{\text {nonsubject }}=$ Non-subject/F-marked $>$ Non-subject/Non-F-marked

Of one harmony scale, $\mathrm{H}_{\text {subject }}$, the more prominent member of the scale $\mathrm{D}_{1}$ is mapped onto the other scale $\mathrm{D}_{2}$ in $\mathrm{D}_{2}$ 's order. Hence, a prominent element on one scale combines most felicitously with a prominent element on the other scale, and so on down the line. The prominent Subject combines least felicitously with $F$-marked, which is least prominent on $\mathrm{D}_{2}$. Conversely, in $\mathrm{H}_{\text {Nonsubject }}$, the less prominent member of the (binary) scale $D_{1}$ is mapped onto $D_{2}$ in the opposite of $D_{2}$ 's order. The least prominent element on one scale combines most felicitously with the least prominent element on the other scale, and so on up the line.

From the harmony scales the constraint hierarchies are derived via contraposition. The notation Subject/Non-F-marked describes a linguistic element that combines the properties of being subject and non-F-marked. Consequently, the notation *SUBJECT/NON-F- 
MARKED denotes a constraint that Subject/Non-F-marked violates. From the harmony scales in (30), the following pair of constraint hierarchies are derived:

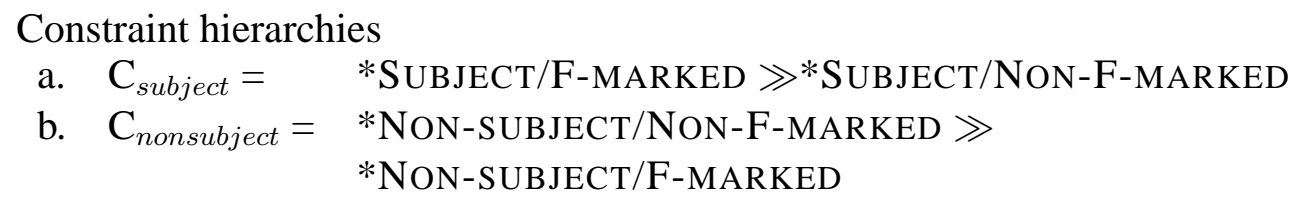

The notation *SUBJECT/F-MARKED denotes a constraint that a constituent displaying the properties Subject/F-marked violates. Both constraint hierarchies in (31) have empirical consequences: The subject hierarchy in (31-a) accounts for the observation that some languages do not allow a focused constituent in subject position, as is the case with Northern Sotho e.g. The object hierarchy in (31-b) accounts for the observation that objects tend to be (part of the) F-marked information.

\section{Prominence scales}

The prominence scales in (29), which were used for the derivation of the crucial interface constraint, have their precedents in the literature. The relational scale is uncontroversial and has been assumed (or proposed) by linguists working in a variety of frameworks (see Aissen 1999 for references).

A discourse prominence scale different from the one in (29) can be found in the work by Aissen (1999) and Lee (2000). Their proposals are given in (32).

Discourse prominence scale
a. Aissen (1999): Topic $>$ Focus
b. Lee (2000): $[-\mathrm{NEW}]>[+\mathrm{NEW}]$

By aligning the discourse prominence scale in (32) to the relational scale, Aissen (1999) derives constraints which are similar to the ones proposed in the preceding section. The constraint *SUBJECT/F-MARKED is similar in its idea to the constraint *SU/X proposed in Aissen (1999: 684). ${ }^{*} \mathrm{SU} / \mathrm{X}$ together with $* \mathrm{SU} / \mathrm{X}$ are constraints that encode pressure on subject choice which is grounded in discourse prominence (Aissen 1999: 684). Capital $\mathrm{X}$ represents a more prominent element (Topic in (32)), lowercase $\mathrm{x}$ a less prominent one (Focus in (32)). Prominence is to be understood as thematic prominence which equals topicality in the discussion here. ${ }^{*} \mathrm{SU} / \mathrm{X}$ therefore means that subjects should be avoided which are low in thematic prominence, i.e. which are discourse new.

This thesis argues for the discourse-prominence scale in (29) that represents a split of the prominence scale as proposed by Aissen (1999), and a reinterpretation of the scale proposed by Lee (2000). The necessity of splitting Aissen's scale is that topic and focus are not elements of the same category. In general, linguistic elements belong to one and only one of the categories a scale consists of. A personal pronoun, for example, belongs to one and exactly one category of the number scale, a syntactic constituent belongs to exactly one category of the grammatical relations scale, either subject or non-subject. With respect to information structure it has been shown in chapter 1 that topic and focus are not in complementary distribution. A discourse-pragmatic entity can therefore be either or, or neither nor, or both. Respective examples are given in (33), where the subject 
is the grammatical function under consideration.

In (33-a), the subject is the focus of the sentence, in (33-b) it can be considered the topic of the sentence, whereas in (33-c) the subject is neither topic nor focus, as it constitutes only part of the all-new focus. The example in (33-d) displays a contrastive topic. In (33-d), the subject can be considered to have both focus and topic properties (Molnár 1998). The topic property is that the first clause is about 'Peter', the focus property is that 'Peter' is an alternative to 'Paul' in the second clause.
a. Context: Who ate pizza?
PETER ate pizza.
b. Context: What did Peter eat?
Peter ate PIZZA.
c. Context: What happened at the party?
Pèter àte the pízza.
d. Context: Who ate what?
PETER ate pizza, PAUL ate salade.

The reason for the reinterpretation of the scale proposed by Lee (2000) is along the same lines. It has been shown in the preceding section that the relevant criterion for the distribution of the preverbal subject is not its discourse status as old or new constituent, but the presence or absence of F-marking.

The two discourse prominence scales that are consequently proposed are given in (34).
a. Focus scale: Non-F-marked $>$ F-marked
b. Topic scale: Topic/Satzgegenstand $>$ Comment/Satzaussage

In harmonic alignment, the basic idea is that a position which is structurally more prominent attracts elements which are prominent along some relevant substantial dimension, while a position which is low in structural prominence attracts elements which are low on relevant structural dimensions. The subject is the most prominent structural position and thereby attracts elements which are releatively prominent on other substantial dimensions. Dependent on the language, subject position may attract local persons over third, proximates over obviatives, agents over patients, and so on.

The order of the members of the discourse prominence scale is argued to be grounded in discourse salience and accessibility (Aissen1999). Both topics and background (non-Fmarked) are the more 'prominent' members of the respective scale as they are more easily accessible. Taken together the discourse prominence scales and the grammatical function scale, the subject position attracts topics over non-topics and non-F-marked constituents over F-marked constituents.

The two scales proposed in (34) together with the relational scale given in (21) are independent scales and can interact in any language. The harmonic alignment of the topic scale with the grammatical relation-scale gives the constraint hierarchy of *SUBJECT/ COMMENT $>*$ SUBJECT/TOPIC (see preceding section for the parallel derivation of the alignment of relational scale and focus scale).

\footnotetext{
*SubJect/Topic

'Don't have a subject that is (part of) the comment.'
} 
If the constraint *SUBJECT/COMMENT is sufficently high-ranked in a grammar, the subject is always a topic. If the constraint *SUBJECT/COMMENT is ranked below SUBJECT, there is always a subject in a sentence independent of its information structure. In Northern Sotho, we have seen that the subject is not obligatorily a topic. Evidence is missing so far for the relevance of the topic category in Northern Sotho. *SUBJECT/COMMENT is therefore ranked below SUBJECT.

\section{Discussion}

The preceding section has technically derived the constraint *SUBJECT/F-MARKED that can account for the observable ungrammaticality of focused subjects in preverbal position. Through harmonic alignment of the relational scale and the focus scale one arrives at markedness constraints which capture cross-linguistically observable patterns. Consequently, by aligning two universal prominence scales, the observed effect is derived by means which are grounded in language universals, not stipulation. To the extent that the rankings found in particular languages instantiate universal rankings, they should not be stipulated.

One common objection against harmonic alignment concerns the ordering of elements on the scales that are to be aligned. Zeevat \& Jäger (2002) e.g. criticize that Aissen's approach (1999) is too explicit as it is as easy to formulate the inverse form/meaning associations, yielding the exact opposite languages. They argue in favor of statistical asymmetries and bidirectional learning (Zeevat \& Jäger 2002, Jäger 2004, Mattausch 2004). One response to this criticism is that at least empirically, the predicted patterns of inverse form/meaning associations are unattested.

The approach proposed here has one important implication that has not been mentioned so far. Harmonic alignment produces fixed hierarchies. Though languages vary with respect to how they rank a constraint with respect to other constraints of the grammar, the ranking of harmonically aligned constraints remains fixed. For the example discussed here, that means that *SUBJECT/NON-F-MARKED is never ranked above *SUBJECT/ FMARKED in any language.

Assuming that sentences tend to have subjects, the harmonic alignment approach consequently predicts, that there is no language for which the generalization holds that only a focused subject appears in subject position. Such a language could only be derived by a ranking as in (36), which is claimed to be excluded when the constraint originates from harmonic alignment.

\section{*SUBJECT/NON-F-MARKED $\gg$ SUBJECT}

Immediately, Hungarian comes to mind as a language where seemingly exactly this generalization holds, namely that only focused subjects appear in preverbal position. This apparent counterexample can easily be rejected, as the constraint proposed does not refer to a linear surface position but to a structural position. The preverbal position in Hungarian is not the subject position, as can be seen from the fact, that in Hungarian not only focused subjects, but any focused constituent appears in preverbal position.

This section has argued that the impossibility of a focused subject in preverbal position in Northern Sotho does not arise as a result of a syntactic focus marking strategy, but can 
be accounted for independently by the unharmonic status of F-marked preverbal subjects. The next section implements the constraint motivated here into the OT-analysis.

\subsubsection{Analysis}

This section shows how the influence of information structure on syntax is modeled in the framework of OT. It uses the interface constraint that has been motivated in the preceding section in order to account for the ungrammaticality of a focused subject in preverbal position.

Because the interface constraint is in conflict with purely syntactic requirements, it is first shown how the basic syntactic assumptions concerning agreement are translated into OT. Therefore, the syntactic constraints SUBJECT, STAY and FOC-SPEC are introduced (see also chapter 1).

Then, focus-related contexts are considered in which the interface constraint plays a crucial role. It will be shown how the interaction and ranking of the constraints postulated can account for the appearance of a focused logical subject in postverbal position.

The OT-account proposed here for the subject/object asymmetry in Northern Sotho is compared to the approach proposed by Sabel \& Zeller (to appear) for a similar asymmetry in Nguni languages (which are the Southern neighbor of the Sotho languages). This happens for three reasons: First, the account by Sabel \& Zeller (to appear) is to my knowledge the only theoretical account for the subject/object asymmetry in Bantu languages. Second, in their approach information structure is integrated by means of a fixed Focus Phrase. It will be argued below that the observable patterns in Northern Sotho cannot be accounted for likewise. Third, Sabel \& Zeller (to appear), though integrating information structural aspects into the syntax via a Focus Phrase, eventually propose a syntactic approach to the asymmetry in Nguni. The comparison of the two approaches is therefore meant to show in exactly which points a syntactic and functional approach differ.

The discussion in the following subsections expands on and supercedes Zerbian (under review b).

\section{Agreement}

The canonical sentence in Northern Sotho shows agreement between the preverbal subject and the verb. One can therefore argue that sentences in Northern Sotho need subjects in SpecIP-position, where agreement is established via Spec-Head-Agremeent. The tendency of sentences to have subjects is captured by the constraint SUBJECT (Grimshaw \& Samek-Lodovici 1998) in (37).

\section{SUBJECT}

'Sentences have overt subjects in SpecIP.'

This constraint is violated whenever a sentence does not have an overt subject.

The constraint is violated by impersonal constructions, both in languages like English and German which use expletives (Speas 1997, Legendre 2001), as well as in Northern Sotho where class 17-agreement appears on the verb and the logical subject appears postverbally. 
The subject is assumed to be base-generated in VP-internal position in Northern Sotho (e.g. Demuth \& Gruber 1995). The constraint SuBJECT in (37) is therefore in conflict with a constraint that bans movement. This constraint is given in (38).

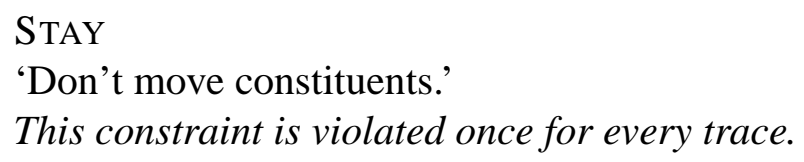

The constraint in (38) is a basic faithfulness constraint that bans movement of constituents (Grimshaw 1997, *t in Legendre et al. 1995). The more complex a movement is, that is, the more traces it creates, the more it is violated. If the constraint in (38) is ranked high, the structure and order of the input are preserved in the output. Assuming that the subject raises from VP-internal position to SpecIP-position, the occurrence of the preverbal subject in Northern Sotho shows that the constraint SUBJECT has to be ranked above the constraint banning movement. This is shown in tableau 12 for the sentence in (39).

$$
\begin{aligned}
& \text { Mo-nna o ngwal-ela ba-sadi. } \\
& \text { CL1-man CL1 write-APPL CL2-woman } \\
& \text { 'The man writes to (the) women.' }
\end{aligned}
$$

Tableau 12: Subject-verb agreement in Northern Sotho

\begin{tabular}{|ll||l|l|}
\hline & Candidates & SUBJECT & STAY \\
\hline \hline a. & {$\left[I P\left[I^{\prime}\right.\right.$ go ngwalela monna basadi $\left.]\right]$} & $* !$ & \\
\hline b. & {$\left[I P\right.$ monna $\left[I^{\prime}\right.$ o ngwalela $t$ basadi $]$} & & $*$ \\
\hline
\end{tabular}

Candidate (a) shows class 17-agreement on the verb, which is an indicator for a subject missing in SpecIP position. It violates the constraint SubJECT. As SUBJECT is ranked above STAY, the violation is fatal and candidate (b) emerges as winner. By moving the subject from VP-internal position to SpecIP, candidate (b) violates STAY. This violation can be accommodated, as STAY is ranked below SUBJECT.

There is no universal restriction that prevents GEN from creating candidates showing additional functional structure (see also Grimshaw 1997: 376). I therefore follow Grimshaw (1997) in assuming that the least complex syntactic structure emerges as a winner, all else being equal (see also Demuth 1995). This can be accounted for by the constraint in (40).

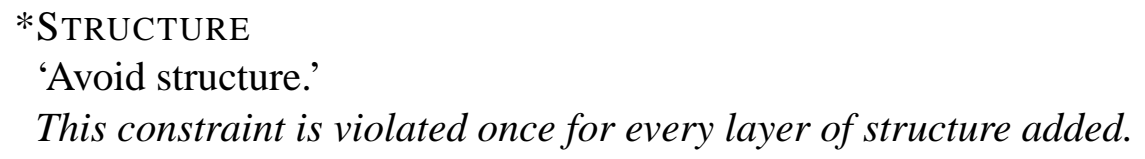

The constraint bans any additional structure and therefore prefers simpler expressions. Its presence is decisive when comparing candidates that differ only in the wealth of syntactic structure displayed. For tableau 12, a candidate such as (41) loses because it always shows one violation more than the winning candidate with respect to the constraint given in (40).

$$
\left[{ }_{C P}\left[{ }_{I P} \text { monna }\left[I^{\prime} \text { o ngwalela } t \text { basadi }\right]\right]\right]
$$


Candidates such as (41), which show additional structure, will not be considered in the tableaus unless the actual winner is among them. The reason for neglecting them in the following is that they are harmonically bound by competing candidates like the actual winner in tableau 12 . Harmonically bound means that under no constraint ranking they can emerge as winner because they always show exactly the same violations as a competing candidate plus at least one further violation (Prince \& Smolensky 1993: 162).

The constraints used in tableau 12 in order to account for subject agreement in Northern Sotho reflect the fact that subjects raise to SpecIP for reasons independent of information structure in Northern Sotho. The account of agreement does not differ substantially from the treatment of agreement in other approaches (Demuth \& Gruber 1995, Sabel \& Zeller to appear, van der Spuy 1993). In all these accounts, the preverbal subject position is considered a derived position to which the subject has moved from VP-internal position. Analyses differ with respect to the denomination of the phrase of which the subject occupies the specifier position between SpecIP (van der Spuy 1993), SpecAgrP (Demuth \& Gruber 1995) and SpecTP (Sabel \& Zeller). As this difference is not important for the phenomenon under consideration here, it can be neglected.

It is not surprising that the account of agreement does not differ when comparing the derivational approaches with the output-oriented OT-approach. As OT is only a metatheory of how grammar works, it relies on substantial syntactic theories, such as G\&B-style theories, with respect to input form and candidates.

\section{In situ focus of non-subjects}

Non-subjects are focused in their canonical position in Northern Sotho (see chapter 2). In other languages, however, focused constituents are preferred to occur in a certain syntactic position. This is the case for $w h$-words in languages like English or German, where $w h$ words have to occur in a Specifier position. Because of the universality of constraints in OT, the constraint favoring movement of $w h$-words is also present in Northern Sotho. It is called OP-SPEC (Operators must be in Specifier position, Grimshaw 1997). As focus structure behaves parallel to $w h$-structure in Northern Sotho, this constraint will be reformulated as in (42) for reasons of illustration.

$$
\begin{aligned}
& \text { FOC-SPEC } \\
& \text { 'Focused constituents must be in Specifier position.' } \\
& \text { This constraint is violated whenever a focused constituent is not in a specifier } \\
& \text { position. }
\end{aligned}
$$

The constraint in (42) is in conflict with STAY. Because postverbal constituents do not move in Northern Sotho if focused, neither in questions nor in other focus-related contexts, the constraint STAY must be ranked above the constraint favoring movement of wh-constituents in other languages. Tableau 13 illustrates the OT-account of in situ focusing for Northern Sotho. The example sentence is given in (43) and shows a double object construction in which the direct object is questioned.

$$
\begin{aligned}
& \text { Mo-nna o fa mang se-hlare? } \\
& \text { CL1-man CL1 give who CL7-medicine } \\
& \text { 'Who is the man giving medicine?' }
\end{aligned}
$$


Tableau 13: In situ focus of non-subjects

\begin{tabular}{|c|c|c|c|}
\hline & & STAY & FOC-SPEC \\
\hline a. & [ $_{C P}$ Mang $_{i F}\left[{ }_{I P}\right.$ monna o fa ${ }_{k}\left[V P t_{i} t_{k}\right.$ sehlare $\left.\left.]\right]\right]^{9}$ & *! & \\
\hline b. & {$\left[I_{I P}\left[I_{P}\right.\right.$ Monna o fa $t_{i}$ sehlare $\left.] \operatorname{mang}_{i F}\right]$} & $* !$ & $*$ \\
\hline $\mathrm{c}$. & {$\left[C P \mathrm{Ke} \mathrm{mang}_{i F}\left[I P\right.\right.$ monna a fa-ng $t_{i}$ sehlare $\left.]\right]$} & $* !$ & \\
\hline d. 棵 & [IP Monna o fa mang ${ }_{F}$ sehlare $]$ & & $*$ \\
\hline
\end{tabular}

A moved constituent to sentence-initial position (candidate a) fulfills the requirement that a focused constituent (such as a wh-operator) be in Specifier-position. However, it violates the constraint against movement (STAY), and as the latter is ranked higher in Northern Sotho, the violation is fatal. A $w h$-word moved to sentence-final (candidate b) or cleft position (candidate c) also violates the STAY-constraint crucially and these two candidates are ruled out as winners. ${ }^{10}$ Candidate (d), which does not show movement, satisfies the high-ranked constraint STAY. Though candidate (d) violates the constraint FOC-SPEC, the violation is not fatal as FoC-SPEC is ranked below STAY.

The alternative account proposed for questions in Nguni by Sabel \& Zeller (to appear) is outlined here. Their account is based on the feature checking machinery as proposed in the Minimalist Program (Chomsky 1995) and on the analysis of wh-constructions as proposed in Sabel (2000 a.o.). According to these approaches, $w h$-phrases do not check [+wh]-features but also [+focus]-features. That $w h$-words must also check a [+focus]feature is motivated by the observation that wh-words correspond to the focused constituent in an answer to a question.

The [+wh]-feature that needs to be checked by the $w h$-word is located in $\mathrm{C}^{0}$, whereas the [+focus]-feature is located in Foc ${ }^{0}$, the head of a Focus Phrase. This Focus Phrase is activated automatically in all $w$ h-questions and is generated above VP/vP and below TP (for illustration see below, see also Ndayiragije 1999). Features can be strong and weak which is subject to language-specific variation. Generally, only strong features need to be checked via a local head-specifier constellation. Sabel \& Zeller (to appear) claim that Zulu has a weak [+wh]-feature. This claim is based on the possibility of $w h$-in situ in embedded sentences and is motivated further in Sabel (1998). Because Zulu also exhibits $w h$-ex situ, they claim that Zulu optionally realizes a strong [+focus]-feature. The ex situ variant will not be discussed in detail. Here, I will concentrate on the realization of the weak [focus]-feature that accounts for in situ focus with objects.

As mentioned above, a Focus Phrase is activated automatically in all wh-questions. The resulting syntactic structure according to Sabel \& Zeller (to appear) is illustrated in (44).

\footnotetext{
${ }^{9}$ In Northern Sotho the verb moves from its base position for discourse-independent reasons. Its trace and the resulting violation of STAY are not included in the following tableaus as they are constant across all candidates. Neither is the movement of the subject to SpecIP position considered in this tableau, as it too is constant across all candidates.

${ }^{10}$ Candidate (c) has to be understood as the cleft structure that is syntactically derived from the declarative structure, as e.g. in the proposal by Sabel \& Zeller (to appear). This candidate violates further constraints that are not given here, such as *STRUCTURE.
} 
(44) In situ focus in Nguni (Sabel \& Zeller, to appear)

a. U-bona ini?

2-see what

'What do you see?'

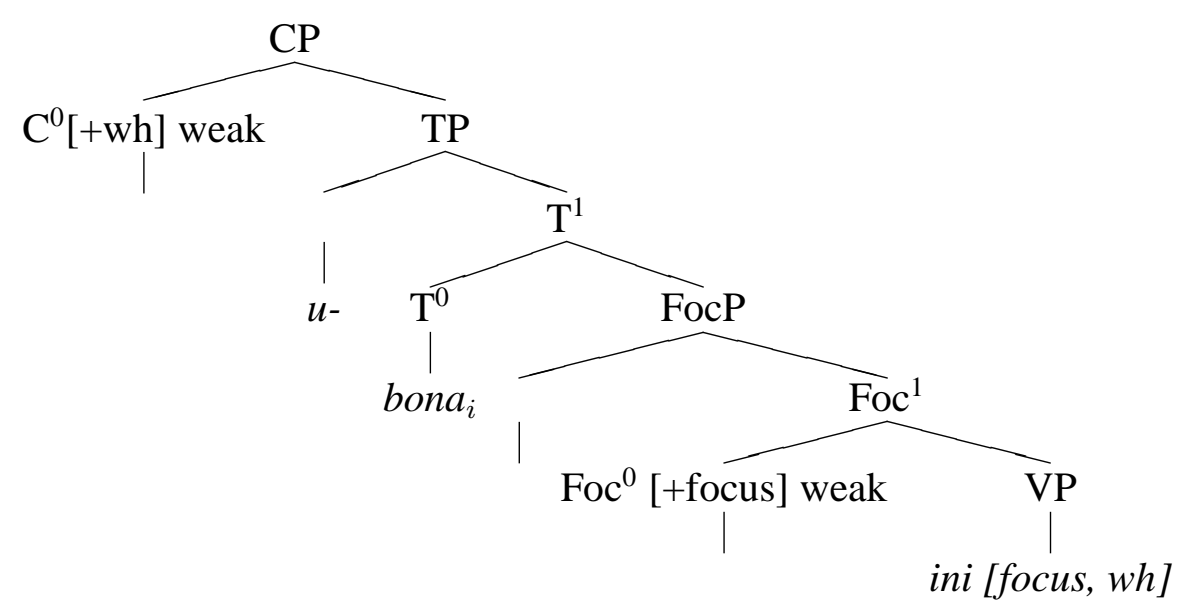

In in situ questions, both the [+wh]- and the [+focus]-feature are weak. Since weak features do not need to be checked in a specifier-head-relation, both features can be checked by 'unselective binding', i.e. non-local licensing via binding through a [+wh]-head (see Chomsky 1995: 291). Consequently, the non-subject $w h$-phrase remains in situ.

This account of $w h$-questions in Nguni is attractive because the semantic interpretation of focus is ensured by the Focus Phrase. However, the need for interpreting focus in a corresponding phrase together with the position of this phrase above VP predicts an immediately postverbal focus position. For Northern Sotho, this prediction is not born out by the empirical data, as shown in chapter 2 . Therefore, the approach cannot be adopted for Northern Sotho.

The non-local checking relation that Sabel \& Zeller (to appear) propose for in situ focus in Nguni, is mirrored by a morphosyntactic feature in the OT-approach proposed here.

\section{Subject focus with intransitive verbs: the impersonal construction}

The canonical position for subjects in Northern Sotho is preverbally. This generalization is derived by ranking the constraint SUBJECT over STAY. However, the subject does not appear in this position when it is focused. In an OT-approach, this is captured by competing constraints. The constraint that competes with SUBJECT and STAY is the constraint in (45).

\section{*SUBJECT/F-MARKED}

'The grammatical subject of the sentence must not be F-marked.'

This constraint is violated whenever a grammatical subject is narrowly focused.

The constraint proposed in (45) serves as an abbreviation for the markedness effects that can be derived by harmonic alignment of two scales, as has been motivated in section 4.3.1 in detail. 
The observation that in Northern Sotho focused subjects do not appear in preverbal position leads to the conclusion that the constraint in (45) outranks SUBJECT and STAY. ${ }^{11}$ Tableau 14 illustrates the interplay of the three constraints presented so far by means of a focus-related context, as in (46).

$$
\begin{aligned}
& \text { Intransitive sentence } \\
& \text { Go bina mang? } \\
& \text { CL17 dance who }
\end{aligned}
$$

'Who is dancing?'

Tableau 14: Focus in intransitive sentences

\begin{tabular}{|ll||l|l|l|}
\hline & $*$ SUBJECT/F-MARKED & SUBJECT & STAY \\
\hline \hline a. $\left[{ }_{I P} \operatorname{mang}_{F}\left[I_{I^{\prime}}\right.\right.$ bina $\left.\left.\left[{ }_{V P} t\right]\right]\right]$ & $* !$ & & $*$ \\
\hline b. $\left[{ }_{I^{\prime}}\right.$ go bina $\left.\left[{ }_{V P} \operatorname{mang}_{F}\right]\right]$ & & $*$ & \\
\hline
\end{tabular}

Although an impersonal construction (candidate b) violates the SUBJECT constraint in lacking a grammatical subject, it emerges as winner because it satisfies the higher-ranked interface constraint that prohibits F-marked grammatical subjects. The violation of this constraint by candidate (a) leads to its exclusion, as the interface constraint is the highest ranked constraint. ${ }^{12}$ The same ranking can also account for the fact that, if the verb is in focus, we find the normal SVO order. The high-ranked interface constraint is vacuously fulfilled. The impersonal construction, however, crucially violates the lower ranked constraint SUBJECT in this case.

Sabel \& Zeller (to appear) show how a focused subject in preverbal position can be excluded on purely syntactic grounds. Recall that a question word bears a [wh]- and a [focus]-feature that need to be checked. Furthermore, a Focus Phrase above VP is automatically generated in all $w h$-questions. Therefore, SpecFocP intervenes between the base position of the subject (VP-internal) and the preverbal subject position SpecTP where agreement with the verb is expressed. On its way from the VP-internal position to SpecTP, a question word with the grammatical function of subject would need to move to Spec FocP first in order to check the weak [+focus]-feature, which is associated with the head of the Focus Phrase. The necessity to check weak features in such a constellation is termed 'free rider' (see Sabel 2000: 440 for discussion). Consequently, the subject question word moves from SpecVP to Spec FocP and further on to SpecTP. This equals movement from an A- to an A-bar- and then again to an A-position which is ruled out by Improper Movement as an illegitimate operation.

Consequently, the subject is left in SpecVP-position and the weak [+focus]-feature is checked via 'unselective binding'. An expletive is inserted to check the EPP-feature. The

\footnotetext{
${ }^{11}$ The data in section 2.2.3 have shown that also focused modifiers of the subject are prohibited in preverbal position. Therefore, this constraint is to be understood as ruling out partiell F-marking of the preverbal subject as well.

${ }^{12}$ Northern Sotho allows also cleft structures for intransitive sentences. The use of the in situ or the cleft structure is optional with no special discourse-pragmatic implications for clefts, contrary to what is observed for object clefts. The case of optionality will be considered in detail in chapter 5 .
} 
resulting construction in Nguni is the impersonal $k u$-construction, which is parallel to the impersonal go-construction in Northern Sotho.

Alternatively, one could argue that the subject moves from internal VP-position to the Specifier of the Focus Phrase in order to check the [focus]-feature, and consequently stays there. This view is attractive, because for one, the focused subject is than interpreted within the Focus Phrase, and for the other, this derivation complies with the view that positions within a Focus Phrase are 'freezing' positions where derivations stop (Aboh, p.c.). However, overt movement to a focus position can only be justified by a strong focus feature, that Sabel \& Zeller (to appear) have reserved in order to account for cleft constructions.

\section{Subjects under wide focus}

The discussion in the preceding section has treated narrow focus on subjects and objects. It has been shown that the subject-specific constraint, that is derived from the alignment of prominence scales, is highly ranked in Northern Sotho as preverbal subjects which are focused are excluded in this language. This section now turns to wide focus and the appearance of preverbal subjects.

Wide focus and narrow focus differ in the assignment of the F-feature. Whereas in wide focus the whole sentence bears the F-feature, under narrow focus only the constituent in question bears the F-feature (Jackendoff 1972). Transferring this to the Fmarking of subjects under wide and narrow focus, one can state that a narrowly focused subject bears an F-feature whereas a widely focused subject does not. Therefore, although the subjects in both structures are evaluated against the subject-specific constraint, only the narrowly focused subject violates it, as it bears an F-marking. The subject appearing in a wide focus context satisfies the constraint, as it itself does not bear an F-marking. The actual outcome is therefore determined by the lower ranked syntactic constraints. This is shown in tableau 15 for the example in (47).

(47) [Go direga eng? - 'What is happening?']

Lesea le robetše.

'A baby is sleeping.'

Tableau 15: Subjects under wide focus

\begin{tabular}{|c|c|c|c|c|}
\hline & wide focus & 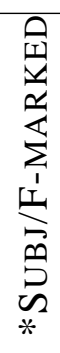 & 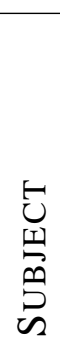 & 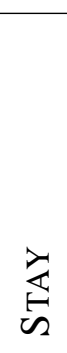 \\
\hline a. 呢 & {$\left[{ }_{I P} \text { lesea }\left[I^{\prime} \text { le robetše }\left[V_{P} t\right]\right]\right]_{F}$} & & & (* \\
\hline b. & {$\left[{ }_{C P}\right.$ ke lesea $_{i C F}\left[{ }_{I P} t\left[{ }_{I 0}\right.\right.$ le robetše-ng $\left.\left.\left.\left[{ }_{V P} t\right]\right]\right]\right]$} & & $* !$ & \\
\hline & {$\left[\left[I^{\prime} \text { go robetše }\left[V_{P} \text { lesea }\right]\right]_{F}\right.$} & & $* !$ & \\
\hline
\end{tabular}


In tableau 15, all possible output structures observed so far for narrow focus are represented: Candidate (a) shows the preverbal occurrence of the subject, candidate (b) shows the cleft structure, and candidate (c) shows an impersonal go-construction. As in neither candidate the subject is F-marked, none of these structures violates the interface constraint *SUBJECT/F-MARKED. However, both candidate (b) and (c) violate the constraint SuBJECT which is ranked above the constraint banning movement. As there is a competing candidate that satisfies this constraint (candidate a), the violation is fatal.

The tableau shows that because a subject under wide focus does not bear F-marking, it satisfies the high ranked interface constraint, and syntactic faithfulness and markedness constraints decide on the winner, favoring the unmarked SVO word order that shows a semantic structure equivalent to the input.

In the syntactic account by Sabel \& Zeller (to appear) wide focus is not addressed. Although they restrict their analysis to $w h$-questions, they acknowledge the distributional similarities of focus phrases and $w h$-words and use exactly this similarity to motivate the [+focus]-feature a $w h$-word bears. It is not expected, however, that the appearance of a subject in preverbal position under wide focus poses any problem for a syntactic account. Nevertheless, one question that remains unclear and that hinders to make exact predictions or even provide an analysis is, if there is a [+focus]-feature under wide focus that needs to be checked and if so, on which constituent it is realized and how it can be checked. (Note that a [+focus]-feature on the whole sentence cannot be checked via unselective binding as the subject which is part of the wide focus is not bound by the head $\left(\mathrm{Foc}^{0}\right)$ where the [+focus]-feature is interpreted.) It turns out that the [+focus]-feature which is crucial in Sabel \& Zeller's analysis raises further issues. This is especially so as the [+focus]feature of the feature checking machinery of the Minimalist Program is not comparable to the semantic F-feature introduced by Jackendoff (1972), which is used in the tableaus above.

\subsubsection{Summary}

The preceding sections presented an OT-analysis for focus in Northern Sotho. The constraint *SUBJECT/F-MARKED has been proposed to account for the ungrammaticality of a focused subject in canonical preverbal position. This is a constraint referring to the syntax-information structure interface. The subject is defined syntactically as the constituent being in SpecIP-position, and the constraint relates this syntactic position to a specific information structural status.

The data give evidence for the following constraint ranking in Northern Sotho:

$*$ SUBJ/F-MARKED $\gg$ SUBJ $\gg S T A Y ~ \gg * S T R U C T U R E$, FOC-SPEC

\subsection{Conclusion}

The chapter started by presenting claims about the discourse function of topics in Bantu which are prevalent in the literature. It then presented data that show that under wide focus a subject does appear in preverbal position. These data speak against an aboutness topic interpretation of the subject in Northern Sotho. If the subject is to be accommodated 
as an aboutness topic under wide focus, the notion of topic is stretched so far as to lose its linguistic relevance. The valid generalization that can be drawn from the data is that the preverbal subject in Northern Sotho must not be F-marked.

The chapter then presented a formal approach to capture the described data, to account for the asymmetry of focus in subjects and non-subjects, and also to incorporate the observable tendency of subjects to be topics. The framework chosen is OT which has been presented in chapter 1 in detail. A new constraint has been proposed in order to account for the Northern Sotho data: *SUBJECT/F-MARKED. Though the constraint may look like a mere formulation of the observation at first sight, it is grounded in cross-linguistic tendencies and is formulated according to valid constraint schemata. It can be derived by harmonic alignment of the grammatical function scale and the focus scale. Contrary to Aissen (1999), two discourse-prominence scales are argued for in this thesis, one scale referring to topic, another referring to focus.

In the conclusion of chapter 3 the question has been risen if the grammar of Northern Sotho needs a morphosyntactic F-feature considering its lack of grammatical marking of focus in the postverbal domain. The processes auch as pronominalization, deletion and dislocation only refer to given elements instead. This chapter argues that also in the preverbal domain, the F-feature does not trigger a certain syntactic construction neither. This is in line with the overall claim of the thesis that there is no systematic grammatical focus marking in Northern Sotho. Consequently, one could assume that the F-feature is dispensable in the grammar of Northern Sotho. The case of subject focus, however, provides crucial evidence for the existence of an F-feature in the grammar of Northern Sotho. The F-feature on a narrowly focused subject violates a universal constraint that bans focused subjects from preverbal position. This constraint is high-ranked in Northern Sotho. The emerging impersonal construction can be seen as a grammatical reflex of information structure, though not as grammatical focus marking according to the differentiation made in section 1.3.

\subsubsection{Discussion}

As constraints are claims about Universal Grammar (UG) with typological consequences, an OT-analysis is not complete without investigating the typological predictions made by the constraints proposed. A re-ranking of the constraint * SUBJECT/F-MARKED can have the effect of rendering it inactive. If *SUBJECT/F-MARKED is ranked below SUBJECT, it will always be more optimal in a grammar to have the subject in subject position even if it is focused. Consequently, we find focused subjects in preverbal position. This is the case in English and German, and one can therefore argue for an opposite ranking of *SUBJECT/F-MARKED and SUBJECT in these languages. A ranking similar to English must be proposed for the Bantu languages Nsenga, Swahili, and Chichewa where an agreed-with subject can be focused in preverbal position (Downing et al. 2004, Marten, p.c.).

However, although in the languages of the world *SUBJECT/F-MARKED might be ranked differently with respect to other constraints in CON, the relative ranking of the constraints *SUBJECT/F-MARKED and *SUBJECT/NON-F-MARKED is always the same in all languages, due to the constraint schema used. Harmonic alignment leads to a fixed 
ordering of the emerging constraints. Whereas languages differ in the importance they give to the constraints in their grammar, it is predicted that no language shows an opposite ranking. The harmonic alignment of the prominence scales predicts that in no language *SUBJECT/NON F-MARKED will be ranked above *SUBJECT/F-MARKED, which would result in only F-marked subjects to appear in preverbal position. Thereby, the crosslinguistic tendency is captured that languages tend to have subjects as topics. Whereas this tendency is not true for all languages, there is no language for which the opposite is true, namely that objects are topics.

Another factorial sub-typology emerges when considering the ranking of the constraints FOC-SPEC and STAY. In a language where FOC-SPEC is ranked above STAY, a focused constituent is always moved to Specifier position. This has been claimed to be the case for the preverbal focus position in Hungarian (e.g. Brody 1990). In a language where STAY outranks FOC-SPEC, a focused constituent remains in situ, as is the case in Northern Sotho.

The current chapter has shown how Optimality Theory accounts for phenomena that have been captured by parameterization in other approaches. First, it has been suggested by Sabel \& Zeller, to appear) that the confinement to a certain discourse notion is a parameterized property of SpecIP. The OT-approach captures this parameterization by the relative ranking of the constraints *SUBJECT/F-MARKED and SUBJECT. Second, focus movement has been claimed by e.g. Sabel $(1998,2000)$ to be related to parameter setting, expressed by either a strong or a weak [wh]-feature. A weak [wh]-feature results in in situ focus, whereas a strong [wh]-feature results in focus movement. The OT-account captures the parameterization of feature strength by the relative ranking of the constraints FOC-SPEC and STAY.

\subsubsection{Area of further research}

Analyses within OT, however, go beyond the mere formalization of parametrization. Parametrization remains always stipulative in accounting for the observable facts only. Accounts within Optimality Theory are designed not to be stipulative due to the nature of their constraints. Constraints within OT are not mere formulations of observations, but are restricted by cross-linguistic tendencies, laws of communication and general schemata for constraint formulation. They are supposed to be universals.

Nevertheless, critique has been raised that, despite guidelines for the formulation of constraints, the opposite constraints can be as easily formulated and used in analyses. This is especially true for constraints derived by harmonic alignment. Zeevat \& Jäger (2002) e.g. criticize that the ordering of elements on the prominence scales is too explicit as it is as easy to formulate the inverse form/meaning associations, yielding the exact opposite languages. One response to this criticism is that at least empirically, the predicted patterns of inverse form/meaning associations are unattested. They argue in favor of statistical asymmetries and bidirectional learning (Zeevat \& Jäger 2002, Jäger 2004, Mattausch 2004). It remains an issue for further research to ground the constraint *SUBJECT/FMARKED, that was proposed here to account for the ban of narrowly focused logical subjects from preverbal position, in these computational aspects. 


\section{Chapter 5}

\section{The use of clefts in Northern Sotho}

The preceding chapter investigated the information structural properties of the preverbal subject in Northern Sotho. It emerged from the data that the preverbal subject must not be F-marked in this language. This observation has been formalized as a violable constraint which is derived through harmonic alignment of the focus scale and the grammatical relation scale. The constraint is ranked high in the grammar of Northern Sotho and can account for the fact that the logical subject cannot be questioned in its canonical preverbal position. In intransitive sentences, the focused logical subject therefore appears in situ, i.e. in postverbal position where it is argued to be base-generated.

The question that remained open is why a cleft sentence is obligatory when the logical subject of transitive verbs is focused. Cleft sentences have not been dealt with so far in this thesis. Therefore this chapter investigates the use of cleft sentences for the expression of focus. It starts by investigating the meaning of cleft sentences in Northern Sotho, and shows that whereas clefting is an unmarked focusing strategy for logical subjects, it is marked when used for objects (for which reason it has not been discussed before). This claim is supported by frequency tendencies that were collected via a corpus study. The additional semantic specification of clefts can be described by making reference to a preconstructed domain.

Then, assumptions about the status of cleft sentences are discussed. It will be outlaid that cleft sentences in Northern Sotho are not derived from declarative sentences via movement but constitute a grammatical form of its own rights in Northern Sotho.

The relation that establishes itself with objects between in situ focus and unmarked focus interpretation on the one hand, and cleft structure and specified focus interpretation on the other hand can be captured within bidirectional OT, as it constitutes a case of "unmarked forms for unmarked meaning and marked forms for marked meanings". The account within bidirectional OT will be spelt out in this chapter.

The question then poses itself why normal subject focus in transitive verbs (and optionally also in intransitive verbs) makes use of such a syntactically and semantically marked form. It will be argued that the impersonal construction is excluded for transitive verbs by a higher ranked syntactic principle that bans transitive expletive constructions and which is active in many other languages of the world.

Before concluding, the chapter turns to issues of further research, which includes ambiguity within bidirectional OT and the elicited optionality between cleft structure and 
in situ structure for focused logical subjects of intransitive verbs. Though no final analysis can be presented, issues pertaining to optionality within OT in general and in the case of intransitive subjects specifically will be discussed.

\subsection{Cleft sentences in Northern Sotho}

Chapter 2 illustrated the syntactic asymmetry of subjects and non-subjects in Northern Sotho that manifests itself in focus-related contexts like e.g. in questions. Whereas focused non-subject constituents remain in their canonical situ position, focused logical subjects appear in a cleft construction. Cleft constructions are also possible with objects and with a restricted class of adverbials (temporal and local adverbs only). They resemble subject clefts in their syntactic structure. This is illustrated in (1).

Example (1-a) shows a subject cleft. Object clefts, as in (1-b, c) for [+/- human]objects respectively, are constructed parallel to subject clefts. The copula ké is followed by the head noun which is the object of the following relative clause. An obligatory relative pronoun follows, that agrees with the head noun in noun class features. In the relative clause, SVO word order is retained, and the verb shows an object marker in its verbal template that is coreferent with the head noun. With temporal and local adverbs as in (1-d,e), the relative pronoun is invariably the locative particle mo (class 18) which also is the local adverb. There is no morpheme in the verbal template that relates back to the head noun.

(1) Cleft structures in Northern Sotho
a. Ké mang a tlhokomela-ng mo-kgalabje.
COP who CL1 look.after-REL CL1-old.man
'Who is looking after the old man?'
b. Ké mang o ngaka a mo nyaka-ng?
COP who CL1 CL9.doctor CL1 CL1 look.for-REL
Lit. 'It is who that the doctor is looking for?'
c. Ké eng se mo-šemane a se jwala-ng?
COP what DEM.CL7 CL1.boy CL1 CL7 plant-REL
Lit. 'It is what that the boy is planting?'
d. Ké neng mo mo-kgalabje a nyaka-ng ngaka?
COP when CL18 CL1-old.man CL1 look.for-REL CL9.doctor
Lit. 'It is when that the old man is looking for the doctor?'
e. Ké kae mo mo-kgalabje a nyaka-ng ngaka?
CoP where CL18 CL1-old.man CL1 look.for-REL CL9.doctor
Lit. 'It is where that the old man is looking for the doctor?'

Though the syntactic structure of subject and non-subject clefts is comparable, the semantics of a non-subject cleft differ from that of a subject cleft in Northern Sotho. For other Bantu languages, however, it has been either explicitly claimed that no such semantic distinction exists (see Schwarz 2003 for Kikuyu) or it has been implicitly suggested that a semantic difference is not relevant (Sabel \& Zeller, to appear, for Nguni).

Whereas cleft sentences are the standard way of questioning and focusing the logical 
subject in Northern Sotho, non-subject clefts have a more specific meaning. The meaning of cleft sentences will be dealt with in this section, first in general in section 5.1.1, then for subject clefts in Northern Sotho in section 5.1.2, finally for non-subject clefts in section 5.1.3. The aim is to show that cleft sentences for non-subjects cannot be used interchangeably with corresponding in situ structures, but are conditioned by specific discourse contexts. The required context for non-subject cleft constructions goes beyond focus of a constituent as defined in section 1.2.3. The claims made are supported by quantitative evidence which is presented in section 5.1.4. Consequently, the in situ option refers to a focus-feature that induces a normal set of alternatives whereas the cleft bears a marked focus-feature that restricts the set of possible alternatives.

\subsubsection{The meaning of cleft sentences}

The apparent co-existence of two syntactic structures for focus (in situ and cleft construction) in Northern Sotho is reminiscent of the distinction most vehemently argued for by É. Kiss (1998) to distinguish between two kinds of focus: identificational focus and information focus. The definition of these terms is motivated by syntactic as well as prosodic and semantic aspects. Semantically, identificational focus (also called contrastive focus) represents

"a subset of the set of contextually or situationally given elements for which the predicate phrase can potentially hold; it is identified as the exhaustive subset of this set for which the predicate phrase actually holds" (É. Kiss 1998: 245)

Syntactically, identificational focus is associated with movement into a scope position in the specifier of a functional phrase, normally associated with the sentence-initial position in SVO languages. Information focus (also called presentational focus), on the other hand, is not associated with movement but with pitch accents, and conveys new, nonpresupposed information without expressing exhaustive identification. Semantically, the exhaustivity aspect is the distinguishing characteristic between these two kinds of focus.

É. Kiss (1998: 247) gives an example from Hungarian to illustrate the claim for the differentiation of these two types of focus which are associated with divergent semantic and syntactic features. In Hungarian, the two types of focus are associated with distinct positions, as shown in (2).

Hungarian (É. Kiss 1998: 247)

a. Tegnap este Marinak mutattam be Pétert. last night Mary.DAT introduced.1 PERF Peter.ACC 'It was to Mary that I introduced Peter last night.'

b. Tegnap este be mutattam Pétert Marinak. last night PERF introduced.1 Peter.ACC Mary.DAT 'Last night I introduced Peter to Mary.'

É. Kiss (1998) describes that the immediately preverbal focus in (2-a) expresses exhaustive interpretation; it means that of a set of individuals present in the domain of discourse, 
it was to Mary and no one else that the speaker introduced Peter the previous night. The postverbal focus in (2-b) exemplifies information focus as it merely presents 'Mary' as nonpresupposed information without suggesting that Mary was the only one of a set of relevant persons that the speaker introduced Peter to the previous night. Syntactically, in (2-a) 'Mary' is moved from its postverbal base position into the immediately preverbal position. Prosodically, the information focus in (2-b), Marinak, bears a pitch accent.

Further languages that show a similar distinction in formally different foci are Greek, Finnish, and Catalan (for references see É. Kiss 1998).

Furthermore, É. Kiss (1998) shows on the basis of eight languages that there is languagespecific variation in the actual feature content of identificational focus. The identificational foci of different languages are specified for the positive value of either or both of the features [+/- exhaustive] and [+/- contrastive]. Exhaustiveness has been defined above. É. Kiss (1998: 267) regards an identificational focus [+contrastive] if it operates on a closed set of entities whose members are known to the participants in the discourse. The identification of a subset of the given set therefore also identifies the contrasting complementary subset. For the Hungarian example in (2), it has been claimed that the focus in immediately preverbal position expresses exhaustiveness. With respect to contrastiveness, identificational focus in Hungarian is unspecified. It can be either [+contrastive] or [-contrastive].

The following two subsections will investigate for subjects and non-subjects separately if the syntactic distinction between in situ and cleft focus in Northern Sotho correlates to a semantic distinction along the lines proposed by É. Kiss (1998), therefore investigating exhaustiveness and contrastiveness in Northern Sotho.

\subsubsection{Subject clefts in Northern Sotho}

Focused logical subjects must not appear in preverbal position in Northern Sotho. They appear either postverbally, as in (3-a), or in a cleft construction, as in (3-b).

Subject questions in Northern Sotho
a. Go fihla mang?
CL17 arrive who
b. Ké mang (yo) a fihla-ng?
COP who DEM.CL1 CL1 arrive-REL
'Who is arriving?'

Under the assumption that the subject is base-generated in VP-internal position, the inversion structure in (3-a) is the construction in which the logical subject appears in situ.

The question arises if the distribution of cleft versus in situ construction with focused subjects in Northern Sotho is governed by semantic factors as claimed by É. Kiss (1998). This means, is the use of a cleft determined by exhaustiveness or contrastiveness of the focused constituent?

Native speakers intuitions assign the two constructions illustrated in (3) no difference in usage. Intuitions might not be sufficient as reliable evidence. However, they are remarkable in the light that native speakers uniformly assign different usages to clefts for non-subjects (see next section). 
Evidence for the semantic identity of the in situ and cleft construction for subjects in Northern Sotho comes from the lack of optionality of these two constructions for transitive and ditransitive verbs. Transitive and ditransitive verbs do not show subject inversion constructions (Demuth \& Mmusi 1997 for Tswana, Machobane 1995 for Southern Sotho). Transitive and ditransitive verbs only show cleft constructions, as in (3-b). Any semantic differentiation that might exist for intransitive verbs collapses for transitive verbs.

Therefore, one can assume that synchronically, there is no semantic differentiation between clefts and in situ for subjects in Northern Sotho, and that cleft structures serve as the unmarked way for questioning logical subjects.

\subsubsection{Non-subject clefts in Northern Sotho}

Non-subjects can also be focused in situ, as in (4-a), and by means of a cleft structure, as in (4-b).

Object questions in Northern Sotho

a. Mo-kgalabje o nyaka mang?

CL1-old.man CL1 look.for who

'Who is the old man looking for?'

b. Ké mang yo mo-kgalabje a mo nyaka-ng?

COP who DEM.CL1 CL1-old.man CL1 CL1 look.for-REL

Lit. 'It is who that the old man is looking for?'

Again, the question arises if the distribution of cleft versus in situ focusing strategy is guided by semantic factors, such that the use of the cleft sentence expresses exhaustiveness or contrastiveness of the constituent in its scope, as proposed by É. Kiss (1998). Interestingly, native speakers assign the object in situ structure and object cleft structure different meanings.

Testing semantic factors that could be decisive for the use of cleft sentences turns out to be a difficult task without any own native speaker intuitions to rely on. Tests by É. Kiss (1998) and Hartmann \& Zimmermann (to appear b) have been applied to find out whether exhaustiveness is a factor influencing the choice between cleft and in situ structure. One context for exhaustivity exists if the domain of focusation is extended by an also-phrase (É. Kiss 1998, Matthewson 2004), thereby explicitely indicating that the subset contains more than the clefted constituent.

(5) Exhaustivity effects with also
a. Ké mang yo le mmon-e-go?
COP who DEM.CL1 2PL CL1.see-PST-REL
Lit. 'It was who that you saw?'
b. ?Ké mo-kgalabje wo re mmon-e-go. Re bon-e le CoP CL1-old.man DEM.CL1 1PL CL1.see-PST-REL 1PL see-PST also mo-sadi.
CL1-woman
Lit. 'It is the old man that we saw. And we also saw the woman.' 
If exhaustiveness were the decisive factor for the use of cleft structures with non-subjects, the answer in (5-b) should be judged ungrammatical or inapproriate in this discoursecontext. However, language consultants' judgments on the appropriateness of examples such as (5-b) were inconsistent. This could be due to the fact that the extension of the focused subset is only indicated following the cleft, suggesting a corrective answer. In a correction context, a clash between the potentially implicit exhaustiveness of the cleft and a pronounced extension of the subset is not surprising.

In order to avoid the correction interpretation, a context was used in which the subset is explicitly introduced as containing more than the focused entity. If the cleft structure for non-subjects were related to exhaustivity, it is predicted to be illicit in such a context. An example is given in (6), following Hartmann \& Zimmermann (to appear b).

Exhaustivity effects

[Context: I know that Mister Matloga sells many things at the market.]
a. ?Boka, ké di-namune tše Mna Matloga a di example COP CL10-orange DEM.CL10 CL1.mister PROP.NAME CL1 CL10 rekiš-itše-go ma-rake-ng. sell-PST-REL CL6-market-LOC

Lit. 'For example, it is oranges that Mr Matloga sells at the market.' (cleft)

b. Boka, Mna Matloga o rekiš-itše le di-namune example CL1.mister PROP.NAME CL1 sell-PST also CL10-orange ma-rake-ng. CL6-market-LOC

'For example, Mister Matloga also sells oranges at the market.' (in situ)

Again, no strong inappropriate-judgment could be obtained from language consultants (who are non-linguists), although there was a preference for the in situ variant in (6-b).

Hartmann \& Zimmermann (to appear b) discuss a further context for exhaustivity. When assuming (strong) exhaustiveness to be the relevant semantic factor for the use of clefts, inferences can be based on that. This logic is exploited in the example in (7).

\section{Exhausitvity effects}

[Context: A student $(\mathrm{K})$ who is anxious to have failed the tests in both chemistry and physics approaches the teacher (M) and asks: 'Can you tell me whether I have passed the tests or not?' (Naa ke phasetše phišo ya chemistry le physics?) However, teachers are by law forbidden to tell students directly about all their performances. On the other hand, there is no law that forbids them to talk about partial results of their overall performance. So, the teacher could answer either (a) or (b). Can the student deduce from this that he has passed both exams?

a. In situ
N-ka se go bots-e, gomme ga o a hlaela physics.
1-POT Neg 2 tell-NEG but NEG CL1 NEG fail physics

b. Cleft structure

N-ka se go bots-e, gomme ké physics ye ga o a e 1-Pot Neg 2 tell-Neg but Cop physics Dem.CL9 Neg 2 Neg Cl9 
hlaela-go.

fail-REL

'I cannot tell you, but you didn't fail in physics.'

If the use of the cleft were related to exhaustiveness, the student should deduce from the answer in (7-b) that he passed in chemistry and failed in physics. From answer (7-a) he could not deduce anything because the exhaustive as well as non-exhaustive reading of the sentence is possible. No clear judgments could be obtained from language consultants, though it was reported that it is rather the second sentence that entails that the student did not pass both exams.

Hartmann \& Zimmermann (to appear b) point out the possibility of accommodation by conversational implicature (for the Gricean maxims of conversational implicature see section 2.4.1) in all these contexts and tests. It turns out to be a methodological problem how to exclude that language consultants accommodate for a context in which the use of a cleft becomes possible. However, it could not be convincingly established that exhaustiveness is the only relevant factor for the use of cleft sentences for non-subjects in Northern Sotho.

Native speakers intuitions are quite clear that there is a difference between the in situ and cleft strategy for non-subjects. They refer to the in situ strategy as the normal, unmarked strategy. If exhaustiveness cannot shown to be the decisive factor determining the use of cleft versus in situ, what else could it be?

One possible differentiating factor could be presupposition of existence required for one structure but not the other. Presupposition refers to the implicit meaning of an utterance. Presupposition of existence refers to the observation that reference to an entity implies the existence of the entity. The sentence 'The king of France visited the exhibition' implies (=presupposes) that France has a king (cf. Strawson 1964). For Northern Sotho, an example from natural speech, in (8-a), and from elicitation, in (8-b), illustrate that the in situ variant of non-subject questions does not imply a presupposition of existence, as the question can be answered in the negative.

(8) Presupposition of existence

a. (i) [Mo-šemane o dira eng?

CL1-boy CL1 do what

'What is the boy doing?']

(ii) Mo-šemane ga a dir-e se-lo.

CL1-boy NEG CL1 do-NEG CL7-thing

'The boy doesn't do anything.'

(QUIS)

b. [Context: In front of a grocery store. Person A leaves the shop without shopping bags.]

(i) B: O rek-ile eng?

B 2 buy-PsT what

'What did you buy?'

(ii) B: ?Ké eng yeo o e rek-ile-ng?

B COP what DEM.CL9 2 CL9 buy-PST-REL

Lit. 'It is what that you bought?'

(in situ)

(cleft) 
(iii) A: Ga ke a reka se-lo.

A NEG 1 NEg buy CL7-thing

'I didn't buy anything.'

Data from natural speech, as in (8-a) do not provide negative evidence, i.e. it remains unclear if the question can be posed by means of a cleft. In elicitation, language consultants preferred the in situ variant (i) over the cleft constructions (ii) for contexts as in (8-b), leaving it open if a cleft structure requires the presupposition of existence.

The following two dialogues in (9) and (10) suggest that presupposition might be the distinguishing aspect between in situ and cleft structure for non-subjects. Both dialogues are started by the in situ question and are then continued by the cleft question asking for more specific information regarding working place and time of arrival, given in bold. Starting the inquiry for information with the cleft structure is inappropriate according to native speakers' judgments.

a. A: O šoma kae? - 'Where are you working?'

b. $\quad$ B: Ke šoma UNISA. - 'I am working at UNISA.'

(in situ)

c. A: Le nna ke šoma UNISA. - 'Me too, I am working at UNISA.'

d. B: Ke kae mo o šomang? - 'Where exactly are you working?'

(cleft)

e. $\quad$ A: Ke šoma UNISA Tuck shop. - 'I am working at UNISA Tuck shop.'

f. B Nna ke šoma sekgophapuku.- 'Me, I am working at the library.'
a. A: O boa neng Afrika Borwa? -'When are you coming to South Africa?' (in situ)
b. B: Ke boa ngwaga o o tlang. -'I will be coming next year.'
c. A: Ke neng mo a boang? - 'When exactly are you coming?'
d. B: Ke boa 15th March. -'I will be coming 15th March.'
(cleft)

The examples can be interpreted in that there is a pragmatic tendency for the cleft sentence to imply the presupposition of existence and for the in situ variant to have no semantic requirements.

According to Heim's (1991: 515) principle of maximization of presupposition, which basically requires the speaker to presuppose as much as possible in his/her contribution to the conversation, the cleft structure should be used whenever indication for the existence of the questioned entity is given. However, the examples in (11) show contexts in which the existence presupposition is met by providing either visual, as in (11), or olfactory evidence, as in (12). Native speakers nevertheless prefer the in situ variants in (11-a) and (12-a).

Visual evidence for existence

[Context: In front of a grocery store. Person A exits the shop with obviously filled shopping bags.]

a. Question

(i) O rek-ile eng?

2 buy-PST what

'What did you buy?'

(in situ)

\footnotetext{
${ }^{1}=$ University of South Africa, Pretoria
} 
(ii) ?Ke eng yeo o e rek-ile-ng?

COP what DEM.CL9 2 CL9 buy-PST-REL

Lit. 'It is what that you bought?'

(cleft)

b. Answer

Ke rek-ile bo-gobe le nama.

1 buy-PST CL14-porridge and CL9.meat

'I bought porridge and meat.'

(12) Olfactory evidence for existence

[Context: You come home at dinner time and you notice a wonderful but unknown smell of food coming from the kitchen. Your wife is sitting in front of the TV.]

a. O ape-ile eng lehono?

2 cook-PST what today

'What did you cook today?'

b. ?Ké eng se o se ape-ile-ng lehono?

COP what DEM.CL7 2 CL7 cook-PST-REL today

Lit. 'It is what that you cooked today?'

(in situ)

(cleft)

From the examples in (11) and (12) it can be concluded that the use of the cleft sentence implies more than just presupposition of existence, although presupposition of existence is one necessary factor, as seen in (8-b) and (9).

Does that mean that Heim's (1991) generalization is invalid in Northern Sotho or is there something more to the cleft than mere presupposition of existence? The concept of contrast as defined by É. Kiss (1998) becomes relevant, especially because contrastiveness implies presupposition of existence. Contrast can be evoked by correction contexts. In correction contexts, the inappropriately used constituent is contrasted with the correct constituent. However, as has been shown in section 2.2.1, non-subjects can be contrasted in situ. This is illustrated again in (13) by focused negation for both objects and temporal adverbials, and in (14) by correcting answers to yes/no questions.

(13) Contrast by focused negation

a. Mo-šemane ga se a rekiš-e [bo-rotho $]_{F}$, o rekiš-itše

CL1-boy NEG NEG CL1 sell-NEG CL14-bread CL1 sell-PST

[bupi $]_{F}$.

CL9.porridge

'The boy didn't sell BREAD, he sold PORRIDGE.'

b. Ga ke šom-e [mo-segare $]_{F}$, ke šoma [bo-šego $]_{F}$.

NEG 1 work-NEG CL3-midday 1 work CL14-evening

'I do not work DURING THE DAY, I work IN THE EVENING.'

(14) Contrast by correction

a. (i) Naa o thuš-etše mo-sadi na?

QP 2 help-PsT CL1-woman QP

'Did you help the woman?' 
(ii) Aowa, ke thuš-etše $[\text { mo-kgalabje }]_{F}$.

no 1 help-PST CL1-old.man

'No, I helped the OLD MAN.'

b. (i) Naa o dula toropo-ng na?

QP 2 live CL9.town-LOC QP

'Are you living in town?'

(ii) Aowa, ke dula [polase-ng $]_{F}$.

no 1 live CL9.farm-LOC

'No, I am living on A FARM.'

However, contrastiveness as defined by É. Kiss (1998: 267) goes beyond contrast in correction contexts. É. Kiss defines identificational focus as [+contrastive] if it operates on a closed set of entities whose members are known to the participants of the discourse. Therefore, the identification of a subset of the given set also identifies the contrasting complementary subset.

That the familiarity of the hearer with the competing item is one important clue in the choice of the cleft sentence in Northern Sotho comes from the examples in (15).

Cleft sentences in Northern Sotho (contexts provided by language consultants)

[Context: It is the beginning of the month. Two friends A and B talk about the things they want to purchase within the coming weeks. Among the things are clothes, a cell phone, a calculator. At the end of the month, A asks B which of the things s/he could actually afford.]
a. Ké eng yeo o e rek-ile-ng?
COP what DEM.CL9 2 CL9 buy-PST-REL
Lit. 'It is what that you bought?'

(16) [Context: Two friends A and B go window shopping together and admire different clothes. The next day A says that s/he went back to the mall after they separated. B will ask:]
a. Ké di-aparo di-fe
tše o di rek-ile-ng?
COP CL8-cloth CL8-which DEM.CL8 2 CL8 buy-PST-REL
Lit. 'It is which clothes that you bought?'

In both examples, it is inquired which of the things that were talked about or looked at before were actually bought. These examples therefore provide evidence that the cleft sentence for non-subjects in Northern Sotho is used in connection with a closed set of entities whose members are known to both speaker and hearer. Therefore, Northern Sotho clefts can be considered [+contrastive] in the sense of É. Kiss (1998).

In order to avoid confusion with contrast as in correction contexts, I will follow the terminology proposed in Bisang \& Sonayia (2000) for Yoruba and refer to that aspect as 'preconstructed domain' in the following. According to Bisang \& Sonayia (2000: 170)

"the preconstructed domain is an explicitly or implicitly presupposed set of entites [...] from which the speaker selects the ones that are relevant for his/her utterance." 
In terms of alternative semantics, in contrastive focus the set of alternatives must be contextually restricted. Thereby, the definition covers all the aspects that have been mentioned in this section: it captures presupposition of existence and the familiarity aspect, and can also accommodate potential exhaustivity effects. In sum, according to the definition given in chapter 1, focus is expressed in situ when the set of alternatives is not known to the speaker. The cleft structure is used when the set of alternatives is predefined and restricted. Moreover, the use of cleft sentences for non-subjects in Northern Sotho supports the cross-linguistic tendency that more complex meaning is provided using more complex syntactic structures.

\subsubsection{A corpus study}

In order to give quantitative evidence for the claims made in the preceding section, a corpus search was carried out. The following claims were addressed: In section 5.1.2 it was argued that in Northern Sotho, the cleft construction is the unmarked focus strategy for logical subjects both of transitive and intransitive verbs. For intransitive verbs also the impersonal construction can be used where the subject appears postverbally. For nonsubjects, however, the use of the cleft sentence bears a special discourse meaning and is therefore found only in designated contexts, as discussed in section 5.1.3 in detail. The prediction is then, that these claims are reflected in the distribution of syntactic question strategies.

Anticipated frequency effects

-For focused logical subjects of intransitive verbs, the impersonal construction should occur as often as the cleft construction if they do not differ in meaning. If the use of in situ versus ex situ structure with subjects of intransitive verbs is determined by other factors, the distribution will be biased.

-For non-subjects, it is expected that in situ questions occur significantly more often than ex situ questions.

The remainder of this section lays out the methods used to obtain information regarding the hypotheses in (17). The corpus study was done using the Northern Sotho corpus of the University of Pretoria, Department of African Languages. ${ }^{2}$ The corpus consists of texts written in Northern Sotho and contains bible texts (old and new testament), novels, plays, poetry, articles from a magazine (there is no newspaper in Northern Sotho), official internet pages, and academic writing. In total, the corpus comprises approximately 6.2 million words. It is therefore only a small corpus and there are some serious caveats to it, among them: First, the corpus is quite heterogeneous (e.g. the bible texts are in old translation therefore in a formal register and archaic). Second, because texts are scanned in, the quality of the transcripts is partly of poor quality. Nevertheless, it was chosen to work with this corpus for the following reasons: The corpus is specific to the language under investigation and therefore provides quantitative evidence for language-specific structures. Moreover, it broadens the general data base from which to work.

\footnotetext{
${ }^{2}$ Access only on-site via University of Pretoria, Department of African Languages, Prof. Daan Prinsloo or Dr. Elsabé Taljard.
} 
The corpus was searched for $w h$-pronouns because of practical and methodological reasons. Wh-pronouns are claimed to have a distribution parallel to focused constituents. Moreover, because the corpus is not annotated syntactically, a search request for whpronouns is the only feasible search strategy.

Northern Sotho has three question words for arguments: mang for [+human], bomang for [+human, Pl.], and eng for [-human]. The research request was done for mang, bomang and eng on June 30, 2005 using the software WordSmith Tools. It rendered 13.526 sentences whose distribution is shown in table 11.

Table 11: Occurrences of question words in Northern Soho corpus: before clearance

\begin{tabular}{|l|l|}
\hline wh-pronoun & occurrence \\
\hline mang & 6.352 \\
\hline bomang & 330 \\
\hline eng & 6.844 \\
\hline total & 13.526 \\
\hline
\end{tabular}

For the corpus investigation, the sentences containing bomang were not considered further because of their relatively small number. Also, the mang- and eng-occurrences were cleared from sentences containing expressions in which the wh-pronouns do not act as such. Among those were: mang le/goba/kapa mang- 'everybody' and ke ka lebaka la eng- 'why'.

Table 12: Sample files of Northern Soho corpus: after clearance

\begin{tabular}{|l|l|}
\hline wh-pronoun & occurrence \\
\hline mang & 4.518 \\
\hline eng & 6.333 \\
\hline total & 10.851 \\
\hline
\end{tabular}

The distribution of these 10.851 sentences suggests that [+human]-constituents (questioned by mang) are asked for less frequently than [-human]-constituents (questioned by eng).

From the 10.851 sentences, a sample of 544 sentences was analysed with respect to which grammatical function the question word expresses and which syntactic structure it occurrs in. The sentences were chosen randomly by taking every twentieth sentence. In the 544 sentences, only 274 encode logical subjects or non-subjects in active clauses. The other sentences show the distribution given in table 13 .

Table 13: Distribution within sample sentences

\begin{tabular}{|l|l|}
\hline wh-pronoun & occurrence \\
\hline unclassified & 18 \\
\hline others & 48 \\
\hline copula construction & 128 \\
\hline passive construction & 76 \\
\hline subject/non-subject & 274 \\
\hline total & 544 \\
\hline
\end{tabular}


For the unclassified sentences, no translation could be given by the language consultant who translated the sentences from the corpus. This was largely due to illegibility because of poor quality (see above).

The 48 sentences which are listed under 'others' contain wh-pronouns that were not used as such, and which have not been detected in the first clearance procedure. One such case is the use of a question word without any syntax (echo-question). Furthermore, eng occurred in idiomatic phrases where the original meaning as a question word got lost. This is illustrated in (18-a, b) for the use of eng with the meaning of 'why', in (18-c, d) for the use of the question word with the meaning of 'no one', and in (18-e, f) for the use of eng ke eng/mang ke mang, which was often translated as 'what is the matter'.

(18) Idiomatic use of question words ${ }^{3}$

a. Ké eng ba sa ba tliša gotee le Kgadi [...] ?

COP what CL2 NEG CL2 bring together PREP PROP.NAME

'Why didn't they bring them together with Kgadi...' (corpus, C2181)

b. [...], lena le biletš-wa eng?

[...] PRN.2.PL 2PL invite-PASS what

'Why are you invited?'

(corpus, D3881)

c. Mo bo-phelo-ng go phadišan-wa ebile ga go mang

PREP CL14-life-LOC CL17 compete-PASS then NEG CL17 who

yo a rata-go go phal-wa.

DEM.CL1 CL1 like-REL CL17 excel-PASS

'In life, people always compete and nobody wants to loose.' (corpus, B1281)

d. Ga go mang a swar-wa-go ke tlala, ga go mang NEG CL17 who CL1 hold-PASS-REL PREP CL9.hunger NEg CL17 who

a swar-wa-go ke le-nyora.

CL1 hold-PASS-REL PREP CL5-thirst

'Nobody is hungry, nobody is thirsty.'

(corpus, B1461)

e. Mo-tho wa ba-tho o ile a thoma go se

CL1-man Poss.CL1 CL2-man CL1 go.PST CL1 start CL15 NEG

hlw-e a tseba gore eng ké eng, a thoma go thothomela.

tarry-NEG CL1 know that what COP what CL1 start CL15 tremble

'The poor person didn't know what the matter was, he started trembling.' (corpus, C2101)

f. Fela o be o swan-etše go romela mo-laetša gore ba-laodi ba only 2 PST 2 need-PST CL15 send CL3-message that CL2-director CL2 ba-golo ba kgone go tseba gore eng ké eng ka wena. CL2-big CL2 can CL15 know that what COP what PREP PRN.2 'Only you should have sent a message so that your directors should know what is the matter with you.'

(corpus, D1601)

\footnotetext{
${ }^{3}$ All translations of the corpus data have been provided by P. Mogodi, a native speaker of Sepedi. The glosses have been added by me. All errors in interpretation are therefore mine.

${ }^{4}$ The numbers refer to the sentence numbers in the corpus files.
} 
Furthermore, a few instances have been found in the corpus where the question word was used as an indefinite rather than a question word. Two example sentences are reproduced in (19).

Indefinite use of question words

a. Mo-kopa goba eng e šorošoro e tlo bula ba-radia ba CL3-cobra or what CL9 dangerous CL9 FUT open CL2-criminal CL2 yona hlogo tše ka go ba wetša ka PRN.CL9 CL9.head DEM.CL9 PREP CL15 CL2 lead PREP kotsi-ng. CL9.danger-LOC

'The cobra or anything dangerous will teach these criminals a lesson by leading them into danger.'

(corpus, D1541)

b. Mokgadi a ka se o amogel-e, o tla re le o

Prop.NAME CL1 Pot Neg CL1 accept-NEg CL1 Fut say 2Pl CL1

tšhe-tše eng le rata go mmolaya.

pour-PST what 2PL want CL15 CL1.kill

'Mokgadi won't accept it, she will assume you poured something to kill her.'

(corpus, D2561)

Notice the high number of occurrences of copula constructions and passives in the corpus, as shown by the respective numbers in table 13. The high number of passives is especially meaningful, as passive structures are a further alternative for questioning an agent, next to cleft and postverbal constructions. They deserve further investigation.

Among the wh-pronouns referring to logical subjects and non-subjects of active clauses, the distribution as indicated in table 14 is found:

Table 14: Distribution across subject/non-subject

\begin{tabular}{|l|l|}
\hline wh-pronoun & occurrence \\
\hline logical subject & 78 \\
\hline non-subject & 196 \\
\hline total & 274 \\
\hline
\end{tabular}

As a result from table 14 it can be noted that non-subjects are questioned more often than logical subjects, as shown by the distribution. However, it needs to be borne in mind that for one, the coding category non-subject comprises both objects and oblique arguments. Combining these two kinds of arguments seemed necessary because although in some cases it seems straight forward what an argument is and what an oblique complement is (see $(20-a, b))$, in some cases this is more unclear (see (20-c)).

For the other, a potential frequency effect of logical subjects being questioned less often than non-subjects is flawed by the objection that passive structures are listed separately. This is important to note in so far as passive structures question an agent as well, as illustrated in (20-d). Table 13 shows that (logical) subjects and non-subjects seems to be questioned equally often when the frequency of passive questions and subject questions is taken together. 
(20) Arguments

a. Re tlo ruta bana ba rena eng?

1.PL FUT teach CL2-child CL2 PRN.1.PL what 'What will we teach our children?'

(corpus, D0041)

b. La ka le-thabo ga ke tseb-e gore n-ka le POSS.CL5 PRN.1 CL5-happiness NEG 1 know-NEg that 1-POT CL5

le-kantšha le eng; le feta di-thaba ka bo-golo. measure PREP what CL5 exceed CL10-mountain PREP CL14-size 'I don't know how to measure my happiness; it is bigger than a mountain.' (corpus, D3141)

c. Ge ba sega kgoši a se lemog-e gore ba sega while CL2 laugh CL9.chief CL1 NEG understand-NEG that CL2 laugh eng.

what

'While they were laughing, the chief didn't understand what they were laughing about.'

d. O be-il-we ke mang ge o re: Ke phala yola?

2 put.down-PST-PASS PREP who if 2 say 1 exceed DEM.CL9

'Who gave you the responsibility to say that you are better than this one?' (corpus, A0061)

Within logical subjects and objects, the following distribution across syntactic structures can be found:

Table 15: Distribution within subjects/non-subjects

\begin{tabular}{|l|l|}
\hline wh-pronoun & occurrence \\
\hline subject postverbal & 33 \\
\hline subject cleft & 45 \\
\hline object in situ & 179 \\
\hline object cleft & 17 \\
\hline total & 274 \\
\hline
\end{tabular}

Table 15 shows that logical subjects occur approximately equally often in cleft sentences and postverbally when questioned. Objects, however, occur significantly more often in situ, i.e. postverbally, than in a cleft sentence. Two examples of cleft sentences from the corpus are given in (21). The object marker that takes up the object head noun occurs immediately preceding the verb in the relative clause.

(21) Cleft sentences with objects

a. [...], ba be ba i-potš-iše gore seo ba be-go ba se

[...] CL2 PST CL2 ReFL-ask-Pst that DEM.Cl7 CL2 PST-Rel Cl2 Cl7

dira ké eng?

do Cop what

'[...] even asked themselves what exactly they were doing.' (corpus, C0841) 
b. [...] ke tla le kgopela gore na ké mo-rwedi wa mang [...] 1 FUT 2PL ask that QP COP CL1-daughter Poss.CL1 who yo a ka mo tšweša-go thetho.

DEM.CL1 CL1 POT CL1 put.on-REL CL9.apron

'Whose daughter will he put theto ${ }^{5}$ on?'

(corpus, B0821)

The software WordSmith Tools provides a context of roughly 20 words preceding and following the search word. Unfortunately, one can therefore not meaningfully test the hypothesis stated above, that the set of alternatives needs to be defined by discourse. It is interesting to note, however, that the native speaker provides the English translation of 'what is it exactly...' for these sentences.

With respect to the logical subject, it needs to be mentioned that postverbal occurrence occurs almost exclusively with intransitive verbs or verbs which are used intransitively in the respective sentence. Only one example occurs in the sample drawn from the corpus in which the postverbal subject is followed by another (sentential) complement.

Impersonal construction with sentential complement ${ }^{6}$

a. Go tseba mang gore ? se-hlola-nyana seo ga se gona!

CL17 know who that ? CL7-?-DIM DEM.CL7 NEG NEG here

'Who knows whether that little? is not here?' (corpus, B0021)

On the other hand, cleft structures nearly exclusively occur with transitive verbs. Again, only one example is found in which a cleft structure occurs with an intransitive verb.

Cleft sentence with intransitive verb

a. Ké eng seo se be-go se le ka fao ma-ngwalo-ng?

COP what DEM.CL7 CL7 PST-REL CL7 ? PREP there CL6-letter-LOC

'What was in those letters?'

(corpus, C0641)

The data from the corpus therefore show that with respect to the syntactic structure used with intransitive verbs, the impersonal structure is the prevalent structure used. Foreseeing to section 5.5.2, the data do not reflect real optionality of subject in situ/cleft with intransitive verbs. Nevertheless, cleft structures for intransitive verbs are not ungrammatical as the elicitation has shown.

\subsubsection{Summary}

This subsection dealt with the semantic features of cleft sentences in Northern Sotho. Based on the claim by É. Kiss (1998) that identificational focus and information focus have different syntactic and semantic characterizations, this section investigated if the syntactic differences in focus structures displayed by cleft and in situ constructions also imply semantic differences in Northern Sotho.

\footnotetext{
${ }^{5}$ theto $=$ Leather apron for a married woman

${ }^{6}$ This example shows the poor quality that appears now and again in the corpus. One word is illegible, for sehlolanyana the meaning remained unclear. It could be derived from hlola- 'to spy' and therefore mean 'little spy'. However, the appearance of a sentential complement following tseba- 'to know' is evident in this example nevertheless.
} 
It was argued that for subjects there is no semantic difference based on the observation that for transitive and ditransitive verbs both options are not available.

For non-subjects, a semantic difference was attested by native speakers and it was therefore tested by which semantic feature the difference between in situ and cleft could best be captured. Evidence for an exhaustive interpretation could not be reliably gathered. The data suggest instead that cleft structures presuppose the existence of the focused constituent and that moreover and more importantly the potential focused constituents must be known to the hearer. This notion can be captured by the notion of preconstructed domain, as proposed in work by Bisang \& Sonayia (2000) on Yoruba.

A study of the Northern Sotho corpus provided frequency data in support of these findings. It showed that logical subjects are significantly more often focused in cleft structures than objects. It furthermore showed that within logical subjects, the use of cleft and impersonal structure is dependent on the valency of the verb. However, in contrast to object clefts, native speaker did not consider subject clefts with intransitive verbs more marked semantically.

Interestingly, it seems that Northern Sotho uses the syntactically more complex form (cleft sentence as opposed to in situ structure) to express non-prototypical discourse functions of subjects and objects. Subjects are clefted when their prototypical discourse function of topic clashes with focus aspects. For non-subjects, it has been suggested in this section that they are clefted when they refer not to totally new information, but rather to information that is somehow already under discussion in discourse.

\subsection{The structure of clefts in Northern Sotho}

One controversy in the study of cleft constructions is if they are derived by syntactic movement or base-generated (see Collins 1991 for an overview). Therefore this section discusses and motivates the view on cleft sentences that is taken in this thesis. It argues for considering the cleft construction an alternative structure in its own rights. Thereby, it diverges from what has been argued in other treatments of syntactic focus structures in Bantu (e.g. Schwarz 2003 for Kikuyu, Sabel \& Zeller, to appear, for Nguni).

Generally, the conservative view is that a cleft construction consists of a copula and a head noun followed by a relative clause. Consequently, the structure is biclausal: the copula sentence embeds a relative clause. However, there are some arguments for a monoclausal analysis of cleft structures in which the head noun of the copula clause got into this position by movement. For German, the data in (24) remain unexplained when considering the copula sentence being base-generated, but can be accounted for if the cleft part is considered to be moved (for overviews see Meinunger 1998 for English and German, É. Kiss 1999 for English).

Cleft sentences in German (Meinunger 1998)

a. *Es war ein Bild von $\operatorname{mir}_{i}$, dass ich $_{i}$ suchte. 'It was a picture of myself that I was looking for.'

b. Es ist Peter, den wir gestern gesehen haben. 'It is Peter who we met yesterday.' 
c. Es war ihr, der wir geholfen haben.

'It was her who we helped.'

In (24-a), the pronoun in the clefted part can be bound by a constituent in the relative clause, as if it were c-commanded by it. Example (24-b) shows that the tense of the embedded sentence determines the temporal interpretation of the whole structure. This is unexpected, because the tense in relative clauses normally does not influence the temporal interpretation of the main clause. Similarly, in (24-c), the embedded verb determines the case of the complement of the copula. Again, this is unexpected as the case of the head noun is determined by the verb in the main clause, not by the verb embedded in a relative clause.

Deriving cleft sentences by movement has to address the following obvious problems in languages like German: How is the presence of the copula, the double presence of the focused constituent, and the presence of the expletive accounted for (see Meinunger 1998, É. Kiss 1999 for different proposals).

Heine \& Reh (1984: 181) argue that in some African languages cleft constructions provide the diachronic basis from which focus constructions have emerged. This widely adopted view is also followed in the analysis of ex situ focus in Kikuyu (Bergvall 1987a, Clements 1984b, Schwarz 2003). In this language, a preposed focused constituent is preceeded by $n e . N e$ is also used as copula in (some) instances. Moreover, with a preposed focused constituents tonal differences occur on the verb. Despite some similarities to cleft constructions, the focus construction in Kikuyu is argued not to be a biclausal cleft construction synchronically.

Sabel \& Zeller (to appear) follow a similar approach in their work on wh-questions in Nguni. They derive the cleft sentence syntactically by movement. To recapitulate their basic assumptions laid out in the preceding chapter: In wh-questions, a Focus Phrase is automatically generated between VP and TP. Furthermore, $w h$-words in Nguni languages have a weak [+wh]-feature which is located in $\mathrm{C}^{0}$ and can be checked via unselective binding. When the $w h$-word has a weak [+focus]-feature, the question word remains in situ and the feature is likewise checked via unselective binding.

Optionally, wh-words in Nguni can select a strong [+focus]-feature. If the strong [+focus]-feature is selected, the feature needs to be checked via a local specifier-relation. Therefore, the $w h$-word has to be realized in Spec FocP in order to check the [+focus]feature which is located in Foc $^{0}$ (see also the syntactic structure in (25)). ${ }^{7}$

Cleft sentences result from the realization of the strong [+focus]-feature. Next to the wh-word in Spec FocP, the strong [+focus]-feature is assumed to select the copula. The resulting syntactic structure according to Sabel \& Zeller (to appear) is illustrated in (25).

Subject focus in Nguni (following Sabel \& Zeller, example (4), structure (26))
a. Ng-ubani o-banga lowo msindo?
COP-who REL.CL1-cause DEM.CL3 CL3.noise

Lit. 'Who is it that is making that noise?'

\footnotetext{
${ }^{7}$ Evidence for the claim that ex situ wh-phrases in Nguni are not located in SpecCP is provided by word order in embedded sentences (Sabel \& Zeller, to appear).
} 


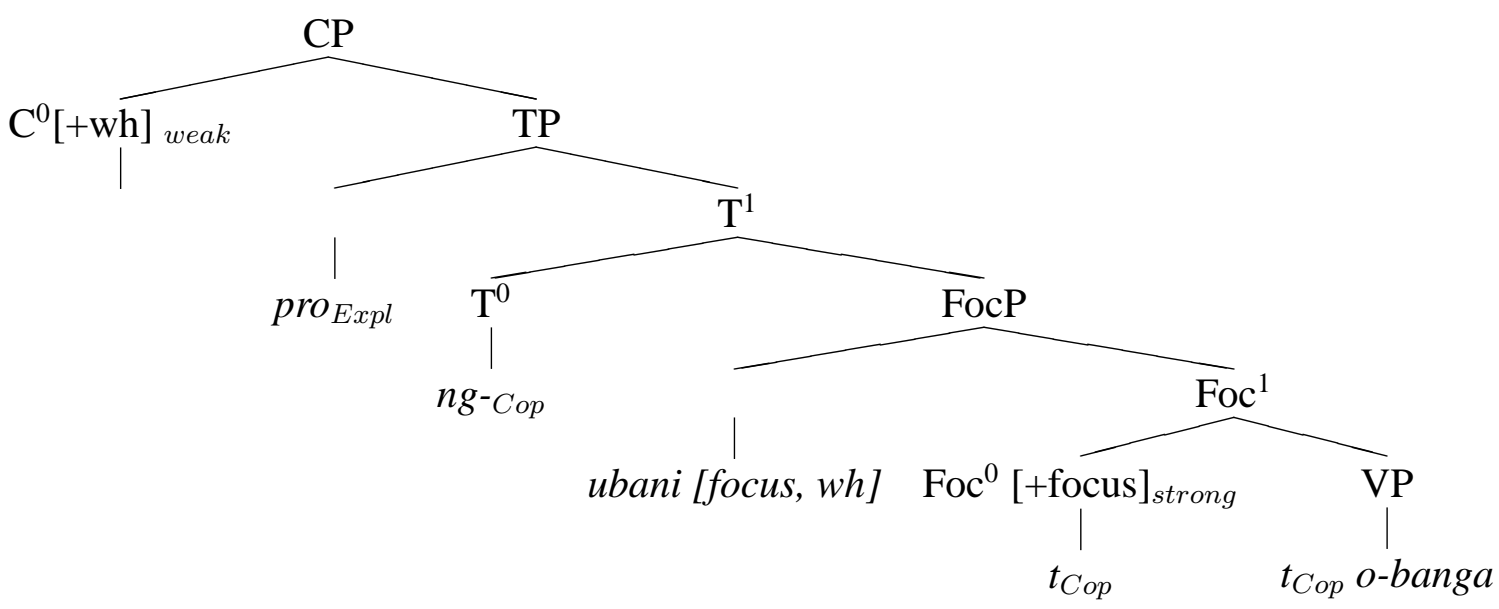

Whereas the $w h$-word moves to SpecFocP in order to check the strong [+focus]-feature, the copula undergoes V-to-T-movement like finite full verbs. According to Sabel \& Zeller (to appear), the prefixal copula verb moves first from $\mathrm{V}^{0}$ to $\mathrm{Foc}^{0}$, where agreement between the copula and the $w h$-phrase in SpecFocP is established via Spec-Head-agreement, and then further on to $\mathrm{T}^{0} .{ }^{8}$ Consequently, the copula precedes the $w h$-pronoun at the surface and is prefixed to the $w h$-phrase in phonology.

Sabel \& Zeller (to appear) address the obvious objections against movement as follows: The copula is generated within the VP triggered by the strong [focus]-feature that is optionally selected by the wh-pronoun. It moves from $\mathrm{V}^{0}$ over $\mathrm{Foc}^{0}$ to $\mathrm{T}^{0}$ and ends up preceding the head noun which is situated in SpecFocP. With respect to the relative clause morphology on the verb, Sabel \& Zeller (to appear) raise the possibility that the particular morphological marking observed in clefts and relative clauses reflects a specific syntactic movement rather than a relative clause per se. The syntactic movement operation that is mirrored by the verb morphology takes place both in relative clauses and in clefts.

Though it seems convincing that some languages, such as Kikuyu, have grammaticalized former cleft structures to focus constructions whereby the cleft sentences have lost some of their prevalent features, the view taken here is that this analysis does not (yet) apply to languages like Northern Sotho that show transparent features of copula plus head noun followed by a relative clause. Among these features are the presence of the copula, the presence of the relative pronoun, and the use of relative clause morphology, which is expressed by a change in the subject marker (from $o$ to $a$ in class 1), suffixation of an affix onto the verb (-go or $-n g$ ). Consequently, the cleft structure is considered a syntactic structure in its own rights which is not derived via movement.

\subsection{Form-meaning correspondence: Clefts with objects}

Having discussed the meaning and structure of clefts in Northern Sotho, we find a correspondence between form and meaning for objects of the following kind: On the one hand, the in situ structure expresses an unmarked focus interpretation in that it simply refers to a set of alternatives. On the other hand, the biclausal cleft structure expresses a

\footnotetext{
${ }^{8}$ Note that restrictions on improper movement (see section 4.3.2) only apply to phrasal movement, not to head movement. Therefore, this chain of movement is possible for the copula.
} 
specified focus interpretation in that it not only refers to alternatives but also marks them as belonging to a preconstructed domain. Bidirectional OT is the framework to model such correspondences where unmarked structures bear unmarked meanings and marked structures bear marked meanings ("Division of pragmatic labor", Horn 1984).

This section shows that the unidirectional approach taken so far can not derive the form-meaning mapping that can be observed for objects in Northern Sotho. It then introduces the extension of OT to "weak bidirectional OT" which comprises both encoding and decoding. This section further derives the analysis for objects, before it turns to clefts for subjects in the succeeding section, where a blocking of the form-meaning correspondence can be observed. It closes with problems and open ends of this analysis that are areas of further research.

\subsubsection{Simple form as the optimal form}

It has been argued in chapter 1 that both form and meaning are evaluated in the OTanalysis followed here. Up to now, only candidates showing the same semantic interpretation have been considered in the tableaus. The reason is that the faithfulness constraints comparing the output and input with respect to semantic structure, can be assumed to be sufficiently high-ranked to have very little effect on grammar (see also Legendre et al. 1998: 257, footnote 8). Tableaus consequently render the optimal expression for a given semantic input.

We have seen in section 4.3.2 that for a focused object the in situ structure is chosen as the optimal output. The analysis is repeated in tableau 16.

Tableau 16: In situ for non-subjects

\begin{tabular}{|c|c|c|c|c|}
\hline & focused direct object & 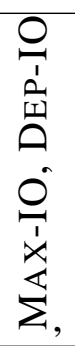 & 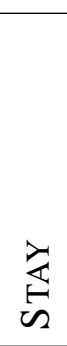 & 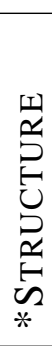 \\
\hline a. & 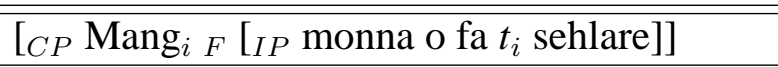 & & $* !$ & * \\
\hline b. & {$\left[I P[I P\right.$ Monna o fa $t$ sehlare $\left.] \operatorname{mang}_{F}\right]$} & & $* !$ & $*$ \\
\hline c. 侢 & {$\left[{ }_{I P}\right.$ Monna o fa mang ${ }_{F}$ sehlare $]$} & & & \\
\hline $\mathrm{d}$. & [IP Monna o fa mang ${ }_{C F}$ sehlare] & $* !$ & & \\
\hline e. & [CP Ke mang ${ }_{C F}[I P$ monna a fa-ng $t$ sehlare $]$ & $* !$ & & $*$ \\
\hline
\end{tabular}

In candidates (a) to (c) in tableau 16, the syntactic structure is evaluated. Candidate (c) emerges as winner because it represents the simplest syntactic structure involving no movement, in contrast to candidate (a) and (b).

Candidate (d) and (e) differ (also) with respect to the semantic structure. Although the input contains a 'simple' focus feature $(F)$, both candidate $(d)$ and (e) realize the complex focus feature $(\mathrm{CF})$ which involves the notion of preconstructed domain. Thereby, both candidates violate faithfulness constraints that evaluate the semantic structure of the 
candidates, and which follow the basic schema of faithfulness constraints. They are given in (26).
a. $\mathrm{MAX}-\mathrm{IO}(\mathrm{LF})$
'All semantic features of the input must be respresented in the output.'
Violated once for every semantic feature of the input which is not present in the output.
b. DEP-IO (LF)
'All semantic features of the output must be rooted in the input.'
Violated once for every semantic feature of the output which is not present in the input.

The precise ranking of the constraints in (26) with respect to the constraints established so far cannot be established. However, they are argueably high-ranked to have very little effect on grammar of Northern Sotho, as the output is generally faithful to the input with respect to its semantic content.

Such a unidirectional view of OT only works in the direction of encoding. This means that the same winner is (incorrectly) chosen also for a focused object which refers to the notion of preconstructed domain. This is mark by the black pointing finger in tableau 17. In tableau 17 , only relevant candidates are listed that either compete with the winning candidate in logical form or in syntactic structure that actually occurs in Northern Sotho, namely the cleft structure. All other syntactic structures are assumed to be excluded by respective constraints. That the same syntactic structure occurs with different semantic structures in the candidate set is due to the concept of Freedom of Analysis that places no restrictions on the creativity of GEN and therefore associates every syntactic structure with every semantic meaning.

Tableau 17: In situ for non-subjects

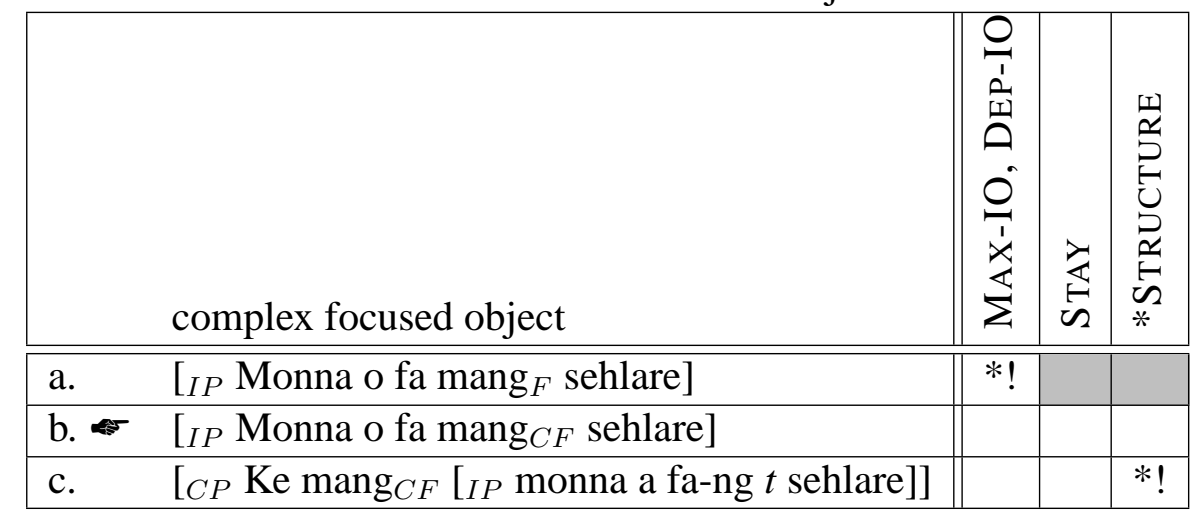

In tableau 17 we see that the (wronlgy chosen) winner (candidate b) is the syntactically simple in situ structure in which the question word bears the specified complex focus meaning. The in situ structure that bears a simple focus feature (candidate a) is excluded because it fatally violates the faithfulness constraints pertaining to logical form (as the input has complex focus). The syntactically complex cleft structure in candidate (c) that bears the specified focus meaning loses because it violates the constraint against additional structure. 
Unidirectional OT, as in tableaus 16 and 17, predicts the same syntactic expression with different semantic meanings. In this case, that means that the in situ structure is used both for expressing simple focus and complex focus. Such a double function is avoided in natural language as it leads to ambiguity. In particular, if there is an a priori tendency for simple focus, then complex focus could not be expressed, a problem known as ineffability.

Therefore, by integrating the semantic decoding of the utterance into the approach, the ambiguity is resolved by taking into consideration what the speaker could have said. The framework for modeling this interaction will be introduced in the next section.

\subsubsection{Essentials of Bidirectional OT}

We want to derive the form-meaning correspondence for focused objects in Northern Sotho, namely that the in situ structure refers to the simple focus feature and the cleft structure refers to the complex focus meaning. This form-meaning correspondence constitutes a case of Horn's 'division of pragmatic labor' (Horn 1984: 26) according to which marked meanings are associated with marked forms, and unmarked meanings are associated with unmarked forms.

In Northern Sotho, the in situ structure can be considered a syntactically unmarked structure as it does not involve movement or additional syntactic structure, in contrast to clefts. The normal focus meaning can be considered unmarked as it only contains one specification, namely for focus, in contrast to two specifications for focus and preconstructed domain.

Other instantiations of Horn's prinicple of 'division of pragmatic labor' can be found a.o. in the preferred interpretation of double negatives (Blutner \& Solstad 2001), in the precise and vague interpretation of numbers cross-linguistically (Krifka 2002), in the interpretation of object shift in Icelandic (Gärtner 2004a, b), or in the morphological marking of themes in Tagalog (Gärtner 2004b).

The concept of 'division of pragmatic labor' can be captured by considering optimal pairs of expression and interpretation. The definition according to which expressioninterpretation pairs can be considered optimal is given in (27).

Weak bidirection (Blutner 2000, Jäger 2002) A form-meaning pair $\langle\mathrm{f}, \mathrm{m}\rangle$ is superoptimal iff $\langle f, m\rangle \in$ GEN and:

a. there is no other super-optimal pair $\left\langle\mathrm{f}, \mathrm{m}^{\prime}\right\rangle:\left\langle\mathrm{f}, \mathrm{m}^{\prime}\right\rangle_{i}\langle\mathrm{f}, \mathrm{m}\rangle$

b. there is no other super-optimal pair $\left\langle\mathrm{f}^{\prime}, \mathrm{m}\right\rangle:\left\langle\mathrm{f}^{\prime}, \mathrm{m}\right\rangle_{i}\langle\mathrm{f}, \mathrm{m}\rangle$

According to (27), a form-meaning pair is super-optimal if there is no pair in which either the form or the meaning is itself optimal. Note that the definition in (27) only allows for comparison between pairs that are identical in one component, either form or meaning. Pairs that differ in both form and meaning are not captured by (27).

This OT variant of "weak bidirectional OT" will be applied to the derivation of the form-meaning correspondence in Northern Sotho in the next section. 


\subsubsection{Analysis}

For a treatment of the form-meaning correspondence in Northern Sotho with respect to object focus, the pairs in (28) are compared.

(28) Form-meaning correspondence in Northern Sotho
a. in situ structure, focus
b. in situ structure, focus \& preconstructed domain
c. cleft structure, focus
d. cleft structure, focus \& preconstructed domain

We need to check which constraints the pairs in (28) violate in order to find the superoptimal expression-interpretation pair, i.e. the pair for which there is no other pair that is more optimal either in form or meaning. The relevant constraints relate to the markedness of the expressions or interpretations. As bidirectional OT evaluates the correspondence of form and meaning, the constraint needs to be formulated independent of the input. The constraint that is adopted here is BRIEFEXPRESSION, following Krifka (2002).

$$
\begin{aligned}
& \text { BRIEFEXPRESSION, BE } \\
& \text { 'Shorter expressions are preferred over longer ones.' }
\end{aligned}
$$

The constraint in (29) captures the intuition that all else being equal, shorter and simpler expressions are preferred (Zipf 1949, Grice 1975/1989). For the meanings, the relevant constraint is given in (30), again following Krifka (2002).

$$
\begin{aligned}
& \text { VAGUEINTERPRETATION[F], VI } \\
& \text { 'The set of alternatives is unrestricted.' }
\end{aligned}
$$

Krifka (2002) alludes to the potential difficulties in motivating a constraint as in (30), as it seems to contradict Grice's first submaxim of quantity, which states that the content of a message should be maximized, and also Heim's (1991) 'Maximize Presupposition' which requires to be as specific as possible with information.

However, at least two arguments have to be considered when objecting to the constraint in (30). First, the second submaxim of quantity also states that a speaker should not give more information than is necessary for the current purpose of communication. Moreover, and this becomes especially evident in questions, if the answer to a question is not known to the speaker, it makes more sense to leave the set of alternatives as open as possible.

Coming back to the pairs in (28), we find the following violations:

(31) Form-meaning correspondence with objects

$$
\text { form-meaning pair violates }
$$

a. in situ structure, focus

b. in situ structure, focus \& preconstructed domain VI

c. cleft structure, focus BE

d. cleft structure, focus \& preconstructed domain $\quad B E, V I$ 
Form-meaning pair (31-a) emerges as the super-optimal pair, because it does not violate any of the constraints, whereas all other pairs violate at least one. Consequently, in situ structures are interpreted without any restrictions on the set of possible alternatives.

Also (31-d) is a super-optimal pair. Although its competitors, (31-b) and (31-c), violate one constraint less than (31-d), they are not themselves super-optimal. Therefore, according to the definition in (27), (31-d) emerges as another super-optimal pair. Note that (31-a) and (31-d) are not in direct competition because they differ in both form and meaning.

Bidirectional OT can therefore derive the form-meaning correspondence for objects in Northern Sotho. Both the in situ structure expressing unrestricted focus, as in (32-a), as well as the cleft structure expressing focus from a preconstructed domain, as in (32-b), emerge as super-optimal form-meaning pairs.

Form-meaning correspondence

a. O rek-ile eng?

2 buy-PST what

'What did you buy?'

b. Ke eng se o se rek-ile-ng?

COP what CL7 2 CL7 buy-PST-REL

Lit. 'It is what that you bought?' (from a set of alternatives)

\subsubsection{Alternative approach}

In the feature checking account proposed by Sabel \& Zeller (to appear), the strength of the [+focus]-feature determines the different syntactic realizations of questions in Nguni languages. Generally, features in the Minimalist Program (MP) initiate movement because of the required syntactic relation necessary for feature checking. Furthermore, features in MP are differentiated into interpretable and uninterpretable features. Interpretable features are relevant for the semantic interpretation at the LF interface. They consequently have a semantic effect. Non-interpretable features do not have a semantic effect. The [+wh]-feature, e.g., that question words bear, is an interpretable feature that establishes the scope of the wh-phrase (Sabel \& Zeller, to appear). With respect to the [+focus]feature, Sabel \& Zeller (to appear) leave the question open about the interpretability of the feature. Neither do they address the semantic interpretation of cleft and in situ structures in Nguni.

If the feature-checking account is transferred to Northern Sotho, one is led to assume that the strength of the [+focus]-feature is interpreted semantically. To recapitulate: A weak [+focus]-feature is realized in situ, and the in situ variant corresponds to a 'normal' focus interpretation in Northern Sotho. A strong [+focus]-feature is realized ex situ, and the ex situ variant corresponds to a more specific focus interpretation in Northern Sotho. Consequently, the semantic feature 'preconstructed domain' is checked by movement of the focused expression. The semantic feature 'focus' is checked via unselective binding and results in focus in situ. Thereby, the approach proposed in Sabel \& Zeller (to appear), though different in its theoretical framework and in theory-specific details, theoretically 
also captures the mapping of form and meaning. ${ }^{9}$

Connecting syntax and semantics is not included in the original syntactic proposal by Sabel \& Zeller (to appear). This step is therefore one crucial difference of the account proposed here. Another crucial difference between the two approaches is that clefts are not necessarily derived via movement but are independent alternative structures that are compared to the in situ structures. Their syntactic form is therefore not crucial in the evaluation. A cleft structure can be expected to have various violations of the syntactic constraints such as *STRUCTURE. However, as these constraints are ranked lower, the violations are irrelevant independent of their number.

\subsection{Blocking: Clefts with subjects}

The correspondence between form and meaning breaks down in the case of subject focus in transitive verbs. Cleft sentences are the only possible focus structure for subjects of transitive verbs, even when bearing an unmarked focus meaning. This section investigates why the form-meaning correspondence observed with objects does not obtain in the case of subjects of transitive verbs. In a first subsection it argues that because of a higherranked syntactic constraint, the in situ structure (impersonal construction) is prohibited for focused logical subjects of transitive verbs, which renders the in situ structure expressing unmarked focus suboptimal.

Given what has been said about the interpretation of clefts in the preceding section, one might predict that if this higher-ranked syntactic constraint blocks in situ structures, the unmarked focus reading can no longer be expressed. However, where the in situ form is lacking, the clefted form also supports the unmarked focus reading. Therefore, in a second subsection it is discussed how the ambiguity in subject clefts in Northern Sotho still emerges from the bidirectional-OT approach.

\subsubsection{Restriction on transitive verbs}

The question that every account of the subject/object asymmetry in Bantu languages has to address is why the impersonal construction, in which the logical subject appears postverbally and cl17-agreement occurs on the verb, is not possible with transitive verbs.

Alexiadou \& Anagnostopoulou (2001) claim that whenever a sentence contains both a subject and a direct object, one of the arguments must vacate the VP because of Case requirements (see also Chomsky 2001). The constraint in (33) is meant to reformulate informally the generalization by Alexiadou \& Anagnostopoulou (2001: 193) that "by Spell-Out the VP can contain no more than one argument with an unchecked Case feature".

\footnotetext{
${ }^{9}$ Grewendorf (2000: 155) raises the question why a grammatical system has uninterpretable features if the output cannot interpret them but the grammatical system is nevertheless crucially determined by them. These basic conceptual issues as well as theory-specific controversies concerning features and their interpretability will not be discussed here but will be left for a more specialized treatment.
} 
*TEC

'In expletive constructions, either subject or object have to have left the VP.' Violated once for every additional constituent within VP.

For apparent counterexamples from languages like French, Japanese, Icelandic, Celtic, Arabic and Italian (among others), Alexiadou \& Anagnostopoulou (2001) bring evidence that shows that indeed one of the arguments has been moved out of the VP.

An alternative view is held by Sabel \& Zeller (to appear) who attribute the lack of transitive expletive constructions in Nguni to a parametric property of SpecTP. Working within the OT-framework, it is unnecessary to show that the generalization in (33) is indeed a universal. Formulating the generalization as a violable constraint as in (33) instead, allows to capture the importance of this generalization by ranking it high in the grammar of a language. Again, Optimality Theory can model the parameterization by (re-)ranking of constraints. ${ }^{10}$

The ungrammaticality of impersonal constructions with transitive verbs in Northern Sotho, supports the view that the constraint in (33) must be ranked high in the grammar of this language, and therefore blocks the emergence of the impersonal construction.

\subsubsection{Emergence of the cleft}

As discussed in the preceding section, the in situ construction (i.e. the impersonal construction) is blocked for logical subjects of transitive verbs by the higher ranked constraint *TEC. Given the form-meaning correspondence established in section 5.3, one might predict that the unmarked focus meaning cannot be expressed for logical subjects of transitive verbs in Northern Sotho. However, what we find is that the unmarked focus meaning is expressed by the marked syntactic expression, i.e. by the cleft. ${ }^{11}$

The selection of super-optimal pairs changes if in an established form-meaning correspondence one form is blocked by higher-ranked syntactic constraints. In the case of focus on the logical subject, the intervening syntactic constraint is *TEC. This is illustrated in (34).

$\begin{array}{ll}\text { Form-meaning correspondence with logical subjects of transitive verbs } \\ \text { form-meaning pair } & \text { violates } \\ \text { a. in situ structure, focus } & \text { *TEC } \\ \text { b. in situ structure, focus \& preconstructed domain } & \text { *TEC, VI } \\ \text { c. cleft structure, focus } & \text { BE } \\ \text { d. cleft structure, focus \& preconstructed domain } & \text { BE, VI }\end{array}$

When evaluating form and meaning for focused logical subjects of transitive verbs according to the concept of weak bidirection in (27), the cleft structure expressing neutral focus, (34-c), emerges as the super-optimal pair: There is no other pair that is more optimal either in form or in meaning. Though the impersonal in situ construction expressing

\footnotetext{
${ }^{10}$ For a different approach within Lexical Mapping Theory see Bresnan \& Kanerva (1989) and Demuth \& Mmusi (1997).

${ }^{11}$ Note that this clearly constitutes one case in which less marked readings get associated with more marked forms, see Gärtner 2004b: 161 and footnote 13.
} 
neutral focus, (34-a), also shows one violation only, this violation is fatal in contrast to the violation of (34-c), as the relevant constraint *TEC is ranked higher. (34-d) is harmonically bound by (34-c), so it will never emerge as a super-optimal pair as it always shows one violation more than (34-c).

In sum, the intervention of the syntactic constraint *TEC shifts the super-optimal pair for the expression of unmarked focus on the logical subject of transitive verbs from an in situ structure to the cleft structure. The principle of 'Division of pragmatic labor' (Horn 1984 ) is violated in this case, as the unmarked meaning associates with a marked form. At closer inspection the scenario in (34) poses further problems. They reveal themselves when investigating if the principle of 'Division of pragmatic labor' still holds for marked meanings: Are marked meanings expressed by marked forms?

The form-meaning correspondence emerged in the case of objects because candidates such as (34-a) and (34-d) were not in direct competition, and the directly competing candidates (34-b) and (34-c) were not themselves super-optimal (see (27) and section 5.3). However, the intervention of the syntactic constraint *TEC and the resulting shift in the super-optimal pair expressing the unmarked focus meaning has consequences for the expression of the marked meaning as well. Candidates such as (34-a) and (34-d) are still not in direct competition, but now there is a super-optimal pair among the directly competing candidates (34-b) and (34-c). Consequently, a cleft sentence expressing a marked focus meaning, (34-d), is never super-optimal. Instead, the cleft structure expressing the unmarked focus meaning, (34-c), emerges as super-optimal even if the input contains a marked focus meaning.

Therefore, the bidirectional approach does not only (correctly) account for the breaking down of the principle of 'division of pragmatic labor' but also predicts that marked focus cannot be expressed for focused logical subjects of transitive verbs in Northern Sotho. The problem that ambiguity cannot be captured by bidirectional OT is known in the literature and will be discussed in the next section as an area for further research, together with the case of optionality in the expression of focus on the logical subject of intransitive verbs.

\subsection{Areas for future research}

It is obvious that both cases of ambiguity and optionality in the grammar of Northern Sotho are areas for future research. Both ambiguity and optionality involve a mismatch between a perfect correspondence of form and meaning and pose problems for Optimality Theory. They are discussed in this section.

\subsubsection{Ambiguity in Bidirectional OT}

In the preceding section it has been shown that because of the syntactic constraint *TEC, the marked form can indeed eventually express the unmarked meaning. However, at the same time the prediction is made that the marked form never expresses the marked meaning.

This prediction excludes ambiguity in meaning. The exclusion of ambiguity of meaning has been identified as a problem of weak bidirectional OT (27) in recent literature (see 
e.g. Beaver \& Lee 2004, Gärtner 2004a, b). Gärtner (2004a, b) discusses object shift in Icelandic as one example. Object shift in Icelandic, which is associated with a strong indefinite reading, is blocked with periphrastic verb forms. The bidirectional OT-approach makes the prediction that the remaining in situ form can only express the weak reading. This is due to the prediction of weak bidirectionality that "for a form $f$, only one meaning is available if one of the meaning in pairs $\langle\mathrm{f}, \mathrm{m}\rangle$ and $\left\langle\mathrm{f}, \mathrm{m}^{\prime}\right\rangle$ incurs a more serious constraint violation" (Beaver \& Lee 2004: 128). As a matter of fact, the in situ form in Icelandic is ambiguous between definite and indefinite reading, as the in situ form can be used in different topic/comment structures. Gärtner (2004a, b) proposes a contextual constraint in order to derive the ambiguity for Icelandic. He concludes that though bidirectional OT provides a 'deeper' understanding of why unmarked forms associate with unmarked meanings and vice versa, it lacks a satisfactory way of treating the phenomena of partial iconicity which involve ambiguity (Gärtner 2004a: 1235).

For Northern Sotho, my research has clearly shown that the cleft sentence can be used for focused logical subjects of transitive verbs when conveying the unmarked focus meaning. However, it has not been tested explicitly if the cleft sentence is also used with focused logical subjects of transitive verbs when referring to a preconstructed domain. The corpus data do not contain enough context in order to check this question. Therefore, no authoritative claim can be made here for the ambiguity of the marked form with respect to meaning in Northern Sotho.

Let us for now assume that in Northern Sotho the cleft structure is used for the expression of marked focus also for logical subjects of transitive verbs. In their overview of how different OT-systems handle input-output mismatches, Beaver \& Lee (2004) show that unidirectional, production-oriented OT-syntax does not encounter any problems in accounting for the expectable ambiguity. And indeed, in unidirectional OT, the ambiguity of the marked form is easily accounted for. This is illustrated in tableau 18 for example (35).

(35) Subject focus by means of cleft

$\mathrm{Ke}$ mang a nyaka-ng ngaka?

COP who CL1 look.for-REL CL9.doctor

'Who is looking for the doctor?' 
Tableau 18: Ambiguity of clefts

\begin{tabular}{|c|c|c|c|c|}
\hline & focused subject of transitive verb & $\begin{array}{l}\text { U } \\
\text { 志 } \\
*\end{array}$ & 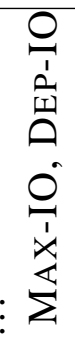 & 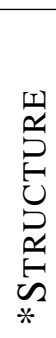 \\
\hline a. & {$\left[I P\right.$ go $\left[I 0\right.$ nyaka $\left[V P\right.$ mang ${ }_{F}$ ngaka $\left.\left.]\right]\right]$} & $*$ & & \\
\hline b. & $\left[I_{I P}\right.$ go [I0 nyaka $\left[V P\right.$ mang $_{C F}$ ngaka $\left.\left.]\right]\right]$ & $*$ & $*$ & \\
\hline c. 拥 & {$\left[{ }_{C P}\right.$ ke $\operatorname{mang}_{F}\left[I_{P} t\left[{ }_{I P}\right.\right.$ a nyaka-ng $t$ ngaka $\left.\left.]\right]\right]$} & & $\vdots$ & * \\
\hline d. & {$\left[{ }_{C P}\right.$ ke $\operatorname{mang}_{C F}\left[{ }_{I P} t\left[{ }_{I P}\right.\right.$ a nyaka-ng $t$ ngaka $\left.\left.]\right]\right]$} & & $*$ & $*$ \\
\hline & complex-focused subject of transitive verb & $\begin{array}{l}\text { U } \\
\text { 丽 } \\
*\end{array}$ & 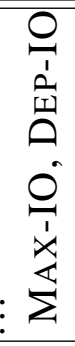 & 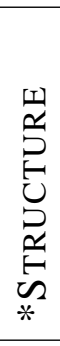 \\
\hline a. & {$\left[{ }_{I P}\right.$ go $\left[I_{0}\right.$ nyaka $\left[V P\right.$ mang ${ }_{F}$ ngaka $\left.\left.]\right]\right]$} & ** & * & \\
\hline b. & $\left[I_{P}\right.$ go [I0 nyaka [VP mang $_{C F}$ ngaka $\left.\left.]\right]\right]$ & $*$ & & \\
\hline c. & {$\left[{ }_{C P}\right.$ ke $\operatorname{mang}_{F}\left[I_{P} t\left[{ }_{I P}\right.\right.$ a nyaka-ng $t$ ngaka $\left.\left.]\right]\right]$} & & $*$ & $*$ \\
\hline d. 唡 & {$\left[C P\right.$ ke $\operatorname{mang}_{C F}\left[I_{P} t\left[I_{P}\right.\right.$ a nyaka-ng $t$ ngaka $\left.\left.]\right]\right]$} & & & $*$ \\
\hline
\end{tabular}

The candidates in tableau 18 show the four form-meaning pairs discussed already in (34): Candidate (a) shows the in situ structure expressing unmarked focus (as marked by the morphosyntactic feature ${ }_{F}$ ). Candidate (b) shows the in situ structure expressing marked focus (as indicated by the morphosyntactic feature ${ }_{C F}$ ). Candidate (c) shows the cleft structure expressing unmarked focus, and candidate (d) shows the cleft structure expressing marked focus. The in situ forms are excluded because of the high-ranked constraint *TEC. From the remaining cleft structures that candidate wins that expresses the focus specification encoded in the input. The other structure loses as it fatally violates the faithfulness constraints pertaining to logical form.

Consequently, tableau 18 derives the ambiguity of the cleft structure that expresses both marked and unmarked focus. The actual interpretation of the cleft structure must eventually be regulated by context. This result reminds of the contextual constraint proposed by Gärtner (2004a, b) and underlines the need for an adequate theory of contextbased interpretation in OT.

A syntactic feature-checking approach in the framework of the Minimalist Program faces similar problems. Both the bidirectional OT-approach proposed in this section and a purely syntactic account with interpretable [+focus]-features make the prediction that first, there is a difference in interpretation with subject focus in intransitive verbs that should equal the semantic difference found with objects, and second, that subject focus with transitive verbs can only express one kind of focus (= the more specialized), as the other is blocked. It remains unclear how the 'weak' focus interpretation of a strong feature 
is captured in the case of focused subjects of transitive verbs.

Similarly, if the specification of the focus features as strong or weak is to be interpreted semantically, it needs to be accounted for why with subjects of intransitive verbs the difference in interpretation seemingly disappears. The next section discusses how the optionality of structures with subjects of intransitive verbs is captured in the OT-approach.

\subsubsection{Optionality within OT}

The preceding sections have established a form-meaning correspondence for objects in which the in situ forms express unmarked focus, and the clefted forms express marked focus. Moreover, it has been shown that for focused logical subjects of transitive verbs, this form-meaning correspondence is blocked and the cleft structure also expresses the unmarked focus meaning.

This section turns to the described optionality of cleft and in situ structure with focused subjects of intransitive verbs. To remind the reader of the relevant data, an example is repeated in (36).

\section{Intransitive subject questions}
a. Go fihla mang?
CL17 arrive who
'Who is arriving?'
b. Ke mang a fihla-ng?
COP who CL1 arrive-REL
'Who is arriving?'
Impersonal go-construction

Elicitation showed that both cleft and in situ structure can be used optionally for focused subjects of intransitive verbs. Synchronically, no semantic difference could be established for the alternatives in (36) which would equate the difference found between cleft and in situ structures with objects. So far the question has not yet been addressed why with intransitive verbs there is optionality between postverbal subject focus and cleft construction. This empirical finding is surprising as it is expected from what has been said before, that with intransitive verbs, the same form-meaning correspondence should be found as for objects. This prediction is based on the fact that the higher-ranked syntactic constraint *TEC does not interfere, because it is not relevant for intransitive verbs.

According to Müller (2000: 189), independent of the theory adhered to one can state that syntactic optionality occurs when there are two or more possibilities to say the same thing. Optionality is expected to pose a problem for OT because the framework predicts that only one candidate is the optimal output and therefore blocks all other candidates as suboptimal. Different strategies are taken to resolve this problem. In the fewest cases, optionality manifests itself as 'true optionality' in that both winning candidates show identical violations of the same constraints (terminology adopted from Müller 2000: 196). More often, candidates violate different constraints. By tieing the relevant constraints, one can account for the observation that a candidate can either violate one constraint or another without consequences ('constraint tie'). Another strategy to deal with optionality is to investigate if the two winning candidates are within the same candidate set, or if they represent the (only) winner in two different evaluations ('pseudo-optionality'). 
It turns out that the optionality in (36) cannot be accounted for straightforwardly along the lines just outlined. The problems and issues at hand are discussed in the succeeding sections. However, a conclusive analysis has to await further research.

\section{True optionality and Constraint tie}

For illustration, tableau 19 repeats the analysis for intransitive sentences based on the constraint ranking established for unidirectional OT-analyses so far.

Tableau 19: Focus in intransitive sentences

\begin{tabular}{|c|c|c|c|c|c|c|}
\hline & focused subject in intransitives verbs & 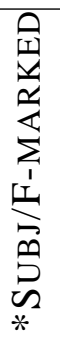 & 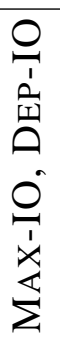 & 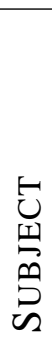 & $\underset{\Delta}{\stackrel{\Delta}{5}}$ & 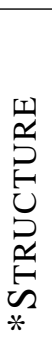 \\
\hline a. & {$\left[{ }_{I P} \operatorname{mang}_{F}\left[I^{\prime}\right.\right.$ o bina $\left.\left.\left[V_{P} t\right]\right]\right]$} & $* !$ & & & * & * \\
\hline b. 吗 & {$\left[I^{\prime}\right.$ go bina $\left[V P\right.$ mang $\left.\left.{ }_{F}\right]\right]$} & & & $*$ & & \\
\hline c. & {$\left[I^{\prime}\right.$ go bina $\left[V P\right.$ mang $\left.\left.C_{C F}\right]\right]$} & & $* !$ & $*$ & & \\
\hline d. & {$\left[I_{I P}\right.$ ke $\operatorname{mang}_{F}\left[{ }_{I P} t\left[I_{0}\right.\right.$ a bina-ng $\left.\left.]\right]\right]$} & & & $*$ & $* !$ & $* *$ \\
\hline e. & {$\left[{ }_{I P}\right.$ ke mang $\operatorname{loF}_{I I P} t\left[I_{0}\right.$ a bina-ng] $\left.]\right]$} & & $* !$ & $*$ & $*$ & ** \\
\hline
\end{tabular}

Candidate (a) shows the focused subject appearing in preverbal position. Chapter 4 has argued in detail that a focused subject in preverbal position is excluded by the high-ranked interface constraint *SUBJECT/F-MARKED. Candidate (b) to (e) show the usual candidates which combine in situ and cleft structure with both the marked and unmarked focus feature. The two candidates (c) and (e), that do not realize the exact focus feature of the input, are excluded because they violate the semantic faithfulness constraints. From the two candidates that realize the unmarked focus feature, the cleft structure (d) is harmonically bound by the in situ structure (b). Both violate the constraint SUBJECT. In addition, the cleft structure always shows further violations of the constraints STAY and STRUCTURE. Consequently, candidate (d) can never emerge as a winner.

Tableau 19 shows that the two candidates (b) and (d) do not emerge as truly optional as the cleft structure violates the STRUCTURE constraint more often than the impersonal structure.

The observed optionality does not constitute a case of 'constraint tie' either. The basic idea of 'constraint tie' is that two (or more) constraints are tied, i.e. they are ranked equally high with respect to each other. If two candidates differ only on the tied constraints then advantages and disadvantages of the candidates can be equaled out and both can be optimal, even if they do not show the same constraint violations on lower ranked constraints. However, if candidates are harmonically bound, which is the case for candidate (b) and (d), then no constraint tie can render both optionally optimal.

The empirically observable optionality does not constitute a case of true optionality, nor can the optionality be captured by a constraint tie. In sum, the optionality cannot be captured by the syntactic constraints. 


\section{Pseudo-optionality}

Another view to come to terms with optionality in OT has been termed pseudo-optionality (Müller 2000, see references therein). The basic idea of 'pseudo-optionality' is that the optionality is not real but that the two (or more) optimal candidates belong to different candidate sets instead. They are therefore not in direct competition but belong to different derivations.

The view that candidates can belong to different candidate sets, can only arise when candidate sets are restricted a priori, as e.g. in Müller (2000: 193). Müller (2000) bases the rules for determining the candidate set on original work by Grimshaw (1997: 375-376) and extends them with a notion from Chomsky (1995).

Candidate set:

a. Two candidates $\mathrm{C} 1, \mathrm{C} 2$ are within the same candidate set iff $\mathrm{C} 1$ and $\mathrm{C} 2$ have the same enumeration (i.e. identical lexical material).

b. $\quad \mathrm{C} 1$ and $\mathrm{C} 2$ have identical LF-structures

As has been argued in section 1.5.2, restricting the set of competing candidates by rules as the ones in (37) infringes upon a basic assumption of the OT-framework. By the principle of Freedom of analysis (Prince \& Smolensky 1993), GEN should technically be allowed to generate any possible output structure for a given input structure. GEN is only restricted by unviolable constraints that are built into GEN and therefore restrict a candidate set. Faithfulness constraints should filter out candidates that differ from the input in either lexical material or semantic structure.

Therefore, the view is adhered to here that the candidates of syntactic alternations belong to the same candidate set. The definition of syntactic alternations is given in (38) (following Müller 2000: 195).

Alternation

Two (or more) constructions can co-occur (=optionality), but under certain circumstances one can block the other.

With intransitive verbs, the impersonal go-construction and the cleft sentence can cooccur in Northern Sotho, as shown in (39-a). With transitive verbs, however, this optionality is blocked and only cleft sentences occur as focusing strategy, which is repeated in (39-b).

Valency-based restrictions on optionality

a. Go fihla mang?

Ké mang a fihla-ng?

'Who is arriving?'

b. *Go ngwala mang lengwalo?

Ké mang a ngwalang lengwalo?

Intended: 'Who is writing a letter?'

Subject focus with intransitive verbs thereby constitutes a case of syntactic alternation according to the definition in (38). Following Müller (2000: 193) the presence of the cleft 
structure in (39-b) shows that both impersonal structure and cleft structure are within the same candidate set for the input, as the cleft in (39-b) emerges as the winner from the derivations comparing impersonal and cleft structures for transitive verbs.

\section{Discussion}

The preceding sections showed that although both cleft structure and in situ structure can be argued to be in direct competition for subject focus of intransitive verbs, there is no way to account for their optionality with the mechanisms proposed in OT so far. Therefore, this section takes a further look at the linguistic behaviour of these two structures.

The status of true optionality becomes doubtful when considering the results from the corpus study, described in section 5.1 .4 of this chapter. With intransitive verbs, subject focus is expressed nearly exclusively by means of the impersonal in situ structure. Assuming real optionality one would expect to find approximately as many cleft structures as impersonal in situ structures with focused logical subjects of intransitive verbs.

Furthermore, question-answer coherence shows that cleft and in situ structure cannot be used interchangeably with focused subjects of intransitive verbs. A question posed in a cleft structure can only be answered by a cleft structure, whereas a question posed in the impersonal construction can only be answered by an impersonal construction. For other languages, like Kikuyu, question-answer coherence has shown that in situ and ex situ forms can be used truely interchangeably (Schwarz 2003).

The results from the corpus study and the need of question-answer coherence suggest that the distribution of cleft and in situ structure with logical subjects of intransitive verbs is biased. Native speakers' judgments exclude a bias triggered by semantic meaning. The distribution could also be biased by considerations of style.

More generally, the information structural restrictions of intransitive verbs in Northern Sotho deserve further detailed study. Another case of potential optionality exists with intransitive verbs under wide focus. At the beginning of texts, impersonal go-constructions were used, (40-a), though these were never used for the description of pictures, (40-b).
a. Go tšwelela mo-sadi gomme o lebantšha mo-nna [...]
CL17 appear CL1-woman then CL1 place.opposite CL1-man
'There appears a woman, she places herself opposite the man.'
b. Le-sea le rob-etše.
CL5-baby CL5 sleep-PST
'A baby is sleeping.'

It is not yet clear of what semantic kind the difference under wide focus between the impersonal construction and the normal SVO structure is. However, if the use of these structures is interchangeable under wide focus in Northern Sotho, the OT-approach has to account for this optionality as well. This remains a topic for further research.

The proposal made here is that the theoretically-possible optionality emerges because of the hybrid status of focused logical subjects of intransitive verbs: Syntactically, they pattern with objects as they allow a form-meaning correspondence. With respect to their grammatical function, however, they pattern with subjects of transitive verbs. This results in theoretically allowing the cleft structure for the expression of unmarked subject focus, 
but practically in obeying the form-meaning correspondence and thereby choosing the syntactically simpler and shorter form for the expression of the unmarked focus meaning.

\subsection{Summary}

This chapter investigated the role of clefting for the expression of focus in Northern Sotho. It has been shown that clefts can carry a semantic interpretation that goes beyond the sole indication of alternatives. If a cleft structure is used for focused objects, it is expressed that the object is chosen from a predefined set of alternatives. As the semantic content of clefts in the case of objects is more complex, it is expected to occur less frequently in natural speech. Frequency tendencies from a corpus study support this view.

Consequently, the unmarked syntactic form corresponds to an unmarked semantic form in the case of objects and vice versa. This correspondence of form and meaning has been derived by means of bidirectional OT, assuming constraints that favor shorter and more vague expressions.

Derivation of form-meaning correspondence through bidirectional OT is also found in other areas of grammar and across languages. The preferred interpretation of double negatives (Blutner \& Solstad 2001), the precise and vague interpretation of numbers cross-linguistically (Krifka 2002), the interpretation of object shift in Icelandic (Gärtner 2004a,b), or the morphological marking of themes in Tagalog (Gärtner 2004b) represent other instantiations of the same phenomenon. All the analyses make use of basically the same constraints whereby simplicity in meaning and form is accommodated for the phenomenon at hand.

Consequently, it is a more general phenomenon that emerges in the case of objects clefts in Northern Sotho, and should as such not be stipulated. This is one advantage of an bidirectional OT approach over a feature checking approach. For a feature checking approach with interpretable features it remains to be shown that the core of the phenomenon, namely unmarked forms for unmarked meanings and vice versa can be captured.

Independent of the theoretical framework, however, the form-meaning correspondence breaks down in the case of focused logical subjects of transitive verbs. It has been argued that in Northern Sotho, a constraint is high-ranked that bans transitive expletive constructions. As has been shown in the previous chapter, the logical subject cannot appear preverbally neither when focused, as this is ruled out by the high ranking of a corresponding interface constraint. The cleft structure remains the only option. In the case of subjects, the cleft structure also expresses the unmarked meaning.

As areas for further research the potential ambiguity in focus meaning of clefted subjects of transitive verbs and the optionality in form of focused logical subjects of intransitive verbs have been isolated. With respect to the potential ambiguity, further research has to clarify if the use of clefts for subject focus with transitive verbs constitutes another case of partial iconicity and is problematic for an account within weak bidirectional OT. With respect to the elicited optionality in the case of subjects of intransitive verbs further research needs to investigate more carefully if there is truly no semantic difference between these two expressions. So far, no satisfying solution could be provided. 


\subsection{Recapitulatory remarks}

The thesis had as its objective to investigate the marking of focus in the grammar of Northern Sotho. It has been shown that there is no grammatical marking of focus in Northern Sotho, neither by syntax nor by morphology nor by prosody. There are, however, grammatical reflexes of focus or information structure more generally, not only in syntax but also in morphosyntax and prosody.

Despite the lack of grammatical F-marking, formal F-marking is nevertheless important for the grammar of Northern Sotho: F-marked logical subjects must not appear in their canonical preverbal position. Although Northern Sotho shows a strict correspondence between form and meaning for different foci in the case of objects, this correspondence breaks down in the case of focused logical subjects of transitive verbs. Because they cannot appear neither postverbally nor preverbally, they have to be focused by means of a cleft sentence.

The thesis derives how all the aspects mentioned above can be modeled in the framework of Optimality Theory (OT). For the modeling of syntactic in situ focus and the lack of prosodic expression of focus, it retreats to constraints which are uncontroversial in the relevant literature. The interface constraint * SUBJECT/F-MARKED which is proposed in chapter 4 to moderate between syntax and discourse-pragmatics, has its precedents in the literature (Aissen 1999, Lee 2000) but differs in that the prominence scales involved are crucially modified. The derivation of the form-meaning correspondence for objects in chapter 5 derives another example of Horn's (1984) 'division of labor' according to which unmarked forms are used for unmarked meanings and vice versa.

The lack of prosodic expression of focus and the ban of F-marked logical subjects in preverbal position in Northern Sotho constitute two 'languages' that are predicted by the factorial typologies of the constraints proposed in the literature. Therefore, the data presented here provide important data for the universality of the constraints proposed.

The overall result of this thesis raises interesting questions for existing focus theories. Focus theories assume that focus is marked somehow in grammar, either by prosody, syntax, or morphology. The data presented in this thesis show that grammatical focus marking is no universal but rather that the role of context deserves more attention. Context is necessary to resolve focus ambiguities in languages like English and German, and the results presented here suggest that focus interpretation through context is the path followed by Northern Sotho in all contexts. 


\section{Appendix}

1 Ke rwála morwálo. - I carry load.

focus on VP, object, verb

2 Ke méma mohúmi. - I invite the rich person.

focus on VP, object, verb; contrastive focus on verb

3 Ke nwá yóna. - I drink this.

focus on VP, object, verb

4 Ke já namúne. - I eat an orange.

focus on VP, object, verb

5 Ke ngwála nónwane. - I write folktales.

focus on VP, object, verb; contrastive focus on verb

6 Ke bína monyányeng. - I dance at the feast.

focus on VP, locative adverb, verb; contrastive focus on verb

7 Ke bóa moláleng. - I come from the old field.

focus on VP, locative adverb, verb; contrastive focus on verb

8 Ke nwá bjále. - I drink now.

focus on VP, temporal adverb, verb; contrastive focus on verb

9 Ke bóa fáo. - I return there.

focus on VP, temporal adverb, verb

10 Ke nyạala/ nyạ́lwa lábone. - I marry for the fourth time.

focus on VP, temporal adverb, verb

11 Ke néa malóme malekere. - I give uncle sweets.

focus on VP, both objects, verb; contrastive focus on verb

12 Ke néa molámo lemáo. - I give brother-in-law a needle. focus on VP, both objects, verb; contrastive focus on verb

13 Ke fá rrá bólo. - I give father a ball.

focus on VP, both objects, verb; contrastive focus on verb 
14 Ke fá mmá hémpe. - I give mother a shirt. focus on VP, both objects, verb

15 Ke néa náre lée. - I give the buffalo an egg. focus on VP, both objects, verb

16 Ke réma morúla moségaré. - I chop the morula tree at midday. focus on VP, object, temporal adverb, verb; contrastive focus on verb

17 Ke aléla morwédi boláong. - I bed the daughter at the sleeping place. focus on VP, object, local adverb, verb

18 Ke já lée léhono. - I eat an egg today. focus on VP, object, temporal adverb, verb

19 Ke fóa moyá lewéng. - I sense the spirit in the cave. focus on VP, object, local adverb, verb; contrastive focus on verb

20 Ke nwá moré lábone. - I drink medicine for the fourth time. focus on VP, object, temporal adverb, verb

21 Ke néa malóme lengwálo bodúlong. - I give the uncle a letter at the dwelling place. focus on VP, both objects, local adverb, verb; contrastive focus on verb

22 Ke néa molámo namáne moségaré. - I give the brother-in-law a calf at midday. focus on VP, both objects, temporal adverb, verb; contrastive focus on verb

23 Ke fá rrá bólo léhono. - I give the father a ball today. focus on VP, both objects, temporal adverb, verb; contrastive focus on verb

24 Ke fá mmá néo bjạle. - I give the mother a gift now. focus on VP, both objects, temporal adverb, verb

25 Ke néa náre lée lábone. - I give the buffalo an egg for the fourth time. focus on VP, both objects, temporal adverb, verb; contrastive focus on verb 


\section{Bibliography}

Aboh, E. O. (1999). From the syntax of Gungbe to the grammar of Gungbe. PhD thesis, Université de Genève, Geneva.

Aboh, E. O. (2004). The Morphosyntax of complement-head sequences. Clause structure and word order patterns in Kwa. New York: Oxford University Press.

Aissen, J. (1999). Markedness and subject choice in Optimality Theory. Natural Language and Linguistic Theory, 17, 673-711.

Alexiadou, A. \& Anagnostopoulou, E. (2001). The Subject-In-Situ Generalization and the Role of Case in Driving Computations. Linguistic Inquiry, 32(2), 193-231.

Alsina, A. \& Mchombo, S. A. (1993). Object Asymmetries and the Chichewa Applicative Construction. In S. A. Mchombo (Ed.), Theoretical Aspects of Bantu Grammar (pp. 17-45). Stanford: CSLI Publications.

Anderson, S. C. (1979). Verb structure. In L. M. Hyman (Ed.), Aghem grammatical structure (pp. 73-136). Los Angeles: University of Southern California.

Archangeli, D. \& Langendoen, D. (1997). Optimality Theory: An overview. Oxford: Blackwell.

Baker, M. C. (1992). Thematic conditions on syntactic structures: evidence from locative applicatives. In I. Roca (Ed.), Thematic Structure- Its Role in Grammar (pp. 23-46). Berlin: Foris Publications.

Baker, M. C. (2003). Agreement, dislocation, and partial configurationality. In A. Carnie, H. Harley, \& M. Willie (Eds.), Formal approaches to function in grammar: In honor of Eloise Jelinek (pp. 107-132). Amsterdam: John Benjamins.

Barbosa, P., Fox, D., Hagstrom, P., McGinnis, M., \& Pesetsky, D. (1998). Introduction. In P. Barbosa, D. Fox, P. Hagstrom, M. McGinnis, \& D. Pesetsky (Eds.), Is the Best Good Enough?- Optimality and Competition in Syntax (pp. 1-14). Cambridge, MA: MIT Press.

Bearth, T. (1992). Constituent structure, natural focus hierarchy and focus types in Toura. Folia Linguistica, 26(1-2), 75-94. 
Bearth, T. (1999). The contribution of African linguistics towards a general theory of focus. Update and critical review. Journal of African Languages and Linguistics, 20, 121-156.

Beaver, D. \& Lee, H. (2004). Input-Output Mismatches in Optimality Theory. In R. Blutner \& H. Zeevat (Eds.), Optimality Theory \& Pragmatics (pp. 112-153). Hampshire: Palgrave.

Beckman, J. \& Pierrehumbert, J. (1986). Intonational Structure in Japanese and English. Phonology Yearbook, 3, 255-309.

Behagel, O. (1932). Deutsche Syntax-Eine geschichtliche Darstellung, Bd. IV Wortstellung. Periodenbau. Heidelberg: Carl Winters Universitätsbuchhandlung.

Belletti, A. \& Shlonsky, U. (1995). The Order of Verbal Complements: A Comparative Study. Natural Language and Linguistic Theory, 13(3), 489-526.

Benmamoun, E. (1998). Spec-head agreement and overt Case in Arabic. In D. Adger, S. Pintzuk, B. Plunkett, \& G. Tsoulas (Eds.), Specifiers: Minimalist approaches (pp. 110-125). Oxford: Oxford University Press.

Bergvall, V. L. (1987a). Focus in Kikuyu and universal grammar. PhD thesis, Harvard University.

Bergvall, V. L. (1987b). The Position and Properties of In situ and Right-Moved Questions in Kikuyu. In D. Odden (Ed.), Current Approaches to African Linguistics, volume 4 (pp. 37-54). Dordrecht: Foris.

Bickmore, L. (1990). Branching Nodes and Prosodic Categories: Evidence from Kinyambo. In S. Inkelas \& D. Zec (Eds.), The Phonology-Syntax Connection (pp. 1-17). Chicago: The University of Chicago Press.

Bickmore, L. (2003). The Use of Feet to Account for Binary Tone Spreading: Evidence from Chilungu. In R.-J. Anyanwu (Ed.), Stress and Tone- the African Experience, Frankfurter Afrikanistische Blätter 15. Köln: Rüdiger Köppe Verlag.

Birch, S. \& Clifton, C. (1995). Focus, Accent, and Argument Structure: Effects on Language Comprehension. Language and Speech, 38(4), 365-391.

Bisang, W. \& Sonaiya, R. (2000). Information structuring in Yoruba. Linguistics, 38(1), 169-197.

Blutner, R. (2000). Some Aspects of Optimality in Natural Language Interpretation. Journal of Semantics, 17, 189-216.

Blutner, R. \& Solstad, T. (2001). Two case studies in lexical pragmatics. In e. Németh \& K. Bibok (Eds.), Pragmatics and the Flexibility of Word Meaning. Amsterdam: Elsevier Science. 
Boas, F. (1911). Handbook of the American Indian Languages. Washington: Gov. Print. Off.

Boersma, P. (1998). Functional Phonology. PhD thesis, University of Amsterdam.

Boersma, P. \& Weenink, D. (2005). Praat: doing phonetics by computer. Software, available online under http://www. fon.hum.uva.nl/praat/, last access 10.12.2005.

Bokamba, E. G. (1976). Question formation in some Bantu languages. PhD thesis, Indiana University.

Bokamba, G. D. (1971). Specificity and Definiteness in Dzamba. Studies in African Linguistics, 2 .

Brazil, D., Coulthard, M., \& Johns, C. (1980). Discourse intonation and language teaching. Essex: Longman.

Bresnan, J. (2001). Lexical-Functional Syntax. Oxford: Blackwell.

Bresnan, J. \& Kanerva, J. M. (1989). Locative Inversion in Chichewa: A Case Study of Factorization in Grammar. Linguistic Inquiry, 20(1), 1-50.

Bresnan, J. \& Mchombo, S. A. (1987). Topic, pronoun, and agreement in Chichewa. Language, 63(4), 741-782.

Brody, M. (1990). Some Remarks on the Focus Field in Hungarian. UCL Working Papers, 2, 201-225.

Buell, L. (2005). Issues in Zulu Verbal Morphosyntax. PhD thesis, University of California, Los Angeles.

Büring, D. (1997). The Meaning of Topic and Focus- The 59th Street Bridge Accent. London: Routledge.

Büring, D. (2001a). What do definites do that indefinites definitely don't? In C. Fery \& W. Sternefeld (Eds.), Audiatur Vox Sapientiae, Festschrift für Arnim von Stechow (pp. 70-100). Berlin: Akademie Verlag.

Büring, D. (2001b). Let's Phrase It! Focus, Word Order, and Prosodic Phrasing in German Double Object Constructions. In G. Müller \& W. Sternefeld (Eds.), Competition in syntax (pp. 69-106). Berlin, New York: Mouton de Gruyter.

Büring, D. (2004). Focus Projection and Default Prominence. In V. Molnar \& S. Winkler (Eds.), The Architecture of Focus. Berlin: Mouton de Gruyter.

Büring, D. \& Gutierrez-Bravo, R. (2002). Focus-related constituent order variation without the NSR: A prosody-based crosslinguistic analysis. In S. M. Bhloscaidh (Ed.), Syntax at Santa Cruz, volume 3 (pp. 41-58). 
Byarushengo, E., Hyman, L., \& Tenenbaum, S. (1976). Tone, accent, and assertion in Haya. In L. Hyman (Ed.), Studies in Bantu Tonology, Southern California Occasional Papers in Linguistics 3 (pp. 183-205). Los Angeles: University of California.

Carstens, V. (2005). Agree and EPP in Bantu. Natural Language and Linguistic Theory, 23, 219-279.

Cassimjee, F. (1992). An autosegmental analysis of Venda tonology. Garland.

Cassimjee, F. (1998). Isixhosa Tonology: An Optimal Domains Theory Analysis. Munich: LINCOM Europe.

Cassimjee, F. \& Kisseberth, C. W. (1998). Optimality Domains Theory and Bantu Tonology: a Case Study from Isixhosa and Shingazidja. In L. Hyman \& C. W. Kisseberth (Eds.), Aspects of Bantu Tone (pp. 33-132). Stanford: CSLI Publications.

Cecchetto, C. (1999). A comparative analysis of left and right dislocation in Romance. Studia Linguistica, 53(1), 40-67.

Chafe, W. L. (1976). Givenness, contrastiveness, definiteness, subjects, topics, and point of view. In C. N. Li (Ed.), Subject and Topic (pp. 25-55). New York: Academic Press.

Chebanne, A., Creissels, D., \& Nkhwa, H. (1997). Tonal Morphology of the Setswana Verb, volume 13 of LINCOM Studies in African Linguistics. Munich: LINCOM Europa.

Chen, M. Y. (1987). The syntax of Xiamen tone sandhi. Phonology Yearbook, 4, 109-149.

Cheng, C.-C. \& Kisseberth, C. W. (1979). Ikorovere Makua Tonology (Part 1). Studies in the Linguistic Sciences, 9(1).

Choe, H.-S. (1995). Focus and topic movement in Korean licensing. In K. É Kiss (Ed.), Discourse Configurational Languages (pp. 269-334). New York/ Oxford: Oxford University Press.

Chomsky, N. (1971). Deep structure, surface structure, and semantic interpretation. In D. Steinberg \& L. Jakobovits (Eds.), Semantics: An Interdisciplinary Reader in Philosophy, Linguistics, and Psychology (pp. 183-216). Cambridge: Cambridge University Press.

Chomsky, N. (1981). Lectures on Government and Binding. Dordrecht: Foris.

Chomsky, N. (1982). Some Concepts and Consequences of the Theory of Government and Binding. Cambridge, Mass.: MIT Press.

Chomsky, N. (1986). Knowledge of Language. New York: Praeger.

Chomsky, N. (1991). Some Notes on Economy of Derivation and Representation. In R. Freidin (Ed.), Principles and Parameters in Comparative Grammar (pp. 417-454). Cambridge, Mass.: MIT Press. 
Chomsky, N. (1995). The Minimalist Program. Cambridge, Mass.: MIT Press.

Chomsky, N. (2001). Derivation by Phase. In M. Kenstowicz (Ed.), Ken Hale: a Life in Language (pp. 1-52). MIT Press.

Cinque, G. (1990). Types of A'-Dependencies. Cambridge, Mass.: MIT Press.

Cinque, G. (1993). A Null Theory of Phrase and Compound Stress. Linguistic Inquiry, 24(2), 239-297.

Clements, G. (1978). Tone and syntax in Ewe. In D. J. Napoli (Ed.), Elements of tone, stress, and intonation (pp. 21-99). Washington, D.C.: Georgetown University Press.

Clements, G. (1984a). Binding Domains in Kikuyu. Studies in the Linguistic Sciences, 14(2), 37-56.

Clements, G. (1984b). Principles of Tone Assignment. In G. Clements \& J. Goldsmith (Eds.), Autosegmental Studies in Bantu Tone (pp. 281-339). Dordrecht: Foris Publications.

Cole, D. (1955). An Introduction to Tswana Grammar. Cape Town: Longman.

Collins, P. C. (1991). Cleft and pseudo-cleft constructions in English. London: Routledge.

Creider, C. (1979). On the explanation of transformations. In T. Givón (Ed.), Syntax and Semantics 12: Discourse and Syntax. New York: Academic Press.

Creissels, D. (1983). Eléments de Grammaire de la Langue Mandinka. Grenoble: Publications de l'Université des Langues et Lettres.

Creissels, D. (1996). Conjunctive and disjunctive verb forms in Setswana. South African Journal of African Languages, 16(4), 109-115.

Danes, F. (1970). One instance of the Prague school methodology: Functional analysis of utterance and text. In P. L. Garvin (Ed.), Method and theory in linguistics. Paris: The Hague.

Demuth, K. (1989). Discourse Functions of Independent Pronouns in Setswana. In I. Haik \& L. Tuller (Eds.), Current Approaches to African linguistics, volume 6 (pp. 176-193). Dordrecht: Foris Publication.

Demuth, K. (1990). Locatives, Impersonals, and Expletives in Sesotho. The Linguistic Review, 7(3), 233-250.

Demuth, K. (1995). Questions, Relatives, and Minimal Projection. Language Acquisition, $4(1 \& 2), 49-71$.

Demuth, K. \& Gruber, J. (1995). Constraining XP sequences. In V. Manfredi \& K. Reynolds (Eds.), Niger-Congo Syntax and Semantics 6 (pp. 3-30). Boston: Boston University African Studies Center. 
Demuth, K. \& Johnson, M. (1989). Interaction between Discourse Functions and Agreement in Setawana. Journal of African Languages and Linguistics, 11, 21-35.

Demuth, K., Machobane, M., Moloi, F., \& Odato, C. (2005). Learning animacy hierarchy effects in Sesotho double object applicatives. Language, 81(2), 421-447.

Demuth, K. \& Mmusi, S. (1997). Presentational focus and thematic structure in comparative Bantu. Journal of African Languages and Linguistics, 18, 1-19.

Denham, K. E. (1997). A minimalist account of optional WH-movement. PhD thesis, University of Washington, Seattle.

Dogil, G. \& Williams, B. (1999). The phonetic manifestation of word stress. In H. v. d. Hulst (Ed.), Word Prosodic Systems in the Languages of Europe (pp. 273-309). Berlin: Mouton de Gruyter.

Doke, C. M. (1927/1992). Textbook of Zulu Grammar (6th ed.). Cape Town: Maskew Miller Longman. Reprint 1992.

Doke, C. M. (1954). The Southern Bantu languages. London: Oxford University Press.

Doke, C. M. \& Mofokeng, S. (1957). Textbook of Southern Sotho grammar. London, Cape Town, New York: Longmans, Green \& Co.

Downing, B. (1970). Syntactic structure and phonological phrasing in English. PhD thesis, University of Texas at Austin.

Downing, L. J. (1990). Local and Metrical Tone Shift in Nguni. Studies in African Linguistics, 21(3), 261-317.

Downing, L. J. (1996). The tonal phonology of Jita. Munich: LINCOM Europa.

Downing, L. J. (2002). Fitting focus into the prosodic hierarchy. SOAS Working Papers in Linguistics, 12, 111-133.

Downing, L. J. (2003). Stress, Tone and Focus in Chichewa and Xhosa. In R.-J. Anyanwu (Ed.), Stress and Tone- the African Experience, Frankfurter Afrikanistische Blätter 15. Cologne: Rüdiger Köppe.

Downing, L. J. (2004). Accent in African Languages. In S. Fuchs \& S. Hamann (Eds.), ZASPiL 37, Papers in Phonetics and Phonology (pp. 101-136). Berlin: ZAS.

Downing, L. J., Mtenje, A., \& Pompino-Marschall, B. (2004). Prosody and Information Structure in Chichewa. In S. Fuchs \& S. Hamann (Eds.), ZASPiL 37, Papers in Phonetics and Phonology (pp. 167-187). Berlin: ZAS.

Drubig, H. B. (2003). Towards a typology of focus and focus constructions. Linguistics, $41(1), 1-50$. 
Drubig, H. B. \& Schaffar, W. (2001). Focus constructions. In M. Haspelmath \& E. König (Eds.), Language Typology and Language Universals, volume 2 (pp. 1079-1104). Berlin: Walter de Gruyter.

Dryer, M. S. (1986). Primary objects, secondary objects, and antidative. Language, 62(4), 808-845.

Du Plessis, J. (1981). Transitivity in Sesotho and Xhosa. South African Journal of African Languages, 1(1), 50-85.

É. Kiss, K. (Ed.). (1995a). Discourse Configurational Languages. New York, Oxford: Oxford University Press.

É. Kiss, K. (1995b). Discourse Configurational Languages - Introduction. In K. É. Kiss (Ed.), Discourse Configurational Languages (pp. 3-27). Oxford: Oxford University Press.

É. Kiss, K. (1998). Identificational focus versus information focus. Language, 74, 245273.

É. Kiss, K. (1999). The English cleft construction as a Focus Phrase. In L. Mereu (Ed.), Boundaries of Morphology and Syntax (pp. 217-229). Amsterdam/ Philadelphia: John Benjamins.

Endemann, C. (1916). Der Tonfall in den südostafrikanischen Bantusprachen. Vox, 26(45), 161-175.

Endemann, K. (1876). Versuch einer Grammatik des Sotho. Berlin: Wilhelm Hertz.

Endemann, K. (1901). Beitrag zu dem Capitel von den Tönen in den sogenannten BantuSprachen. Mitteilungen des Seminars für orientalische Sprachen, 4, 37-41.

Endemann, K. (1911). Wörterbuch der Sotho-Sprache. Hamburg: L. Friedrichsen \& Co.

Endemann, T. (1943). Palatalisierung en Labialisierung in Sepedi. PhD thesis, Unpublished M.A. dissertation. Pretoria: University of Pretoria.

Epée, R. (1976). On some rules that are not successive cyclic in Duala. Linguistic Inquiry, 7(1), 193-197.

Erguvanli, E. E. (1984). The Function of Word Order in Turkish Grammar. Berkeley, CA: University of California Press.

Féry, C. (1993). German Intonational Patterns. Tübingen: Max Niemeyer Verlag.

Firbas, J. (1964). On defining the theme in functional sentence analysis. Traveaux Linguistique de Prague, 1, 267-280.

Firmin, A. \& Leben, W. (2003). Phonological Reflexes of Focus in Kwa Languages of the Ivory Coast. In R.-J. Anyanwu (Ed.), Stress and Tone - the African Experience, Frankfurter Afrikanistische Arbeitsblätter 15. Cologne: Rüdiger Köppe Verlag. 
Frascarelli, M. (2000). The Syntax-Phonology Interface in Focus and Topic Constructions in Italian. Dordrecht: Kluwer Academic Publishers.

Frascarelli, M. \& Puglielli, A. (2004). The Focus System in Cushitic Languages. A comparative-typological analysis. In Fronzaroli, P. \& Marrassini, P. (Eds.), Proceedings of the 10th Hamito-Semitic (Afroasiatic) Linguistics Meeting, Florence.

Frota, S. (2000). Prosody and Focus in European Portuguese. New York: Garland.

Gabelentz, G. v. d. (1891). Die Sprachwissenschaft. Ihre Aufgaben, Methoden und bisherigen Ergebnisse. Leipzig: Weigel.

Gair, J. (1980). Adaptation and naturalization in a linguistic area: Sinhala focused sentences. In B. Caron \& e. al. (Eds.), Proceedings of the 6th Annual Meeting of the Berkeley Linguistics Society.

Gärtner, H.-M. (2004a). On object-shift in Icelandic and partial iconicity. Lingua, 114, $1235-1252$.

Gärtner, H.-M. (2004b). On the Optimality Theoretic Status of "Unambigious Encoding". In R. Blutner \& H. Zeevat (Eds.), Optimality Theory and Pragmatics (pp. 154-172). Hampshire: Palgrave Studies.

Givón, T. (1975). Focus and Scope of Assertion. Some Bantu Evidence. Studies in African Linguistics, 6, 185-205.

Givón, T. (1976). Topic, pronoun, and grammatical agreement. In C. N. Li (Ed.), Subject and Topic. New York: Academic Press.

Givón, T. (1988). The pragmatics of word-order: predictability, importance and attention. In M. Hammond, E. Moravcsik, \& J. Wirth (Eds.), Studies in Syntactic Typology (pp. 243-284). Amsterdam: John Benjamins.

Goldsmith, J. (1987). Tone and accent and getting the two together. BLS, 13, 88-104.

Goldsmith, J., Peterson, K., \& Drogo, J. (1989). Tone and accent in the Xhosa verbal system. In P. Newman \& R. Botne (Eds.), Current approaches to African linguistics, volume 5 (pp. 157-178). Dordrecht: Foris Publications.

Greenberg, J. (1948). The tonal system of Proto-Bantu. Word, 4, 196-208.

Grewendorf, G. (2000). Minimalistische Syntax. Tübingen \& Basel: A. Francke Verlag.

Grewendorf, G., Hamm, F., \& Sternefeld, W. (1987). Sprachliches Wissen: Eine Einführung in moderne Theorien der grammatischen Beschreibung (9.Ed. ed.). Frankfurt/Main: Suhrkamp.

Grice, H. P. (1975/1989). Studies in the way of words. Cambridge, Mass.: Harvard University Press. First published (1975) in Cole \& Morgan (eds.) Syntax and semantics: Speech acts. Page numbers refer to the 1989 edition. 
Grimshaw, J. (1997). Projection, Heads, and Optimality. Linguistic Inquiry, 28(3), 373422.

Grimshaw, J. \& Samek-Lodivici, V. (1998). Optimal Subjects and Subject Universals. In P. Barbosa (Ed.), Is the Best good enough? Optimality and Competition in Syntax (pp. 193-220). MIT Press.

Güldemann, T. (1996). Verbalmorphologie und Nebenprädikation im Bantu. Bochum: Universitätsverlag Dr. N. Brockmeyer.

Güldemann, T. (2003). Present Progressive vis-a-vis predication focus in Bantu: a verbal category between semantics and pragmatics. Studies in Language, 27(2), 323-360.

Güldemann, T. (2004). Linear order as a basic morphosyntactic factor in Non-Khoe Khoisan. Handout presented at 1st International Conference 'Syntax of the World's Languages', Leipzig, 5.-8.8.2004.

Gundel, J. K. (1988). Universals of topic-comment structure. In M. Hammond, E. Moravcsik, \& J. Wirth (Eds.), Studies in Syntactic Typology. Amsterdam: John Benjamins.

Gussenhoven, C. (1983a). Focus, mode, and the nucleus. Journal of Linguistics, 19, 377-417.

Gussenhoven, C. (1983b). Testing the Reality of Focus Domains. Language and Speech, 26(1), 61-80.

Guthrie, M. (1948). The Classification of the Bantu Languages. London: Oxford University Press.

Guthrie, M. (1967-1971). Comparative Bantu. Farnborough: Gregg.

Gutiérrez-Bravo, R. (2002). Focus, Word Order Variation and Intonation in Spanish and English: An OT-account. In C. Wiltshire \& J. Camps (Eds.), Romance Phonology and Variation (pp. 39-53). Amsterdam: John Benjamins.

Haida, A. (in prep.). Focus in Wh-questions. PhD thesis, University of Potsdam.

Hale, K. \& Selkirk, E. (1987). Government and tonal phrasing in Papago. Phonology Yearbook, 4, 151-183.

Halle, M. \& Vergnaud, J.-R. (1987). An Essay on Stress. Cambridge, Mass.: MIT Press.

Halliday, M. (1967). Notes on transitivity and theme in English, Part 2. Journal of Linguistics, 3, 199-.

Hammond, M. (1999). The Phonology of English. Oxford: Oxford University Press.

Harford, C. (1990). Locative inversion in Chishona. In J. Hutchinson \& V. Manfredi (Eds.), Current Approaches to African Linguistics, volume 7 (pp. 137-144). Dordrecht: Foris. 
Harris, A. C. (1982). Towards the universals of q-word formation. In R. Schneider, K. Tuite, \& R. Chametzky (Eds.), Papers from the parasession on nondeclaratives. Chicago: Chicago Linguistics Society.

Hartmann, K. \& Zimmermann, M. (2004). Focus strategies in Chadic: The Case of Tangale Revisited. In S. Ishihara, M. Schmitz, \& A. Schwarz (Eds.), Interdisciplinary Studies on Information Structure (ISIS). Working Papers of the SFB 632. University of Potsdam.

Hartmann, K. \& Zimmermann, M. (2005). Morphological Focus Marking in Gùrùntùm (Western Chadic). Manuscript, Humboldt-University Berlin.

Hartmann, K. \& Zimmermann, M. (to appear a). In Place - Out of Place: Focus in Hausa. In K. Schwabe \& S. Winkler (Eds.), On Information Structure, Meaning and Form. Amsterdam: John Benjamins.

Hartmann, K. \& Zimmermann, M. (to appear b). Exhaustivity Marking in Hausa: A Re-Evaluation of the Particle nee/cee. In E. O. Aboh, K. Hartmann, \& M. Zimmermann (Eds.), Focus Strategies: Evidence from African Languages (Niger-Congo, AfroAsiatic, West-Atlantic). Berlin: de Gruyter.

Hayes, B. (1989). Compensatory Lengthening in Moraic Phonology. Linguistic Inquiry, 20(2), 253-306.

Hayes, B. (1995). Metrical Stress Theory. Principles and Case Studies. Chicago: University of Chicago Press.

Hayes, B. \& Lahiri, A. (1991). Bengali Intonational Phonology. Natural Language and Linguistic Theory, 9, 47-96.

Heck, F., Müller, G., Vogel, R., Fischer, S., Vikner, S., \& Schmid, T. (2002). On the nature of the input in optimality theory. The Linguistic Review, 19, 345-376.

Heim, I. (1991). Artikel und Definitheit. In A. von Stechow \& D. Wunderlich (Eds.), Semantik- Ein internationales Handbuch der zeitgenössischen Forschung (pp. 487535). Berlin, New York: Mouton de Gruyter.

Heine, B. (1976). A Typology of African Languages based on the order of meaningful elements. Berlin: Dietrich Reimer Verlag.

Heine, B. \& Reh, M. (1983). Diachronic Observations on Completive Focus Marking in Some African languages. Sprache und Geschichte in Afrika, 5, 7-44.

Heine, B. \& Reh, M. (1984). Grammaticalization and Reanalysis in African Languages. Hamburg: Helmut Buske Verlag.

Hendriks, P. \& de Hoop, H. (2001). Optimality theoretic semantics. Linguistics and Philosophy, 24, 1-32. 
Herring, S. C. \& Paolillo, J. C. (1995). Focus position in SOV languages. In P. Downing \& M. Noonan (Eds.), Word Order in Discourse (pp. 163-198). Amsterdam/ Philadelphia: John Benjamins.

Heusinger, K. v. (1999). Intonation and Information Structure. University of Konstanz. Habilitationsschrift.

Heuven, V. v. \& Sluijter, A. (1996). Notes on the Phonetics of Word Prosody. In R. Goedemans, H. v. d. Hulst, \& E. Visch (Eds.), Stress patterns of the world, Part I: Background (pp. 233-269). The Hague: Holland Academic Graphics.

Horn, L. (1984). Toward a new taxonomy for pragmatic inference: Q-based and R-based implicatures. In D. Schiffrin (Ed.), Meaning, Form and Use in Context (pp. 11-42). Washington, DC: Georgetown University Press.

Hyman, L. (1977). On the nature of linguistic stress. In L. Hyman (Ed.), Studies in stress and accent, volume 4 (pp. 37-82).

Hyman, L. (1989). Accent in Bantu: an appraisal. In E. G. Bokamba (Ed.), Proceedings of the 20th Annual Conference on African Linguistics, Studies in the Linguistic Sciences 19,2 (pp. 111-128).

Hyman, L. (1990). Boundary Tonology and the Prosodic Hierarchy. In S. Inkelas \& D. Zec (Eds.), The Phonology-Syntax Connection (pp. 109-126). Chicago: The University of Chicago Press.

Hyman, L. (1999). The interaction between focus and tone in Bantu. In R. Rebuschi \& L. Tuller (Eds.), The Grammar of Focus (pp. 151-177). Amsterdam: John Benjamins.

Hyman, L. \& Duranti, A. (1982). On the Object Relation in Bantu. In P. Hopper \& S. Thompson (Eds.), Syntax and Semantics 15 (pp. 217-239). New York: Academic Press.

Hyman, L. \& Katamba, F. (1993). The Augment in Luganda: Syntax or Pragmatics? In S. A. Mchombo (Ed.), Theoretical Aspects of Bantu Grammar (pp. 209-256). Stanford: CSLI Publications.

Hyman, L. \& Watters, J. R. (1984). Auxiliary Focus. Studies in African Linguistics, 15, 233-273.

Inkelas, S. (1989). Prosodic constituency in the lexicon. PhD thesis, Stanford University.

Inkelas, S. \& Leben, W. R. (1990). Where Phonology and Phonetics Intersect: The Case of Hausa Intonation. In J. Kingston \& M. Beckman (Eds.), Papers in Laboratory Phonology 1: Between the Grammar and Physics of Speech (pp. 17-34). Cambridge: Cambridge University Press.

Jackendoff, R. (1972). Semantic Interpretation in Generative Grammar. Cambridge (Mass.): Massachusetts Institue of Technology. 
Jacobs, J. (2001). The dimensions of topic-comment. Linguistics, 39(4), 641-681.

Jäger, G. (2004). Learning Constraint Sub-hierarchies. The Bidirectional Gradual Learning Algorithm. In R. Blutner \& H. Zeevat (Eds.), Optimality Theory \& Pragmatics (pp. 251-287). Hampshire: Palgrave.

Jannedy, S. (2002). Hat Patterns and Double Peaks: The Phonetics and Psycholinguistics of Broad versus late narrow versus double focus intonations. $\mathrm{PhD}$ thesis, Ohio State University.

Jelinek, E. (1984). Empty Categories, Case, and Configurationality. Natural Language and Linguistic Theory, 2, 39-76.

Jessen, M., Marasek, K., Schneider, K., \& Clahen, K. (1995). Acoustic correlates of word stress and the tense/ lax opposition in the vowel system of German. ICPhS 95 Stockholm, 4, 428-431.

Jokweni, M. W. (1995). Aspects of Isixhosa Phrasal Phonology. PhD thesis, University of Illinois.

Jones, J., Louw, J., \& Roux, J. (2001a). Queclaratives in Xhosa: An acoustic analysis. South African Journal of African Languages, Supplement 36, 3-18.

Jones, J., Louw, J., \& Roux, J. (2001b). Perceptual experiments on Queclaratives in Xhosa. South African Journal of African Languages, Supplement 36, 19-31.

Kager, R. (1999). Optimality Theory. Cambridge: Cambridge University Press.

Kaisse, E. (1985). Connected Speech: The Interaction of Syntax and Phonology. San Diego: Academic Press.

Kanerva, J. M. (1990). Focus and Phrasing in Chichewa Phonology. Outstanding dissertations in linguistics. New York, London: Garland Publishing.

Keenan, E. L. (1976). Towards a universal definition of subject. In C. N. Li (Ed.), Subject and Topic (pp. 303-333). New York: Academic Press.

Kenstowicz, M. (1993). Evidence for metrical structure. In K. Hale \& S. J. Keyser (Eds.), The view from Building 20 (pp. 257-273). Cambridge, Mass.: MIT Press.

Kenstowicz, M. \& Kisseberth, C. W. (1990). Chizigula Tonology: The Word and Beyond. In S. Inkelas \& D. Zec (Eds.), The Phonology-Syntax Connection (pp. 163-194). Chicago: The University of Chicago Press.

Kgatle, I. (1972). Nkgekgetane. King William's Town: Afrikaanse Pers Boekhandel.

Khoali, B. (1991). A Sesotho Tonal Grammar. PhD thesis, University of Illinois.

Khumalo, J. (1987). An Autosegmental Account of Zulu Phonology. PhD thesis, University of the Witwatersrand, South Africa. 
Kimenyi, A. (1980). A Relational Grammar of Kinyarwanda. Berkeley, CA: University of California Press.

Kinyalolo, K. K. (1991). Syntactic Dependencies and the Spec-Head Agreement Hypothesis in Kilega. PhD thesis, University of California, Los Angeles.

Kisseberth, C. W. (1994). On Domains. In J. Cole \& C. W. Kisseberth (Eds.), Perspectives in Phonology (pp. 133-166). CSLI.

Kisseberth, C. W. (2000). The Phonology-Syntax Interface: Chimwiini Revisited. Manuscript, Tel Aviv University.

Kisseberth, C. W. \& Abasheikh, M. I. (1974). Vowel length in Chi-Mwi:ni- A Case Study of the Role of Grammar in Phonology. In A. Bruck \& e. al. (Eds.), Papers from the Parasession on Natural Phonology (pp. 193-209). CLS.

Kisseberth, C. W. \& Odden, D. (2003). Tone. In D. Nurse \& G. Philippson (Eds.), The Bantu languages (pp. 59-70). Routledge.

Kock, J. (1997). The redundancy principle: relative descriptions in Northern Sotho. South African Journal of African Languages, 17(4), 143-146.

Kosch, I. (1988). Imperfect tense -a' of Nothern Sotho revisited. South African Journal of African Languages, 8(1), 1-6.

Kosch, I. (1993). A Historical Perspective on Northern Sotho Linguistics. Pretoria: Via Afrika.

Krejnovich, E. (1968). Yukagirskij jazyk. In V. Vinogradov (Ed.), Jazyki narodov SSSR, vol. 5 (pp. 435-452). Leningrad: Akademija Nauk SSSR.

Krifka, M. (1985). Word order and word order change in Swahili. Kiswahili, Journal of the Institute of Kiswahili Research, 52(1), 13-72.

Krifka, M. (1995). Swahili. In J. Jacobs, A. v. Stechow, W. Sternefeld, \& T. Vennemann (Eds.), Syntax: An International Handbook of Contemporary Research (pp. 1397 1418). Berlin: De Gruyter.

Krifka, M. (1998). Scope Inversion under the Rise-Fall Contour in German. Linguistic Inquiry, 29(1), 75-112.

Krifka, M. (2001). For a Structured Meaning Account of Questions and Answers. In C. Féry \& W. Sternefeld (Eds.), Audiatur Vox Sapientiae (Festschrift für Arnim von Stechow) (pp. 287-319). Berlin: Akademie Verlag.

Krifka, M. (2002). Be Brief and Vague! And how Bidirectional Optimality Theory allows for Verbosity and Precision. In D. Restle \& D. Zaefferer (Eds.), Sounds and Systems. Studies in Structure and Change. A festschrift for Theo Vennemann (pp. 439458). Berlin: Mouton de Gruyter. 
Krifka, M. (2004). Association with Focus Phrases. In V. Molnár \& S. Winkler (Eds.), The Architecture of Focus. Berlin: Mouton de Gruyter.

Kunene, E. (1975). Zulu Pronouns and the Structure of Discourse. Studies in African Linguistics, 6(2), 171-184.

Kuno, S. (1972). Functional sentence perspective. A case study from Japanese and English. Linguistic Inquiry, 3, 269-320.

Kuroda, S.-Y. (1972). The cateorical and the thetic judgment. Evidence from Japanese syntax. Foundations of Language, 9, 153-185.

Ladd, D. R. (1996). Intonational Phonology. Cambridge: Cambridge University Press.

Ladd, D. R., Mennen, I., \& Schepman, A. (2000). Phonological conditioning of peak alignmen in rising pitch accents in Dutch. JAS, 107, 2685-2696.

Ladd, D. R. \& Morton, R. (1997). The perception of intonational emphasis: continous or categorical. Journal of Phonetics, 25, 313-342.

Ladefoged, P. (2001). Vowels and Consonants- An Introduction to the Sounds of Language. Malden, MA: Blackwell.

Ladefoged, P. (2003). Phonetic Data Analysis - An Introduction to Fieldwork and Instrumental Techniques. Malden: Blackwell Publishing.

Lambrecht, K. (1994). Information structure and sentence form: topic, focus and the mental representation of discourse referents. Cambridge: Cambridge University Press.

Larson, R. K. (1988). On the Double Object Construction. Linguistic Inquiry, 19(3), 335-391.

Leben, W. (1973). Suprasegmental Phonology. PhD thesis, Massachussetts Institute of Technology.

Lee, H. (2000). The Emergence of the Unmarked Order in Hindi. In M. Hirotani, A. Coetzee, N. Hall, \& J.-y. Kim (Eds.), Proceedings of the North East Linguistics Society 30 (pp. 469-483). Amherst, Mass.

Legendre, G. (2001). An Introduction to Optimality Theory in Syntax. In G. Legendre, J. Grimshaw, \& S. Vikner (Eds.), Optimality-theoretic Syntax (pp. 1-27). Cambridge, Mass.: MIT Press.

Legendre, G., Smolensky, P., \& Wilson, C. (1998). When is Less More? Faithfulness and Minimal Links in wh-Chains. In P. Barbosa, D. Fox, P. Hagstrom, M. McGinnis, \& D. Pesetsky (Eds.), Is the Best Good Enough? Optimality and Competition in Syntax (pp. 249-290). Cambridge, Mass.: MIT Press.

Letele, G. (1955). The Role of Tone in the Southern Sotho language. PhD thesis, University College of Fort Hare, Lovedale. 
Lets'eng, M. C. (1994). Les tiroirs verbaux du Sesotho. PhD thesis, Grenoble III.

Levinson, S. C. (1983). Pragmatics. Cambridge: Cambridge University Press.

Li, C. N. (1976). Subject and topic: A New typology of Language. In C. N. Li (Ed.), Subject and Topic (pp. 457-489). New York: Academic Press.

Lombard, D. P. (1976). Aspekte van Toon in Noord-Sotho. PhD thesis, University of South Africa.

Lombard, D. P. (1979). Duur en Lengte in Noord-Sotho. Studies in Bantoetale, 39-69.

Louwrens, L. (1979a). Naamwoord-funksies in Noord-Sotho. PhD thesis, University of Pretoria.

Louwrens, L. (1979b). Die sintaksis van interrogatiewe naamwoorde en die interrogatiewe bepaler -fe in Suid-Sotho. Studies in Bantoetale, 6(1).

Louwrens, L. (1981a). The relevance of the notions given and new discourse information in the study of North Sotho syntax. South African Journal of African Languages, 1, $21-49$.

Louwrens, L. (1981b). 'n Perspektief op Wilkes se delesiehipotese oor pronominalisasie in Bantoe. Studies in Bantoetale, 8, 36-57.

Louwrens, L. (1982). Remarks on some grammatical and pragmatic functions of the object concord in Northern Sotho. South African Journal of African Languages, 2, $19-35$.

Louwrens, L. (1985). Contrastiveness and the so-called absolute pronoun in Northern Sotho. South African Journal of African Languages, 5(2), 58-61.

Louwrens, L. (1991). Aspects of Northern Sotho Grammar. Pretoria: Via Afrika Limited.

Louwrens, L., Kosch, I., \& Kotzé, A. (1995). Northern Sotho. Munich: LINCOM Europe.

Machobane, M. (1995). The Sesotho locative constructions. Journal of African Linguistics, 16, 115-136.

Machobane, M. (2001). Questions in Sesotho. Afrikanistische Arbeitspapiere, 66, 67-83.

Makwala, S. (1958). Kgashane. Pretoria: Van Schaik.

Marten, L. (2002). At the Syntax-Pragmatics Interface: Verbal Underspecification and Concept Formation in Dynamic Syntax. Oxford: Oxford University Press.

Marten, L. (to appear). Focus strategies and the incremental development of semantic representations: evidence from Bantu. In E. O. Aboh, K. Hartmann, \& M. Zimmermann (Eds.), Focus Strategies: Evidence from African Languages. Berlin/ New York: Mouton de Gruyter. 
Marten, L., Kula, N., \& Thwala, N. (2005). Parameters of morpho-syntactic variation in Bantu. Handout presented at LSSA 2005, Pretoria, 6-8 July 2005.

Matabane, A., Leshilo, M., \& NVanyaza, M. (1998). Ntwa ya dinonyana le diphoofolo. Cape Town: Juta \& Co.

Mattausch, J. (2004). Optimality Theoretic Pragmatics and Binding Phenomena. In R. Blutner \& H. Zeevat (Eds.), Optimality Theory \& Pragmatics (pp. 63-90). Hampshire: Palgrave.

Matthewson, L. (2004). On the Methodology of Semantic Fieldwork. International Journal of American Llinguistics, 70(4), 369-415.

McCarthy, J. (1986). OCP Effects: Gemination and Antigemination. Linguistic Inquiry, $17,207-264$.

McCarthy, J. (2002). A Thematic Guide to Optimality Theory. Cambridge: Cambridge University Press.

McCarthy, J. \& Prince, A. (1993). Generalized Alignment. In G. Booij \& J. v. Marle (Eds.), Yearbook of Morphology 1993 (pp. 79-153). Dordrecht: Kluwer.

McCawley, J. D. (1970). Some tonal systems that come close to being pitch accent systems but don't quite make it. CLS, VI, 526-532.

McCawley, J. D. (1978). What is a Tone language? In V. Fromkin (Ed.), Tone: A Linguistic Survey (pp. 113-131). New York: Academic Press.

Mchombo, S. A. (2004). The syntax of Chichewa. Cambridge: Cambridge University Press.

McHugh, B. (1999). Cyclicity in the Phrasal Phonology of KiVunjo Chaga. Munich: LINCOM Europe.

Meeussen, A. (1967). Bantu grammatical reconstruction. Africana Linguistica, 3, 81121.

Meinhof, C. (1899). Grundriss einer Lautlehre der Bantusprachen. Berlin: Dietrich Reimer \& Ernst Vohsen.

Meinhof, C. (1948). Grundzüge einer vergleichenden Grammatik der Bantusprachen (2nd ed.). Hamburg.

Meinunger, A. (1998). A monoclausal structure for (pseudo-) cleft sentences. In P. Tmanji \& K. Kusumoto (Eds.), Proceedings of NELS 28 (pp. 283-297).

Mischke, G. (1998). Southern Sotho verbal relative constructions. South African Journal of African Languages, 18(4), 106-111.

Mmusi, S. (1992). Obligatory Contour Principle Effects and Violations: the Case ofSetswana Verbal Tone. PhD thesis, University of Illinois at Urbana-Champaign. 
Möhlig, W. J. G., Marten, L., \& Kavari, J. (2002). A grammatical sketch of Herero. Cologne: Rüdiger Köppe.

Mojapelo, M. L. (2003). Introductory Remarks on An Investigation Into Definiteness in Northern Sotho. Handout ALASA conference, University of Stellenbosch, 7-11 July 2003.

Mojapelo, M. L. (in prep.). Definiteness in Northern Sotho. $\mathrm{PhD}$ thesis, University of Stellenbosch.

Mokgokong, P. (1966). A dialect-geographical survey of the phonology of the Northern Sotho area. $\mathrm{PhD}$ thesis, University of South Africa.

Molnár, V. (1998). Topic in Focus: On the syntax, phonology, semantics and pragmatics of the so-called 'contrastive topic' in Hungarian and German. Acta Linguistica Hungarica, 45(1-2), 89-166.

Monareng, W. M. (1992). A Domain-based Approach to Northern Sotho Tonology: A Setswapo Dialect. PhD thesis, University of Illinois at Urbana-Champaign.

Morimoto, Y. (2000). Discourse Configurationality in Bantu Morphosyntax. PhD thesis, Stanford University.

Morolong, M. \& Hyman, L. (1977). Animacy, objects and clitics in Sesotho. Studies in African Linguistics, 8(3), 199-218.

Müller, G. (2000). Elemente der optimalitätstheoretischen Syntax. Tübingen: Stauffenberg-Verlag.

Müller, G. \& Sternefeld, W. (2001). The Rise of Competition in Syntax: A Synopsis. In G. Müller \& W. Sternefeld (Eds.), Competition in Syntax (pp. 1-68). Berlin: Mouton de Gruyter.

Muriungi, P. (to appear). Wh-questions in Kitharaka. Studies in African Linguistics.

Myers, S. (1985). Tone and the Structure of Words in Shona. PhD thesis, University of Massachusetts.

Myers, S. (1991). Tone and the Structure of Words in Shona. New York: Garland.

Myers, S. (1997). OCP Effects in Optimality Theory. Natural Language and Linguistic Theory, 15(4), 847-892.

Myers, S. (1999). Tone Association and F0 Timing in Chichewa. Studies in African Linguistics, 28(2), 215-239.

Myers, S. (2003). F0 timing in Kinyarwanda. Phonetica, 60, 71-97.

Ndayiragije, J. (1999). Checking Economy. Linguistic Inquiry, 30(3), 399-444.

Nespor, M. \& Vogel, I. (1986). Prosodic Phonology. Dordrecht: Foris Publications. 
Nsuka, N. (1982). Les Structures Fondamentales du Relatif dans les Langues Bantues. Tervuren: Musee Royal de l'Afrique Centrale.

Nurse, D. \& Philippson, G. (2003). Introduction. In D. Nurse \& G. Philippson (Eds.), The Bantu languages (pp. 1-12). London \& New York: Routledge.

Odden, D. (1984). Formal correlates of Focusing in Kimatuumbi. Studies in African Linguistics, 15(3), 275-299.

Odden, D. (1987). Kimatuumbi phrasal phonology. Phonology Yearbook, 4, 13-36.

Odden, D. (1988). Predictable Tone Systems in Bantu. In H. v. d. Hulst \& N. Smith (Eds.), Autosegmental Studies on Pitch Accent (pp. 225-251). Dordrecht: Foris Publications.

Odden, D. (1995a). Tone: African Languages. In J. Goldsmith (Ed.), The Handbook of Phonological Theory (pp. 444-475). Cambridge, MA: Blackwell.

Odden, D. (1995b). Phonology at the Phrasal Level in Bantu. In F. Katamba (Ed.), Bantu Phonology and Morphology (pp. 40-68). Munich: Lincom.

Odden, D. (1999). Typological Issues in Tone and Stress in Bantu. In S. Kaji (Ed.), Proceedings of the Symposium on Cross-Linguistic Studies of Tonal Phenomena: Tonogenesis, Typology, and Related Topics (pp. 187-215). Tokyo: ILCAA.

Oppenrieder, W. (1989). Fokus, Fokusprojektion und ihre intonatorische Kennzeichnung. In H. Altmann, A. Batliner, \& W. Oppenrieder (Eds.), Zur Intonation von Modus und Fokus im Deutschen (pp. 267-280). Tübingen: Niemeyer.

Osborne, A. G. (1975). A transformational analysis of tone in the verb system of Zahao (Laizo). PhD thesis, Cornell University, Ithaca, NY.

Ouhalla, J. (1993). Focus in Standard Arabic. Linguistics in Potsdam, 1, 65-92.

Paul, H. (1880). Prinzipien der Sprachgeschichte. Leipzig: Niemeyer.

Payne, D. L. (1990). The Pragmatics of Word Order: Typological Dimensions of Verb Initial Languages. Berlin/ New York: Mouton de Gruyter.

Pesetsky, D. (1997). Optimality Theory and Syntax: Movement and Pronunciation. In D. Archangeli \& D. Langendoen (Eds.), Optimality Theory- An overview. Malden, Mass.: Blackwell.

Pesetsky, D. (1998). Some Optimality Principles of Sentence Pronunciation. In P. Barbosa, D. Fox, P. Hagstrom, M. McGinnis, \& D. Pesetsky (Eds.), Is the Best Good Enough? Optimality and Competition in Syntax (pp. 337-384). Cambridge, Mass.: MIT Press.

Peterson, K. (1989). A comparative look at Nguni verbal tone. In I. Haik \& L. Tuller (Eds.), Current Approaches to African linguistics, volume 6 (pp. 115-137). Dordrecht: Foris Publications. 
Pierrehumbert, J. \& Beckman, M. (1988). Japanese Tone Structure. Cambridge, Mass.: MIT Press.

Poulos, G. \& Louwrens, L. (1994). A Linguistic Analysis of Northern Sotho. Hatfield: Via Afrika.

Primus, B. (1993). Word Order and Information Structure: A Performance-Based Account of Topic Positions and Focus Positions. In J. Jacobs, A. v. Stechow, W. Sternefeld, \& T. Vennemann (Eds.), Syntax- An International Handbook of Contemporary Research, volume 1 (pp. 880-896). Berlin: Walter de Gruyter.

Prince, A. (1983). Relating to the Grid. Linguistic Inquiry, 14(19-100).

Prince, A. \& Smolensky, P. Optimality Theory: constraint interaction in generative grammar.

Prince, E. F. Toward a Taxonomy of Given-New Information. In P. Cole (Ed.), Radical Pragmatics.

Reinhart, T. (1981). Pragmatics and Linguistics: An analysis of Sentence Topics. Philosophica, 27(1), 53-94.

Rialland, A. \& Robert, S. (2001). The intonational system of Wolof. Linguistics, 39(5), 893-939.

Rizzi, L. (1997). The fine structure of the left periphery. In L. Haegemann (Ed.), Elements of Grammar (pp. 281-333). Dordrecht: Kluwer Academic Publishers.

Rooth, M. (1992). A Theory of Focus Interpretation. Natural Language Semantics, 1, $75-116$.

Rooth, M. (1996). Focus. In S. Lappin (Ed.), Handbook of Contemporary Semantic Theory (pp. 271-297). Oxford \& Cambridge, MA: Blackwell.

Sabel, J. (1998). Principles and Parameters of Wh-Movement. Frankfurt/Main.

Sabel, J. (2000). Partial Wh-Movement and The Typology of Wh-Questions. In U. Lutz, G. Müller, \& A. v. Stechow (Eds.), Wh-Scope Marking (pp. 409-446). Amsterdam: John Benjamin Publishing Company.

Sabel, J. \& Zeller, J. (to appear). Wh-question formation in Nguni. In J. Mugane, J. P. Hutchison, \& D. A. Worman (Eds.), Selected Proceedings of the 35th Annual Conference on African Linguistics (pp. 271-283). Somerville, MA: Cascadilla Proceedings Project.

Saltarelli, M. (1988). Basque. London: Croom Helm Ltd.

Samek-Lodovici, V. (2005). Prosody-Syntax Interaction in the Expression of Focus. Natural Language and Linguistic Theory, 23, 687-755.

Sasse, H.-J. (1987). The thetic/categorical distinction revisited. Linguistics, 25, 511-580. 
Schiefer, L. \& Batliner, A. (1991). A ramble round the order effect. Forschungsberichte des Instituts für Phonetik und Sprachliche Kommunikation der Universität München (FIPKM), 29, 125-180.

Schmerling, S. (1976). Aspects of English Sentence Stress. Austin: University of Texas Press.

Schwarz, F. (2003). Fokus marking in Kikuyu. In R. Eckardt (Ed.), ZAS Papers in Linguistics, 30 (pp. 41-118). Berlin: ZAS.

Schwarzschild, R. (1999). GIVENness, AvoidF and other Constraints on the Placement of Accent. Natural Language Semantics, 7, 141-177.

Schwellnus, P. (1942). Kima le Kxalo le Meshito ya Direto. Cape Town: Nasionale Pers.

Selkirk, E. (1978). On Prosodic Structure and its Relation to Syntactic Structure. In T. Fretheim (Ed.), Nordic Prosody II. Trondheim: TAPIR.

Selkirk, E. (1980). On Prosodic Structure and its Relation to Syntactic Structure. Bloomington, Indiana: Indiana University Linguistics Club.

Selkirk, E. (1984). Phonology and Syntax: The Relation between Sound and Structure. Cambridge, MA: MIT Press.

Selkirk, E. (1986). On Derived Domains in Sentence Phonology. Phonology Yearbook, 3, 371-405.

Selkirk, E. (1995). Sentence prosody: Intonation, stress, and phrasing. In J. Goldsmith (Ed.), Handbook of Phonological Theory (pp. 550-569). Oxford \& Cambridge, MA: Blackwell.

Selkirk, E. (1996). The Prosodic Structure of Function Words. In J. Morgan \& K. Demuth (Eds.), Signal to Syntax: bootstrapping from speech to grammar in early acquisition (pp. 187 -213). Mahwah, N.J.: Lawrence Erlbaum Associates.

Selkirk, E. (2004). Bengali intonation revisited. In Lee, Gordon, \& D. Büring (Eds.), Topic and Focus: A Cross-Linguistic Perspective (pp. 217-246). Dordrecht: Kluwer Academic Publishers.

Selkirk, E. \& Shen, T. (1990). Prosodic Domains in Shanghai Chinese. In S. Inkelas \& D. Zec (Eds.), The Phonology-Syntax Connection (pp. 313-337). Chicago: The University of Chicago Press.

Selkirk, E. \& Tateishi, K. (1991). Syntax and Downstep in Japanese. In C. Georgopolous \& R. Ishihara (Eds.), Interdisciplinary Approaches to Language: Essays in Honor of S.-Y. Kuroda (pp. 519-543). Dordrecht: Kluwer.

Silverstein, M. (1976). Hierarchies of Features and Ergativity. In R. Dixon (Ed.), Grammatical Categories in Australian Languages (pp. 112-171). Canberra: Australian Institute of Aboriginal Studies. 
Sluijter, A. (1995). Phonetic Correlates of Stress and Accent. The Hague: Holland Academic Graphics.

Speas, M. (1995). Generalized control and null objects in optimality theory. In J. Beckman, L. Walsh-Dickie, \& S. Urbanczyk (Eds.), Papers in Optimality Theory, volume 18. Amherst, MA: UMass.

Speas, M. (1997). Optimality Theory and Syntax: Null Pronouns and Control. In D. Archangeli \& D. Langendoen (Eds.), Optimality Theory: An overview (pp. 171199). Oxford \& Malden, MA: Blackwell.

Sperber, D. \& Wilson, D. (1995). Relevance: Communication and Cognition (2nd ed.). Oxford: Blackwell.

Strawson, P. (1964). Intention and Convention in Speech Acts. Philosophical Review, 73, 439-460.

Stucky, S. (1979). The interaction of tone and focus in Makua. Journal of African Languages and Linguistics, 1(2), 189-198.

Stucky, S. (1981). Word Order Variation in Makua: A Phrase Structure Grammar Analysis. PhD thesis, University of Illinois, Urbana.

Swerts, M., Krahmer, E., \& Avesani, C. (2002). Prosodic marking of information status in Dutch and Italian: a comparative analysis. Journal of Phonetics, 30, 629-654.

Szendröi, K. (2001). Focus and the Syntax-Phonology Interface. PhD thesis, University College London.

Truckenbrodt, H. (1995). Phonological phrases: Their relation to syntax, focus, and prominence. PhD thesis, Massachussetts Institute of Technology.

Truckenbrodt, H. (1999). On the Relation between Syntactic Phrases and Phonological Phrases. Linguistic Inquiry, 30(2), 219-255.

Truckenbrodt, H. (2002). Variation in p-phrasing in Bengali. Linguistic Variation Yearbook, 2, 259-303.

Truckenbrodt, H. (2005). A Short Report on Intonation Phrase Boundaries in German. Linguistische Berichte, 203, 273-296.

Truckenbrodt, H. (2006). Phrasal Stress. In K. Brown (Ed.), Elsevier Encyclopedia of Languages and Linguistics (2nd ed.). (pp. 572ff). Oxford: Elsevier.

Truckenbrodt, H. (to appear). The syntax-phonology interface. In P. de Lacy (Ed.), The Cambridge Handbook of Phonology. Cambridge: Cambridge University Press.

Trümpelmann, H. (1942). Intonasie in Sepedi. PhD thesis, Unpubished M.A. dissertation. Pretoria: University of Pretoria. 
Tsimpli, I. M. (1995). Focusing in Modern Greek. In K. É. Kiss (Ed.), Discourse Configurational Languages (pp. 176-206). New York/ Oxford: Oxford University Press.

Tucker, A. N. (1929). The Comparative Phonetics of the Suto-Chuana Group of Bantu languages. Gregg International Publishers Limited.

Tucker, A. N. (1932). Some Little Known Dialects of SePedi. Mitteilungen des Seminars für orientalische Sprachen, 35, 133-142.

Tuller, L. (1992). The Syntax of Postverbal Focus Constructions in Chadic. Natural Language and Linguistic Theory, 10(2), 303-334.

Uhmann, S. (1991). Fokusphonologie. Eine Analyse deutscher Intonationskonturen im Rahmen der nicht-linearen Phonologie. Tübingen: Niemeyer.

Vallduví, E. \& Engdahl, E. (1995). Information Packaging and Grammar Architecture. Proceedings of NELS 25, 1, 519-533.

Vallduví, E. \& Engdahl, E. (1996). The linguistic realization of information packaging. Linguistics, 34, 459-519.

Vallduví, E. \& Vilkuna, M. (1998). On rheme and kontrast. In P. Culicover \& L. McNally (Eds.), The limits of syntax. New York: Academics.

Van der Spuy, A. (1993). Dislocated noun phrases in Nguni. Lingua, 90, 335-355.

Van Valin, R. D. J. (1999). A Typology of the Interaction of Focus Structure and Syntax. In E. Raxilina \& J. Testelec (Eds.), Typology and the Theory of Language: From Description to Explanation. Moscow.

Van Wyk, E. B. (1958). Woordverdeling in Noord-Sotho en Zoeloe: 'n Bydrae tot die vraagstuk van woord-identifikasie in die Bantoetale. $\mathrm{PhD}$ thesis, University of Pretoria.

Van Wyk, E. B. (1969). Die Indeling van die Sotho-taalgroep. In Ethnological and linguistic studies in Honour of N.J.Warmelo (pp. 169-179). Pretoria.

Visser, M. (1985). Aspects of empty categories in Xhosa within the theory of government and binding. South African Journal of African Languages, 5(1), 24-33.

Vogel, I. \& Kenesei, I. (1990). Syntax and semantics in Phonology. In S. Inkelas \& D. Zec (Eds.), The Phonology-Syntax Connection (pp. 339-365). Chichago \& London: The University of Chicago Press.

Wald, B. (1979). The development of the Swahili object marker: A study of the interaction of syntax and discourse. In T. Givón (Ed.), Discourse and Syntax (pp. 505-524). New York: Academic Press.

Watters, J. R. (1979). Focus in Aghem. A study of its formal correlates and typology. In L. Hyman (Ed.), Aghem Grammatical Structure, Southern California Occasional Papers in Linguistics no.7 (pp. 137-197). Los Angeles: University of Southern California. 
Watters, J. R. (1989). Bantoid Overview. In J. Bendor-Samuel \& R. L. Hartell (Eds.), The Niger-Congo Languages: A Classification and Description of Africa's Largest Language Family (pp. 400-420). Lanham, MD: University Press of America.

Xu, L. (2004). Manifestation of informational focus. Lingua, 114, 277-299.

$\mathrm{Xu}, \mathrm{Y}$. (1999). Effects of tone and focus on the formation and alignment of f0 contours. Journal of Phonetics, 27, 55-105.

Zeevat, H. \& Jäger, G. (2002). A Reinterpretation of Syntactic Alignment. In D. d. Jongh, M. Nilsenova, \& H. Zeevat (Eds.), Proceedings of the Fourth International Tbilisi Symposium on Language, Logic and Computation. Amsterdam: University of Amsterdam.

Zeller, J. (2004a). Relative clause formation in the Bantu languages of South Africa. Southern African Linguistics and Applied Language Studies, 22/1-2, 75-93.

Zeller, J. (2004b). Left dislocation in Zulu. Manuscript, University of KwaZulu-Natal, available online under http: \\www.jzeller. de \, last access 10.12.2005.

Zeller, J. \& Ngoboka, J.-P. (2005). Kinyarwanda locative applicatives and the Minimal Link Condition. Manuscript, University of KwaZulu-Natal, available online under http: \\www.jzeller.de \, last access 10.12.2005.

Zerbian, S. (2004a). Locative inversion in Northern Sotho. Manuscript, ZAS Berlin.

Zerbian, S. (2004b). Phonological Phrases in Xhosa (Southern Bantu). In S. Fuchs \& S. Hamann (Eds.), ZASPiL 37, Papers in Phonetics and Phonology (pp. 71-100). Berlin: ZAS.

Zerbian, S. (to appear). High Tone Spread in the Sotho Verb. In J. Mugane, J. P. Hutchison, \& D. A. Worman (Eds.), Selected Proceedings of the 35th Annual Conference on African Linguistics (pp. 147-157). Somerville, MA: Cascadilla Proceedings Project.

Zerbian, S. (under review a). Investigating prosodic focus marking in Northern Sotho. In E. O. Aboh, K. Hartmann, \& M. Zimmermann (Eds.), Focus Strategies: Evidence from African Languages (Niger-Congo, Afro-Asiatic, West-Atlantic). Berlin: de Gruyter.

Zerbian, S. (under review b). Subject/object-asymmetry in Northern Sotho. In K. Schwabe \& S. Winkler (Eds.), Information Structure and the Architecture of Grammar: A Typological Perspective. Amsterdam: John Benjamins.

Ziervogel, D. (1954). The Eastern Sotho. Pretoria: Van Schaik.

Ziervogel, D., Lombard, D., \& Mokgokong, P. (1969). A Handbook of the Northern Sotho language. Pretoria: Schaik.

Ziervogel, D. \& Mokgokong, P. (1961). Klein Noord-Sotho Woordeboek. Pretoria: Schaik.

Zipf, G. K. (1949). Human behavior and the principle of least effort. Cambridge: Addison-Wesley. 
Zubizaretta, M. (1994). On Some Prosodically Governed Syntactic Operations. In G. Cinque (Ed.), Path towards universal grammar: studies in honor of Richard S. Kayne (pp. 473-485). Washington: Georgetown University Press.

Zubizaretta, M. (1998). Prosody, Focus and Word Order. Cambridge, MA: The MIT Press. 


\section{Erklärung}

Hiermit versichere ich an Eides statt, die vorliegende Dissertation "Expression of Information Structure in the Bantu language Northern Sotho" selbständig angefertigt und keine anderen als die aufgeführten Hilfsmittel verwendet zu haben.

Berlin, 10.Januar 2006 


\section{Lebenslauf}

Lebenslauf von Sabine Zerbian:

27.06.1975 Geburt in Berlin

15.07.1994 Abitur in Berlin

12.02.2002 Magister Artium: 1.Hauptfach Germanistische Linguistik (Humboldt-Universität zu Berlin), Nebenfächer: Anglistik, Psychologie (Freie Universität Berlin)

2002-2005 Wissenschaftliche Mitarbeiterin, Projekt: Ausdruck von Informationsstruktur in Sprachen des südlichen Afrika, Zentrum für Allgemeine Sprachwissenschaft, Typologie und Universalienforschung (Berlin), Projektleiter: Prof. Dr. Manfred Krifka (Humboldt-Universität Berlin), PD Dr. Tom Güldemann (MPI für Evolutionäre Anthropologie, Leipzig). 